\title{
Investigation of EGR and Fuel Property Effects on Advanced Combustion Strategies Using In-cylinder Combustion Analyses
}

Jason D. Ice

West Virginia University

Follow this and additional works at: https://researchrepository.wvu.edu/etd

\section{Recommended Citation}

Ice, Jason D., "Investigation of EGR and Fuel Property Effects on Advanced Combustion Strategies Using In-cylinder Combustion Analyses" (2010). Graduate Theses, Dissertations, and Problem Reports. 4607. https://researchrepository.wvu.edu/etd/4607

This Thesis is protected by copyright and/or related rights. It has been brought to you by the The Research Repository @ WVU with permission from the rights-holder(s). You are free to use this Thesis in any way that is permitted by the copyright and related rights legislation that applies to your use. For other uses you must obtain permission from the rights-holder(s) directly, unless additional rights are indicated by a Creative Commons license in the record and/ or on the work itself. This Thesis has been accepted for inclusion in WVU Graduate Theses, Dissertations, and Problem Reports collection by an authorized administrator of The Research Repository @ WVU. For more information, please contact researchrepository@mail.wvu.edu. 


\title{
Investigation of EGR and Fuel Property Effects on Advanced Combustion Strategies Using In-cylinder Combustion Analyses
}

\author{
Jason D. Ice \\ Thesis submitted to the \\ College of Engineering and Mineral Resources \\ at West Virginia University \\ in partial fulfillment of the requirements \\ for the degree of \\ Master of Science \\ in \\ Mechanical Engineering \\ Benjamin Shade, Ph.D., Chair \\ John Nuszkowski, Ph.D. \\ Hailin Li, Ph.D. \\ Department of Mechanical and Aerospace Engineering \\ Morgantown, West Virginia
}

2010

Keywords: Advanced Combustion, EGR, Fuel Properties, In-cylinder Combustion, Diesel 


\title{
Abstract \\ Investigation of EGR and Fuel Property Effects on Advanced Combustion Strategies Using In- cylinder Combustion Analyses
}

\author{
Jason D. Ice
}

Advanced combustion has progressively become a topic of interest as government regulations have stringently reduced the allowable limits of engine-out emissions from internal combustion engines. Advanced combustion can typically be classified as homogeneous charge compression ignition $(\mathrm{HCCl})$ or premixed charge compression ignition $(\mathrm{PCCl})$. In $\mathrm{HCCl}$ combustion, a well mixed fuel and air solution is spontaneously combusted, thus providing a homogeneous burn throughout the combustion process. By having an evenly distributed, homogeneous burn, fuel economy is not only significantly increased, but both oxides of nitrogen $\left(\mathrm{NO}_{\mathrm{x}}\right)$ and particulate matter (PM) can drastically be reduced from that of conventional combustion. $\mathrm{HCCl}$ has the ability to incorporate the low PM emissions of a spark ignited (SI) engine as well as the high thermal efficiency of a compression ignited $(\mathrm{Cl})$ engine. Similar to $\mathrm{HCCl}, \mathrm{PCCl}$ offers low $\mathrm{NO}_{x}$ and $\mathrm{PM}$ within a part load operating range with a quasi-homogenous fuel and air mixture. Other than identifying $\mathrm{HCCl}$ or $\mathrm{PCCl}$ as having very limited $\mathrm{NO}_{\mathrm{x}}$ and $\mathrm{PM}$ production, in-cylinder combustion techniques can also be utilized to characterize these forms of advanced combustion.

An experimental study was performed at West Virginia University (WVU) in an attempt to achieve $\mathrm{HCCl}$ or $\mathrm{PCCl}$ operation by implementing a number of engine control strategies using a range of fuels with varying fuel properties. The test engine, a GM 1.9L, was incorporated with an ECU controller capable of controlling engine operating parameters such as rail pressure, start of injection (SOI), fuel quantity injected and exhaust gas recirculation (EGR) valve position. Piezoelectric crystal pressure transducers were introduced into each cylinder via glow plug adapters and a custom WVU data acquisition system was used to evaluate in-cylinder combustion parameters. Testing was performed at a $2100 \mathrm{RPM}, 53 \mathrm{~N}-\mathrm{m}$, steady-state set point using an engine dynamometer. By implementing high levels of $E G R, \mathrm{NO}_{x}$ emissions were reduced nearly $90 \%$ due to lower cylinder pressures and increased ignition delay. PM emissions were also reduced by $15 \%$ within a specific EGR range due to increased mixing time available from a longer ignition delay as verified by in-cylinder pressure, heat release rate and mass fraction burned data. Fuel characteristics were compared at a single operating condition and at an optimized control strategy with increased thermal efficiency, for low $\mathrm{NO}_{\mathrm{x}}$ and $\mathrm{PM}$ emissions that were determined from a range of EGR, pilot injection, main injection, rail pressure and fuel split sweeps. The cetane number $(\mathrm{CN})$ of the fuel was found to be the contributing factor affecting the combustion process compared to fuel properties such as aromatics and volatility while the net heat of combustion per unit volume effected the brake specific fuel consumption. Low CN fuels resulted in a PM reduction of $30 \%$ but showed a $50 \%$ increase in $\mathrm{NO}_{x}$ emissions over the higher $\mathrm{CN}$ fuels at the same operating condition. 


\section{Table of Contents}

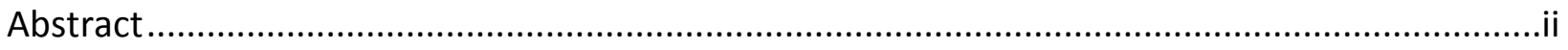

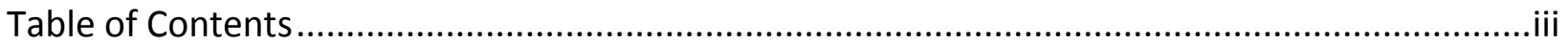

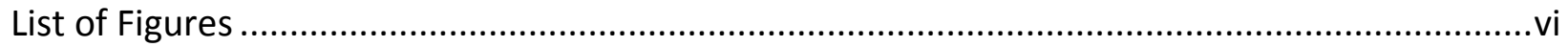

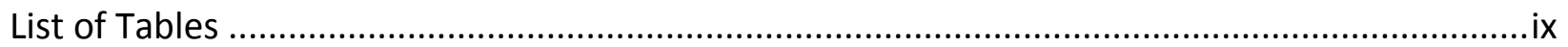

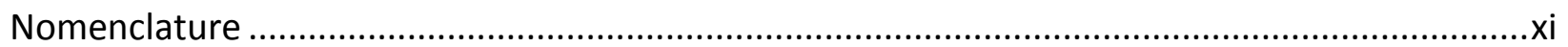

1 Introduction and Objectives ........................................................................................ 1

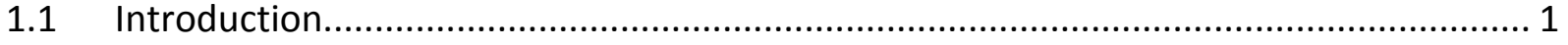

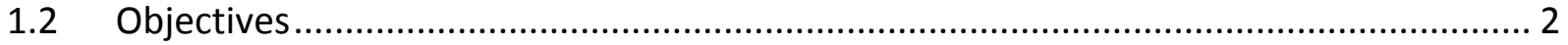

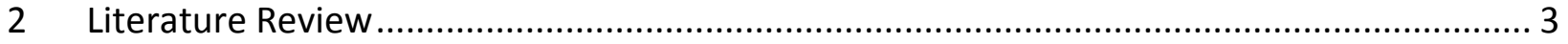

2.1 Advanced Combustion in Diesel Engines ………………......................................... 3

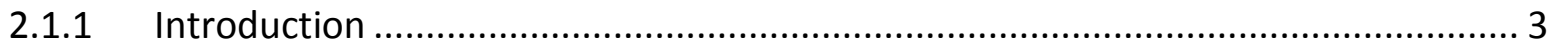

2.1.2 Homogeneous Charge Compression Ignition .................................................. 4

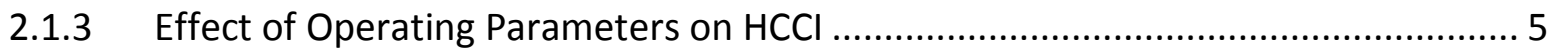

2.1.4 Effect of Engine Geometry on $\mathrm{HCCl}$.................................................................. 6

2.1.5 FACE and the Effect of Fuel Characteristics on Advanced Combustion ................... 8

2.1.6 Premixed Charge Compression Ignition and Low Temperature Combustion .......... 9

2.1.7 Summary of Advanced Combustion in Diesel Engines ......................................... 10

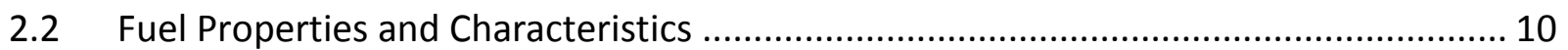

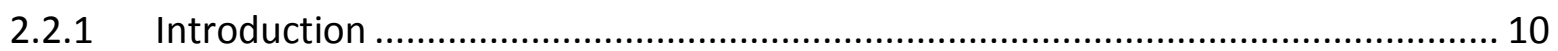

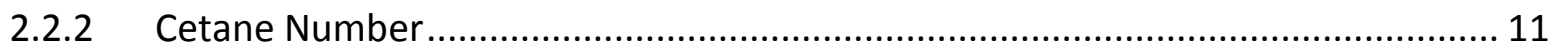

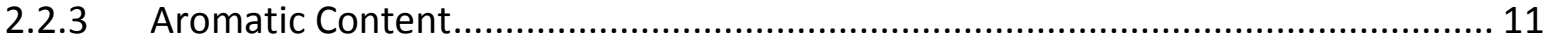

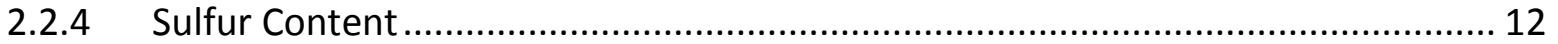

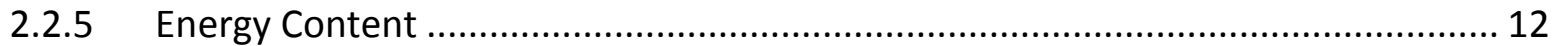

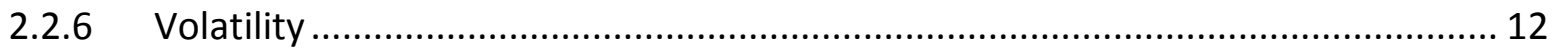

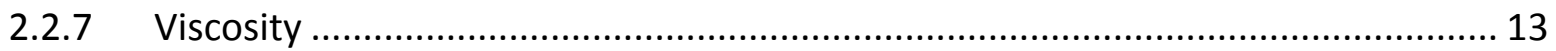

2.2.8 Summary of Fuel Properties and Characteristics .............................................. 13

2.3 In-cylinder Pollutant Formation and Analysis Techniques........................................... 14

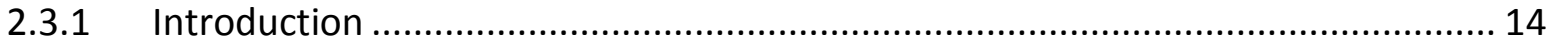

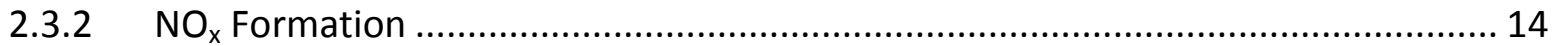

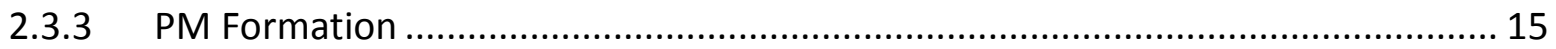

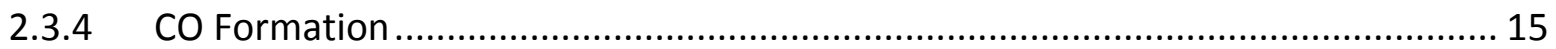




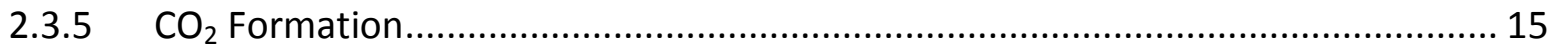

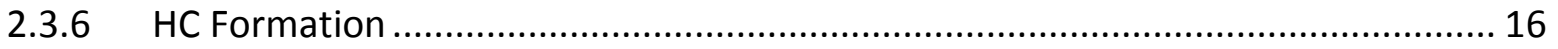

2.3.7 Heat Release Rate .............................................................................. 16

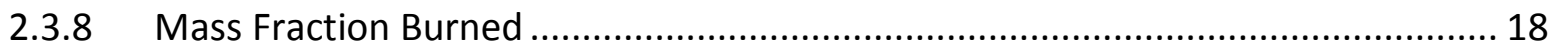

2.3.9 Brake Specific Fuel Consumption................................................................ 19

2.3.10 Brake Thermal Efficiency............................................................................... 19

2.3.11 In-cylinder Pressure.................................................................................... 19

2.3.12 Summary of In-cylinder Pollutant Formation and Analysis Techniques .................20

2.4 Exhaust Gas Recirculation in Diesel Engines ................................................................ 20

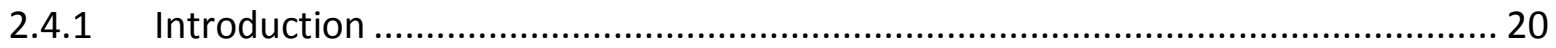

2.4.2 Constraints Placed on $\mathrm{NO}_{x}, \mathrm{PM}$ and Fuel Consumption ...................................... 22

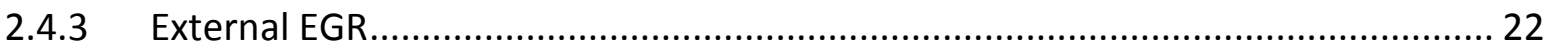

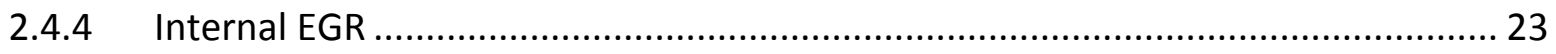

2.4.5 High Pressure EGR.................................................................................... 23

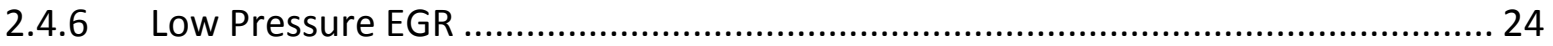

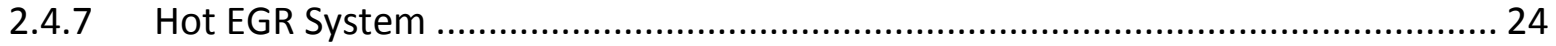

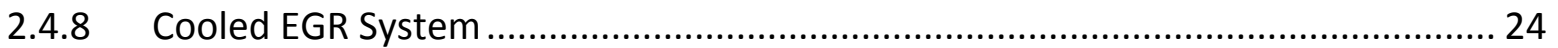

2.4.10 Effect of EGR on Fuel Consumption ................................................................ 26

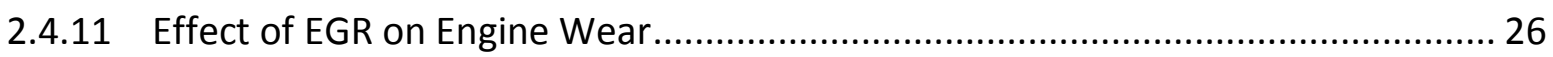

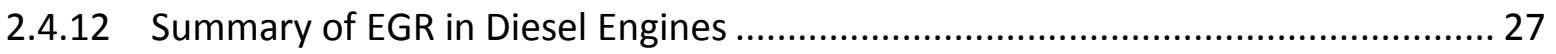

3 Experimental Setup and Test Equipment ................................................................. 28

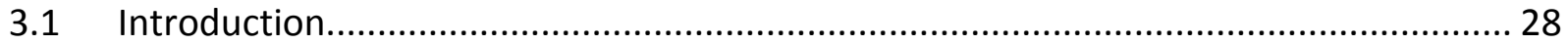

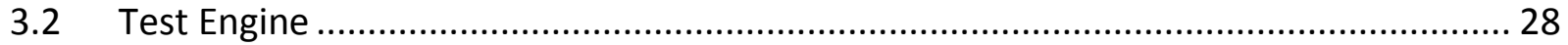

3.3 In-cylinder Pressure Measurement...................................................................... 30

3.4 Measured and Calculated Combustion Parameters ................................................. 32

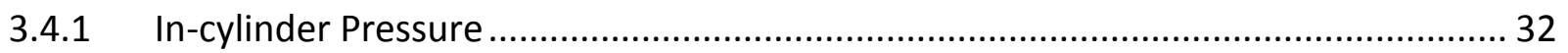

3.4.2 Heat Release Rate........................................................................................... 33

3.4.3 In-cylinder Gas Temperature ................................................................................ 33

3.5 Control of Engine Operating Parameters ................................................................... 34

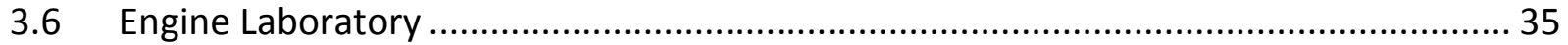

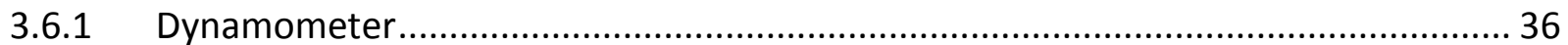

3.6.2 Full-Scale Dilution Tunnel and Sampling System................................................ 36

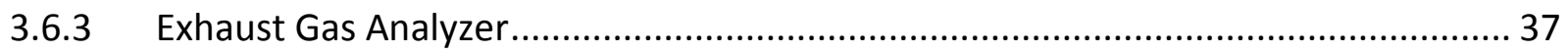


3.6.4 Carbon Monoxide and Carbon Dioxide Analyzer ................................................. 38

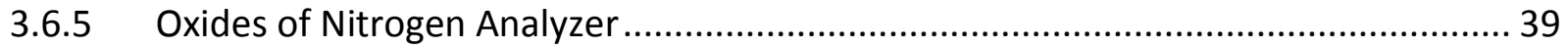

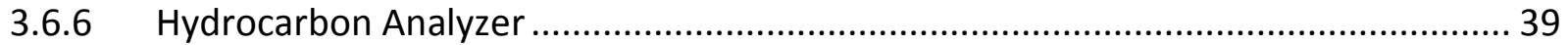

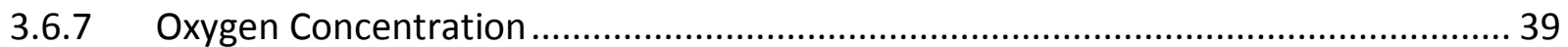

3.6.8 Particulate Matter Sampling System ................................................................. 40

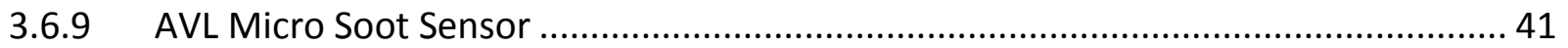

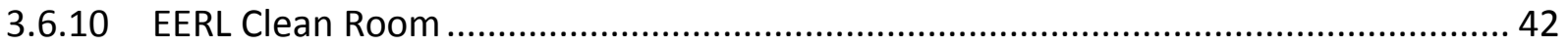

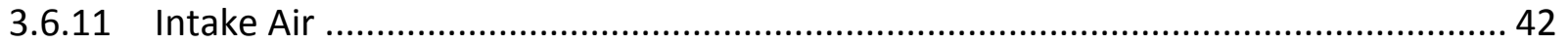

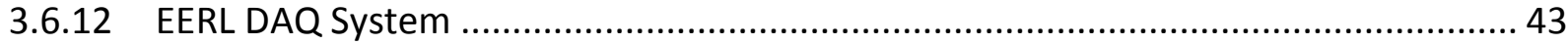

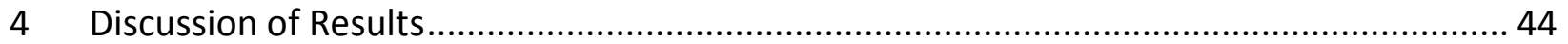

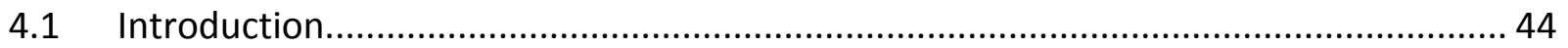

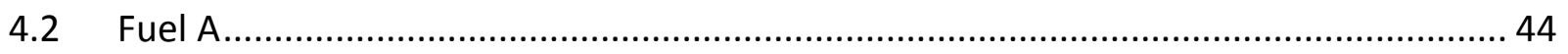

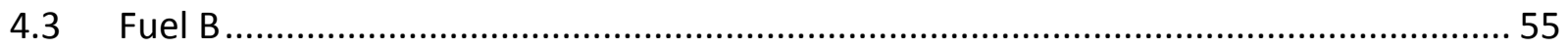

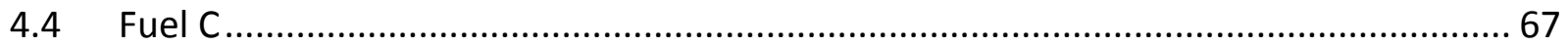

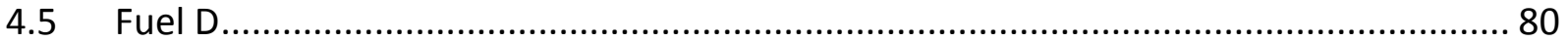

4.6 Fuel Characteristic Effects at a Specified Operating Condition .................................. 87

4.7 Fuel Characteristic Effects at Optimized Control Strategies ....................................... 94

5 Conclusions and Recommendations .............................................................................. 103

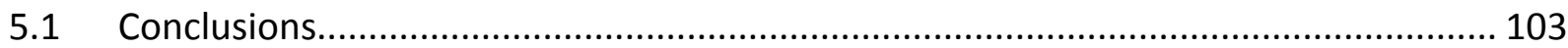

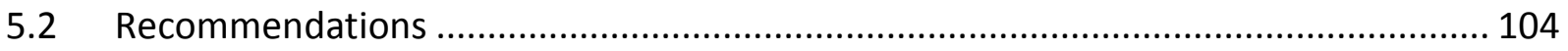

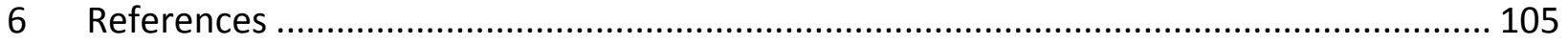

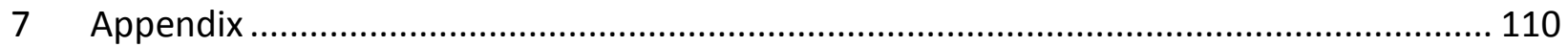




\section{List of Figures}

Figure 1: $\mathrm{HCCl}$ Combustion versus Conventional Diesel Combustion [3] ................................... 4

Figure 2: Local Equivalence Ratio versus Local Temperature for Various Advanced Combustion

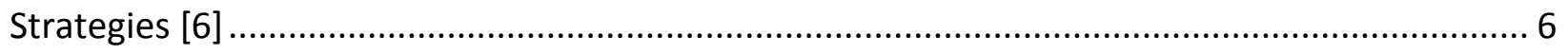

Figure 3: Mean Velocity, Turbulence and ROHR of Flat Combustion Chamber [7] .................... 7

Figure 4: Mean Velocity, Turbulence and ROHR of Square Combustion Chamber [7] ................ 8

Figure 5: FACE Design Matrix [9]..................................................................................... 9

Figure 6: Engine-Out Emissions of Conventional versus PCCI Combustion [12] ..................... 10

Figure 7: Heat Release Rate Curve for Conventional Combustion [29].................................. 17

Figure 8: Advanced Combustion Heat Release Rate Curve for Single and Split Injection Events

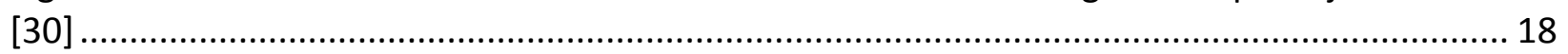

Figure 9: On Road Heavy Duty Diesel Engines Emission Regulations Requirements [36].......... 21

Figure 10: Effect of Hot and Cooled EGR on NOx Emissions vs. EGR Rate [45] ....................... 25

Figure 11: Effect of Hot and Cooled EGR on PM Emissions [45] ........................................... 26

Figure 12: Component Wear and Carbon Content versus EGR Rate [47] .............................. 27

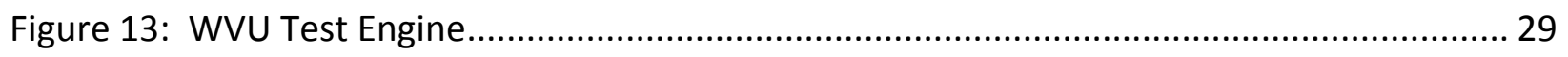

Figure 14: Kistler 6056A41 Pressure Sensor ......................................................................... 31

Figure 15: Pressure Sensor Glow Plug Adapter ............................................................... 31

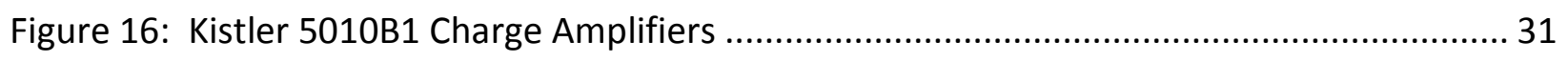

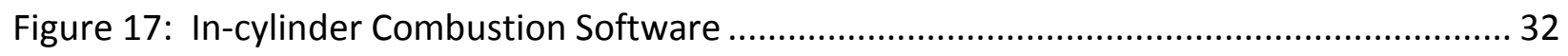

Figure 18: Open Engine Controller Purchased from Drivven, Inc .......................................... 34

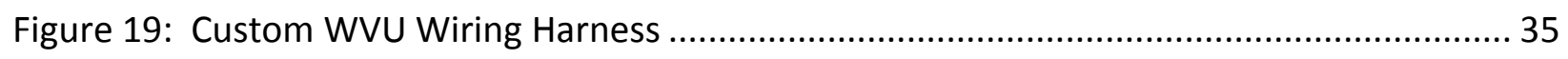

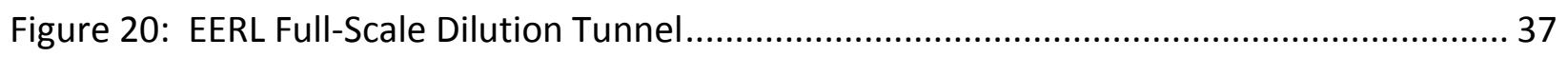

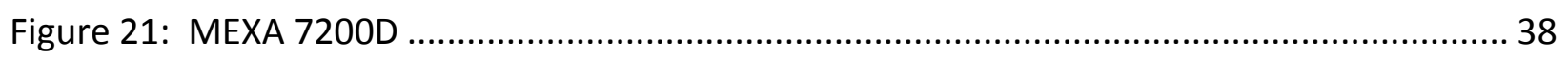

Figure 22: Custom WVU PM Collection Box ........................................................................ 40

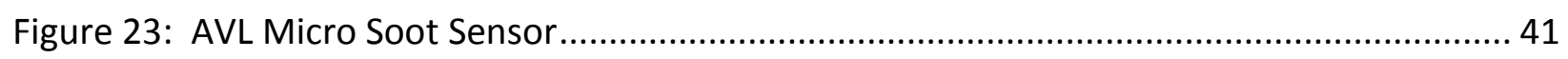

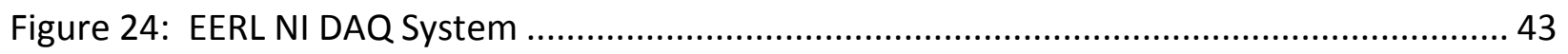

Figure 25: In-cylinder Pressure versus Crank Angle of EGR Sweeps for Fuel A ......................... 45

Figure 26: Gross HRR versus Crank Angle of EGR Sweeps for Fuel A .................................... 46

Figure 27: Mass Fraction Burned versus Crank Angle of EGR Sweeps for Fuel A..................... 47

Figure 28: CA 10-90\% Burn Duration and Max PRR of EGR Sweeps for Fuel A ....................... 48

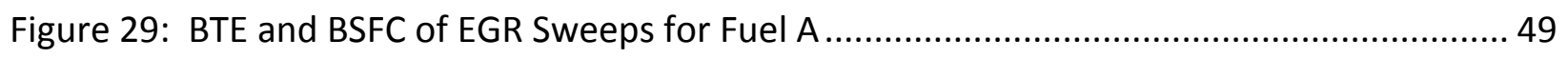

Figure 30: In-cylinder Pressure versus Crank Angle of Pilot Injection Sweeps for Fuel A .......... 51 
Figure 31: Gross HRR versus Crank Angle of Pilot Injection Sweeps for Fuel A........................ 51

Figure 32: BTE and BSFC of Pilot Injection Sweeps for Fuel A ............................................ 52

Figure 33: In-cylinder Pressure versus Crank Angle of EGR Sweeps for Fuel B ....................... 55

Figure 34: Gross HRR versus Crank Angle of EGR Sweeps for Fuel B ..................................... 56

Figure 35: Mass Fraction Burned versus Crank Angle of EGR Sweeps for Fuel B ...................... 57

Figure 36: CA 10-90\% Burn Duration and Max PRR of EGR Sweeps for Fuel B ........................ 58

Figure 37: BTE and BSFC of EGR Sweeps for Fuel B ........................................................ 59

Figure 38: In-cylinder Pressure versus Crank Angle of Pilot Injection Sweeps for Fuel B .......... 61

Figure 39: Gross HRR versus Crank Angle of Pilot Injection Sweeps for Fuel B......................... 61

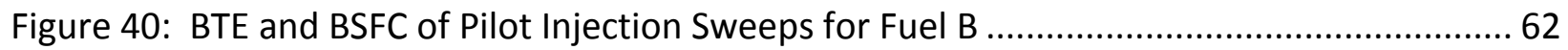

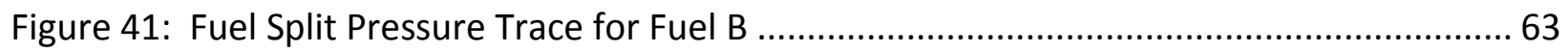

Figure 42: Rail Pressure Sweep Pressure Trace for Fuel B.................................................. 64

Figure 43: Gross HRR versus Crank Angle of Rail Pressure Sweeps for Fuel B ......................... 64

Figure 44: In-cylinder Pressure versus Crank Angle of EGR Sweeps for Fuel C ........................ 67

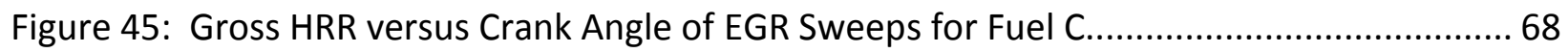

Figure 46: Mass Fraction Burned versus Crank Angle of EGR Sweeps for Fuel C ...................... 69

Figure 47: CA 10-90\% Burn Duration and Max PRR of EGR Sweeps for Fuel C ......................... 70

Figure 48: BTE and BSFC of EGR Sweeps for Fuel C .......................................................... 71

Figure 49: CA 10-90\% Burn Duration and Max PRR of Pilot Injection Sweeps for Fuel C........... 72

Figure 50: In-cylinder Pressure versus Crank Angle of Rail Pressure Sweeps for Fuel C............ 73

Figure 51: Gross HRR versus Crank Angle of Rail Pressure Sweeps for Fuel C ........................ 73

Figure 52: BTE and BSFC of Rail Pressure Sweeps for Fuel C ............................................... 74

Figure 53: In-cylinder Pressure versus Crank Angle of Fuel Split Sweeps for Fuel C................. 75

Figure 54: Gross HRR versus Crank Angle of Fuel Split Sweeps for Fuel C ................................ 76

Figure 55: Maximum Pressure Rise Rate of Fuel Split Sweeps for Fuel C................................ 77

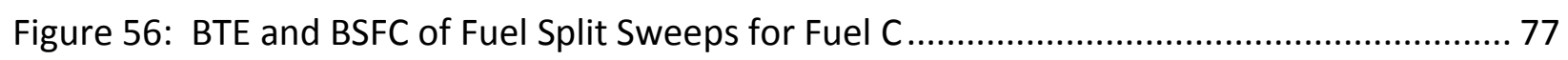

Figure 57: In-cylinder Pressure versus Crank Angle of EGR Sweeps for Fuel D ....................... 80

Figure 58: Gross HRR versus Crank Angle of EGR Sweeps for Fuel D ..................................... 81

Figure 59: Mass Fraction Burned versus Crank Angle of EGR Sweeps for Fuel D...................... 82

Figure 60: CA 10-90\% Burn Duration and Max PRR of EGR Sweeps for Fuel D ........................ 83

Figure 61: BTE and BSFC of EGR Sweeps for Fuel D ......................................................... 84

Figure 62: In-cylinder Pressure versus Crank Angle of Pilot Injection Sweeps for Fuel D .......... 85 
Figure 63: In-cylinder Pressure versus Crank Angle at Specified Operating Condition of Each Fuel 87

Figure 64: Gross HRR versus Crank Angle at Specified Operating Condition of Each Fuel.......... 88

Figure 65: Ignition Delay versus CN at Specified Operating Condition .................................... 89

Figure 66: Mass Fraction Burned versus Crank Angle at Specified Operating Condition............ 90

Figure 67: Maximum Average Bulk Mixture Temperature from Each Fuel at Specified Operating

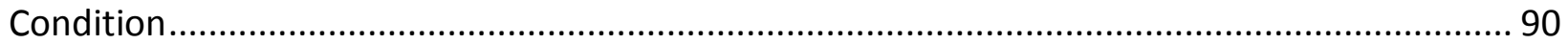

Figure 68: CA 10-90\% Burn Duration and Max PRR of Each Fuel at Specified Operating Condition 91

Figure 69: BTE and BSFC at Specified Operating Condition of Each Fuel ............................... 92

Figure 70: Radar Plots of NOx, HC, BTE and PM of Each Fuel at Specified Operating Condition 94

Figure 71: In-cylinder Pressure versus Crank Angle at Optimized Control Strategy of Each Fuel95

Figure 72: Gross HRR versus Crank Angle at Optimized Control Strategy of Each Fuel .............. 96

Figure 73: Mass Fraction Burned versus Crank Angle at Optimum Control Strategy of Each Fuel

Figure 74: CA 10-90\% Burn Duration and Max PRR at Optimum Control Strategy of Each Fuel 98

Figure 75: BTE and BSFC at Optimum Control Strategy of Each Fuel ..................................... 99

Figure 76: Maximum Average Bulk Mixture Temperature from Each Fuel........................... 101

Figure 77: Radar Plots of $\mathrm{NO}_{\mathrm{x}}, \mathrm{HC}, \mathrm{BTE}$ and PM at Optimized Control Strategy of Each Fuel ... 102

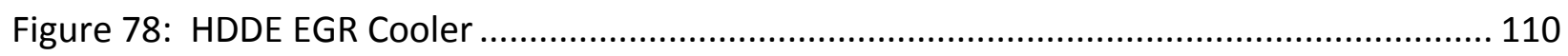

Figure 79: Engine Retrofitted with HDDE EGR Cooler and Heating Element ......................... 111

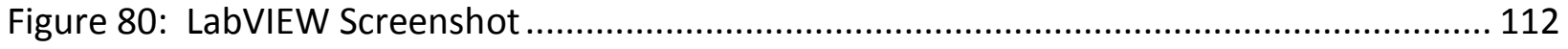




\section{List of Tables}

Table 1: General Effect of Increasing Fuel Property Quantities on $\mathrm{NO}_{\mathrm{x}}$ and PM Emissions........ 13

Table 2: General Effect of Decreasing Fuel Property Quantities on NOx and PM Emissions...... 13

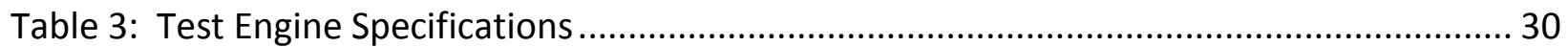

Table 4: AVL Micro Soot Sensor Specifications [52] .............................................................. 42

Table 5: Calculated In-cylinder Combustion Parameters of EGR Sweeps for Fuel A................. 50

Table 6: EGR Sweep Emissions Data for Fuel A.................................................................... 50

Table 7: Rail Pressure Sweep Emissions Data for Fuel A ................................................... 53

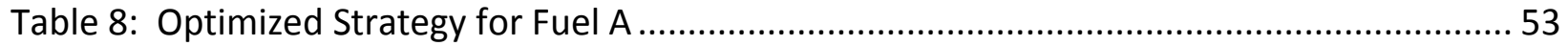

Table 9: Optimum Operating Strategy Emissions Results for Fuel A ................................... 53

Table 10: Calculated In-cylinder Combustion Parameters at Optimized Strategy for Fuel A ..... 54

Table 11: EGR Sweep Emissions Data for Fuel B................................................................ 56

Table 12: Calculated In-cylinder Combustion Parameters of EGR Sweeps for Fuel B ................60

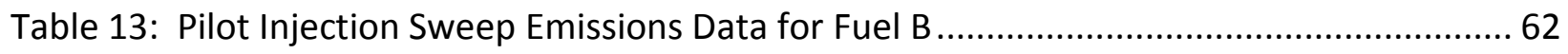

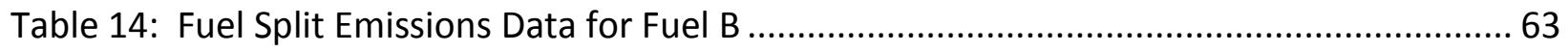

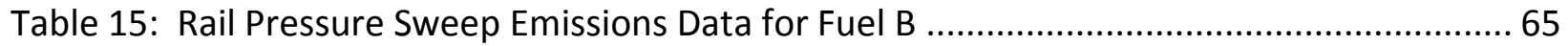

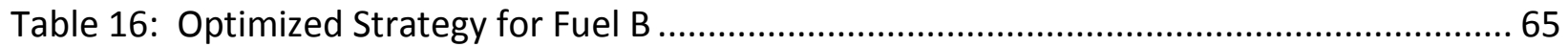

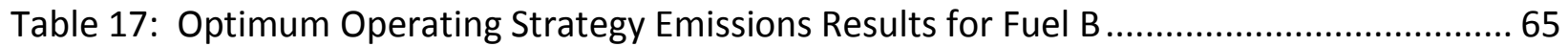

Table 18: Calculated In-cylinder Combustion Parameters at Optimized Strategy for Fuel B...... 66

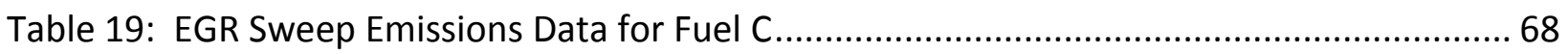

Table 20: Calculated In-cylinder Combustion Parameters of EGR Sweeps .............................. 71

Table 21: Pilot Injection Sweep Emissions Data for Fuel C .................................................... 72

Table 22: Rail Pressure Sweep Emissions Data for Fuel C ................................................ 74

Table 23: Fuel Split Sweep Emissions Data for Fuel C ............................................................. 78

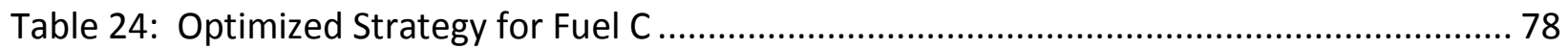

Table 25: Optimum Operating Strategy Emissions Results for Fuel C .................................... 78

Table 26: Calculated In-cylinder Combustion Parameters at Optimized Strategy for Fuel C...... 79

Table 27: EGR Sweep Emissions Data for Fuel D ............................................................... 81

Table 28: Calculated In-cylinder Combustion Parameters of EGR Sweeps for Fuel D................ 84

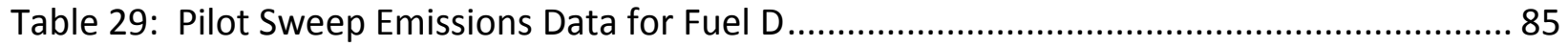

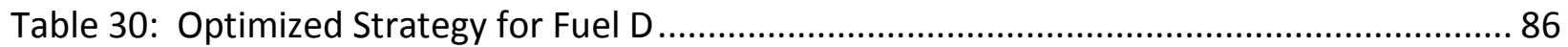

Table 31: Optimum Operating Strategy Emissions Results for Fuel D.................................. 86 
Table 32: Calculated In-cylinder Combustion Parameters at Optimized Strategy for Fuel D ..... 86

Table 33: Operating Condition to Examine Fuel Characteristic Effects .................................. 87

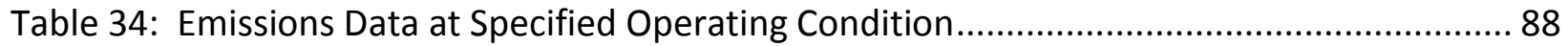

Table 35: Calculated In-cylinder Combustion Parameters of Each Fuel at Specified Operating

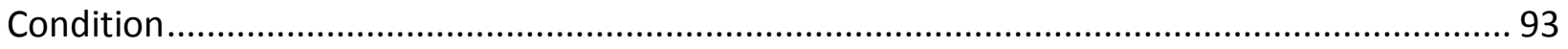

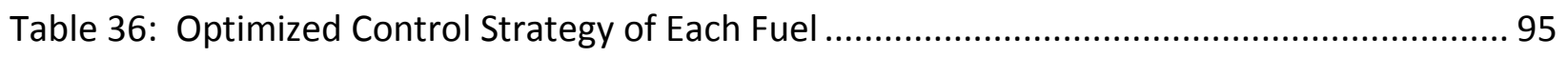

Table 37: Emissions Data at Optimized Control Strategy ....................................................... 96

Table 38: Calculated In-cylinder Combustion Parameters at Optimized Control Strategy of Each

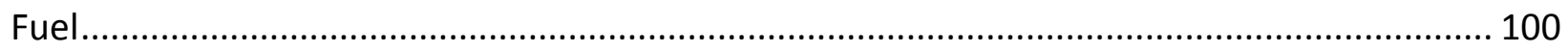

Table 39: Test Fuel Properties ..................................................................................... 110

Table 40: In-cylinder Pressure Sensor Manufacturer Specifications ..................................... 111

Table 41: Single Injection Emissions Data for Fuel A ..................................................... 112 


\section{Nomenclature}

$\beta$ $\theta$

ค

$\rho$ V

$\mathrm{AF}$

ASTM American Society for Testing and Materials

ATDC After Top Dead Center

AVFL Advanced Vehicle, Fuels and Lubricants

bmep Brake Mean Effective Pressure

BTDC Before Top Dead Center

BSFC Brake Specific Fuel Consumption

CAFE Corporate Average Fuel Economy

CAFEE Center for Alternative Fuels, Engines and Emissions

$C_{d} \quad$ Coefficient of Discharge

CFR Code of Federal Regulations

$\mathrm{Cl} \quad$ Compression Ignited

CO Carbon Monoxide

$\mathrm{CO}_{2} \quad$ Carbon Dioxide

CVS Constant Volume Sampling

d Venturi Throat Diameter

DAQ Data Acquisition

DPF Diesel Particulate Filter

ECU Engine Control Unit

EERL Engines and Emissions Research Laboratory

EGR Exhaust Gas Recirculation

EOC End of Combustion

FACE Fuels for Advanced Combustion Engines 


\begin{tabular}{|c|c|}
\hline $\mathrm{H}_{2} \mathrm{O}$ & Water \\
\hline $\mathrm{HC}$ & Hydrocarbon \\
\hline $\mathrm{HCCl}$ & Homogeneous Charge Compression Ignition \\
\hline HDDE & Heavy Duty Diesel Engine \\
\hline HECC & High Efficiency Clean Combustion \\
\hline HEPA & High Efficiency Particulate Air (Filter) \\
\hline HFID & Heated Flame Ionization Detector \\
\hline HRR & Heat Release Rate \\
\hline IVC & Intake Valve Closing \\
\hline $\mathrm{K}_{\mathrm{q}}$ & Venturi Flow Coefficient \\
\hline LFE & Laminar Flow Element \\
\hline LHV & Lower Heating Value \\
\hline \multirow[t]{2}{*}{ LTC } & Low Temperature Combustion \\
\hline & Mass Flowrate of Fuel \\
\hline MEXA & Motor Exhaust Gas Analyzer \\
\hline \multirow[t]{2}{*}{ MFB } & Mass Fraction Burned \\
\hline & Number of Cylinders \\
\hline $\mathrm{N}_{2}$ & Diatomic Nitrogen \\
\hline $\mathrm{N}_{2} \mathrm{O}$ & Nitrous Oxide \\
\hline NDIR & Non-Dispersal Infrared \\
\hline $\mathrm{NI}$ & National Instruments \\
\hline NO & Nitric Oxide \\
\hline $\mathrm{NO}_{x}$ & Oxides of Nitrogen \\
\hline $\mathrm{O}_{2}$ & Diatomic Oxygen \\
\hline OEM & Original Equipment Manufacturer \\
\hline \multirow[t]{3}{*}{ ORNL } & Oak Ridge National Laboratory \\
\hline & Pressure at Intake Valve Closing \\
\hline & Pressure at Specified Crank Angle \\
\hline $\mathrm{P}$ & Cylinder Pressure \\
\hline
\end{tabular}




\begin{tabular}{|c|c|}
\hline$\Delta \mathrm{P}$ & Pressure Drop across Venturi Throat \\
\hline $\mathrm{PCCl}$ & Premixed Charge Compression Ignition \\
\hline PM & Particulate Matter \\
\hline Q & Heat Released \\
\hline$Q_{s}$ & Standard Volumetric Flowrate \\
\hline $\mathrm{R}$ & Universal Gas Constant \\
\hline ROHR & Rate of Heat Release \\
\hline RPM & Revolutions per Minute \\
\hline RTD & Resistance Temperature Device \\
\hline SCR & Selective Catalytic Reduction \\
\hline SI & Spark Ignited \\
\hline SOC & Start of Combustion \\
\hline SOF & Soluble Organic Fraction \\
\hline SOI & Start of Injection \\
\hline \multirow[t]{3}{*}{ SSV } & Subsonic Venturi \\
\hline & Temperature at Intake Valve Closing \\
\hline & Temperature at Specified Crank Angle \\
\hline T50 & Temperature at $50 \%$ Burn \\
\hline T90 & Temperature at $90 \%$ Burn \\
\hline T95 & Temperature at $95 \%$ Burn \\
\hline TDC & Top Dead Center \\
\hline \multirow[t]{3}{*}{$\mathrm{THC}$} & Total Hydrocarbons \\
\hline & Volume at Intake Valve Closing \\
\hline & Volume at Specified Crank Angle \\
\hline V & Cylinder Volume \\
\hline VCR & Variable Compression Ratio \\
\hline VGT & Variable Geometry Turbocharger \\
\hline WVU & West Virginia University \\
\hline $\mathrm{Y}$ & Expansion Factor \\
\hline
\end{tabular}




\section{Introduction and Objectives}

\section{$1.1 \quad$ Introduction}

Advanced combustion has progressively become a topic of interest as government regulations have stringently reduced the allowable limits of engine-out emissions from internal combustion engines. A recent global proposal imposed by the Environmental Protection Agency (EPA), proposed a $20 \%$ reduction in both greenhouse gas emissions (GHG) emissions and fuel consumption by 2018 [1], leading advanced combustion techniques as an alternative to hybrid vehicle technology as a means to achieve the initiative.

Advanced combustion can typically be classified as homogeneous charge compression ignition $(\mathrm{HCCl})$ or premixed charge compression ignition $(\mathrm{PCCl})$. In $\mathrm{HCCl}$ combustion, a well mixed fuel and air mixture is spontaneously combusted, thus providing a homogeneous burn throughout the combustion process. By having an evenly distributed burn, fuel consumption is not only significantly decreased, but both oxides of nitrogen $\left(\mathrm{NO}_{\mathrm{x}}\right)$ and particulate matter (PM) are also drastically reduced compared to that of conventional combustion. $\mathrm{HCCl}$ has the ability to achieve the low PM emissions of a spark ignited (SI) engine and the high thermal efficiency of a compression ignited $(\mathrm{Cl})$ engine [2]. Similar to $\mathrm{HCCl}, \mathrm{PCCl}$ offers low $\mathrm{NO}_{x}$ and $\mathrm{PM}$ within a part load operating range with a quasi-homogenous fuel and air mixture.

A great deal of research has been performed on ways of controlling and sustaining $\mathrm{HCCl}-$ like events during steady state and transient engine operation. Simultaneous reductions in $\mathrm{NO}_{\mathrm{x}}$ PM and fuel consumption are mainly dependent on engine design, fuel properties and engine operating parameters such as exhaust gas recirculation (EGR) fraction and injection strategies. It is often important, in advanced combustion studies, to examine both the advantages and disadvantages of different fuels over a range of operating conditions and their effect on engine performance characteristics. The main disadvantage of advanced combustion, especially $\mathrm{HCCl}$, is the difficulty of controlling the combustion phasing on a transient basis. Other than identifying $\mathrm{HCCl}$ or $\mathrm{PCCl}$ as very limited $\mathrm{NO}_{\mathrm{x}}$ and $\mathrm{PM}$ emissions, computational in-cylinder combustion analyses such the heat release rate and mass fraction burned curves, can be utilized to characterize these forms of advanced combustion. 


\subsection{Objectives}

The main objective of this research was to experimentally examine the effect of EGR and fuel properties on advanced combustion strategies through in-cylinder pressure analyses. The secondary objectives of this research were to improve brake thermal efficiency without compromising the integrity of the engine and to determine the characteristics of a fuel that affect the achievable advanced combustion operating range of the test engine. 


\section{$2 \quad$ Literature Review}

This section examines the concept of advanced combustion operation and strategies associated with lowering engine-out emissions without the use of aftertreatment systems. Section 2.1 describes different advanced combustion techniques along with the operating parameters and engine geometries that may affect the quest for a simultaneous reduction in both $\mathrm{NO}_{\mathrm{x}}$ and $\mathrm{PM}$ from diesel engines. Section 2.2 examines in-cylinder pollutant formation and analysis techniques used to identify advanced combustion or predict engine-out emissions. Section 2.3 describes various fuel properties that may affect the pursuit of advanced combustion and the consequence they have on pollutant formation. Finally, $\$ 2.4$ examines a number of EGR configurations and how they are used to meet the very stringent regulations set forth by government agencies.

\subsection{Advanced Combustion in Diesel Engines}

\subsubsection{Introduction}

Diesel engines have historically been used in many production applications including heavy duty vehicles and numerous commercial products. Not only do they have high thermal efficiencies, but diesel engines are also very durable. A common dilemma with the diesel engine is the excess emissions of $\mathrm{NO}_{\mathrm{x}}$ and $\mathrm{PM}$. $\mathrm{NO}_{\mathrm{x}}$ is formed in the high temperature regions of combustion while PM is formed mainly within the fuel-rich regions of combustion. With emissions regulations becoming increasingly stringent, a simultaneous reduction in both $\mathrm{NO}_{\mathrm{x}}$ and $\mathrm{PM}$ is highly sought after. There are many ways to reduce both $\mathrm{NO}_{\mathrm{x}}$ and $\mathrm{PM}$ through advanced combustion methods, but $\mathrm{HCCl}$ is seemingly the most promising. 


\subsubsection{Homogeneous Charge Compression Ignition}

The concept of $\mathrm{HCCl}$ has been around for nearly two decades. First introduced as a way to reduce unburned hydrocarbon emissions and enhance part-load performance of a 2-stroke $\mathrm{SI}$ engine [2], $\mathrm{HCCl}$ has now become a method of simultaneously reducing both $\mathrm{NO}_{\mathrm{x}}$ and $\mathrm{PM}$ emissions without decreasing the thermal efficiency of diesel engines. The goal of $\mathrm{HCCl}$ is to eliminate locally rich or lean mixture regions through combusting a homogeneous mixture of fuel and air. By obtaining a homogenous fuel and air mixture, in theory, combustion will occur spontaneously throughout the combustion chamber as seen in Figure 1.
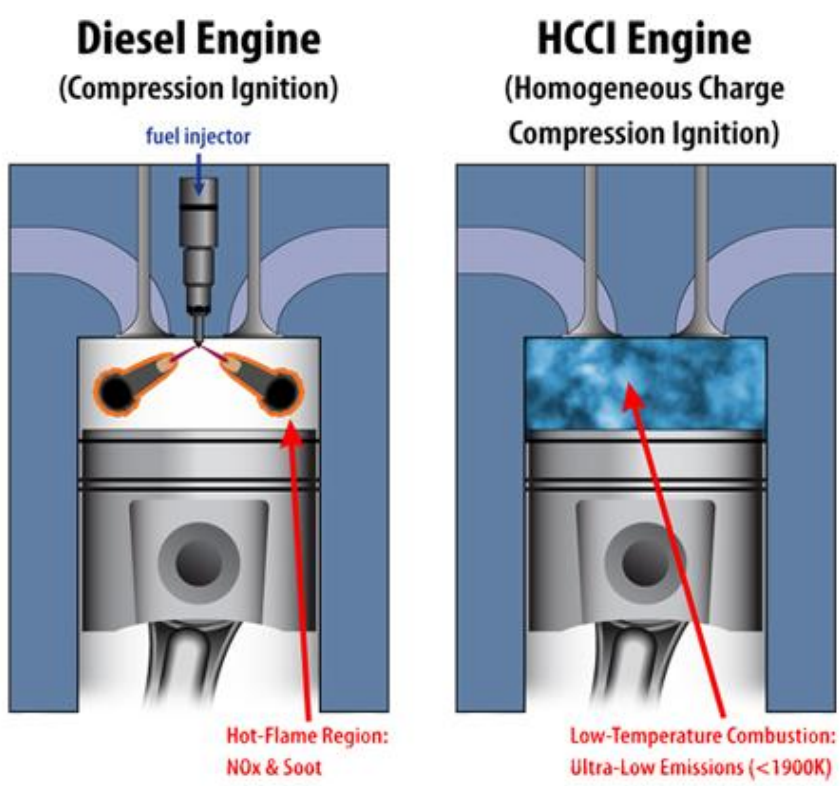

Figure 1: HCCI Combustion versus Conventional Diesel Combustion [3]

In order to have an effective $\mathrm{HCCl}$ combustion event, engine operating parameters and fuel characteristics must be optimized to enhance homogenous mixing. Typical engine operating parameters that must be controlled include injection timing, injection pressure, EGR, and valve timing [4]. Fuel characteristics such as cetane number, aromatics and fuel volatility also play a major role in the development of a homogenous mixture. Once $\mathrm{HCCl}$ combustion has occurred, it is very difficult to maintain and control throughout various engine speeds and loads. Due to the complexity of controlling $\mathrm{HCCl}$, various strategies have been developed to obtain stable $\mathrm{HCCl}$ under various operating conditions. 


\subsubsection{Effect of Operating Parameters on HCCI}

$\mathrm{HCCl}$ is difficult to control and maintain but can be achieved by optimizing engine operating parameters. Specific engine parameters such as EGR, start of injection, boost pressure, rail pressure, etc. can be controlled through the use of open source software such as Drivven or dSPACE controllers connected directly to an OEM wiring harness. The primary complexity in controlling $\mathrm{HCCl}$ is control of combustion near TDC without the occurrence of knock [2]. Injection timing must generally be advanced for a longer ignition delay to achieve true $\mathrm{HCCl}$, however advancing the injection timing typically leads to wall wetting, low combustion temperatures and high $\mathrm{HC}$ emissions. In this regard, injection timing must be optimized with other parameters such as injection pressure and intake air temperature to avoid misfire and knock. Engine knock is often associated with advanced combustion regimes but can be detrimental to an engines structural integrity, especially during single injection events. Engine knock can be quantified by a ringing intensity and corresponding "knock index". The intensity of knock can be identified based on an acoustic wave generated by pressure oscillations within the cylinder, often measured with a knock analyzer [5]. To suppress engine knock and limit fuel impinges on the cylinder wall, a dual injection or split-injection strategy is often used for advanced combustion studies. In a split-injection strategy, a pilot injection precedes the main injection by a specified duration to limit pressure rise rates and suppress $\mathrm{HC}$ emissions by allowing an extra stage of heat release prior to the main injection.

To compensate for the low combustion temperatures, intake air temperature is generally raised to increase the chance of auto-ignition. Increasing intake air temperatures reduce $\mathrm{PM}$ and $\mathrm{HC}$ emissions by elevating combustion flame intensity due to enhanced vaporization, as well as shifts the start of combustion closer to TDC for a more homogenous mixture [2]. EGR also plays an important role for determining homogeneity within the combustion chamber. By implementing EGR, a reduction in combustion temperature is observed due to EGR products entering the combustion chamber. Components of EGR, especially $\mathrm{CO}_{2}$ and $\mathrm{H}_{2} \mathrm{O}$, have a higher specific heat ratio than air thus act as a heat sink. The use of EGR, with proper EGR rates, can phase combustion near TDC and when combined with 
optimized injection timing, can lead to a homogenous mixture ultimately promoting $\mathrm{HCCl}$ operation.

Another important operating parameter to promote $\mathrm{HCCl}$ operation is equivalence ratio. The equivalence ratio is defined as the stoichiometric AF ratio divided by the actual AF ratio. The equivalence ratio has the largest effect on local combustion temperatures during the combustion process. Operating toward stoichiometric conditions can lead to rapid combustion that can be detrimental to an engine's integrity. For advanced combustion it is important to operate very lean by utilizing a higher AF ratio (lower equivalence ratio) than conventional $\mathrm{Cl}$ combustion as seen in Figure 2.

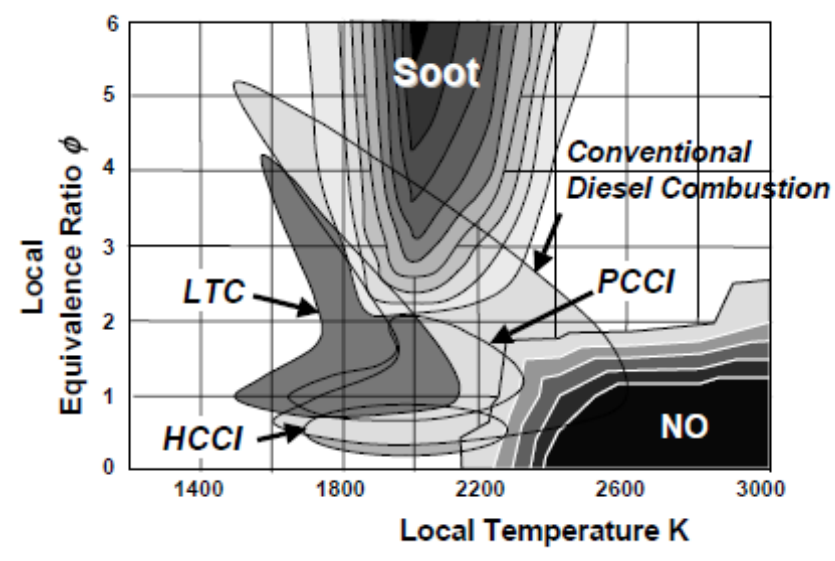

Figure 2: Local Equivalence Ratio versus Local Temperature for Various Advanced Combustion Strategies [6]

\subsubsection{Effect of Engine Geometry on HCCI}

The compression ratio of an engine plays a crucial role for the development of $\mathrm{HCCl}$. As compression ratio increases, auto-ignition of the fuel and air mixture occurs much before TDC. At low compression ratios, better efficiencies and power output are observed by shifting ignition timing toward an optimized location [2]. In order to optimize the compression ratio of an engine and to promote an $\mathrm{HCCl}$ combustion event, various operating parameters must be controlled over a range of compression ratios, hence a variable compression ratio (VCR) engine. Since VCRs are expensive and generally only used as single cylinder research engines, the combustion chamber is often modified to promote $\mathrm{HCCl}$ operation. The combustion chamber 
can have a significant effect on heat release rate due to turbulent mixing and mean velocity within the piston bowl. Generally, the heat release rate in direct injection (DI) and SI engines is proportional to turbulence and mean velocity; however in $\mathrm{HCCl}$ the opposite is observed [7]. A study at the Lund Institute of Technology compared a square bowled combustion chamber to a flat shaped combustion chamber and found that the peak combustion rate varied greatly between the two configurations. The square bowled configuration showed a significantly higher combustion rate, a much faster combustion duration and increased turbulence compared to the flat shaped combustion chamber. It was determined that the low combustion rate and high combustion duration in the square bowled chamber is a direct result of larger heat losses within the design, ultimately lowering combustion efficiency [7]. Figure 3 shows the turbulence, rate of heat release (ROHR) and mean velocity of the flat combustion chamber over a certain crank duration while Figure 4 illustrates the effect of the square combustion chamber on turbulence, ROHR and mean velocity over the same crank duration.

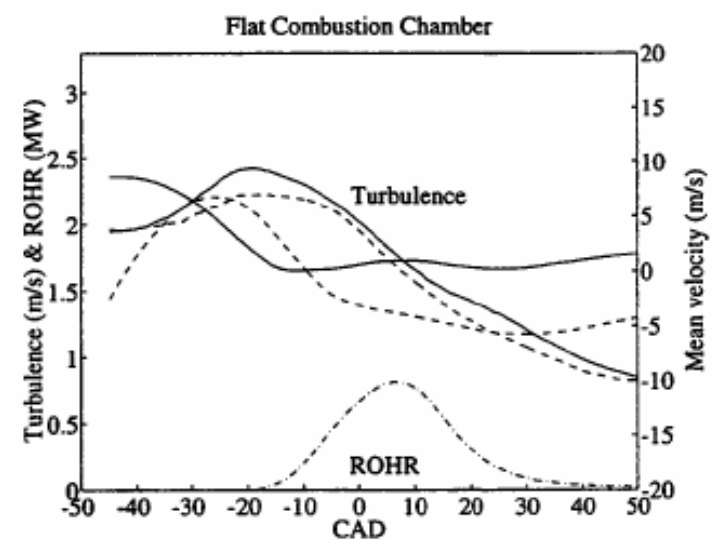

Figure 3: Mean Velocity, Turbulence and ROHR of Flat Combustion Chamber [7] 


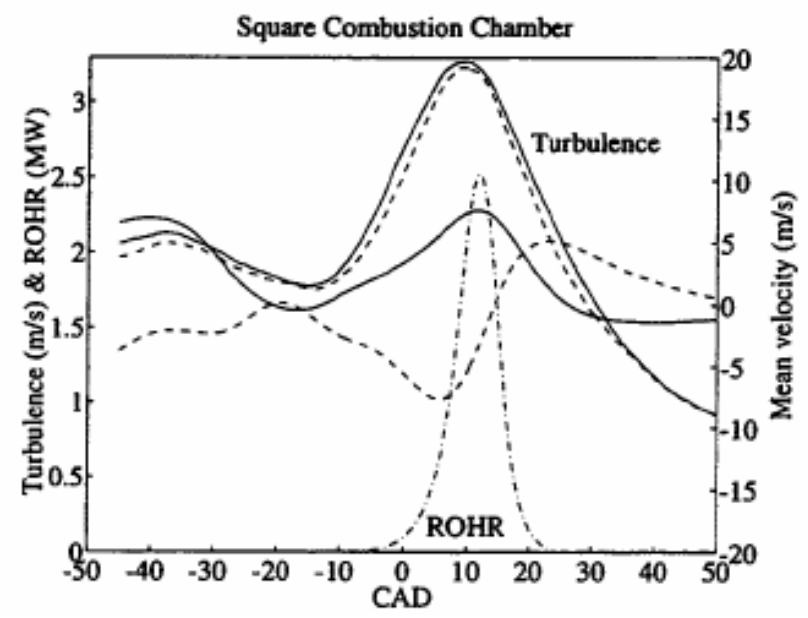

Figure 4: Mean Velocity, Turbulence and ROHR of Square Combustion Chamber [7]

\subsubsection{FACE and the Effect of Fuel Characteristics on Advanced Combustion}

The properties of a fuel can have a large impact on the characterization and operation of the advanced combustion regime, making the selection of a proper fuel crucial for advanced combustion methods. Two of the most important fuel properties when attempting to maintain advanced combustion are the cetane number and aromatic content. Lower cetane fuels typically require heating the intake air to achieve ignition due to combustibility characteristics. Higher cetane fuels generally exhibit a strong low temperature heat release rate as a result of early combustion phasing [8]. To develop a standard of fuel references for advanced combustion research, Fuels for Advanced Combustion Engines (FACE) were developed. The FACE goal is to provide a statistically engineered set of nine different fuels to enable researchers to quantify fuel effects on advanced combustion techniques. Fuel property ranges for the nine fuels were set according to the matrix seen in Figure 5. 


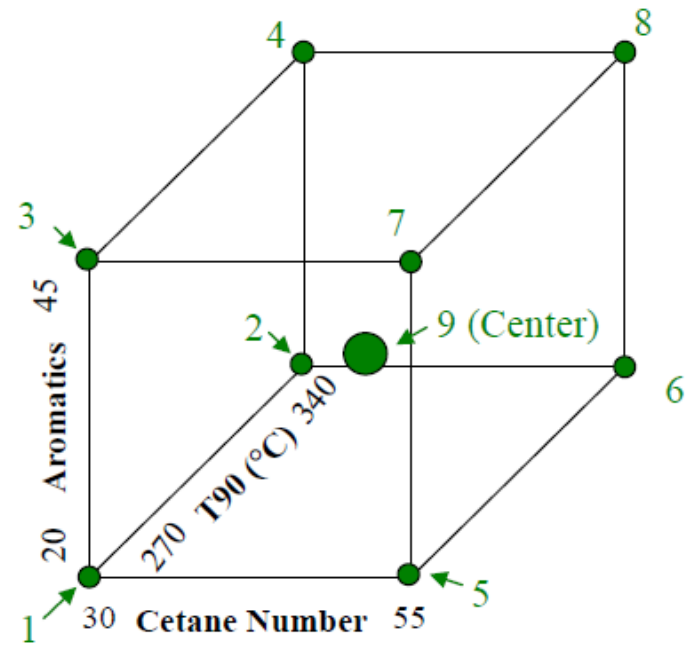

Figure 5: FACE Design Matrix [9]

Studies performed at ORNL using FACE fuels with a "high efficiency clean combustion" (HECC) strategy revealed that the operating range of injection timings was far more advanced for low cetane fuels than high cetane fuels. Low cetane fuels also resulted in nearly zero soot PM emissions with comparable $\mathrm{NO}_{\mathrm{x}}$ and $\mathrm{BSFC}$ of the high cetane fuels due to increased time for mixing from the longer ignition delay - favorable for advanced combustion methods. It was also revealed that fuels with lower aromatic content produce fewer $\mathrm{NO}_{\mathrm{x}}, \mathrm{PM}$ and $\mathrm{HC}$ emissions at the same injection timing [10].

\subsubsection{Premixed Charge Compression Ignition and Low Temperature Combustion}

Premixed charge compression ignition (PCCI) is collectively used as a term to describe a partial $\mathrm{HCCl}$ regime. Since obtaining and maintaining $\mathrm{HCCl}$ is so difficult, $\mathrm{PCCl}$ is simply a term used to describe an attempt toward reaching a homogenous mixture by pre-mixing the air/fuel prior to a combustion event. As seen in Figure 2, PCCl operates within a locally hotter region with a higher equivalence ratio compared to $\mathrm{HCCl}$. Most studies typically investigate $\mathrm{PCCl}$ rather than $\mathrm{HCCl}$ due to its relative ease of achievement in $\mathrm{Cl}$ engines, especially at part load operating conditions [11]. A study at ORNL revealed the traditional trade off of low $\mathrm{NO}_{\mathrm{x}}$ with higher soot PM and $\mathrm{HC}$ emissions. Figure 6 shows the improvement of lower $\mathrm{NO}_{\mathrm{x}}$ emissions with $\mathrm{PCCl}$ compared to conventional combustion. Low temperature combustion (LTC) is another advanced combustion regime that encompasses both $\mathrm{HCCl}$ and $\mathrm{PCCl}$. From Figure 2, 
LTC can be seen to operate at a much lower temperature than traditional $\mathrm{HCCl}$ and $\mathrm{PCCl}$ regimes at similar equivalence ratios.

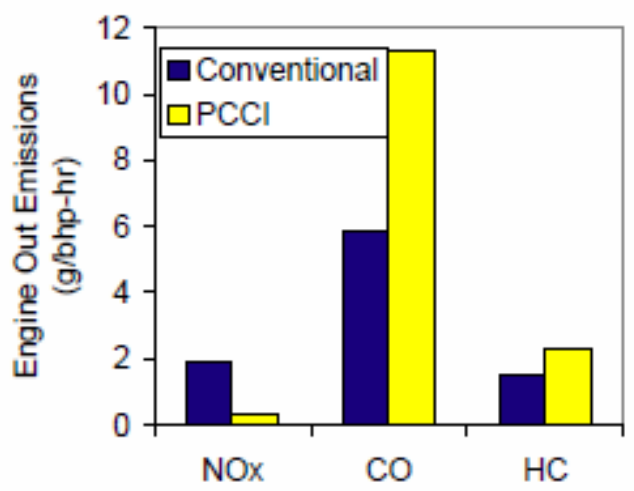

Figure 6: Engine-Out Emissions of Conventional versus PCCI Combustion [12]

\subsubsection{Summary of Advanced Combustion in Diesel Engines}

Although the concept of $\mathrm{HCCl}$ has existed for decades, it has recently become a topic of interest as government regulations on $\mathrm{NO}_{\mathrm{x}}$ and $\mathrm{PM}$ become increasingly stringent.

- $\mathrm{HCCl}$ can simultaneously reduce both NOx and PM emissions.

- Engine operating parameters such as injection timing, rail pressure and EGR ultimately determine advanced combustion.

- Advanced combustion regimes must be operated with higher AF ratios than convention $\mathrm{Cl}$ combustion.

- Lower cetane fuels are more suitable for advanced combustion due to longer ignition delay periods.

\section{$2.2 \quad$ Fuel Properties and Characteristics}

\subsubsection{Introduction}

The new emissions standards imposed by the Code of Federal Regulations (CFR) are set to significantly limit $\mathrm{NO}_{x}$ and $\mathrm{PM}$ emissions from diesel engines. On-road heavy-duty diesel 
emission standards have decreased $\mathrm{NO}_{\mathrm{x}}$ from $6.0 \mathrm{~g} / \mathrm{bhp}-\mathrm{hr}$ in 1990 to $0.20 \mathrm{~g} / \mathrm{bhp}$-hr in 2010. PM emissions went from $0.60 \mathrm{~g} / \mathrm{bhp}-\mathrm{hr}$ in 1990 to $0.01 \mathrm{~g} / \mathrm{bhp}-\mathrm{hr}$ in 2007 . In order to achieve such low emission requirements, various fuels and additives have been developed since the imposition, each one with various macroscopic properties and characteristics. This section describes some of the most important fuel properties that effect emissions such as cetane number, aromatic content, sulfur content, energy content, volatility and viscosity.

\subsubsection{Cetane Number}

The cetane number of a fuel is a measure of ignition quality or an ability to auto-ignite. There are various ways to determine the cetane number of a fuel such as the Cetane Index method (ASTM D4737) [13] or the ASTM D6890-04 Ignition Quality Tester [14], but the most reliable and current method to determine cetane number is the ASTM D613 method. The ASTM D613 method uses a VCR CFR certified engine and is based on the percentage of n-cetane and heptamethyl nonane in a proprietary blend that produces the same compression ratio to that of a test fuel [14]. An increase in cetane number typically reduces ignition delay and ultimately lowers cylinder temperatures and pressure rise rates. Due to the reduction in ignition delay, $\mathrm{HC}$ and $\mathrm{PM}$ emissions are higher but $\mathrm{NO}_{\mathrm{x}}$ is reduced as a result of low cylinder temperatures [10].

\subsubsection{Aromatic Content}

The aromatic hydrocarbon content is related to the amount of heat needed to initiate combustion and is determined by ASTM test method D1319 [16]. Hydrocarbons consist of carbon molecular rings of singular or double bonds. A single ring is referred to as a monocyclic aromatic while a double bond is considered a polycyclic aromatic. The D1319 test method uses a fluorescent indicator absorption technique. In this method, a sample of fuel is placed in a glass column packed with silica and fluorescent gel. Alcohol is then introduced into the glass column to separate out the hydrocarbons. The hydrocarbons are then visible under ultra-violet light as a layer whose volume percentage corresponds to the aromatic content of the fuel [17]. Studies have shown that $\mathrm{NO}_{\mathrm{x}}$ may increase as aromatic content rises due to higher cylinder 
temperatures needed to break the polycyclic bonds $[18,19]$. An increase in aromatic content is also known to lower the cetane number [19].

\subsubsection{Sulfur Content}

Since 2007, ultra-low sulfur fuel has been required for heavy-duty on-road diesel engines to initiate aftertreatment devices such as catalytic DPFs. Along with the regulated 0.01 g/bhp-hr PM in 2007, sulfur content was set to a maximum of $15 \mathrm{ppm}$ in fuel and consequently reduced in lube oil as well. The low sulfur fuel has proven to lower PM emissions by reducing sulfates formed during combustion [20]. A study by Navistar revealed that brake specific particulates increased by $0.025 \mathrm{~g} / \mathrm{bhp}$-hr for an increase of $0.1 \%$ sulfur content [21]. A catalytic process known as hydrodesulfurization is commonly used to separate the sulfur from heavy oils. In this process, a fraction of crude oil is mixed with hydrogen and passed over a catalyst bed at very high temperatures and pressures [22].

\subsubsection{Energy Content}

The energy content of diesel fuel is defined as the amount of energy per unit mass/volume released when combusted. Low-density fuel will have higher energy content per unit mass compared to a high-density fuel which will have higher energy content per unit volume. The specific energy content of a fuel can significantly affect engine power output unless a fuel quantity optimization injection strategy has been developed. Studies have shown an increase in fuel consumption and $\mathrm{CO}_{2}$ for lower energy content fuel [23].

\subsubsection{Volatility}

The volatility of a fuel is often referred to as the distillation temperature and usually given as T50, T90 or T95. The distillation temperature is the point at which $50 \%, 90 \%$ or $95 \%$ of the fuel, by volume, has condensed into a separate sample. Low volatility is then quantified by elevated T95 temperatures [24]. Some studies have suggested that an increase in volatility will increase PM emissions while others contribute the PM increase to fuel density [25]. Since volatility is a function of other fuel properties such as viscosity, cetane number and density, it is often difficult to determine the effect that volatility has on emissions. 


\subsubsection{Viscosity}

The viscosity of a liquid or gas is a property that refers to an ability to resist shear. Viscosity is mainly dependant on temperature while pressure has minimal effect. At high temperatures, viscosity for a liquid has a low resistance to shear and is therefore easier to flow. The opposite occurs for a gas, as temperature increases, viscosity also increases. The difference between the two lies within the molecular structure of the substance. Viscosity mainly affects fuel injection systems, especially the spray pattern [26], as low viscosity fuels can leak through injector seals.

\subsubsection{Summary of Fuel Properties and Characteristics}

Fuel properties can have a large effect on achieving advanced combustion and initiating aftertreatment devices, especially on modern on-road heavy-duty diesel engines. Depending on the fuel property, $\mathrm{NO}_{\mathrm{x}}$ and $\mathrm{PM}$ emissions can greatly be affected. Table 1 summarizes an increase in some of the common fuel property quantities and their corresponding effect on engine out $\mathrm{NO}_{\mathrm{x}}$ and $\mathrm{PM}$ emissions. Table 2 illustrates the $\mathrm{NO}_{\mathrm{x}}$ and $\mathrm{PM}$ emissions as a result of decreasing fuel property quantities. Note Table 1 and Table 2 were developed from research studies utilizing typical diesel combustion without aftertreatment devices.

Table 1: General Effect of Increasing Fuel Property Quantities on $\mathrm{NO}_{\mathrm{x}}$ and PM Emissions

\begin{tabular}{|l|c|c|}
\hline & NO $_{\mathbf{x}}$ & PM \\
\hline Increased Cetane Number & $\downarrow$ & $\uparrow$ \\
\hline Increased Aromatic Content & $\uparrow$ & $\uparrow$ \\
\hline Increased Sulfur Content & 0 & $\uparrow$ \\
\hline Increased Volatility & $\uparrow$ & $\uparrow$ \\
\hline
\end{tabular}

Table 2: General Effect of Decreasing Fuel Property Quantities on NOx and PM Emissions

\begin{tabular}{|l|c|c|}
\hline & NO $_{\mathbf{x}}$ & PM \\
\hline Decreased Cetane Number & $\uparrow$ & $\downarrow$ \\
\hline Decreased Aromatic Content & $\downarrow$ & $\downarrow$ \\
\hline Decreased Sulfur Content & 0 & $\downarrow$ \\
\hline Decreased Volatility & $\downarrow$ & $\downarrow$ \\
\hline
\end{tabular}




\subsection{In-cylinder Pollutant Formation and Analysis Techniques}

\subsubsection{Introduction}

$\mathrm{Cl}$ engines typically operate much leaner and use expensive aftertreatment devices to reduce $\mathrm{NO}_{\mathrm{x}}$ and $\mathrm{PM}$ emissions while $\mathrm{SI}$ engines operate at stoichiometric conditions and use catalytic converters to reduce $\mathrm{NO}_{x}, \mathrm{HC}$ and $\mathrm{CO}$. Products of combustion such as $\mathrm{CO}, \mathrm{CO}_{2}$ and $\mathrm{HC}$ that form during the combustion process of $\mathrm{Cl}$ engines are generally less concerning due to the much lower concentration compared to that of SI engines. Understanding how pollutant emissions form develops a basis for knowing how to control emission reducing devices or advanced combustion techniques. In-cylinder combustion analyses, such as the heat release profile, can often be used to quantify emissions and characterize fuel performance on advanced combustion regimes.

\subsubsection{NO Formation}

Due to the higher combustion temperatures of a $\mathrm{Cl}$ engine, the formation and development of oxides of nitrogen $\left(\mathrm{NO}_{\mathrm{x}}\right)$ are ultimately inevitable. $\mathrm{NO}_{\mathrm{x}}$ is produced when normally stable $\mathrm{N}_{2}$ molecules dissociate into monatomic nitrogen $(\mathrm{N})$ and react with oxygen. The dissociation that occurs is highly temperature dependent with excess NO being produced at temperatures of 2500-3000K [27]. NO $\mathrm{NO}_{\mathrm{x}}$ consists of both nitric oxide (NO) and nitrogen dioxide $\left(\mathrm{NO}_{2}\right)$ with $\mathrm{NO}$ comprising $70-90 \%$ of the total $\mathrm{NO}_{\mathrm{x}}[28]$. At temperatures less than $1200 \mathrm{~K}, \mathrm{NO}_{2}$ constitutes the remaining species of $\mathrm{NO}_{x}$ emitted following the combustion process. Three formation mechanisms are generally responsible for the formation of $\mathrm{NO}_{\mathrm{x}}$ : thermal, nitrous oxide $\left(\mathrm{N}_{2} \mathrm{O}\right)$ and prompt. The first and most significant is the thermal mechanism. The thermal mechanism, also referred to as the extended Zeldovich mechanism, accounts for the dissociation of $\mathrm{N}_{2}$ and $\mathrm{O}_{2}$ into their monatomic states (Equation 2-1, Equation 2-2, Equation 23). The $\mathrm{N}_{2} \mathrm{O}$ mechanism is less temperature dependant and occurs when the molecular $\mathrm{N}_{2}$ and $\mathrm{O}_{2}$ form $\mathrm{N}_{2} \mathrm{O}$, which then react with oxygen to form NO . Prompt $\mathrm{NO}_{\mathrm{x}}$, also less temperature dependent, is formed at the early stages of combustion with $\mathrm{N}_{2}$ reacting with fuel radicals that are then oxidized to form $\mathrm{NO}_{\mathrm{x}}$ [28]. Potential health problems associated with $\mathrm{NO}_{\mathrm{x}}$ include a 
number of respiratory diseases as well as toxic compounds being formed when $\mathrm{NO}_{\mathrm{x}}$ reacts with organic compounds.

\subsubsection{PM Formation}

Diesel PM consists mainly of solid carbon soot particles as well as other harmful pollutants such as sulfates, ash and soluble organic fractions. PM is often seen as black smoke emitted from the exhaust under vehicle acceleration. The solid carbon particles are formed as a result of incomplete combustion in fuel-rich zones with maximum PM emissions observed when the engine is at maximum load [27]. Sulfate formation is generally both lube oil and fuel dependant, but due to modern government regulations, ultra-low sulfur fuel is now required for all on-road diesel engines. Fuel additives are often put into the ultra-low sulfur fuel due to lubricating problems causing abnormal cylinder surface wear and sticking of injectors [27]. A diesel particulate filter (DPF) is typically used to control or virtually eliminate traces of PM on modern production vehicles while retrofit DPFs are implemented on older vehicles.

\subsubsection{CO Formation}

Carbon monoxide (CO) is formed from fuel oxidation during combustion and is contributed to insufficient time and oxygen available for the complete oxidation of $\mathrm{CO}$ to $\mathrm{CO}_{2}$. At near stoichiometric conditions, the formation of $\mathrm{CO}$ is highly non-linear with respect to the equivalence ratio. $\mathrm{CO}$ can form at the flame-front as well as from fuel interactions with cylinder walls. Since $\mathrm{Cl}$ engines typically operate much leaner than $\mathrm{SI}$ engines, $\mathrm{CO}$ emissions are much lower and far below government regulations.

\subsection{5 $\mathrm{CO}_{2}$ Formation}

Carbon dioxide $\left(\mathrm{CO}_{2}\right)$, which is considered a greenhouse gas, is a product of combustion that involves a hydrocarbon fuel. Increases in $\mathrm{CO}_{2}$ emissions usually indicate higher fuel 
consumption and higher brake specific PM. The best way to reduce $\mathrm{CO}_{2}$ emissions is to use higher thermal efficiency engines that ultimately consume less fuel [27].

\subsubsection{HC Formation}

Hydrocarbon emissions form due to an insufficient localized AF ratio (too high or too low) for auto-ignition of the fuel to occur. HC particles are condensed onto the surface of solid carbon soot due higher boiling and condensing temperatures of diesel fuel [27]. Two injection strategies lead to excess $\mathrm{HC}$ emissions in diesel engines; over-leaning and under-mixing. An over-leaning injection strategy involves a very lean AF ratio so that ignition delay is increased and complete combustion is limited [28]. Under-mixing involves fuel rich zones of combustion due to incomplete mixing with air. HC emissions can also form as a result of wall wetting or wall quenching due to fuel impingements on the cylinder wall and rapidly cooling prior to combustion. $\mathrm{HC}$ emissions have also been known to form as a result of trapped fuel in cylinder rings, excess fuel emitted after an injection event and from engine oil in the combustion chamber.

\subsubsection{Heat Release Rate}

The heat release rate (HRR) during combustion can reveal a number of characteristics when attempting to classify advanced combustion or predict $\mathrm{NO}_{\mathrm{x}}$ emissions. The HRR can be derived using the first law of thermodynamics combined with a few engineering assumptions. By utilizing the first law and assuming uniform pressure, uniform temperature and an ideal gas, the gross HRR can be written as a combination of specific heat ratios, instantaneous pressure and cylinder volume as well as crank angle (Equation 2-4). The net HRR (Equation 2-5) accounts for heat transfer to the cylinder walls (__ ～) using the well known "Woshni" method. 
In conventional combustion the HRR can be idealized by two different regions on a plot of HRR versus crank angle (Figure 7). The first region, the premixed burn portion, is typically used to predict $\mathrm{NO}_{\mathrm{x}}$ formation and can be denoted by the spike at the beginning of the combustion event. The second region is the diffusion portion, or rate controlled combustion, which occurs after the premix and comes to a gradual end ATDC. In an advanced combustion regime, a more rapid HRR can be observed with the premixed (first stage or low temperature reaction from Figure 8) combustion event occurring over a longer duration and an abrupt end to diffusion combustion event ATDC. Figure 8 depicts an advanced combustion HRR for both a single and split injection strategy.

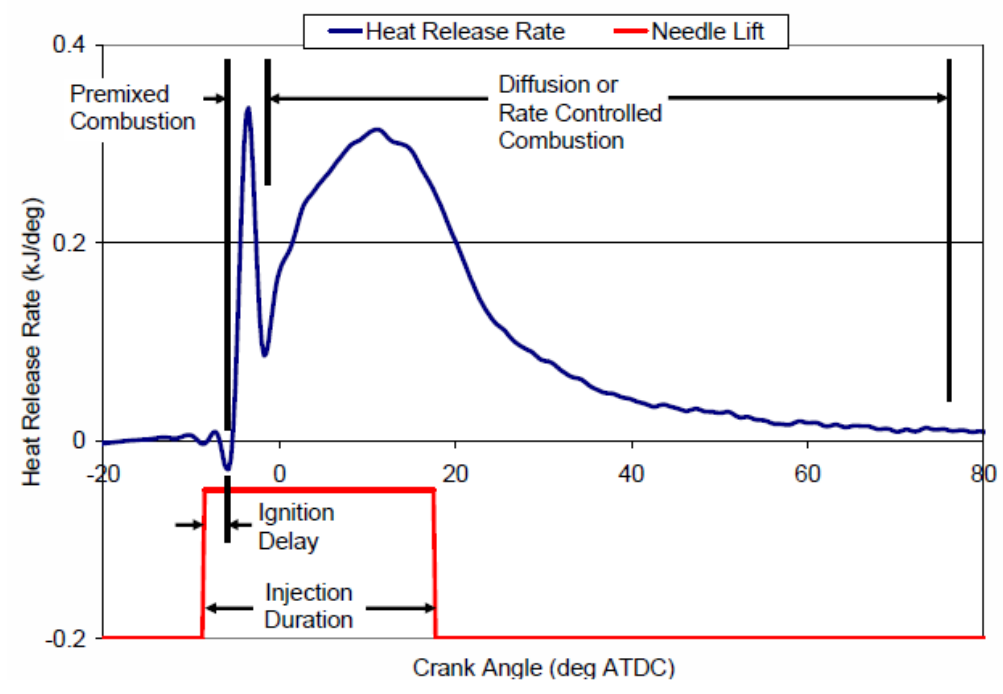

Figure 7: Heat Release Rate Curve for Conventional Combustion [29] 


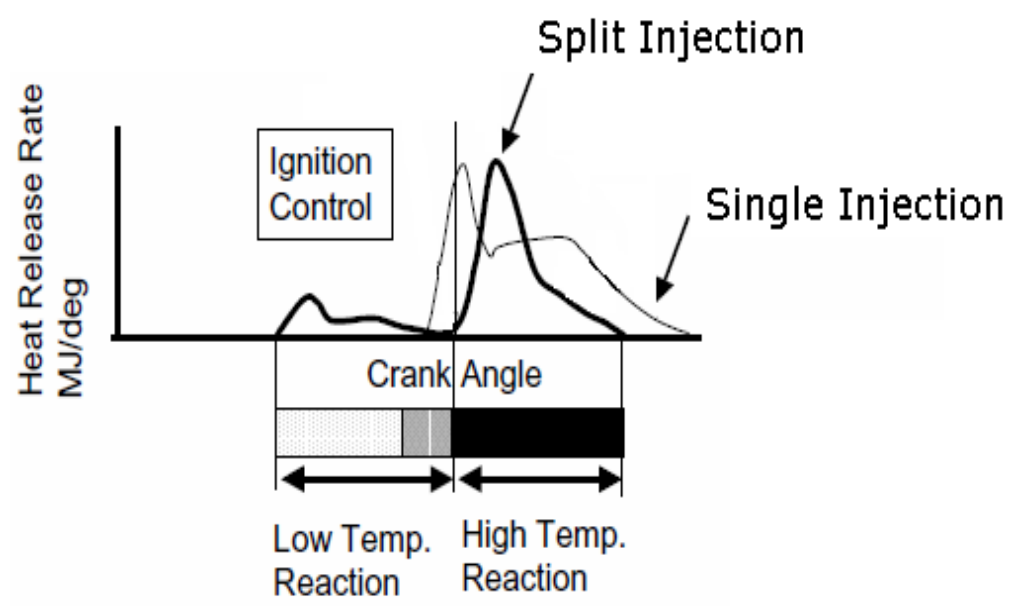

Figure 8: Advanced Combustion Heat Release Rate Curve for Single and Split Injection Events [30]

As previously mentioned, the HRR curve can reveal a number of characteristics about $\mathrm{NO}_{\mathrm{x}}$ formation. An increase in the heat release during premixed combustion alludes to a rapid increase in cylinder pressure and temperature, resulting in higher $\mathrm{NO}_{\mathrm{x}}$ emissions [30]. Similarly, if there is a decrease in the heat release during premixed combustion, $\mathrm{NO}_{\mathrm{x}}$ is elevated due to an increased amount of burning at the flame front [31, 32]. $\mathrm{NO}_{\mathrm{x}}$ may also become increased as the HRR shifts more toward TDC as a result of higher pressure and temperature. Typical $\mathrm{HCCl}$ operation has been associated with a longer ignition delay thus allowing more efficient mixing and overall lean equivalence ratio [33].

\subsubsection{Mass Fraction Burned}

The mass fraction burned (MFB) is analogous to the combustion process and can be used to evaluate fuel consumption over the crank duration. The MFB reflects engine design and overall performance based on the percentage of fuel that is burned at a specific crank angle [34]. Common values of the MFB occur at $10 \%, 50 \%$ and $90 \%$ durations. Values of MFB from the start of combustion to $50 \%$ indicate the intensity of the premixed combustion while the remaining duration indicates the intensity of the diffusion burn. Equation 2-6 represents the MFB as derived from the first law of thermodynamics. 


\subsubsection{Brake Specific Fuel Consumption}

The brake specific fuel consumption (BSFC) is a measure of engine fuel efficiency. BSFC is a function of speed and load and is therefore independent of engine size, making it a useful tool for the comparison of various internal combustion engines. Equation 2-7 represents the determination of BSFC, where is the mass flow of fuel to the engine and is the brake power calculated from brake torque and engine speed.

\subsubsection{Brake Thermal Efficiency}

An important parameter when evaluating the effectiveness of an engine is the brake thermal efficiency (BTE). BTE can be thought of as a ratio of work produced by the engine to the energy of the fuel needed to produce the work within a specific time. Ideally the BTE of an engine would be $100 \%$ but due to mechanical and heat losses within the engine; the typical BTE of a conventional diesel engine is only $25-40 \%$. The BTE of an engine can be calculated as a function of BSFC and the lower heating value of the fuel, Equation 2-7.

\subsubsection{In-cylinder Pressure}

In-cylinder pressure measurement provides an approach to obtain and evaluate both the HRR and MFB to establish real-time combustion characteristics. In-cylinder pressure can also be used to evaluate the effects on structural integrity of an engine by examining maximum cylinder pressures and determining maximum pressure rise rates. The in-cylinder pressure is typically obtained by a pressure sensor mounted in the cylinder head. Other methods include measuring the cylinder pressure via the force exerted on cylinder head bolts during operation [35]. Due to the cost of the sensors and instrumentation involved, in-cylinder pressure measurement is generally restricted to research specific engines. In this study, in-cylinder pressure was obtained via piezoelectric pressure transducers housed within custom glow plug adapters. 


\subsubsection{Summary of In-cylinder Pollutant Formation and Analysis Techniques}

The importance of understanding how pollutants are formed and ways to characterize emissions based on in-cylinder combustion measurements are crucial for the development and establishment of modern emissions reducing devices. Harmful emissions, especially $\mathrm{NO}_{x}, \mathrm{PM}$, and $\mathrm{HC}$ have become the focus of modern regulations involving both on-road and off-road diesel engines. These pollutants and in-cylinder techniques to identify these pollutants were researched with the following conclusions.

- $\mathrm{NO}_{\mathrm{x}}$ is formed through three formation mechanisms: thermal, $\mathrm{N}_{2} \mathrm{O}$ and prompt

- Thermal $\mathrm{NO}_{x}$ has the greatest effect on $\mathrm{NO}_{x}$ formation

- PM is a result of incomplete combustion

- HC emissions can result from unburned fuel in crevices or due to wall wetting

- An increase in heat release rate during premixed combustion results in higher $\mathrm{NO}_{\mathrm{x}}$ emissions

- Decrease in heat release rate during premixed combustion results in higher $\mathrm{NO}_{\mathrm{x}}$ emissions due to increased burning at the flame front

- $\mathrm{HCCl}$ is more likely to be achieved with longer ignition delay due to sufficient mixing

- Mass fraction burned gives the percentage of fuel burned over a particular crank angle

\subsection{Exhaust Gas Recirculation in Diesel Engines}

\subsubsection{Introduction}

Unlike spark ignited engines, compression ignition engines operate leaner with a much higher combustion temperature, as they rely on compressing a gas to achieve combustion. $\mathrm{NO}_{\mathrm{x}}$ is generally formed during combustion by the nitrogen, from the air and fuel, reacting with oxygen, from the intake air, at very high temperatures in the combustion chamber, typically above 2000K. Since diesel engines operate with such high combustion temperatures, $\mathrm{NO}_{\mathrm{x}}$ formation is inevitable. PM can vary with EGR rates but is generally controlled by increasing injection pressure and using a better quality fuel, while $\mathrm{HC}$ and $\mathrm{CO}$ are secondary to $\mathrm{NO}_{x}$ and PM formation. Over the years, stringent emissions regulations have forced manufacturers to 
produce cleaner diesel engines. Figure 9 depicts the increasing emission regulations set forth by the governments of Europe, Japan and the United States upon heavy duty diesel engine manufacturers.

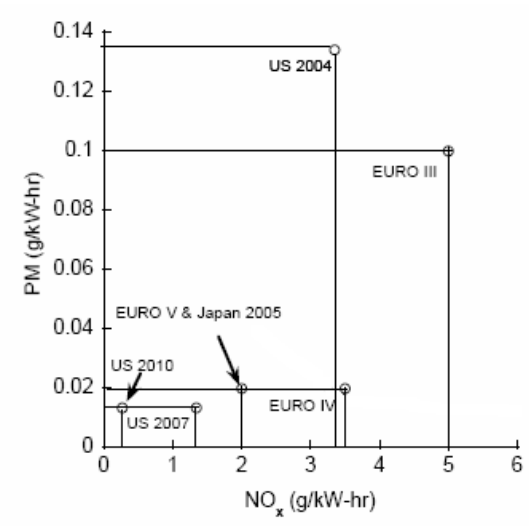

Figure 9: On Road Heavy Duty Diesel Engines Emission Regulations Requirements [36]

One of the leading ways to reduce $\mathrm{NO}_{\mathrm{x}}$ in diesel engines is through the use of EGR. EGR allows a portion of the exhaust gas to be re-circulated into the intake manifold of the engine prior to entering the cylinder. By introducing a diluting gas into the intake stream, the intake charge of the engine is diluted and the adiabatic flame temperature is significantly reduced. A typical problem in utilizing EGR is that if the EGR rate is too high, combustion temperature decreases so much that combustion may become very erratic. Although EGR reduces $\mathrm{NO}_{\mathrm{x}}$ formation, there is generally a trade off with the formation of PM. At higher EGR rates, PM becomes more apparent as combustion is becoming inherently less efficient. Many studies are being examined to optimize EGR rates to have less of an effect on PM formation [37].

With the introduction of EGR into the intake, three effects work in conjunction to modify combustion and ultimately lower $\mathrm{NO}_{x}$ production: dilute, thermal and chemical. The dilute effect is achieved by reducing the amount of oxygen available for combustion by replacing the incoming fresh air with exhaust gas. Studies have shown that an oxygen reduction for combustion reduces $\mathrm{NO}_{x}$, increases $\mathrm{PM}$, and produces a significantly longer ignition delay [38]. The thermal effect takes place due to the increasing heat capacity of the intake charge from the high concentrations of $\mathrm{CO}_{2}$ and water vapor in the re-circulated exhaust gas. This increased heat capacity correspondingly causes a lower combustion (peak) cylinder 
temperature that ultimately reduces $\mathrm{NO}_{\mathrm{x}}$ production. The chemical effect is a direct result of dissociation of $\mathrm{CO}_{2}$ and water vapor at very high temperatures. Dissociation absorbs thermal energy from the combustion process to lower peak cylinder temperatures.

By comparing each of the three effects, $\mathrm{CO}_{2}$ has a higher dilute effect than the water vapor due to its high specific heat in the exhaust gas. The thermal effect is higher for water vapor than $\mathrm{CO}_{2}$ since water vapor has a higher specific heat capacity. The chemical effect is higher for $\mathrm{CO}_{2}$ than water vapor since water vapor requires higher combustion temperatures to dissociate [39].

\subsubsection{Constraints Placed on $\mathrm{NO}_{\mathrm{x}}, \mathrm{PM}$ and Fuel Consumption}

With the growing demand for cleaner, more efficient engines comes the declaration of government impositions for lower $\mathrm{NO}_{\mathrm{x}}$ and $\mathrm{PM}$ emissions as well as increased fuel economy. All emissions regulations are imposed under the Code of Federal Regulations and are classified in Tiers for light duty engines. Tier 1 standards are imposed for all light duty vehicles from 19941997. Tier 2, which is a more stringent regulation, are set for all light duty vehicles produced from 2004-2009. In $2004 \mathrm{NO}_{\mathrm{x}}$ production for light duty vehicles was regulated at approximately $0.20 \mathrm{~g} / \mathrm{mile}$ while PM was regulated at $0.01 \mathrm{~g} / \mathrm{mile}$. Growing concerns between the connection of global warming and vehicle emissions pushed the $\mathrm{NO}_{\mathrm{x}}$ production limit to $0.07 \mathrm{~g} /$ mile under the new Tier 2 Emissions Standards and PM to $0.01 \mathrm{~g} / \mathrm{mile}$. Heavy duty diesel engines were regulated from $6.0 \mathrm{~g} / \mathrm{bhp}-\mathrm{hr} \mathrm{NO}$ x production in 1990 to just $0.20 \mathrm{~g} / \mathrm{bhp}-\mathrm{hr}$ in 2010 . PM emissions went from $0.60 \mathrm{~g} / \mathrm{bhp}-\mathrm{hr}$ in 1990 to $0.01 \mathrm{~g} / \mathrm{bhp}-\mathrm{hr}$ in 2007 . The fuel economy of vehicles is set by the Corporate Average Fuel Economy (CAFE). In 1990, light duty vehicles were regulated at a combined $20.5 \mathrm{mpg}$ while in 2009 fuel economy is regulated at $23.1 \mathrm{mpg}$ [40].

\subsubsection{External EGR}

EGR is a fairly simple concept that allows exhaust gases to re-enter the intake manifold to decrease $\mathrm{NO}_{\mathrm{x}}$ production by lowering peak cylinder temperatures. As previously mentioned, EGR has had advancements throughout the years, but the most common EGR system consists of an EGR valve, flow tubes, heat exchanger and a pulse width modulation control unit. The external EGR process begins at the exhaust manifold. After in-cylinder combustion has 
occurred, the exhaust valve is opened and gas is introduced into the exhaust manifold. Once in the manifold, the desired amount of exhaust gas is driven through a tubing network and into a tube and shell heat exchanger. Although an EGR system can be implemented without a heat exchanger (hot EGR), studies have shown that cooled EGR can be up to $30 \%$ more efficient in reducing $\mathrm{NO}_{\mathrm{x}}$ emissions [41]. Post heat exchanger, an EGR valve is electronically controlled to regulate exhaust flow, while a variable diameter orifice plate regulates the flow rate of exhaust gas. After a proper dosing of EGR has been introduced into the intake, the dilution process occurs. The intake charge temperature depends on a number of factors. The most important factor affecting intake charge temperature is the gas temperature exiting the heat exchanger. To insure proper temperature and ultimately EGR rate, coolant can flow to and from the heat exchanger to either increase or decrease the intake charge temperature. EGR rate is determined, via the engine ECU, from a number of factors including engine temperature, engine speed and manifold air pressure, which are all monitored electronically. Studies have been examined to achieve optimum EGR rate by balancing the reduction in $\mathrm{NO}_{\mathrm{x}}$ and the formation of PM.

\subsubsection{Internal EGR}

As opposed to external EGR, internal EGR traps a portion of exhaust gas within the combustion chamber after a complete cycle has taken place. The trapped exhaust gas is then mixed with incoming air to reduce cylinder temperatures. The advantage of an internal EGR system is that it requires no additional hardware to regulate EGR flow and is far less complex than the external EGR system but may require VVT. The main disadvantage of an internal EGR system is excessive valvetrain wear due to high soot concentrations in the oil as a result of high EGR rates.

\subsubsection{High Pressure EGR}

High pressure EGR systems route a portion of the exhaust gas taken before the turbocharger, relying on a differential pressure to supply EGR back into the intake. High pressure control is either monitored through the VGT or a back pressure valve located downstream of the turbocharger. A typical complication of the high pressure system is that 
particulate matter or soot that remains in the exhaust gas upon entering the intake stream. By introducing "polluted" exhaust gas, engine wear rate may also be significantly increased [42]. High pressure EGR systems are typically implemented into many production vehicles compared to low pressure EGR systems.

\subsubsection{Low Pressure EGR}

As opposed to the high pressure EGR system, the low pressure EGR system is often used in retrofit applications where $\mathrm{NO}_{\mathrm{x}}$ and $\mathrm{PM}$ emissions need to be significantly reduced on vehicles not originally equipped with an EGR system. The low pressure EGR system takes a portion of the exhaust gas after the turbocharger and any aftertreatment devices. By taking a sample of exhaust gas downstream of the turbocharger and aftertreatment devices, PM or soot re-entering the combustion chamber is virtually eliminated. Another advantage of a low pressure system is that it can be implemented on virtually any engine without engine modifications. Many retrofit, low pressure EGR systems offer $\mathrm{NO}_{\mathrm{x}}$ reductions of $25-50 \%$ and a reduction in PM of over $90 \%$ along with proper aftertreatment systems [43].

\subsubsection{Hot EGR System}

Unlike a cooled EGR system, the hot EGR system does not require a sophisticated control scheme or the use of a heat exchanger. Instead of routing the exhaust gas through an air to water heat exchanger, a hot EGR system simply routes the hot exhaust gas back into the combustion chamber. Although peak combustion temperatures may not be as low compared to a cooled EGR system, the hot EGR system does significantly reduce $\mathrm{NO}_{\mathrm{x}}$ and $\mathrm{PM}$ emissions however, especially in high pressure retrofit applications.

\subsubsection{Cooled EGR System}

Cooled EGR systems have been employed into production heavy duty diesel engines since late 2002. A cooled EGR system contains a heat exchanger as described in $\$ 2.4 .3$ to

ultimately lower the temperature of the re-circulated exhaust gas. Depending on the application, most cooled EGR systems divert anywhere from 5-30\% of the engines' exhaust through an air to water heat exchanger [44]. Although a cooled EGR system requires a more 
sophisticated control system, all of the sensors and electronics are monitored by the engines' ECU. Cooled EGR systems, implemented on most modern production diesel engines, are typically combined with the high pressure systems. Figure 10 shows the effect of hot and cooled EGR on $\mathrm{NO}_{x}$ emissions versus EGR rate. A study at Tsinghua University found that $\mathrm{NO}_{\mathrm{x}}$ decreased $70-80 \%$ by using EGR within a certain operating range [45]. The effect of EGR in direct injection diesel engines has been extensively investigated and led research to conclude that the rate of EGR plays the biggest role in $\mathrm{NO}_{x}$ emissions and PM production. The study revealed that at lower rates of EGR, higher injection pressure and a reduction in EGR orifice diameter was needed to effectively lower $\mathrm{NO}_{x}$ and PM emissions. At higher EGR rates, lower $\mathrm{NO}_{x}$ was observed at the expense of high PM concentration. It was concluded that an EGR rate of $40 \%$ achieved lowest $\mathrm{NO}_{\mathrm{x}}$ emissions without the tradeoff of high PM.

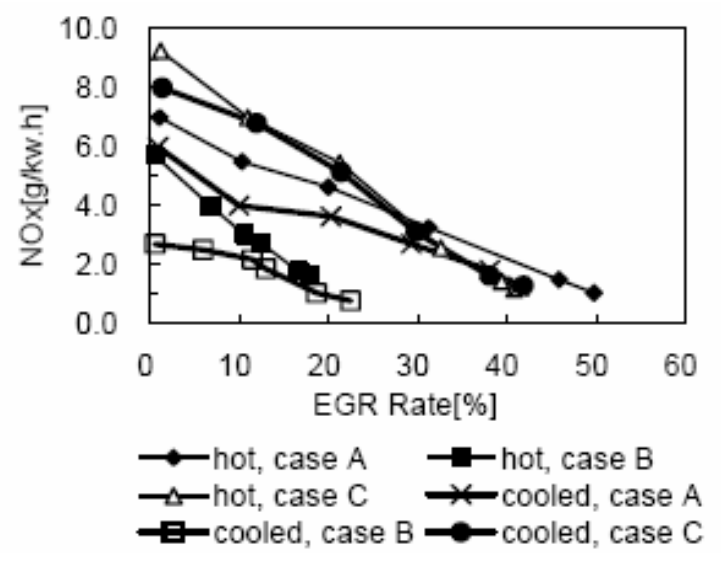

Figure 10: Effect of Hot and Cooled EGR on NOx Emissions vs. EGR Rate [45]

As seen from the figure, $\mathrm{NO}_{x}$ emissions drastically decrease with an increase in EGR rate. Note cases $A, B$ and $C$ are tests performed at different engine loads. Since hot EGR brings heat into the cylinder, an increase in in-cylinder temperatures and ultimately the thermal charge of the engine occurs. For hot EGR systems, low $\mathrm{NO}_{x}$ emissions are typically counteracted by EGR. From Figure 10 it can be determined that cooled EGR results in a much greater $\mathrm{NO}_{\mathrm{x}}$ reduction in a common rail injection system compared to a hot EGR system. Following a similar trend, Figure 11 illustrates the PM emissions for a cooled EGR system compared to a hot EGR system. From Figure 11 it is clear that cooled EGR produces a significantly less amount of PM compared to the hot EGR system, especially at higher EGR rates. 


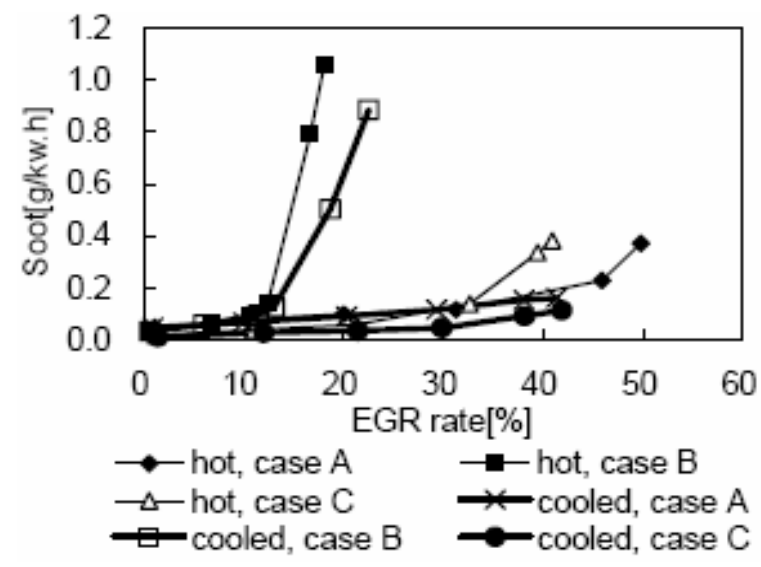

Figure 11: Effect of Hot and Cooled EGR on PM Emissions [45]

\subsubsection{Effect of EGR on Fuel Consumption}

Fuel consumption is heavily influenced by the amount of EGR entering each cylinder. If EGR rates are minimal or too great, fuel consumption may increase due to incomplete combustion. To reduce the chance of incomplete combustion, optimization of engine operating parameters is often maximized to provide desired fuel consumption. A study at Central Engineering Laboratories discovered that fuel consumption steadily increased at EGR rates of $10-20 \%$ under light loads [46]. A reduction in pumping losses and cooling losses (due to decreased combustion temperatures) were found to be the main contributors of the increase in fuel economy. With a demand from the EPA to produce near zero emissions and meet fuel economy criteria, many manufacturers are moving to a modern SCR-EGR system.

\subsubsection{Effect of EGR on Engine Wear}

A common conception is that an EGR system will decrease an engine's life and lead to excessive engine wear. It is thought that the soot generated from EGR can absorb anti-wear additives in oil. A study at Loughborough University examined the effect of high pressure EGR on piston rings, cylinder liner and engine oil. The study showed that the wear on piston rings and cylinder liner increased as the level of EGR increased. "At full load, EGR rates above 10\% increased engine wear. Engine wear also increased with oil age" [47]. The rate of oil aging also increased as the EGR level increased. The study also concluded that high pressure EGR increased component wear at high loads but at low loads, component wear was very low. The 
wear increase from EGR can be contributed to the increase in carbon content as seen in Figure 12.

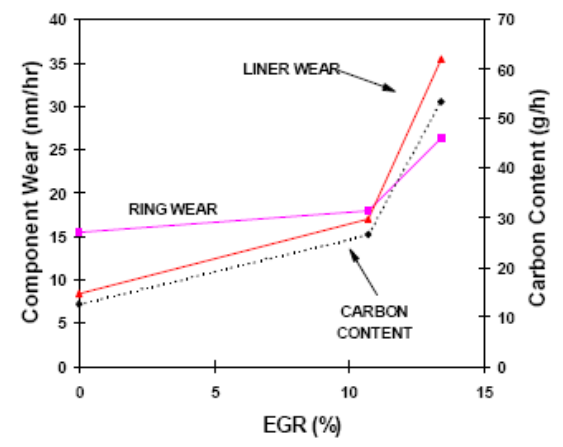

Figure 12: Component Wear and Carbon Content versus EGR Rate [47]

\subsubsection{Summary of EGR in Diesel Engines}

EGR has been used in diesel engines since the early 1970's as a method to control harmful emissions such as $\mathrm{NO}_{x}$ and PM. Since the introduction of EGR in consumer available vehicles, EGR technology has become increasingly advanced.

- Low Pressure EGR systems can reduce $\mathrm{NO}_{x}$ and PM emissions by, $25-50 \%$ and $90 \%$, respectively, in retrofit applications.

- Cooled EGR systems can be up to $30 \%$ more efficient than hot EGR systems.

- $\mathrm{NO}_{\mathrm{x}}$ and PM can fluctuate with $\mathrm{EGR}$ rate in DI engines.

- Component wear of an EGR equipped vehicle increases with EGR rate.

- Engine wear becomes significant at EGR rates above $10 \%$.

- The rate of engine oil aging increases as EGR rate is increased. 


\section{Experimental Setup and Test Equipment}

\subsection{Introduction}

All testing discussed in this document was conducted at West Virginia University's Center for Alternative Fuels, Engines and Emissions (CAFEE) and performed in the Engines and Emissions Research Laboratory (EERL). The EERL implements a full-scale dilution tunnel thought to accurately simulate the mixing of exhaust gas with ambient air conditions to replicate a "real-world" environment. The test engine was purchased for testing incorporated by the project sponsor and was intended to replicate the engines used by ORNL and Argonne National Laboratory in similar testing platforms. No internal parts of the engine were altered to enhance or initiate an advanced combustion strategy throughout the test period.

\section{$3.2 \quad$ Test Engine}

Experiments were conducted on the engine shown in Figure 13. Throughout the testing performed at WVU, a much larger EGR cooler from a heavy duty diesel engine (HDDE) was used to replace the OEM EGR cooler which was unable to provide sufficient cooling of the exhaust gas under high EGR percentages (see Appendix). A heated intake element was also added to the test engine to assist the combustion process during cold starts with low cetane fuels by elevating intake temperatures and enhancing any advanced combustion regimes through timing advancement and EGR rates. Figure 79 shows the test engine with the oversized EGR cooler and heated intake element. 


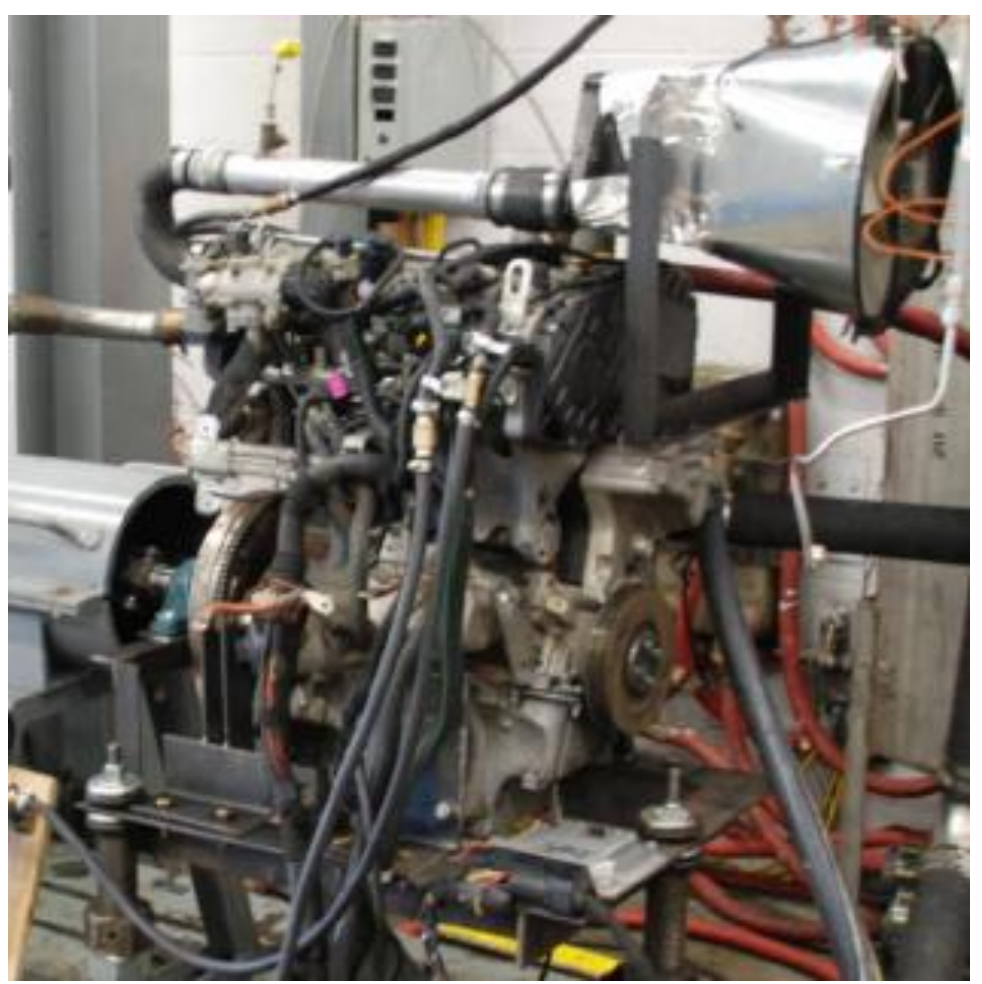

Figure 13: WVU Test Engine

The engine was attached at the driveshaft, to the dynamometer, through a custom flywheel/clutch assembly. A custom flywheel was designed and implemented onto the test engine due to an insufficient dual-mass flywheel setup on the stock configuration. Thermocouples were added at each intake and exhaust port to record temperatures at these locations. Couplings were fabricated into the intake and exhaust manifold to measure oxygen concentration. Existing laboratory thermocouples were used at other locations of significance such as intake air, exhaust, fuel, coolant and oil to measure temperature. Table 3 shows specifications of the test engine used by WVU. 
Table 3: Test Engine Specifications

\begin{tabular}{|l|c|}
\hline Type & CDTi Diesel Engine \\
\hline Manufacturer & General Motors \\
\hline Model & Z19DT \\
\hline Intake System & VGT \\
\hline Valve Configuration & 2 valves per cylinder \\
\hline Year & 2005 \\
\hline Configuration & In-line 4 Cylinder \\
\hline Displacement & $1.9 \mathrm{~L}$ \\
\hline Bore & $82 \mathrm{~mm}$ \\
\hline Stroke & $90.4 \mathrm{~mm}$ \\
\hline Compression Ratio & $18: 1$ \\
\hline Injection System & Common Rail \\
\hline EGR & Cooled, External \\
\hline Rated Power & $88 \mathrm{~kW} @ 4000$ RPM \\
\hline
\end{tabular}

\subsection{In-cylinder Pressure Measurement}

In order to determine the in-cylinder pressure during engine operation, Kistler 6056A41 piezoelectric crystal pressure sensors (Figure 14) were implemented into each of the four cylinders of the engine. Each sensor was adapted into the engine cylinder via custom glow plug adapters that replaced the stock glow plug, as seen in Figure 15. The manufacturer specifications for the pressure sensors are provided Table 40. Due to the accumulation of carbon on the pressure sensors, cleaning was crucial in order to obtain accurate combustion data. Cleaning was periodically performed on each sensor with a special solvent, while the adapters were cleaned with traditional oven cleaner. Each end of the sensor wire, which connects to the charge amplifier, was also cleaned with special solvent to remove any accumulation of oil and surface debris. Figure 16 shows the Kistler 5010B1 charge amplifiers which were used to convert the dynamic charge from the pressure sensor, to an amplified voltage that was easily read by the DAQ system. 
Figure 14: Kistler 6056A41 Pressure Sensor

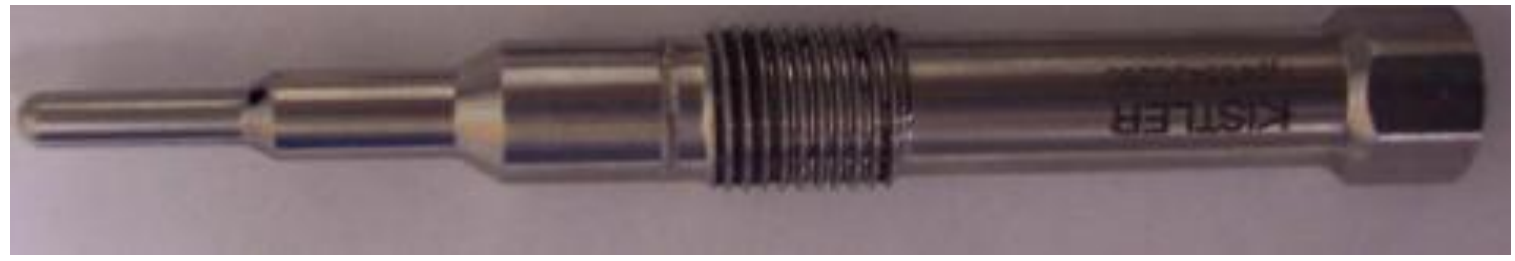

Figure 15: Pressure Sensor Glow Plug Adapter

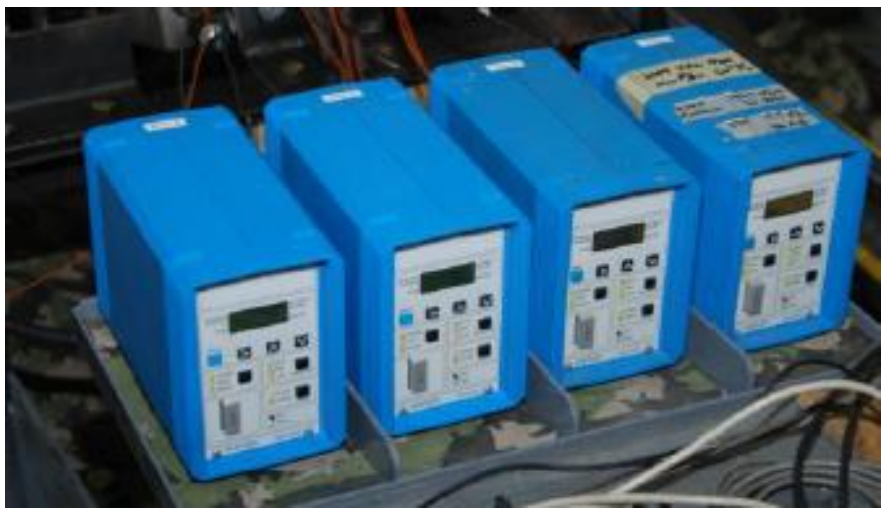

Figure 16: Kistler 5010B1 Charge Amplifiers

A custom analysis software and data acquisition system, developed by Dr. John Nuszkowski of West Virginia University, was used for the combustion analysis. The custom software allowed for real-time pressure, temperature, HRR and MFB plots to be accessed during testing to verify engine operation and/or misfiring events. Numerous derived and calculated combustion characteristics such as the maximum pressure, pressure rise rates, start of combustion, end of combustion, maximum temperature, etc. were also available in real-time during testing. Figure 17 depicts a real-time screenshot captured during a testing event. The combustion acquisition system used a stand-alone computer located in the test cell for ease of access. Due to computational limitations, the combustion acquisition system was only associated with the laboratory DAQ system through PM triggering i.e. to start and stop data collection. 

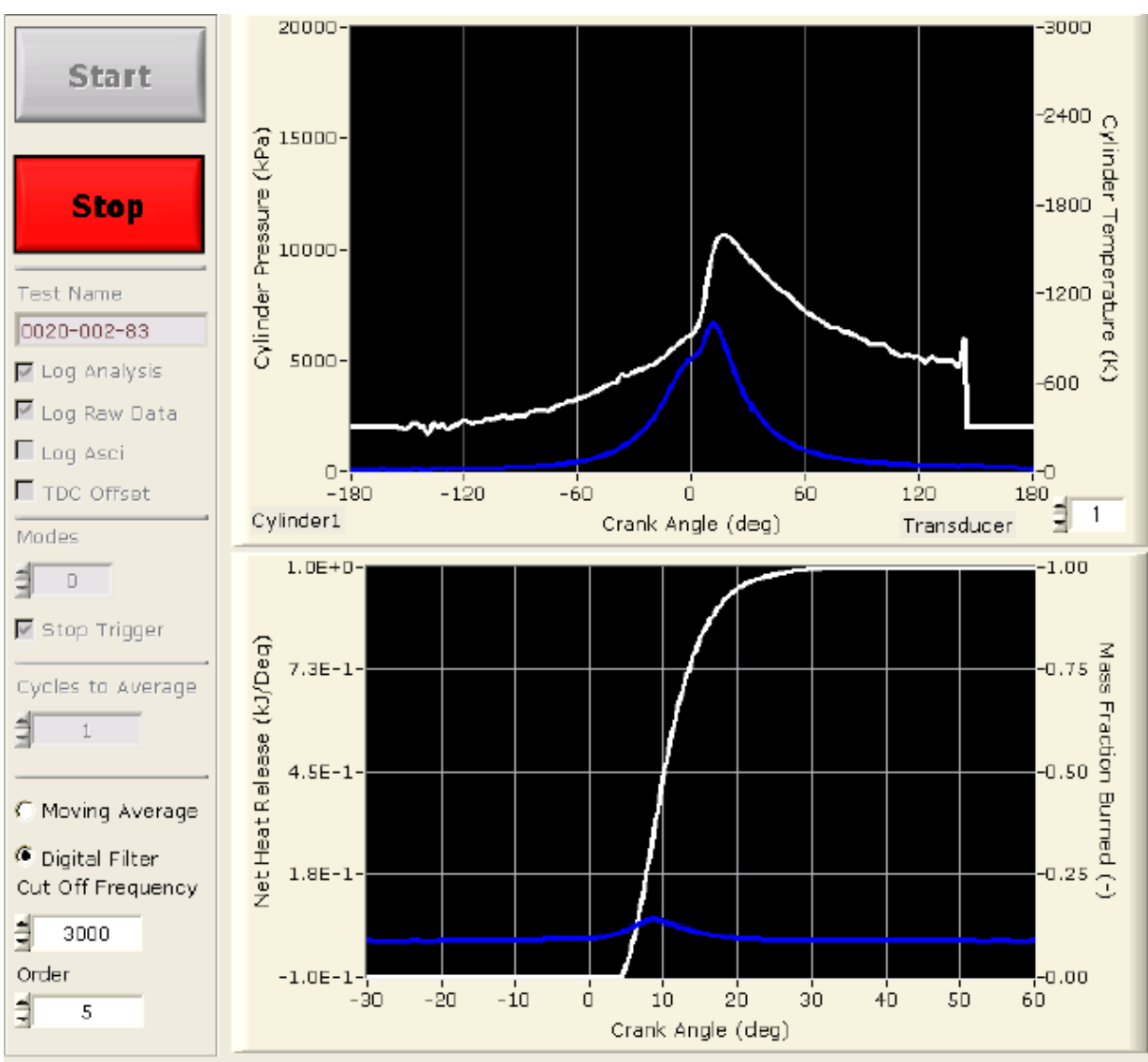

\begin{tabular}{|c|c|}
\hline Max Qnet (1) & 426.99 \\
\hline Max oggr (J) & 479.46 \\
\hline Max dQ netctheta (Y) gi) & 49.85 \\
\hline Max dQnetatheta (de g) & 8.75 \\
\hline Max Press (kPa) & 6649.25 \\
\hline Max Press (deg) & 11.75 \\
\hline Max dP_dtheta (KPa/deg) & 265.49 \\
\hline Max dP_atheta (deg) & 7.75 \\
\hline SOC (deg) & 4.75 \\
\hline EEOC (ded) & 33.00 \\
\hline JMEPg $(\mathrm{kPa})$ & 589.90 \\
\hline $10 \%$ Burn (deg) & 6.00 \\
\hline $50 \%$ Burn (deg) & 10.00 \\
\hline $90 \%$ Burn (deg) & 17.25 \\
\hline Max Terro (K) & 1597,88 \\
\hline Max Temp (deg) & 17.50 \\
\hline Avg Temp (K) & 755.73 \\
\hline Press Corr (kPa) & 359.59 \\
\hline Eng Spd (mp) & 2090.94 \\
\hline Intake Temp (K) & 300.73 \\
\hline Exhaust Temo (K) & 305.25 \\
\hline Temp $\$ O C(\mathrm{~K})$ & 1016.85 \\
\hline Prew IVC (KPa) & 94.87 \\
\hline Start Irjection (deg) & -360.00 \\
\hline Stop Injection (deg) & -360.00 \\
\hline TDC Offset (ideg) & 0.00 \\
\hline Time (s) & 179.53 \\
\hline
\end{tabular}

Figure 17: In-cylinder Combustion Software

\subsection{Measured and Calculated Combustion Parameters}

Although most of the combustion parameters were calculated using in-cylinder pressure measurements from pressure sensors, exhaust temperature was recorded as separate parameter. Exhaust temperature was recorded from a K-type thermocouple, installed in the exhaust manifold of the engine, while engine speed was measured by a BEI shaft encoder connected to the engine crank via a helical coupling.

\subsubsection{In-cylinder Pressure}

As mentioned in §3.3, the in-cylinder pressure was obtained from a piezoelectric crystal pressure sensor signal which was then converted to a voltage by a charge amplifier. By measuring the in-cylinder pressure directly, the maximum in-cylinder pressure and location of maximum in-cylinder pressure can be calculated. Determining these parameters is useful for identifying potential engine integrity issues associated with high pressures and can also be used 
to determine in-cylinder temperatures. The dynamic pressure signal from each sensor was referenced by assuming a constant polytropic constant to give an absolute pressure measurement [29].

\subsubsection{Heat Release Rate}

Determining the heat release rate can offer predictions of $\mathrm{NO}_{\mathrm{x}}$ emissions, as higher $\mathrm{HRR}$ is generally associated with higher $\mathrm{NO}_{x}[48]$. From the heat release data obtained by Equation 2-5, parameters such as maximum HRR, location of maximum HRR, net heat released during combustion, gross heat released during combustion and fuel flow can be determined. Equations 3-3 and 3-4 show the calculation for determining net and gross heat released during combustion from start of combustion to end of combustion (SOC-EOC).

Once the gross heat released during combustion is determined, total fuel flow can then be calculated using the LHV of the fuel then multiplied by the number of cylinders, see Equation 3-5. Note this equation is valid for 4 -stroke engines only with $100 \%$ combustion efficiency.

\subsubsection{In-cylinder Gas Temperature}

Since $\mathrm{NO}_{\mathrm{x}}$ and other pollutants are a function of temperature, the in-cylinder gas temperature is an important parameter to evaluate during combustion. For the work presented in this document, in-cylinder gas temperature is presented as the mean of the gas temperature; however local temperatures may be higher or lower. The in-cylinder temperature can be determined by assuming an ideal gas at intake valve closure with constant molecular weight. Consequently location of the maximum temperature can then be determined. Location of the maximum temperature is thought to influence $\mathrm{NO}_{\mathrm{x}}$ formation regardless of the diesel fuel type [48]. Equation 3-6 depicts the rearranged ideal gas equation with temperature at any crank angle on the left, while Equation 3-7 shows the pressure at intake valve closure 
and temperature at intake valve closure in terms of Equation 3-6. Combining Equations 3-6 and 3-7, the temperature at any crank angle can be determined.

\subsection{Control of Engine Operating Parameters}

As discussed in $§ 2.1 .3$, the ability to control engine operating parameters is crucial for obtaining advanced combustion. Accessing the engine's ECU allows for full control of operating parameters such as SOI, EGR rate, fuel injection quantity, fuel duration, rail pressure, etc. To access such operating parameters, WVU purchased an open engine controller based on $\mathrm{NI}$ hardware developed by Drivven, Inc (Figure 18).

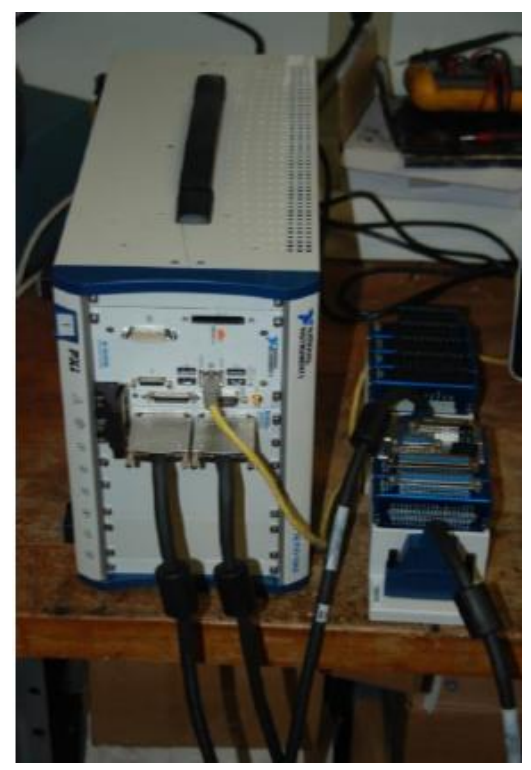

Figure 18: Open Engine Controller Purchased from Drivven, Inc

A custom wiring harness, constructed by Ross Ryskamp of West Virginia University, allowed the Drivven controller to connect directly to the OEM wiring harness as seen in Figure 19. The custom wiring harness also allowed for the OEM ECU to be connected directly to the 
OEM wiring harness for test evaluation and comparison to the Drivven controller. Additionally, the Drivven controller was pre-programmed with "baseline" operating parameters relative to the test engine as purchased by WVU.

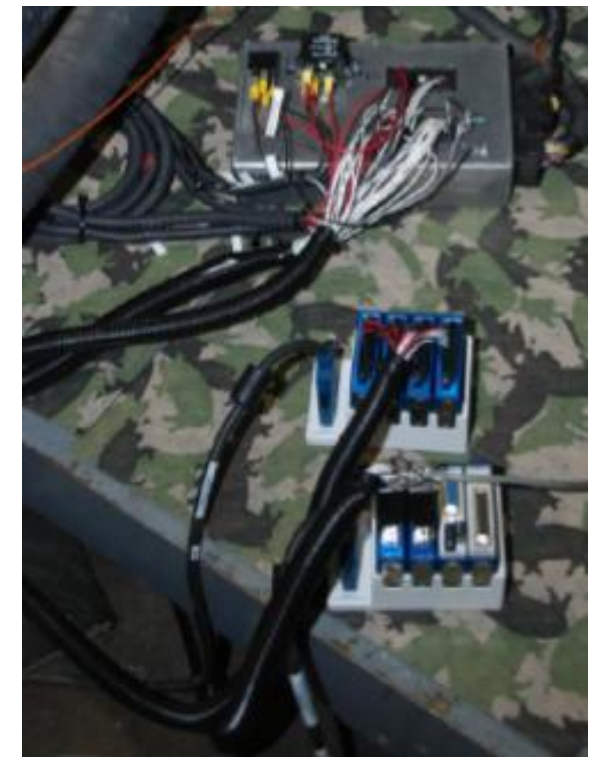

Figure 19: Custom WVU Wiring Harness

The Drivven controller used LabVIEW software for the user interface which was initiated on a stand-alone computer outside of the test cell. The software allowed for real-time observation and full control of quantities based on voltage signals received by the controller during engine operation. Operating parameters of concern such as the SOI, EGR valve position, rail pressure, fuel quantity, fuel duration and pre-injection quantities were easily controlled by the user-friendly interface seen in the Appendix.

\subsection{Engine Laboratory}

Testing of the engine was performed at the EERL on the WVU campus. The EERL is a unique test laboratory with a full-scale dilution tunnel designed to the guidelines outlined in Title 40 CFR Part 1065. The laboratory includes a three dynamometer test cell, gaseous emission measurement devices, particulate matter sampling systems, Class 1000 clean room, DAQ systems and intake air conditioning devices. 


\subsubsection{Dynamometer}

The test engine was run by an Eaton alternating current dynamometer capable of delivering up to $400 \mathrm{hp}$. The engine was connected to the dynamometer through a clutch system that was attached to a custom driveshaft. Throttle is generally controlled using a proportional integral derivative technique to allow the dynamometer to measure, and ultimately match, the desired engine torque. However, throttle was controlled using the Drivven controller for the testing presented in this report. Torque was measured using a strain gauge on a lever arm located on the side of the dynamometer. To maintain quality assurance, the dynamometer was calibrated using specific weights that hung from a basket on the end of the lever arm. No less than 10 points were taken to generate a calibration curve in accordance with 40 CFR $\S 1065.310$ (c) [49]. Once the calibration curve was established, coefficients were entered into the DAQ system to correspond to the measured torque of the dynamometer.

\subsubsection{Full-Scale Dilution Tunnel and Sampling System}

Emissions testing for the work presented in this report were conducted using the fullscale dilution tunnel seen in Figure 20. The dilution tunnel allowed the exhaust gas to mix and react with ambient air. By mixing with ambient air, the exhaust gas is perceived to replicate the reaction with the atmosphere in real-world conditions, outside of the test cell, and to allow for proper particulate formation. Dilution air was obtained from ambient air and filtered using an approximately $99.99 \%$ efficient HEPA filter to remove any particulate matter. The air was maintained at an approximate dew point of $14.5^{\circ} \mathrm{C}$ and conditioned/humidified to approximately $25^{\circ} \mathrm{C} \pm 5^{\circ} \mathrm{C}$. To account for $\mathrm{CO}, \mathrm{CO}_{2}, \mathrm{NO}_{\mathrm{x}}$ and $\mathrm{THC}$ in the dilution air, a sample of the air was collected in a Tedlar bag during each test, known as the background bag. At the end of each test, the bag sample was sent to analyzers for determination of the quantity of each pollutant in the dilution air. 


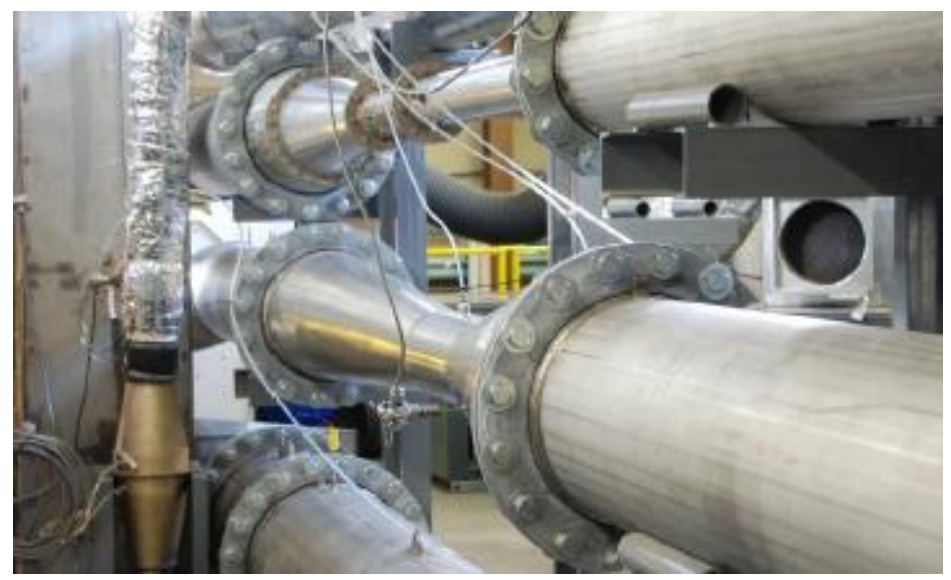

Figure 20: EERL Full-Scale Dilution Tunnel

In accordance to Title 40 CFR Part 1065, a constant volume sampling system (CVS) was used for measuring engine out emissions. A blower was located downstream of the sampling system to pull the diluted exhaust through the dilution tunnel. A subsonic venturi (SSV), located downstream of the sampling plane, was used to measure and sustain the flow rate of the diluted exhaust. For the testing performed in this study, the tunnel flow rate was set to a constant 400scfm and calculated using Equation 7-1 in the Appendix. The sampling plane, located upstream of the SSV, consisted of probes and heated transfer lines that connected to a Horiba exhaust gas analyzer (MEXA) to begin the gas measurement process. Samples of each gas ( $\mathrm{CO}, \mathrm{CO}_{2}, \mathrm{NO}_{\mathrm{x}}$ and $\mathrm{THC}$ ) were maintained at a specified temperature compliant to $40 \mathrm{CFR}$ $\S 1065.145$ [49]. To maintain quality assurance of the volumetric flow rate, propane injections were periodically performed on the dilution tunnel. During a propane injection, propane is injected into the tunnel where the engine exhaust mixes with the dilution air. After the injections occur over a period of 300 seconds, the recovered quantity of propane is then compared to a known injection quantity within a specified tolerance. For consistency, three consecutive tests were run with no more than $2 \%$ deviation.

\subsubsection{Exhaust Gas Analyzer}

Gaseous emissions were analyzed using the Horiba MEXA 7200D seen in Figure 21. The MEXA features an automated calibration system with the capability of simultaneously measuring and recording $\mathrm{CO}_{2}, \mathrm{CO}, \mathrm{NO}_{x}$, and $\mathrm{THC}$ species. Real-time emission concentrations, calibrated using gases of known concentrations, were available on a user-friendly interface. 
Prior to each test, the MEXA was automatically zeroed and spanned to account for analyzer drift. The methods of measuring gaseous emissions via the MEXA 7200D are further discussed in this section.

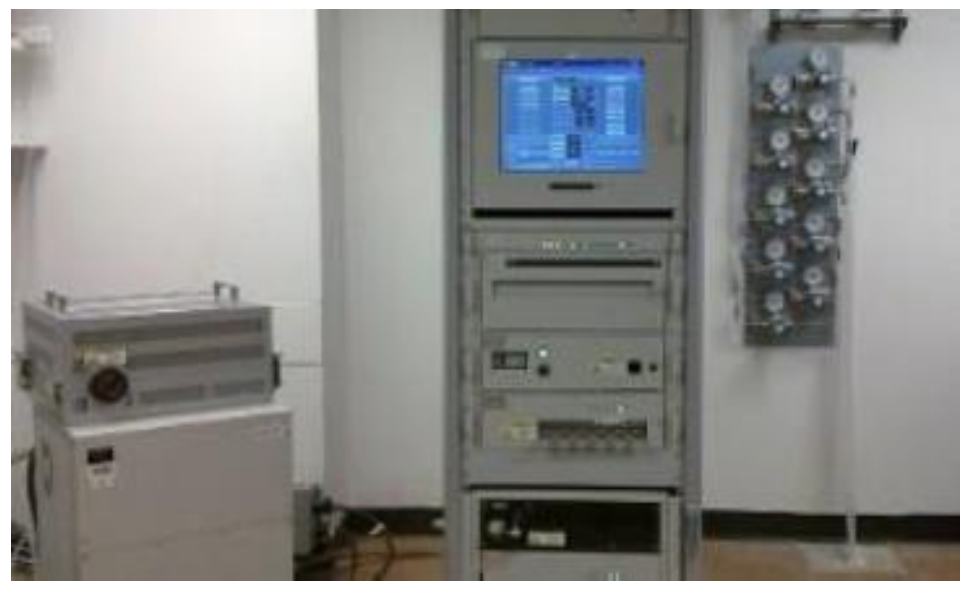

Figure 21: MEXA 7200D

\subsubsection{Carbon Monoxide and Carbon Dioxide Analyzer}

$\mathrm{CO}$ and $\mathrm{CO}_{2}$ emissions concentrations were measured using a non-dispersive infrared (NDIR) method. The NDIR method utilizes the conversion of light energy to vibrational energy to detect and measure $\mathrm{CO}$ and $\mathrm{CO}_{2}$ species in the form of infrared radiation absorption. Concentrations of $\mathrm{CO}$ and $\mathrm{CO}_{2}$ are then proportionally related to the degree of absorption [50]. Prior to entering the NDIR, the exhaust gas was sent through a chiller to minimize the interference of existing water vapor. Additionally, intake $\mathrm{CO}_{2}$ was measured separately using a Horiba AIA-220 gas analyzer to determine EGR rate. Neglecting background $\mathrm{CO}_{2}$ concentrations, EGR rate was then calculated using Equation 3-9, where "DR" is the dilution ratio obtained by dividing the tunnel flowrate by intake air flow. To account for analyzer drift, both the MEXA and intake $\mathrm{CO}_{2}$ analyzers were zeroed and spanned between tests. Analyzer response was obtained by generating a calibration curve of no less than 10 points prior to testing. 


\subsubsection{Oxides of Nitrogen Analyzer}

$\mathrm{NO}_{\mathrm{x}}$ was measured using a chemiluminescence technique. In chemiluminescence, light is emitted when $\mathrm{NO}$ reacts with ozone $\left(\mathrm{O}_{3}\right)$. Since $\mathrm{NO}_{\mathrm{x}}$ consists primarily of $\mathrm{NO}_{2}$ and $\mathrm{NO}$ in a diesel engine, the gas is passed through a $\mathrm{NO}_{2}$ to $\mathrm{NO}$ converter, with a known efficiency, prior to the reaction with ozone. During the reaction, photons emit light that is proportional to the concentration of NO. Similar to the NDIR analyzer, the chemiluminescence device was also zeroed and spanned prior to each test. In accordance to 40 CFR $\$ 1065.370$ [49], a calibration curve was generated prior to testing to ensure the analyzer response was linear.

\subsubsection{Hydrocarbon Analyzer}

Gaseous hydrocarbon concentrations were measured by an ionization process using a heated flame ionization detector (HFID). During this process, a sample of the exhaust gas is passed through a hydrogen flame causing the gas to ionize and produce heat energy. Concentrations are then determined by relating a current that is proportional to the number of carbon atoms during the ionization process, to a corresponding voltage output. To ensure minimal drift, the HFID was zeroed and spanned prior to each test. In accordance to 40 CFR $\S 1065.360$ [49], a calibration curve was generated to ensure linearity.

\subsubsection{Oxygen Concentration}

Both intake and exhaust oxygen concentrations were measured by a Horiba MEXA 720 analyzer located in the intake manifold and exhaust pipe, post VGT, respectively. For a consistency check, a Rosemont 755R Paramagnetic oxygen analyzer was used to verify the

intake oxygen content. The paramagnetic analyzer works by drawing a sample of gas over a magnetodynamic sensor. The sensor consists of a "dumbbell" shaped glass that is filled with an inert gas such as nitrogen. The dumbbell is suspended from a platinum wire within a nonuniform magnetic field and allowed to rotate when a sample gas is introduced. The corresponding rotation is caused by the attraction from the oxygen molecules to the stronger magnetic field. Optical systems are used to measure the dumbbell rotation and oxygen 
percentage is then correlated to the amount of current it takes to stabilize the rotating dumbbell [51].

\subsubsection{Particulate Matter Sampling System}

Once the exhaust gas was diluted in the dilution tunnel, particulate matter was then collected on a filter using a gravimetric measurement method. Located near the sampling plane, a stainless steel tube diverted the exhaust gas into a custom WVU PM box. The PM box, pictured in Figure 22 , was maintained at $115^{\circ} \mathrm{F}\left(46^{\circ} \mathrm{C}\right)$ with a filter face temperature of $47 \pm 5^{\circ} \mathrm{C}$ to eliminate the possibility of condensation on the filter face. Prior to entering the filter, the gas was passed through a cyclone with a specific cut size at variable flowrates. The PM was then collected on a TX-40 $47 \mathrm{~mm}$ filter, housed within the filter holder. Prior to each test, a filter was pre-conditioned and pre-weighed in the EERL clean room. After a test, the filter was then post-conditioned and post-weighed to determine the amount of PM that was produced during the test. A digital mass flow controller was used to control the flowrate of exhaust gas that entered the filter face. Note this system accounts for PM deposited on the filter which may also include soluble organic fraction (SOF). In some cases raw fuel (SOF) may be deposited on the filter which cannot be classified as "soot based" PM. In order to directly measure soot based PM, an AVL Micro Soot Sensor was installed in the exhaust pipe.

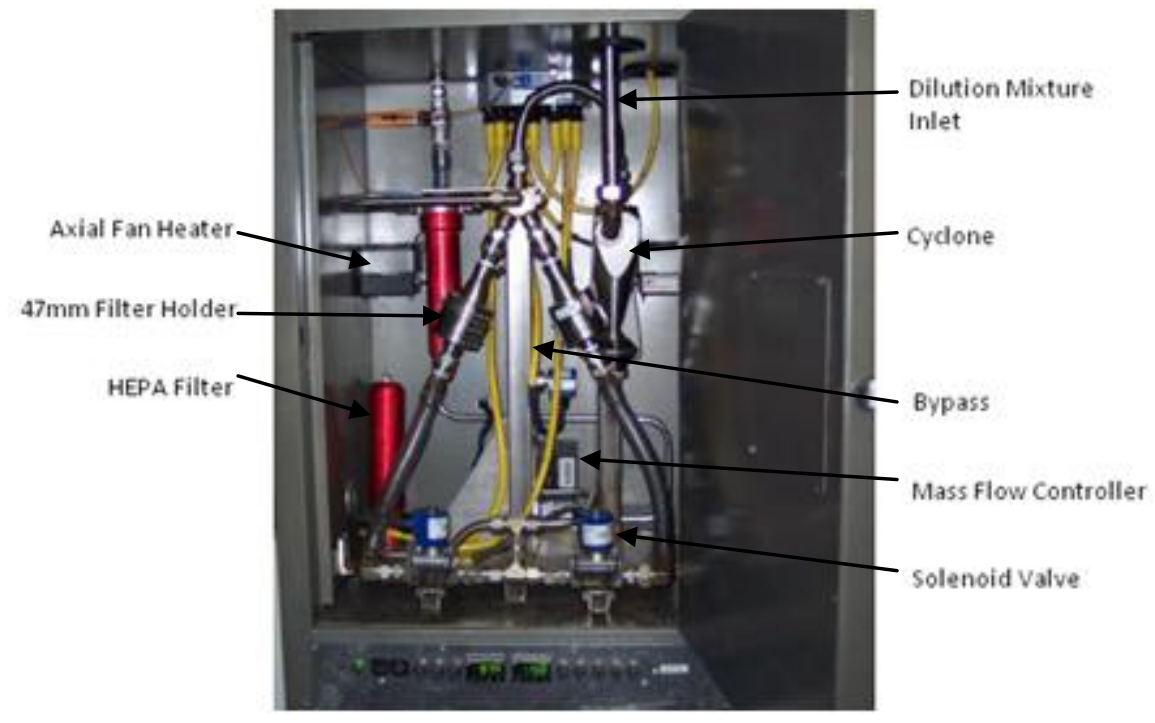

Figure 22: Custom WVU PM Collection Box 


\subsubsection{AVL Micro Soot Sensor}

In order to determine the soot based PM and continuously measure the PM concentration in real-time, an AVL micro soot sensor, seen in Figure 23, was placed in the exhaust prior to the dilution tunnel.

The micro soot sensor measures the diluted elemental carbon concentration in the exhaust gas from a photoacoustic technique. With this measurement technique, a sample of the "black" exhaust gas is exposed to modulated light. A corresponding sound wave is then recorded due to the expanding and contracting from the periodic cooling and heating of soot particles. Since clean air does not produce a signal, the sound wave signal increases proportionally to the concentration of soot within the measured volume [52]. The signal is then translated into a real-time carbon concentration.

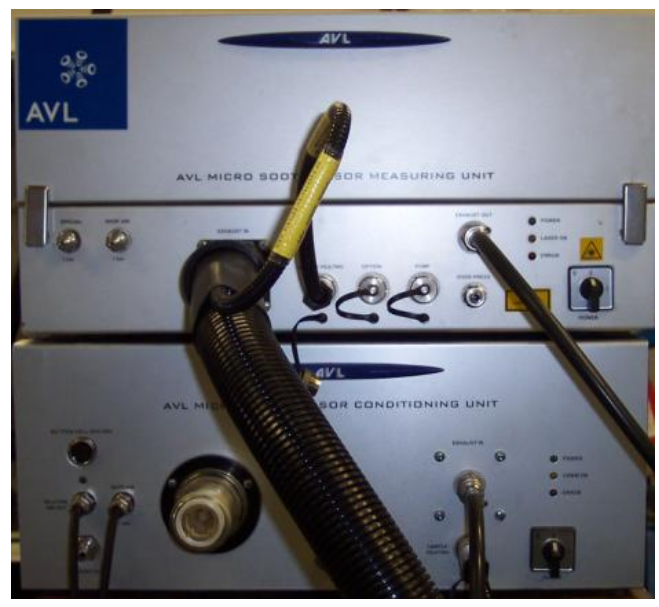

Figure 23: AVL Micro Soot Sensor 
Table 4: AVL Micro Soot Sensor Specifications [52]

\begin{tabular}{|l|r|}
\hline Measured Value & Concentration of Soot $\left(\mathrm{mg} / \mathrm{m}^{3}, \mu \mathrm{g} / \mathrm{m}^{3}\right)$ \\
\hline Measuring Range & $0-50 \mathrm{mg} / \mathrm{m}^{3}$ \\
\hline Display Resolution & $0.001 \mathrm{mg} / \mathrm{m}^{3}$ \\
\hline Detection Limit & $\sim 5 \mu \mathrm{g} / \mathrm{m}^{3}$ \\
\hline Turndown Ratio & $1: 5.000$ \\
\hline Data Rate & $\leq 1 \mathrm{seC}$ \\
\hline Rise Time & Digital $=10 \mathrm{~Hz}$, Analog $=100 \mathrm{~Hz}$ \\
\hline $\begin{array}{l}\text { Operation } \\
\text { Temperature }\end{array}$ & $5^{\circ} \mathrm{C}$ to $43^{\circ} \mathrm{C}$ \\
\hline Probe/Bypass Flow & $\sim 2 \pm 2 \mathrm{~L} / \mathrm{min}$ \\
\hline Interfaces & RS232, Digital I/O, Analog I/O, Ethernet \\
\hline Laser Class & Class 1 laser product \\
\hline
\end{tabular}

\subsubsection{EERL Clean Room}

As discussed in $§ 2.6 .4$, each filter was pre-conditioned and pre-weighed prior to testing, then post-conditioned and post-weighed after each test to determine the amount of PM that was produced during the specific test. The WVU Class 1000 EERL clean room utilizes a Sartorius SE2-F micro balance with a repeatability of $0.25 \mu \mathrm{g}$ and a readability of $0.1 \mu \mathrm{g}$ to weigh PM filters. To ensure proper filter weights by accounting for buoyancy corrections, the clean room temperature was maintained at $22^{\circ} \mathrm{C} \pm 1^{\circ} \mathrm{C}$ with a dew point of $9.5^{\circ} \mathrm{C} \pm 1^{\circ} \mathrm{C}$, compliant to $40 \mathrm{CFR}$ $\S 1065.190$ [49]. All personnel that entered the clean room wore booties to reduce the chance of tracking in contaminants.

\subsubsection{Intake Air}

The test engine was provided with conditioned intake air received from the ambient atmosphere. Prior to entering the engine, the ambient air was passed through a HEPA filter to remove any particulates. The air was then sent to handling units where moisture was removed. To ensure repeatability, the air was then re-humidified and maintained at $25^{\circ} \mathrm{C} \pm 5^{\circ} \mathrm{C}$ with a relative humidity of approximately $50 \%$ and a $\mathrm{NO}_{\mathrm{x}}$ correction factor of $1.00 \pm 1 \%$. The volumetric airflow rate entering the engine was determined from a laminar flow element (LFE) device. The LFE used for the test engine was a 4 inch Meriam Instruments 50MC2-1 capable of 
$386.13 \mathrm{scfm}$ at a differential pressure of 9in. $\mathrm{H}_{2} \mathrm{O}$. A differential pressure sensor by Omega and a resistance temperature device (RTD) was used to determine the differential pressure and inlet air temperature of the LFE, respectively. By knowing the differential pressure over the LFE and air temperature entering the LFE, a volumetric airflow rate was then calculated.

\subsubsection{EERL DAQ System}

The National Instruments SCXI 1001 data acquisition system (DAQ), pictured in Figure 24 , was used to measure various laboratory and engine parameters such as temperatures or emission concentrations. The DAQ system works by receiving current or voltage signals and converting it to engineering units that are proportional to the input signal. Such received current or voltage signals may come from the MEXA, thermocouples or pressure transducers.

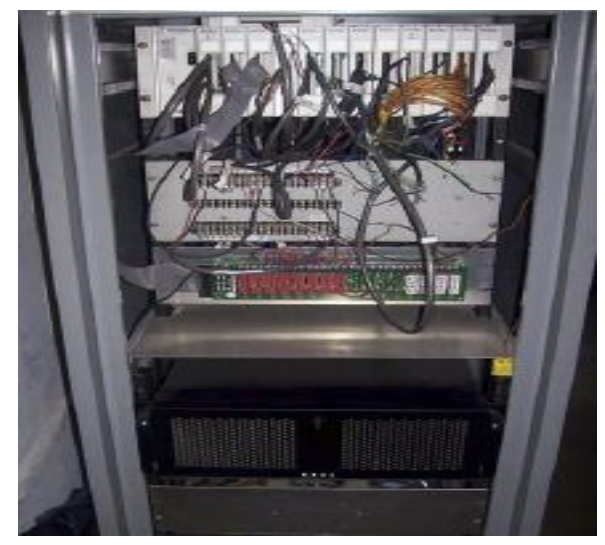

Figure 24: EERL NI DAQ System 


\section{$4 \quad$ Discussion of Results}

\subsection{Introduction}

The following sections will provide test data from each fuel and corresponding incylinder combustion parameters. All testing was performed at a steady state 2100 RPM and a bmep of 3.5 bar $(53 \mathrm{~N}-\mathrm{m})$. The steady state tests were created with 240 seconds of stabilization time and 180 seconds of data acquisition. Stabilization time was created to allow for stable engine temperatures and to provide sufficient time for the EGR fraction to sustain a desired percentage. Since the percentage of EGR is calculated as a function of the dilution ratio, intake $\mathrm{CO}_{2}$ and diluted exhaust $\mathrm{CO}_{2}$, a lag time is associated with the actual amount of EGR entering the intake of the engine. For ease of demonstration, EGR fractions have been rounded to the nearest whole number i.e. $50.8 \%$ becomes $51 \%$. Also note that only Cylinder 1 data are presented in this document. For pilot sweeps, a $20 \%$ fuel split indicates $20 \%$ of the fuel is delivered on the pilot injection while the remaining $80 \%$ is supplied during the main injection. Combustion data are presented in this section while the corresponding emissions data are presented in the Appendix. Throughout the series of testing, misfire, especially in cylinder 2 was observed at specific operating conditions. Misfire was then classified as a visual, erratic change in the real-time pressure versus crank angle data, resembling a motoring pressure curve, in at least one of the cylinders and present in one more cycles as verified by high $\mathrm{HC}$ emissions. Also note that the presented pressure curve data is averaged for 200 cycles.

\subsection{Fuel A}

Fuel A was designed with a very high cetane number (CN), high aromatics and high volatility. Specific properties for Fuel A are listed in Table 39 from the Appendix. From Table 1, the high aromatic and high volatility may increase both $\mathrm{NO}_{\mathrm{x}}$ and $\mathrm{PM}$ but the extremely high $\mathrm{CN}$ may promote a reduction of $\mathrm{NO}_{\mathrm{x}}$. Due to the high $\mathrm{CN}$, intake heating was not implemented for each series of testing. The first series of testing consisted of performing EGR sweeps to identify an optimum range of EGR fractions that resulted in the lowest $\mathrm{NO}_{\mathrm{x}}$ and PM emissions. Table 6 shows the emission concentrations of the EGR sweeps. Single injection sweeps were also performed but resulted in extremely high $\mathrm{HC}$ and PM emissions, see Table 41. As seen in the 
table, BSFC decreases $27 \%$ from $50 \%$ EGR to $60 \% \mathrm{EGR}$. This decrease may be contributed to the instability in load as seen in the variability of BMEP. For the following EGR sweeps, main SOI and pilot SOI were fixed at $0^{\circ}$ and $40^{\circ}$ BTDC respectively with a 50\% injection split at 800 bar rail pressure. Figure 25 illustrates the in-cylinder pressure as a function of crank angle for the EGR fraction sweeps.

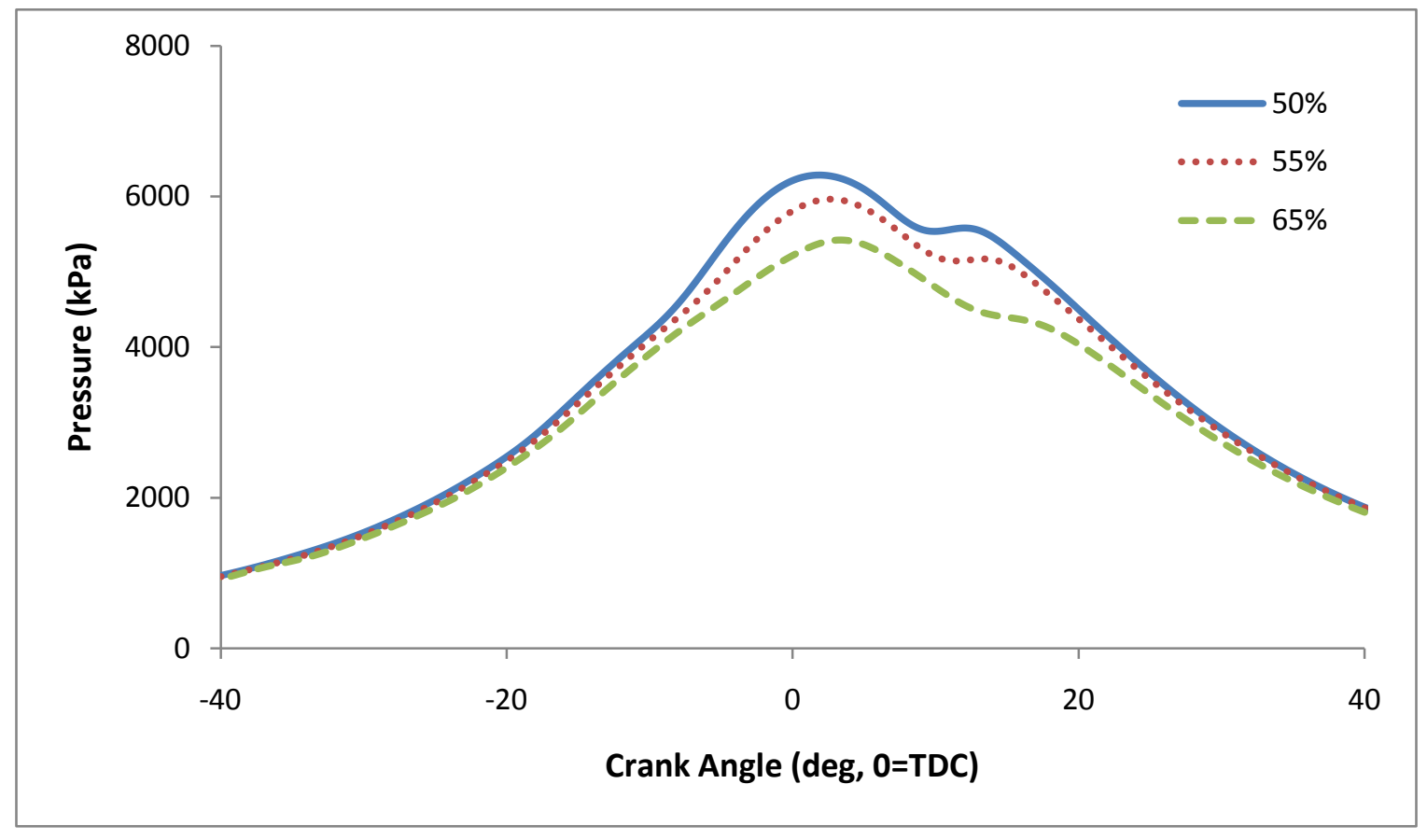

Figure 25: In-cylinder Pressure versus Crank Angle of EGR Sweeps for Fuel A

As seen in Figure 25, increasing EGR reduced the peak cylinder pressure and retarded the phasing when peak cylinder pressure was observed. When operated with $50 \% \mathrm{EGR}$, the peak pressure of $6284 \mathrm{kPa}$ was observed at $1.75^{\circ}$ ATDC while at $65 \%$ EGR a peak pressure of $5424 \mathrm{kPa}$ was observed at $3.25^{\circ} \mathrm{ATDC}$. The reduction in pressure can be correlated to the increasing heat capacity of the intake charge as EGR fraction is increases, resulting in lower cylinder pressure and ultimately lower cylinder temperatures. At a 65\% EGR fraction, raw fuel was deposited on the PM filter along with elevated $\mathrm{HC}$ and $\mathrm{NO}_{x}$ emissions, as seen in Table 6, possibly due to incomplete combustion. Figure 26 shows the HRR as a function of crank angle for the EGR fraction sweeps. 


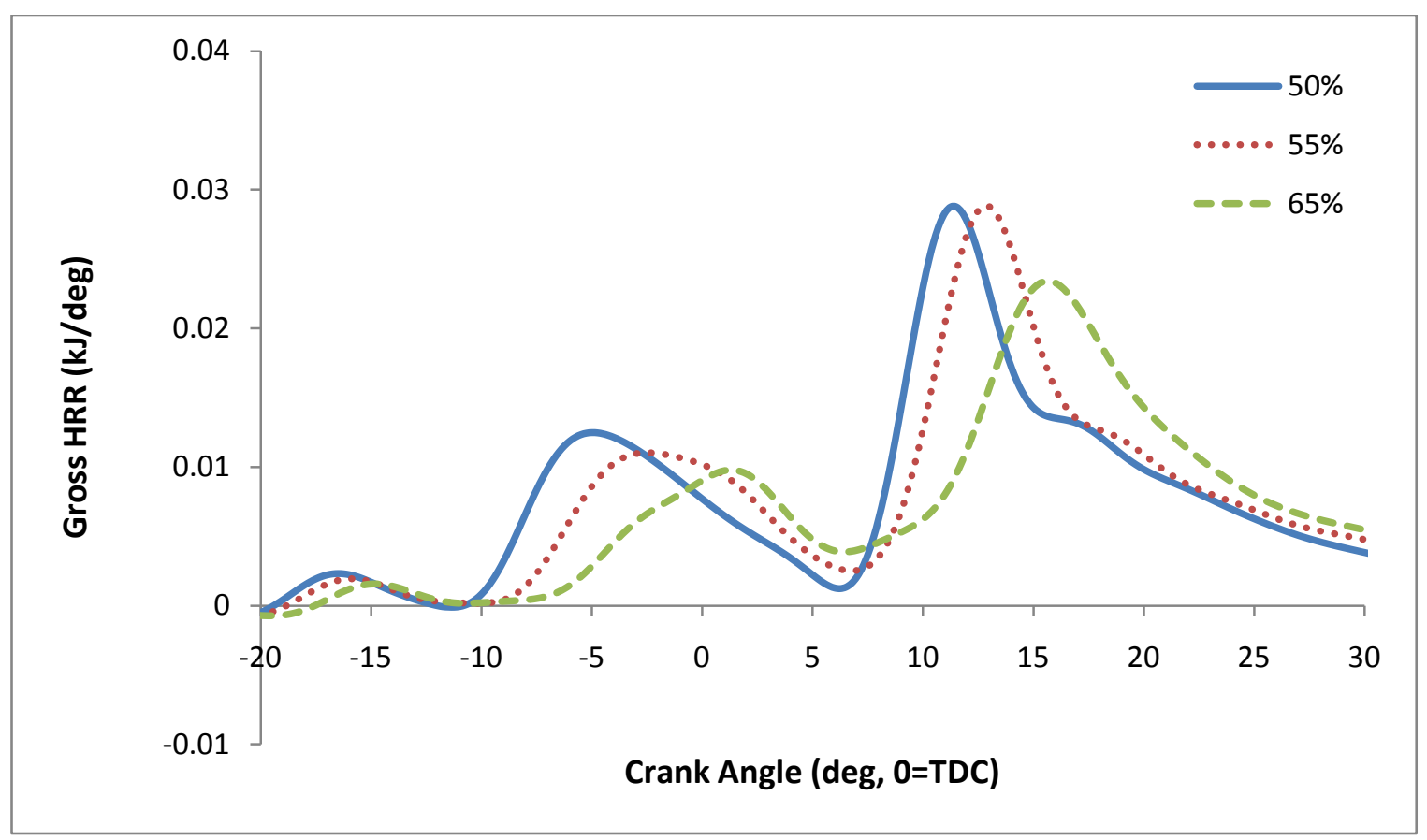

Figure 26: Gross HRR versus Crank Angle of EGR Sweeps for Fuel A

From Figure 26, an increasing EGR fraction reduces the peak of first stage heat release and increases ignition delay, indicating the importance of $\mathrm{CN}$. This trend was also observed in a study at Lund Institute of Technology and is thought to be due to an increase in heat lost to the cylinder wall as EGR increases [53]. The conditions during the first stage or low temperature heat release event appear to have a strong impact on $\mathrm{NO}_{x}$ formation with increasing $\mathrm{EGR}$ as seen in Table 6. At 50\% EGR, the first stage heat release peak is approximately $0.012 \mathrm{~kJ} / \mathrm{deg}$, while at $65 \%$ EGR is $0.01 \mathrm{~kJ} / \mathrm{deg}$. An EGR fraction of $55 \%$ was thought to be the optimum operating point due to lower $\mathrm{NO}_{\mathrm{x}}$ and PM compared to $50 \%$ and $65 \%$ EGR. Figure 27 shows the mass fraction burned as a function of crank angle for the EGR sweeps. 


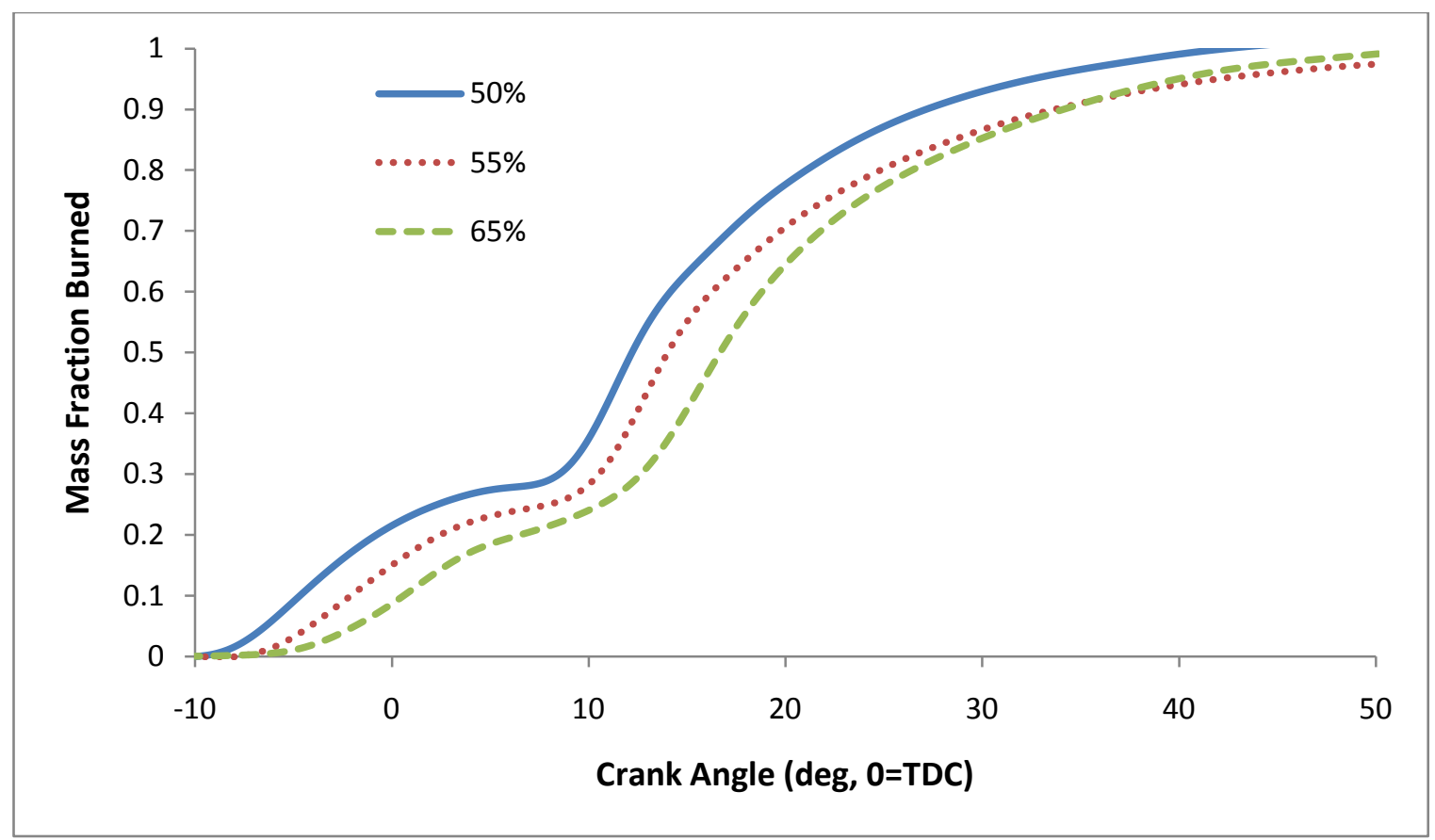

Figure 27: Mass Fraction Burned versus Crank Angle of EGR Sweeps for Fuel A

As illustrated in Figure 27, an increasing EGR fraction retards combustion. This trend is due to lower cylinder temperatures as EGR increases and reduced oxidation rate due to the increased $\mathrm{CO}_{2}$ and reduced $\mathrm{O}_{2}$. The effect of the pilot injection can also be identified from the MFB curve as the initial spike around TDC. Additionally, a crank angle (CA) $10-90 \%$ was calculated to determine the approximate duration of combustion, see Figure 28 . The CA 10$90 \%$ burn duration was calculated by subtracting the location of mass fraction burned at $10 \%$ from the location when $90 \%$ of the mass fraction is burned. Although the CA $10-90 \%$ burn duration is a good indicator of how fast a combustion event occurs, for split injection events it may not be as accurate due to the extended first stage combustion duration. From Figure 28, an EGR fraction of $55 \%$ results in the longest burn duration, $40.25^{\circ}$, while $50 \%$ EGR results in the shortest burn duration, $31.75^{\circ}$. The decreased burn duration at $50 \%$ and $55 \%$ EGR can be related to the increased slope during the first stage heat release as denoted from Figure 26. At the $55 \%$ EGR fraction the $10-90 \%$ burn duration is longest due to the increased length of first stage heat release as seen in Figure 26. Figure 28 also shows the maximum pressure rise rates for the EGR sweeps. 


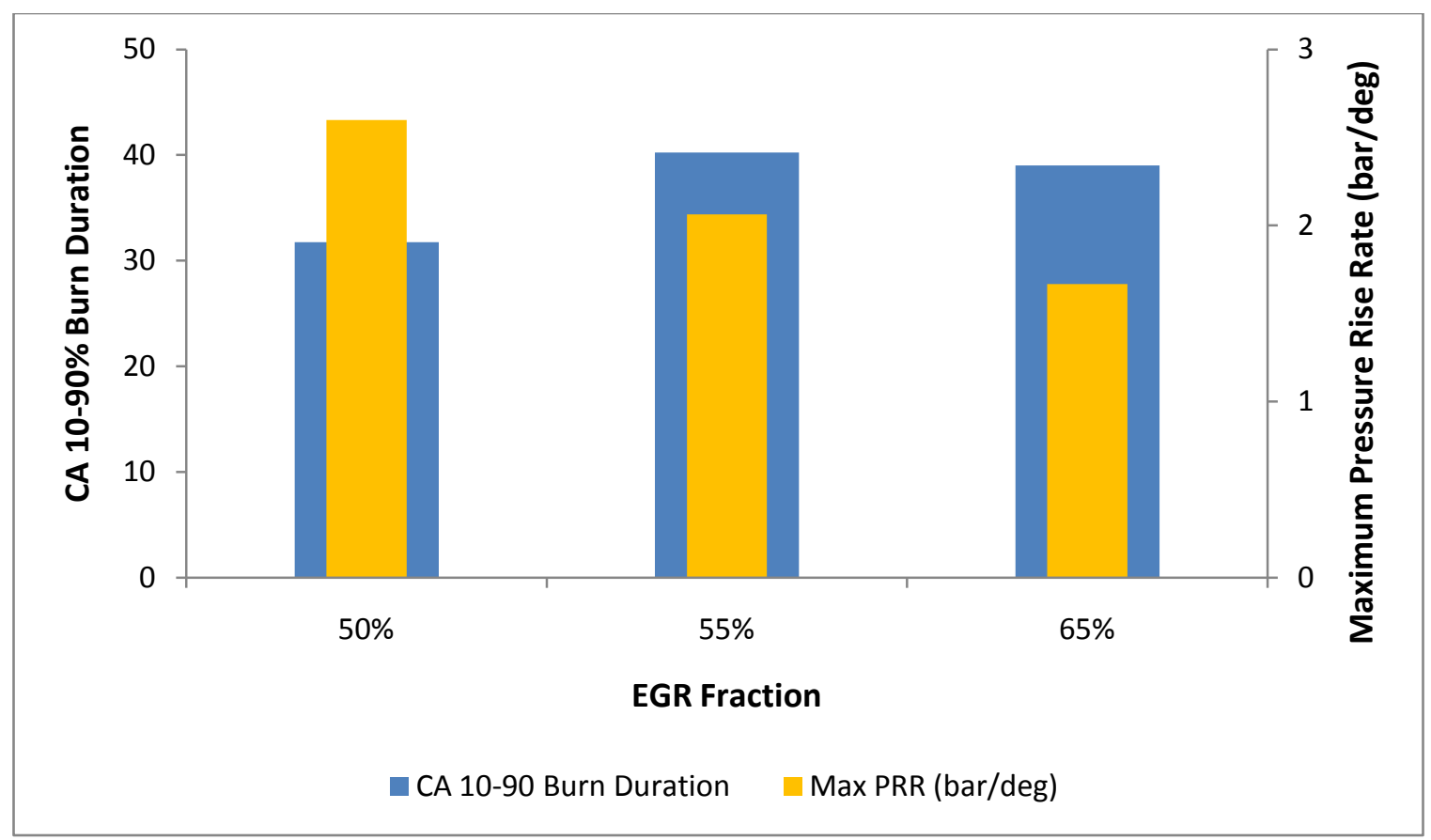

Figure 28: CA 10-90\% Burn Duration and Max PRR of EGR Sweeps for Fuel A

As shown in Figure 28, the maximum pressure rise rate (PRR) decreases linearly with increasing EGR fraction. The decrease in PRR may be due to the lower oxygen content available for combustion as EGR and ultimately ignition delay is increased. The reduction in PRR can also be correlated to the much longer $10-90 \%$ burn duration at the highest EGR fraction (refer to Figure 28). Ideally a maximum pressure rise rate of less than $10 \mathrm{bar} / \mathrm{deg}$ is sought during advanced combustion events based on research performed at ORNL [10], any higher and the engine's integrity may be compromised. An EGR fraction of $50 \%$ results in a maximum PRR of approximately $2.5 \mathrm{bar} / \mathrm{deg}$, well within the limits of typical advanced combustion regimes. Figure 29 shows the corresponding brake thermal efficiency (BTE) and brake specific fuel consumption (BSFC). The decrease in BTE at the high EGR fraction is a result of a larger quantity of fuel i.e. increased BSFC, being needed to sustain the operating point. BSFC at $50 \%$ and $55 \%$ EGR is significantly lower than the $65 \%$ EGR fraction but PM emissions were elevated at $50 \%$ EGR as seen in Table 6. 


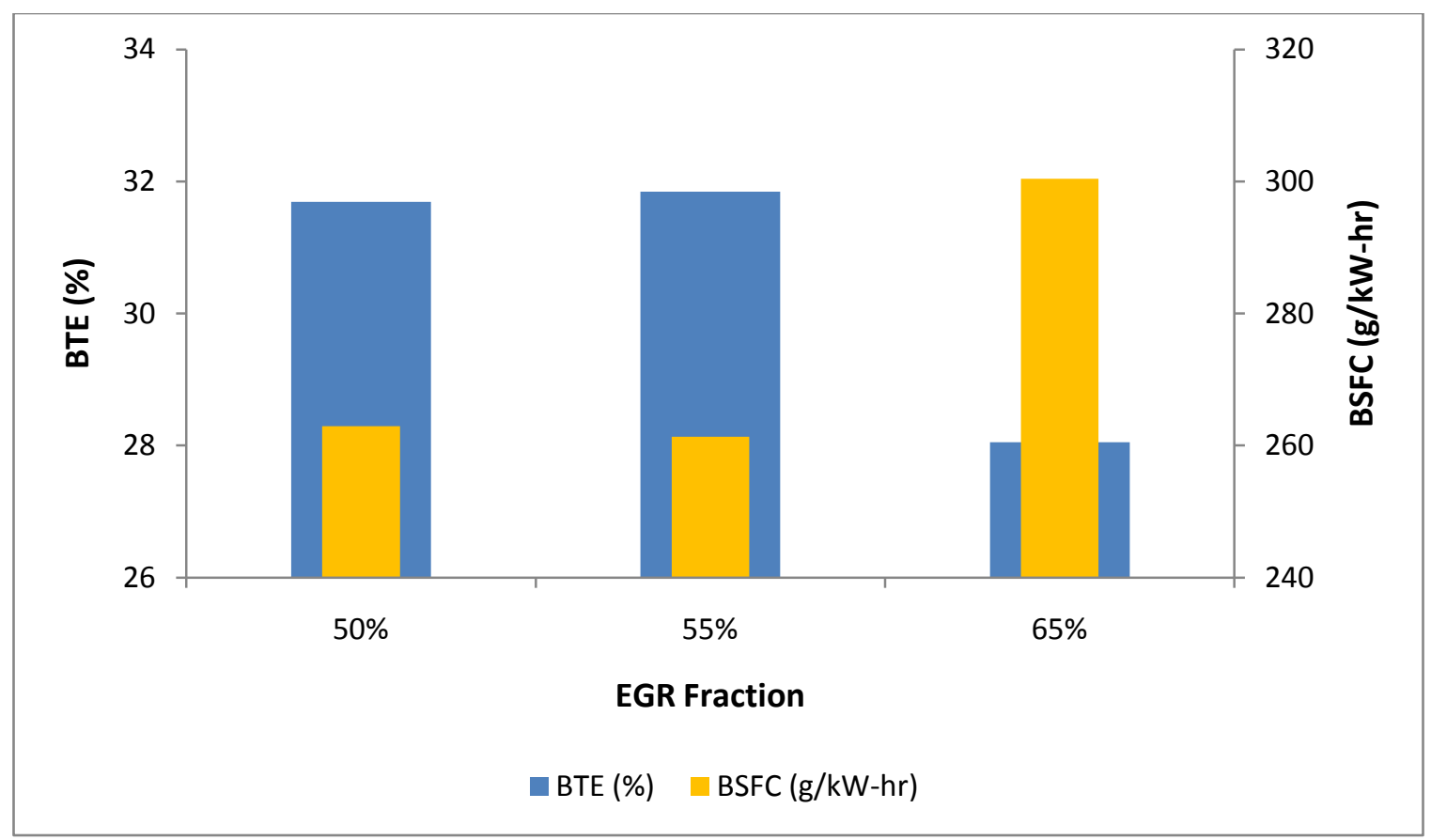

Figure 29: BTE and BSFC of EGR Sweeps for Fuel A

Table 5 shows the calculated in-cylinder pressure parameters for the EGR sweeps. As depicted by the pressure traces in Figure 25, the location of maximum pressure and temperature retards as EGR fraction increases, namely due to the increased ignition delay. Also depicted in the table, and as shown in Figure 27, the start of combustion (approximated as $5 \%$ mass fraction burned) retards as EGR fraction is increased, at 55\% EGR the start of combustion is $7.75^{\circ} \mathrm{BTDC}$ compared to $11.5^{\circ} \mathrm{BTDC}$ at $50 \% \mathrm{EGR}$. At $65 \% \mathrm{EGR}$, the trend appears to dissociate as the start of combustion is $10.5^{\circ}$ BTDC, which may be due to a lower BMEP for this specific test (3.0 bmep). 
Table 5: Calculated In-cylinder Combustion Parameters of EGR Sweeps for Fuel A

\begin{tabular}{|l|c|c|c|c|}
\hline EGR Fraction & - & $\mathbf{5 0 \%}$ & $\mathbf{5 5 \%}$ & $\mathbf{6 5 \%}$ \\
\hline Maximum Pressure & kPa & 6284 & 5965 & 5424 \\
\hline Location of Maximum Pressure & deg ATDC & 1.75 & 2.75 & 3.25 \\
\hline Maximum Pressure & kPa & 6284 & 5965 & 5424 \\
\hline Location of Maximum Pressure & deg ATDC & 1.75 & 2.75 & 3.25 \\
\hline Maximum Pressure Rise & bar/deg & 2.60 & 2.06 & 1.67 \\
\hline Location of Maximum Pressure Rise & deg ATDC & -6.0 & -4.25 & -14.25 \\
\hline Maximum Average Bulk Mixture Temperature & K & 1255 & 1254 & 1219 \\
\hline Location of Maximum Temperature & deg ATDC & 20.25 & 21.5 & 24.25 \\
\hline Location of 10\% Mass Fraction Burned & deg ATDC & -4.5 & -6.5 & -5.0 \\
\hline Location of 50\% Mass Fraction Burned & deg ATDC & 12.25 & 14.0 & 16.75 \\
\hline Location of 90\% Mass Fraction Burned & deg ATDC & 27.25 & 33.75 & 34.0 \\
\hline
\end{tabular}

Table 6: EGR Sweep Emissions Data for Fuel A

\begin{tabular}{|c|c|c|c|c|c|c|}
\hline EGR & HC (ppm) & NO $_{\mathbf{x}}$ (ppm) & $\begin{array}{c}\text { HC } \\
\text { (g/kW-hr) }\end{array}$ & $\begin{array}{c}\text { NOx } \\
\text { (g/kW-hr) }\end{array}$ & $\begin{array}{c}\text { BSFC } \\
\text { (g/kW-hr) }\end{array}$ & $\begin{array}{c}\text { Gravimetric PM } \\
\text { (mg/kW-hr) }\end{array}$ \\
\hline $50 \%$ & 1484 & 21.14 & 4.566 & 0.211 & 262.9 & 368.6 \\
\hline $55 \%$ & 1911 & 13.66 & 5.216 & 0.118 & 261.4 & 319.2 \\
\hline $65 \%$ & 4076 & 8.210 & 11.44 & 0.064 & 300.4 & 332.5 \\
\hline
\end{tabular}

Pilot injection sweeps were performed from $20-60^{\circ} \mathrm{BTDC}$ at 1000 bar rail pressure, $50 \%$ EGR and 20\% fuel split. As seen in Figure 30, retarding the timing of the pilot injection was found to advance combustion phasing due to the initiation of a later combustion event. An increase in $\mathrm{NO}_{\mathrm{x}}$ was observed as the pilot injection occurred closer to TDC, as a result of a less homogenous combustion event, indicating an increase in cylinder temperature as the pilot injection is retarded, see Figure 31. The effect of advancing the pilot on the HRR can be seen in Figure 31. 


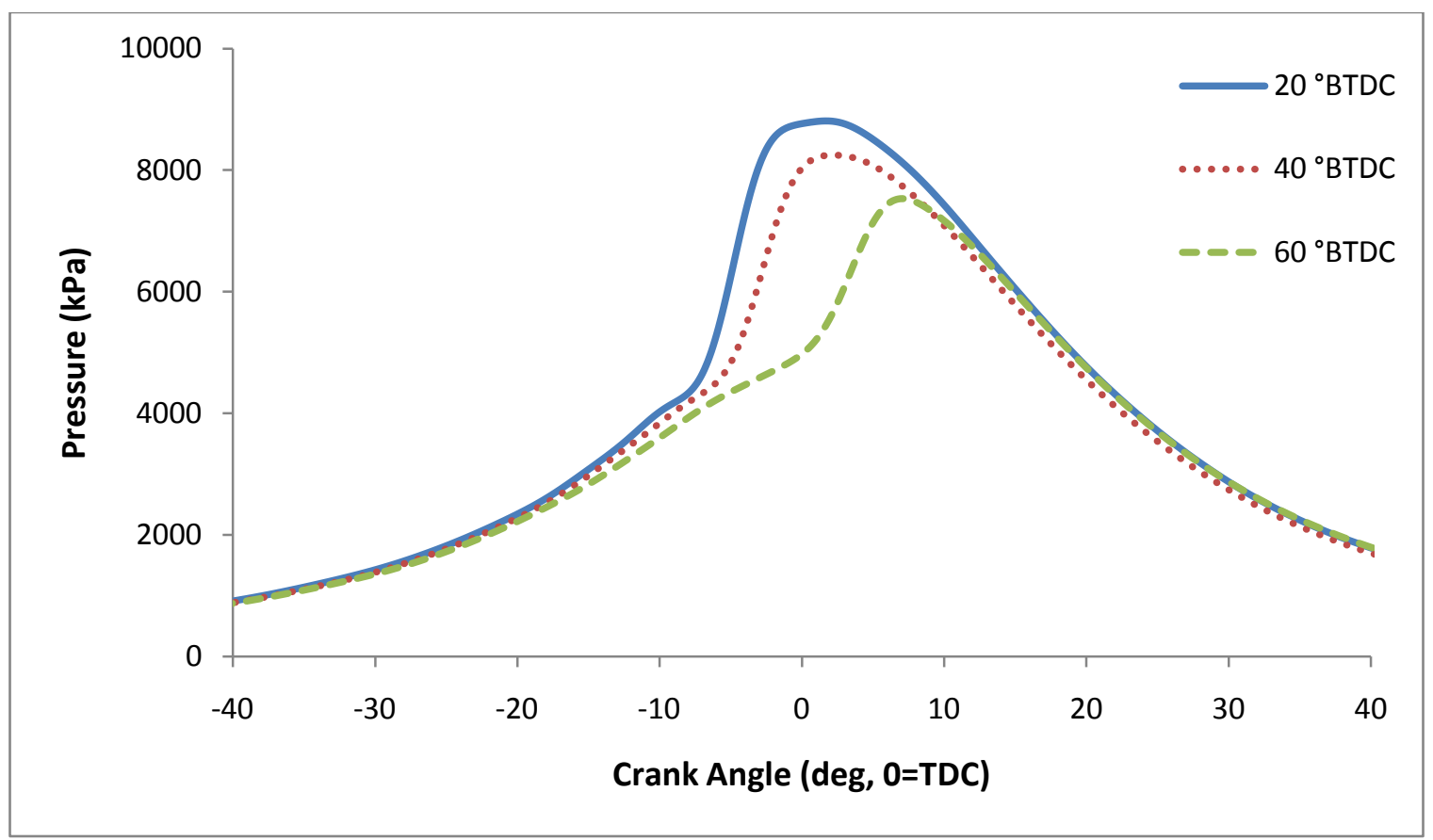

Figure 30: In-cylinder Pressure versus Crank Angle of Pilot Injection Sweeps for Fuel A

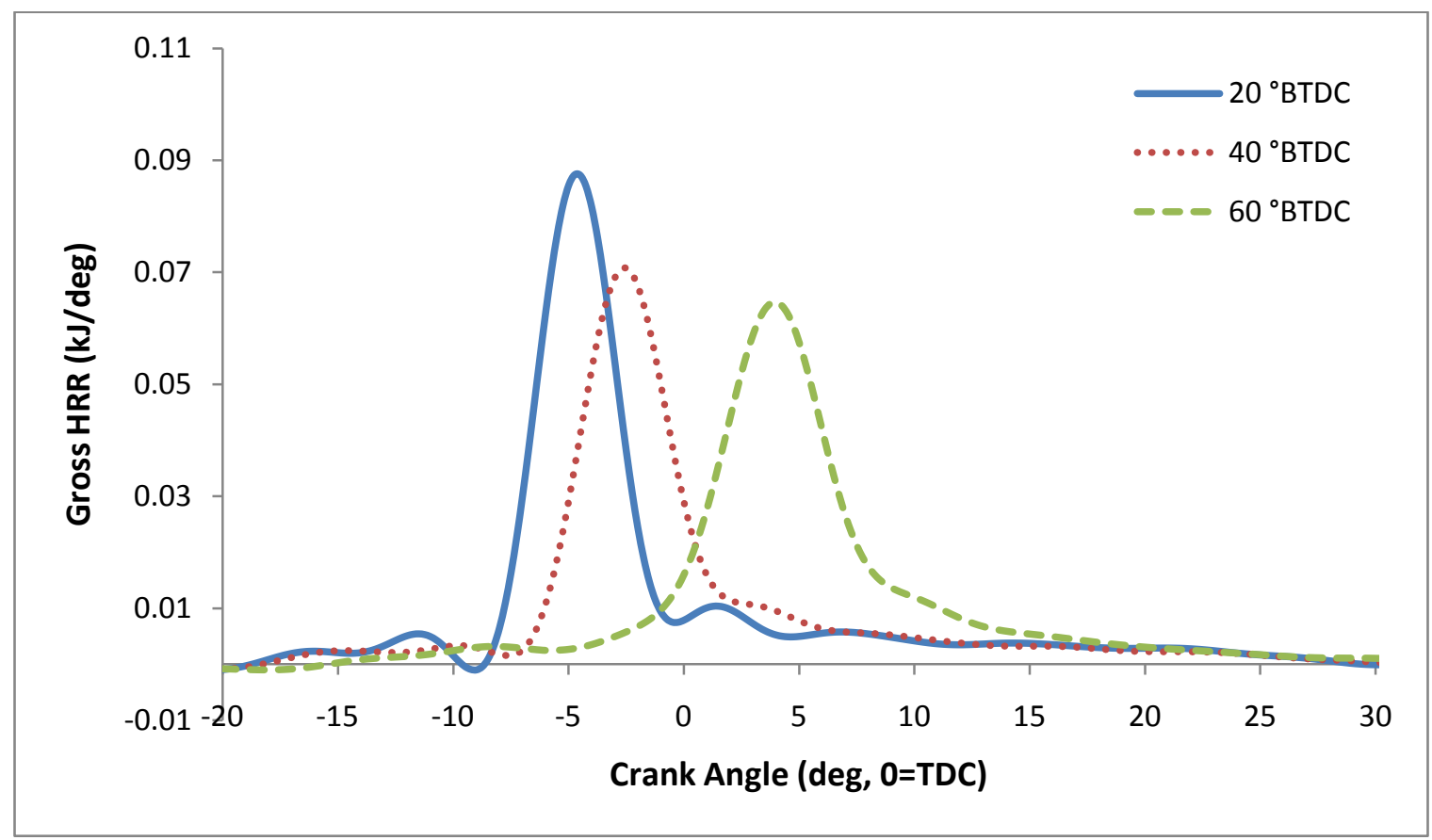

Figure 31: Gross HRR versus Crank Angle of Pilot Injection Sweeps for Fuel A

As seen in Figure 31, a more advanced pilot injection results in a lower peak HRR and a longer ignition delay, ultimately retarding the timing of the combustion event. Although the 
$20^{\circ}$ pilot injection produces a more rapid HRR curve, misfiring established from extremely high HC ( 2000 ppm) emissions limit it from an optimization strategy. Similarly, at $60^{\circ}$ BTDC HC and gravimetric PM emissions were elevated, thought to be due to wall wetting. Figure 32 shows the BTE and BSFC for the respective pilot injection sweeps.

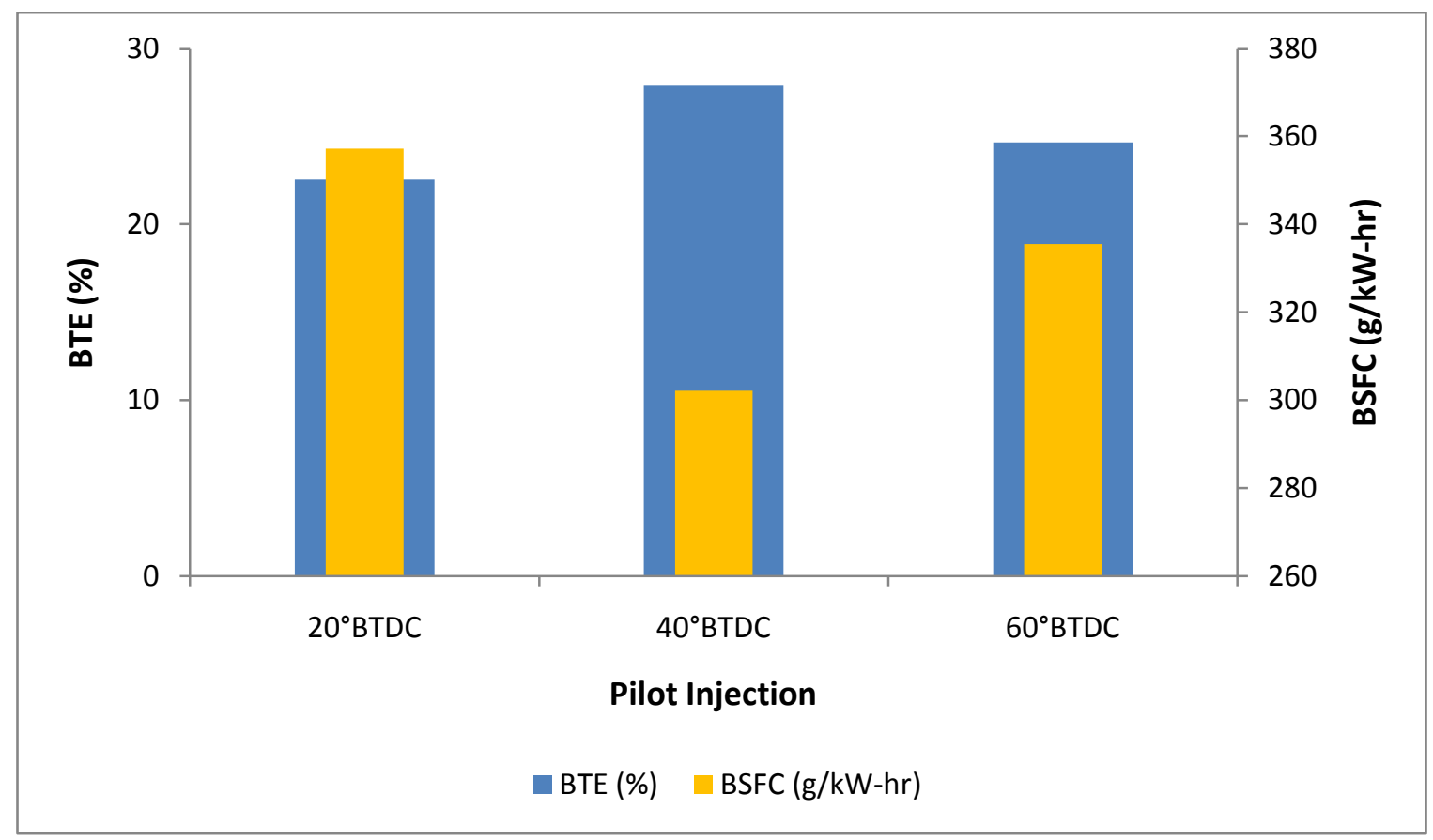

Figure 32: BTE and BSFC of Pilot Injection Sweeps for Fuel A

From Figure 32, an extremely low BTE is observed for the pilot injection sweeps. At $20^{\circ} \mathrm{BTDC}, \mathrm{BTE}$ is just $22.5 \%$ while the highest BTE occurs at $40^{\circ} \mathrm{BTDC}(\sim 27.9 \%)$. Since the LHV of the fuel remains constant, the low BTE is a direct result of incomplete combustion due to wall wetting and increased BSFC. Rail pressure sweeps were also performed from 800 to 1800 bar, with a main SOI at TDC, a $40^{\circ}$ BTDC pilot, 50\% fuel split and 55\% EGR with 800 bar producing the lowest HC and PM emissions, see Table 7. Upon completion of the discussed engine sweeps, the optimum strategy of the data set for Fuel A is summarized in Table 8 while Table 9 shows the emission concentrations at the respective optimized strategy. Note soot based PM is unavailable for Fuel A, as the AVL soot sensor was not installed at this time. Table 10 shows the calculated in-cylinder combustion parameters at the optimized strategy. 
Table 7: Rail Pressure Sweep Emissions Data for Fuel A

\begin{tabular}{|c|c|c|c|c|c|c|}
\hline $\begin{array}{c}\text { Rail Pressure } \\
\text { (bar) }\end{array}$ & $\mathrm{HC}(\mathbf{p p m})$ & $\mathbf{N O}_{\mathbf{x}}$ (ppm) & $\begin{array}{c}\mathbf{H C} \\
\text { (g/kW-hr) }\end{array}$ & $\begin{array}{c}\mathbf{N O}_{\mathbf{x}} \\
\text { (g/kW-hr) }\end{array}$ & $\begin{array}{c}\text { BSFC } \\
\text { (g/kW-hr) }\end{array}$ & $\begin{array}{c}\text { Gravimetric PM } \\
\text { (mg/kW-hr) }\end{array}$ \\
\hline 800 & 2176 & 11.58 & 5.981 & 0.101 & 268.5 & 319.3 \\
\hline 1200 & 3977 & 8.61 & 10.218 & 0.065 & 276.8 & 444.6 \\
\hline 1600 & 3931 & 7.984 & 9.67 & 0.059 & 350.0 & 358.8 \\
\hline 1800 & 3135 & 9.945 & 8.332 & 0.0787 & 275.9 & 355.3 \\
\hline
\end{tabular}

Table 8: Optimized Strategy for Fuel A

\begin{tabular}{|l|c|}
\hline EGR & $55 \%$ \\
\hline Rail Pressure & $800 \mathrm{bar}$ \\
\hline Fuel Split & $50 \%$ \\
\hline Pilot Injection & $40^{\circ} \mathrm{BTDC}$ \\
\hline
\end{tabular}

Table 9: Optimum Operating Strategy Emissions Results for Fuel A

\begin{tabular}{|l|c|}
\hline $\mathrm{NO}_{\mathrm{x}}(\mathrm{ppm})$ & 13.6 \\
\hline $\mathrm{HC}(\mathrm{ppm})$ & 1911 \\
\hline Soot Based PM (mg/kW-hr) & $\mathrm{N} / \mathrm{A}$ \\
\hline Gravimetric PM (mg/kW-hr) & 319.2 \\
\hline BSFC (g/kW-hr) & 261.4 \\
\hline BTE (\%) & 31.8 \\
\hline
\end{tabular}


Table 10: Calculated In-cylinder Combustion Parameters at Optimized Strategy for Fuel A

\begin{tabular}{|l|c|c|}
\hline Heat Released & $\mathrm{kJ}$ & 0.606 \\
\hline Maximum Heat Release Rate & $\mathrm{kJ} / \mathrm{deg}$ & 0.029 \\
\hline Location of Maximum Heat Release Rate & $\mathrm{deg}$ ATDC & 12.75 \\
\hline Maximum Pressure & $\mathrm{kPa}$ & 5965 \\
\hline Location of Maximum Pressure & $\mathrm{deg}$ ATDC & 2.75 \\
\hline Maximum Pressure Rise & $\mathrm{bar} / \mathrm{deg}$ & 2.06 \\
\hline Location of Maximum Pressure Rise & deg ATDC & -4.25 \\
\hline Maximum Average Bulk Mixture Temperature & $\mathrm{K}$ & 1254 \\
\hline Location of Maximum Temperature & deg ATDC & 21.50 \\
\hline Location of 10\% Mass Fraction Burned & deg ATDC & -1.75 \\
\hline Location of 50\% Mass Fraction Burned & deg ATDC & 14.0 \\
\hline Location of 90\% Mass Fraction Burned & deg ATDC & 33.75 \\
\hline
\end{tabular}




\subsection{Fuel B}

Fuel B was designed with a medium CN, low aromatics and high volatility. Specific properties for Fuel B are listed in Table 39 from the Appendix. From Table 1, the low aromatic content may decrease both $\mathrm{NO}_{x}$ and $\mathrm{PM}$ but may be counterbalanced by the increased volatility. Due to a high $\mathrm{CN}$, the intake heating element was not implemented for each series of testing. The first series of testing consisted of performing EGR sweeps to identify an optimum range of EGR fractions that resulted in the lowest $\mathrm{NO}_{\mathrm{x}}$ and $\mathrm{PM}$ emissions, refer to Table 11 for emission concentrations. For the following EGR sweeps, main SOI and pilot SOI were fixed at $0^{\circ}$ and $40^{\circ}$ BTDC, respectively, with a $50 \%$ injection split at 800 bar rail pressure. Figure 33 illustrates the in-cylinder pressure as a function of crank angle for the EGR fraction sweeps.

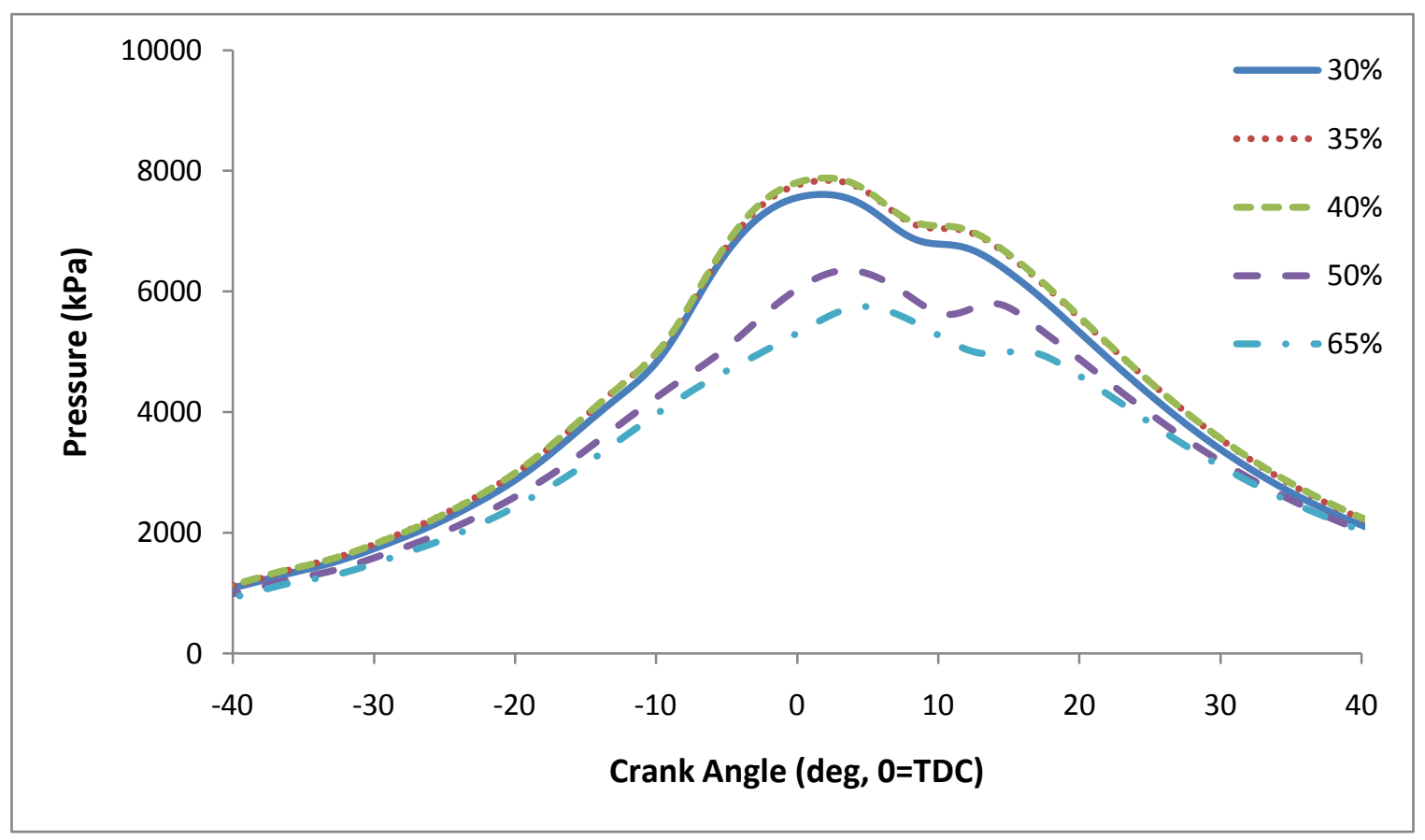

Figure 33: In-cylinder Pressure versus Crank Angle of EGR Sweeps for Fuel B

At an EGR fraction of $40 \%$, the highest peak pressure is observed at $7880 \mathrm{kPa}$, while the highest EGR fraction (65\%) resulted in the lowest peak pressure of approximately $5749 \mathrm{kPa}$. The effect of ignition delay becomes apparent at EGR fractions greater than $50 \%$ as the corresponding decrease in cylinder pressure led to misfire. $\mathrm{NO}_{\mathrm{x}}$ was also significantly decreased with increasing EGR due to lower cylinder temperatures, but HC and PM significantly increased 
at high EGR fractions, possibly due to incomplete combustion and misfires, see Table 11. Soot based PM was only established at $40 \%$ and $50 \%$ EGR but show that approximately $30 \%$ of PM is soot based. Figure 34 shows the HRR as a function of crank angle for the EGR fraction sweeps.

Table 11: EGR Sweep Emissions Data for Fuel B

\begin{tabular}{|c|c|c|c|c|c|c|}
\hline EGR & $\begin{array}{c}\text { HC } \\
(\mathbf{p p m})\end{array}$ & $\mathbf{N O}_{\mathbf{x}}$ (ppm) & $\begin{array}{c}\mathbf{H C} \\
(\mathbf{g} / \mathbf{k W}-\mathbf{h r})\end{array}$ & $\begin{array}{c}\mathbf{N O}_{\mathbf{x}} \\
(\mathbf{g} / \mathbf{k W}-\mathbf{h r})\end{array}$ & $\begin{array}{c}\text { BSFC } \\
(\mathbf{g} / \mathbf{k W}-\mathbf{h r})\end{array}$ & $\begin{array}{c}\text { Gravimetric PM } \\
\text { (mg/kW-hr) }\end{array}$ \\
\hline $30 \%$ & 1376 & 92.25 & 6.314 & 1.416 & 311.7 & 370.5 \\
\hline $35 \%$ & 942.8 & 79.48 & 4.227 & 1.207 & 311.6 & 313.7 \\
\hline $40 \%$ & 973.4 & 76.29 & 4.729 & 1.249 & 311.0 & 364.1 \\
\hline $50 \%$ & 1589 & 39.92 & 5.741 & 0.470 & 285.5 & 330.7 \\
\hline $65 \%$ & 4690 & 11.52 & 13.18 & 0.103 & 302.0 & 1104 \\
\hline
\end{tabular}

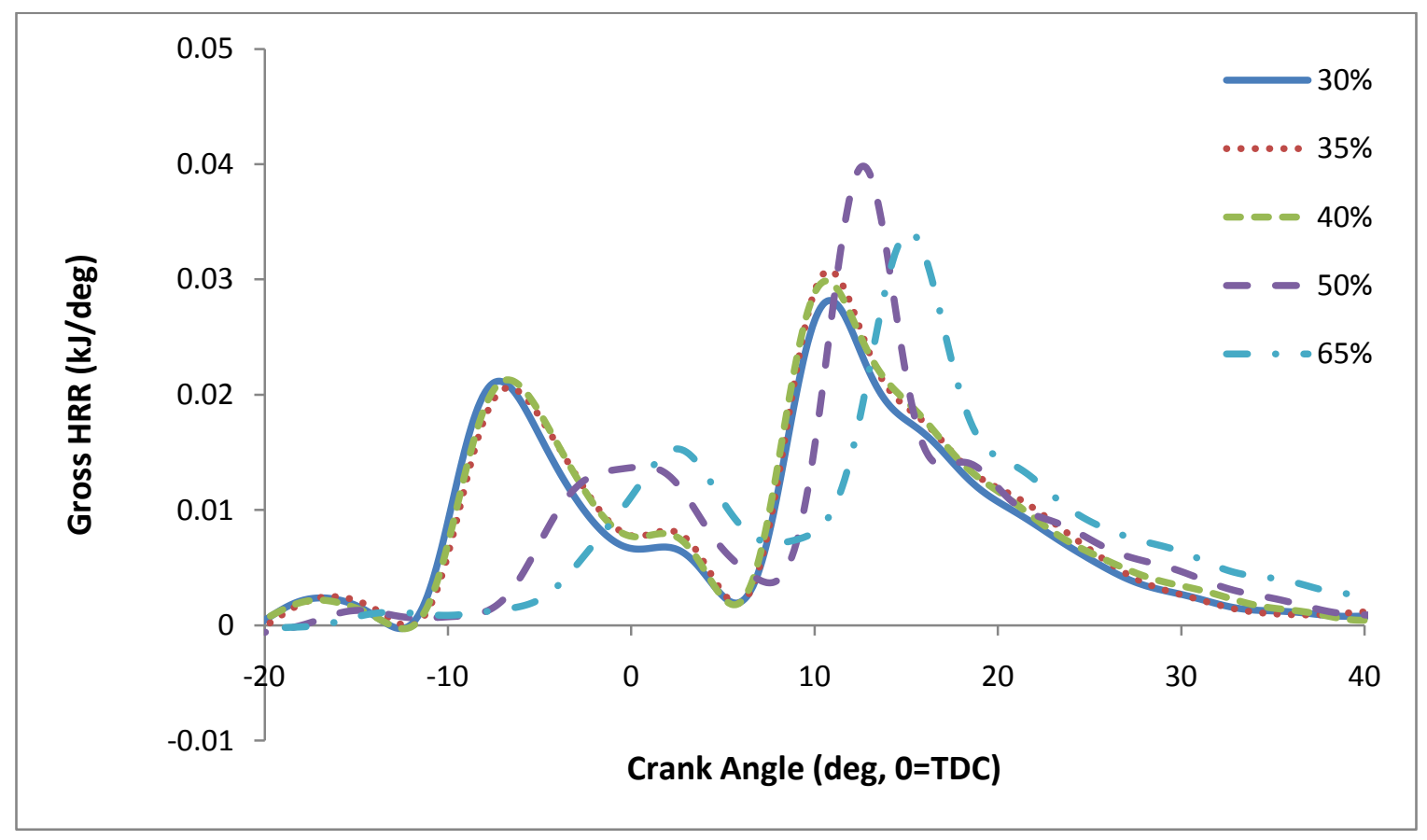

Figure 34: Gross HRR versus Crank Angle of EGR Sweeps for Fuel B

EGR fractions from $30-40 \%$ appear to have similar HRR curves while the increase in ignition delay can be observed at 50\% and 65\%. At 30\% EGR, the first stage heat release is approximately $0.02 \mathrm{~kJ} / \mathrm{deg}$ while at $65 \%$ the peak HRR in the first stage of combustion is 0.015 $\mathrm{kJ} /$ deg and retarded approximately $10^{\circ}$. From Figure 34 , a $50 \% \mathrm{EGR}$ fraction may represent an advanced combustion event more closely than the $30-40 \%$ EGR fractions based on the minimal 
peak of first stage heat release and a rapid diffusion combustion. The 50\% EGR fraction was thought to be the optimum operating point due to lower $\mathrm{NO}_{\mathrm{x}}$ and $\mathrm{HC}$ emissions. Figure 35 shows the mass fraction burned as a function of crank angle for the EGR sweeps.

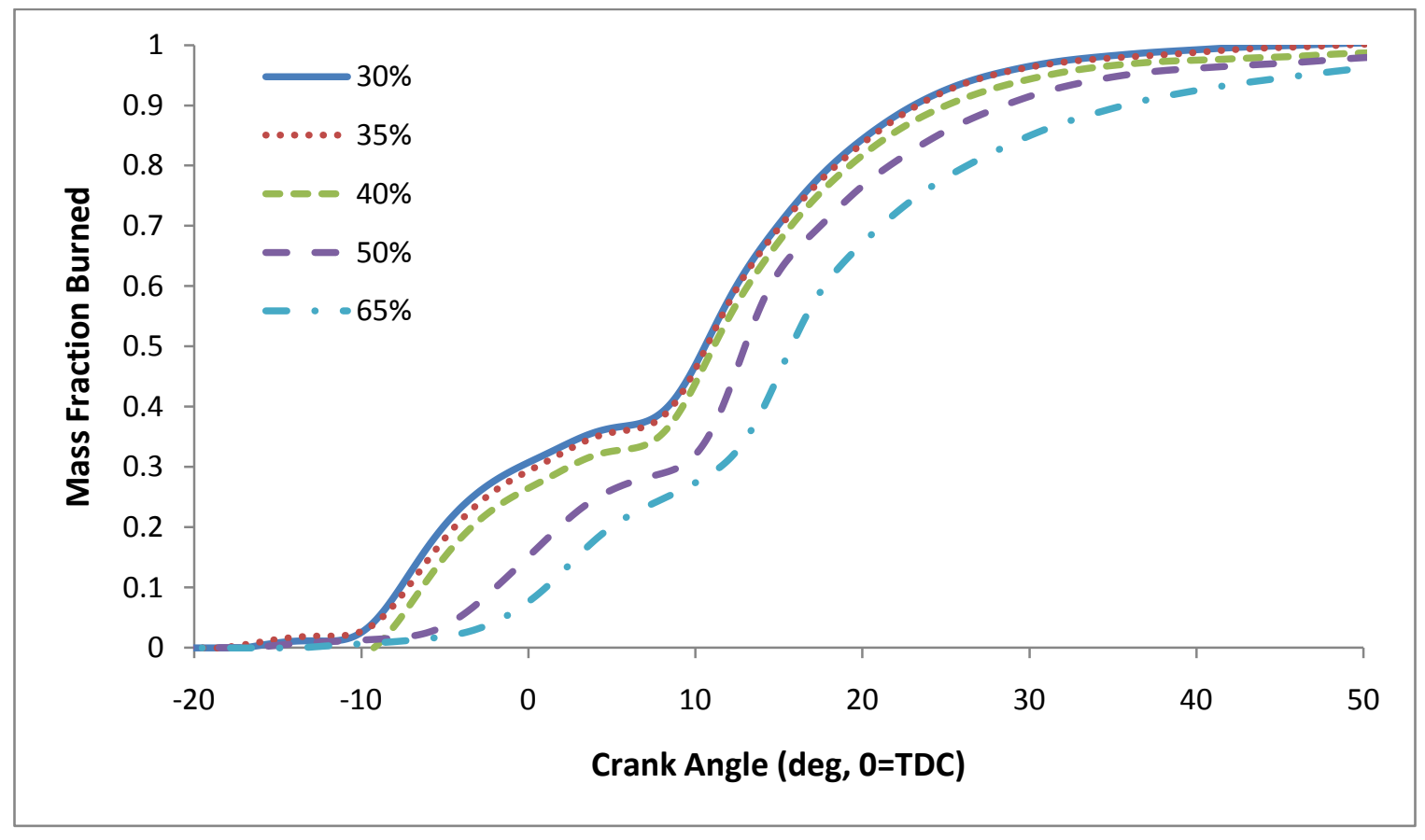

Figure 35: Mass Fraction Burned versus Crank Angle of EGR Sweeps for Fuel B

As illustrated in Figure 35, an increasing EGR fraction further retards combustion near TDC and the effect of ignition delay becomes apparent. EGR fractions of $30-40 \%$ result in a similar mass fraction burned as opposed to 65\% EGR where misfiring became apparent. Additionally, the CA $10-90 \%$ was calculated to determine the approximate duration of combustion, see Figure 36 . An EGR fraction of $65 \%$ resulted in the longest burn duration $\left(\sim 35^{\circ}\right)$ while a $50 \%$ EGR fraction resulted in the longest burn duration $\left(30^{\circ}\right)$. Figure 36 shows the corresponding pressure rise rates for the EGR sweeps. 


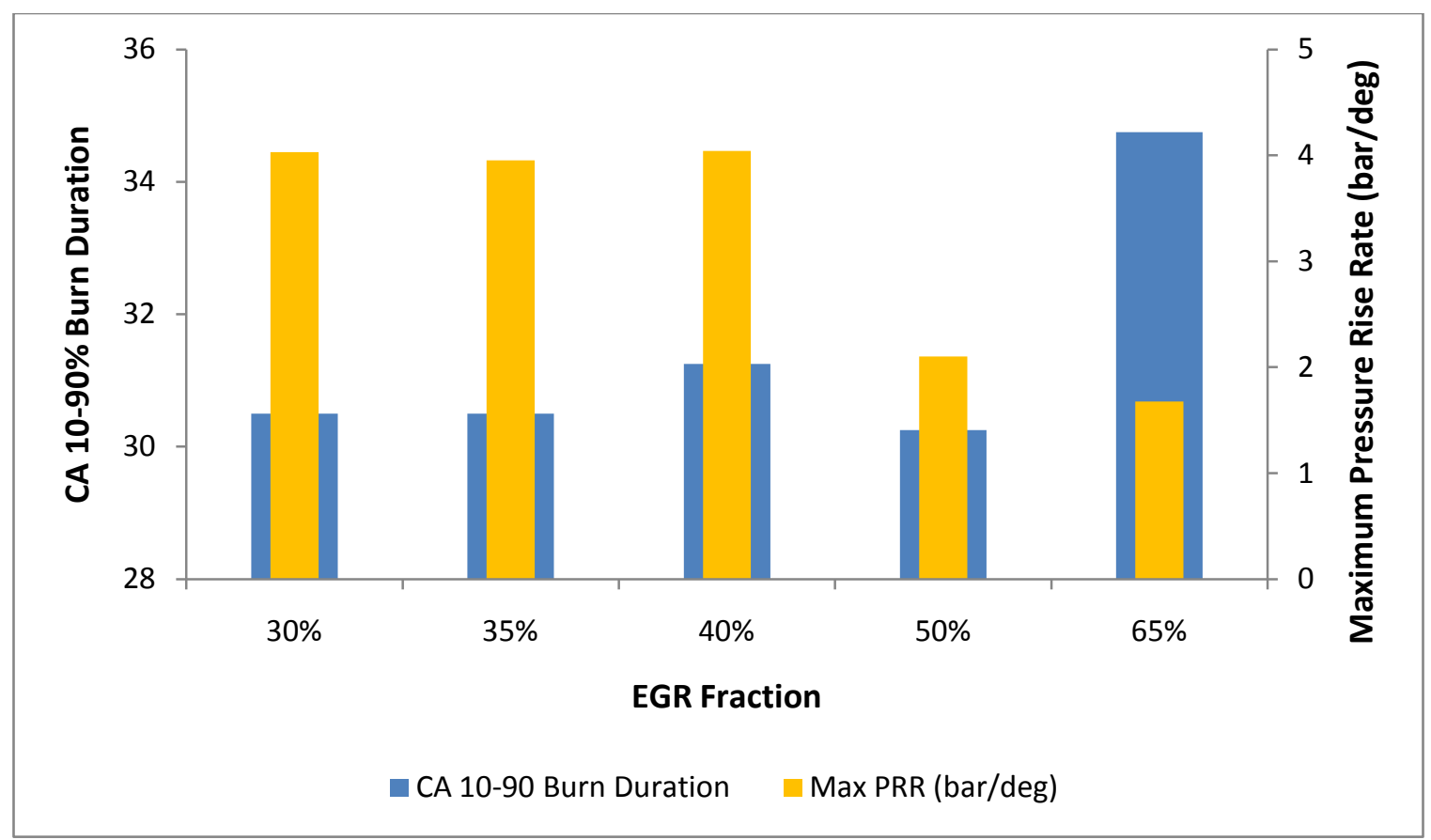

Figure 36: CA 10-90\% Burn Duration and Max PRR of EGR Sweeps for Fuel B

EGR fractions of $30-40 \%$ provide a maximum pressure rise rate of $4 \mathrm{bar} / \mathrm{deg}$ while the $50-65 \%$ EGR fractions result in 2 bar/deg. Figure 37 shows the corresponding BTE and BSFC of the EGR sweeps. As seen from the figure, BTE and BSFC are generally consistent around $27 \%$ and $310 \mathrm{~g} / \mathrm{kW}$-hr with EGR fractions of 30-40\% respectively, while a 50\% EGR fraction provides the highest BTE at $29.5 \%$ and lowest BSFC at $285 \mathrm{~g} / \mathrm{kW}$-hr. From the in-cylinder pressure analysis and calculated emissions concentrations, it was determined that the optimum EGR fraction for Fuel B was 50\%. 


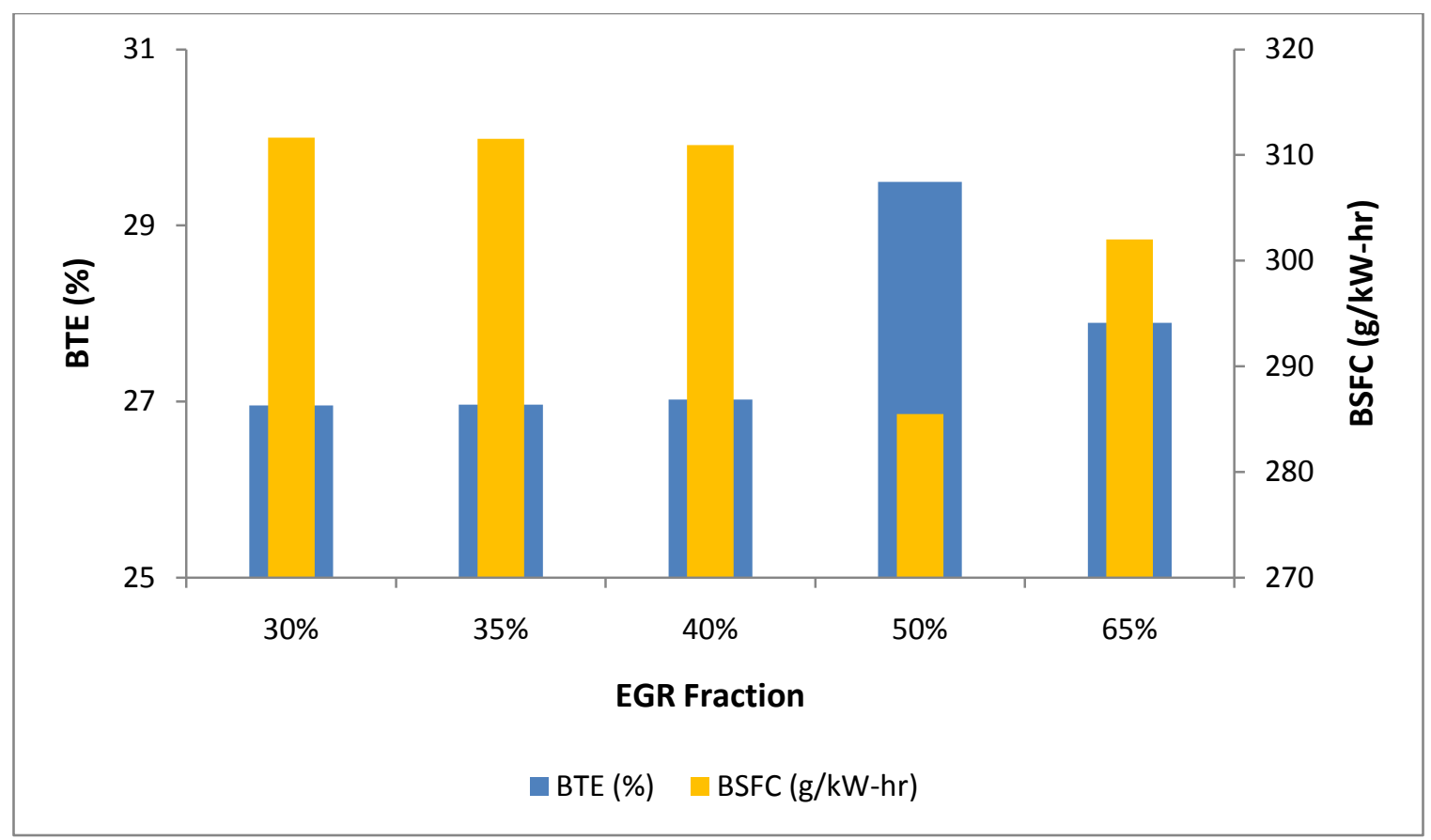

Figure 37: BTE and BSFC of EGR Sweeps for Fuel B

Table 12 shows the calculated in-cylinder parameters for the EGR sweeps. As seen in the table, the location of maximum pressure retards as EGR fraction increases until erratic combustion at $65 \%$ EGR. Maximum temperature is greatest at the optimum EGR point of $50 \%$ but occurs later $\left(22.5^{\circ} \mathrm{ATDC}\right)$ during the combustion phase. Also depicted in the table, and as shown in Figure 35, the start of combustion retards as EGR fraction is increased until 50\% EGR where the maximum pressure rise rate occurs much earlier, similar to Fuel $\mathrm{A}$. 
Table 12: Calculated In-cylinder Combustion Parameters of EGR Sweeps for Fuel B

\begin{tabular}{|l|c|c|c|c|c|c|}
\hline EGR Fraction & - & $\mathbf{3 0 \%}$ & $\mathbf{3 5 \%}$ & $\mathbf{4 0 \%}$ & $\mathbf{5 0 \%}$ & $\mathbf{6 5 \%}$ \\
\hline Heat Released & $\mathrm{kJ}$ & 0.503 & 0.542 & 0.533 & 0.515 & 0.546 \\
\hline Maximum Heat Release Rate & $\mathrm{kJ} / \mathrm{deg}$ & 0.028 & 0.031 & 0.030 & 0.040 & 0.034 \\
\hline Maximum Pressure & $\mathrm{kPa}$ & 7612 & 7843 & 7880 & 6351 & 5749 \\
\hline Location of Maximum Pressure & $\mathrm{deg}$ ATDC & 1.75 & 2.25 & 2.0 & 3.5 & 4.75 \\
\hline Maximum Pressure Rise & bar/deg & 4.03 & 3.95 & 4.04 & 2.10 & 1.68 \\
\hline Location of Maximum Pressure Rise & $\mathrm{deg}$ ATDC & -7.5 & -7.0 & -7.0 & -3.25 & -12.75 \\
\hline Maximum Temperature & $\mathrm{K}$ & 1289 & 1329 & 1326 & 1322 & 1341 \\
\hline Location of Maximum Temperature & deg ATDC & 19.5 & 20.0 & 19.75 & 21.0 & 24.0 \\
\hline Location of 10\% Mass Fraction Burned & deg ATDC & -7.5 & -7.25 & -6.25 & -1.75 & 1.0 \\
\hline Location of 50\% Mass Fraction Burned & deg ATDC & 10.5 & 10.75 & 11.25 & 13.0 & 15.75 \\
\hline Location of 90\% Mass Fraction Burned & deg ATDC & 23.0 & 23.25 & 25.0 & 28.5 & 35.75 \\
\hline
\end{tabular}

Pilot injection sweeps were performed from $40-80^{\circ}$ BTDC at 1200 bar rail pressure, $50 \%$ EGR and $30 \%$ fuel split. As seen in Figure 38, in-cylinder pressure was observed to decrease with advancing pilot injection. At a pilot injection of $40^{\circ}$ BTDC, soot based PM was elevated but $\mathrm{NO}_{\mathrm{x}}$ and $\mathrm{HC}$ were significantly lower compared to the $50-80^{\circ} \mathrm{BTDC}$ injection sweeps, see Table 13. At a pilot injection of greater than $60^{\circ}$, erratic combustion was observed due to wall wetting and can be confirmed by the extremely elevated HC and gravimetric PM emissions. Figure 39 shows the effect of advancing the pilot injection on the gross HRR. 


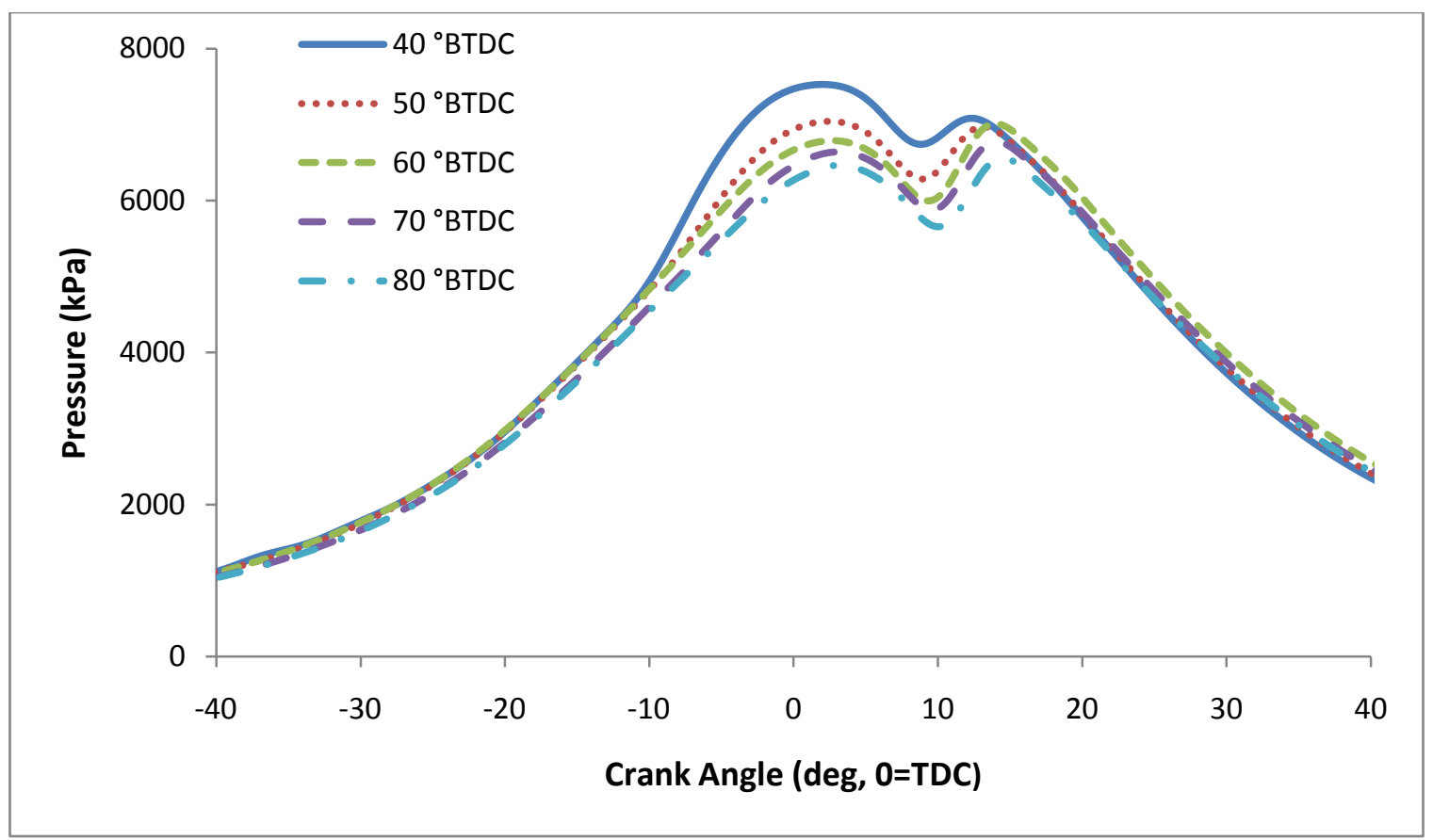

Figure 38: In-cylinder Pressure versus Crank Angle of Pilot Injection Sweeps for Fuel B

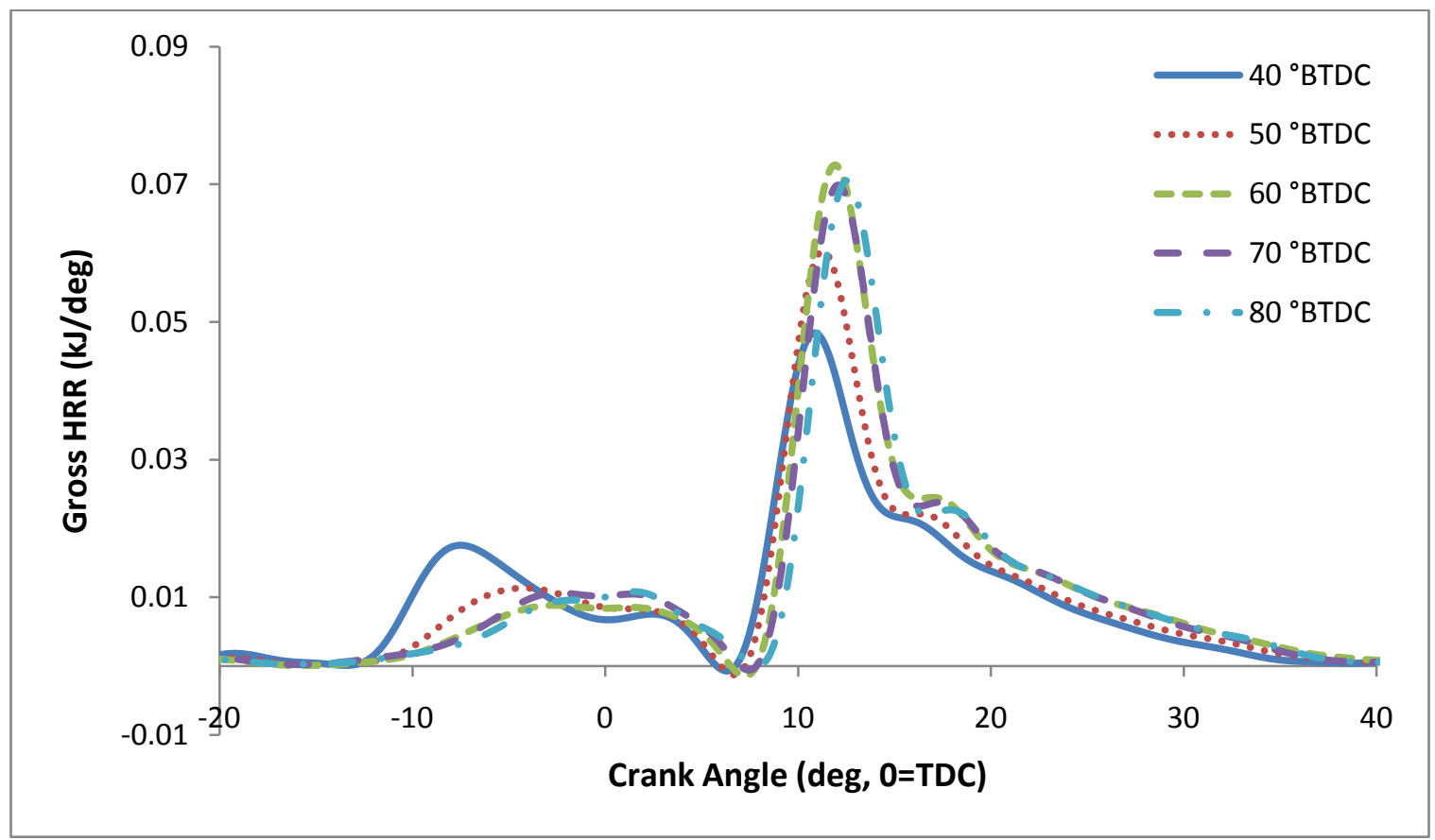

Figure 39: Gross HRR versus Crank Angle of Pilot Injection Sweeps for Fuel B

Figure 39 indicates that early pilot injections retard the start of combustion and lowers the maximum peak HRR. Although the more advanced pilot injections result in more $\mathrm{HCCl}$-like 
HRR curve, ultimately higher emissions due to wall wetting limit them from an optimized strategy. Figure 40 shows the BTE and BSFC for the respective pilot injection sweeps.

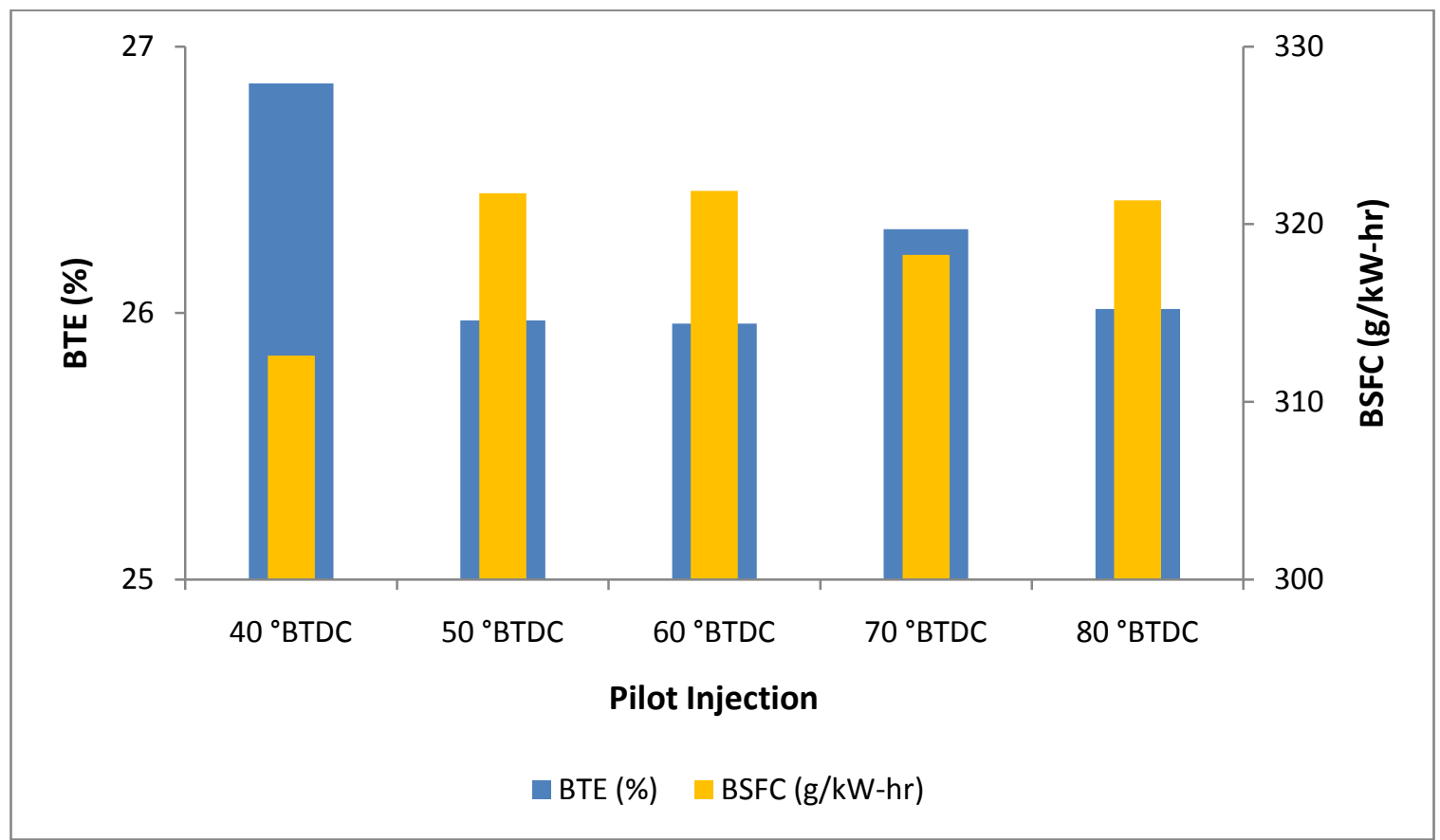

Figure 40: BTE and BSFC of Pilot Injection Sweeps for Fuel B

From Figure 40, a drastic decrease in BTE is observed at the more advanced pilot injections while BSFC is increased. At a $40^{\circ}$ pilot injection BTE is approximately $26.8 \%$ while at $80^{\circ}$ the BTE is $26 \%$. BSFC is increased $3 \%$ from $312 \mathrm{~g} / \mathrm{kW}-\mathrm{hr}$ at $40^{\circ} \mathrm{BTDC}$ to $322 \mathrm{~g} / \mathrm{kW}-\mathrm{hr}$ at $80^{\circ} \mathrm{BTDC}$. The increase in BSFC is a result of the increase in fuel flow to maintain the $3.5 \mathrm{bmep}$ due to erratic combustion from wall wetting at the more advanced pilot injections, also seen by the increase in gravimetric PM but from Table 13.

Table 13: Pilot Injection Sweep Emissions Data for Fuel B

\begin{tabular}{|c|c|c|c|c|c|c|}
\hline Pilot ${ }^{\circ}$ BTDC & HC (ppm) & NO $_{\mathbf{x}}$ (ppm) & $\begin{array}{c}\mathbf{H C} \\
\text { (g/kW-hr) }\end{array}$ & $\begin{array}{c}\mathbf{N O}_{\mathbf{x}} \\
\text { (g/kW-hr) }\end{array}$ & $\begin{array}{c}\text { BSFC } \\
\text { (g/kW-hr) }\end{array}$ & $\begin{array}{c}\text { Gravimetric PM } \\
\text { (mg/kW-hr) }\end{array}$ \\
\hline 40 & 791.6 & 73.20 & 3.345 & 1.050 & 312.6 & 232.7 \\
\hline 50 & 1259 & 64.11 & 5.223 & 0.879 & 321.8 & 302.5 \\
\hline 60 & 1392 & 78.97 & 5.909 & 1.112 & 321.9 & 451.4 \\
\hline 70 & 2128 & 73.33 & 8.686 & 0.986 & 318.3 & 836.3 \\
\hline 80 & 2689 & 60.74 & 10.54 & 0.779 & 321.3 & 1111 \\
\hline
\end{tabular}


Fuel split sweeps were performed with similar decreases in cylinder pressure as the EGR and fuel split sweeps performed for Fuel A, refer to Figure 41. Soot based PM increased as the fuel split increased while gravimetric PM increased $30 \%$ from a $20 \%$ to $50 \%$ fuel split (Table 14 ).

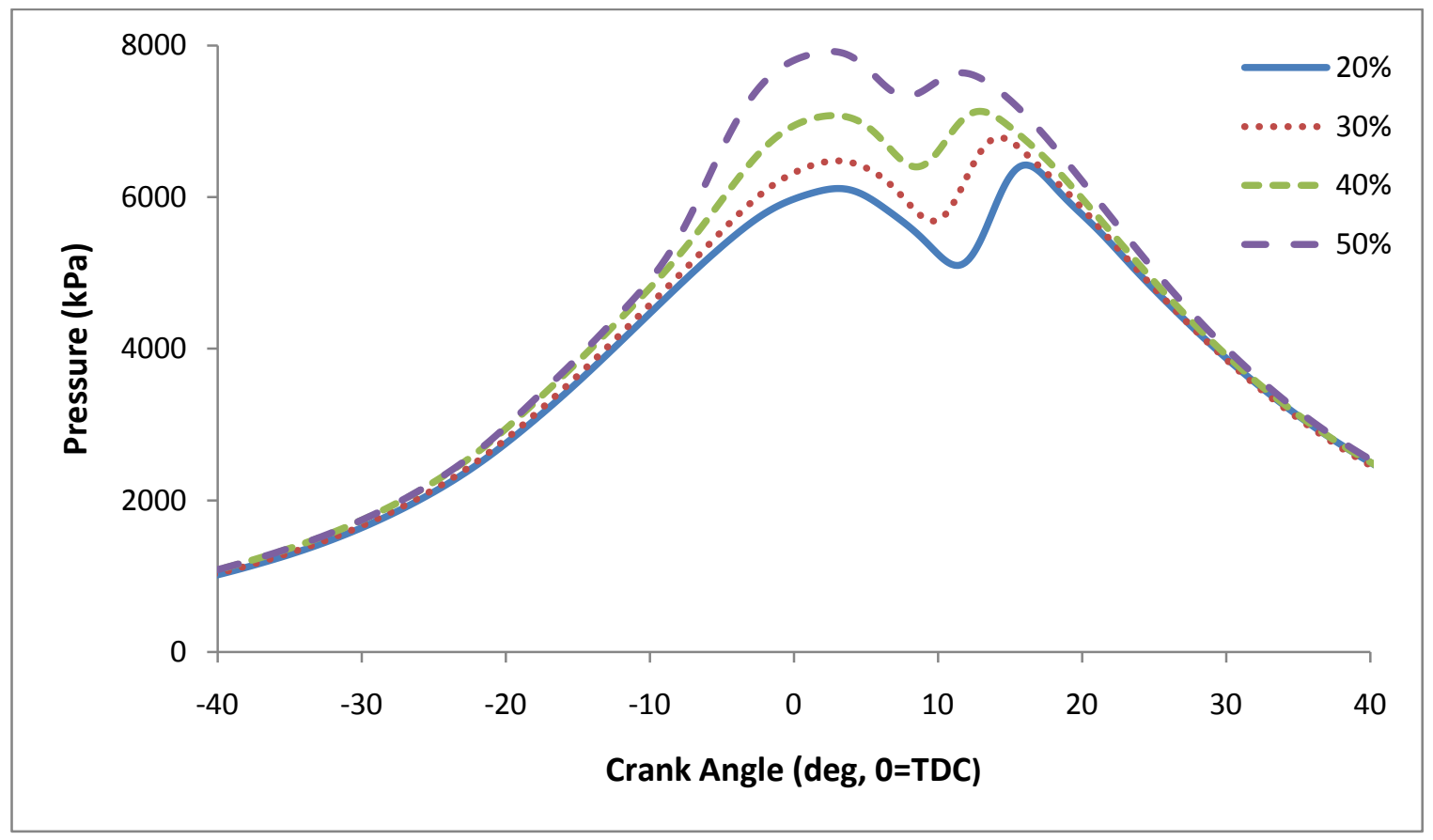

Figure 41: Fuel Split Pressure Trace for Fuel B

Table 14: Fuel Split Emissions Data for Fuel B

\begin{tabular}{|c|c|c|c|c|c|c|}
\hline Fuel Split & $\mathbf{H C}(\mathbf{p p m})$ & $\mathbf{N O}_{\mathbf{x}}$ (ppm) & $\begin{array}{c}\mathbf{H C} \\
\text { (g/kW-hr) }\end{array}$ & $\begin{array}{c}\mathbf{N O}_{\mathbf{x}} \\
\text { (g/kW-hr) }\end{array}$ & $\begin{array}{c}\text { BSFC } \\
\text { (g/kW-hr) }\end{array}$ & $\begin{array}{c}\text { Gravimetric PM } \\
\text { (mg/kW-hr) }\end{array}$ \\
\hline $20 \%$ & 1411 & 74.32 & 5.552 & 0.981 & 305.2 & 381.9 \\
\hline $30 \%$ & 1449 & 87.11 & 6.018 & 1.215 & 321.3 & 509.7 \\
\hline $40 \%$ & 1663 & 61.23 & 6.624 & 0.799 & 319.5 & 465.1 \\
\hline $50 \%$ & 1797 & 62.82 & 7.364 & 0.844 & 330.3 & 560.9 \\
\hline
\end{tabular}

Rail pressure sweeps were also conducted in an attempt to reduce PM emissions but produced minimal differences in the pressure curve as seen in Figure 42 . Figure 43 shows the effect of varying rail pressure on HRR. As expected, maximum peak HRR occurs at the highest rail pressure (1600 bar) although a reduction in PM is observed at 1600 bar, see Table 15. 


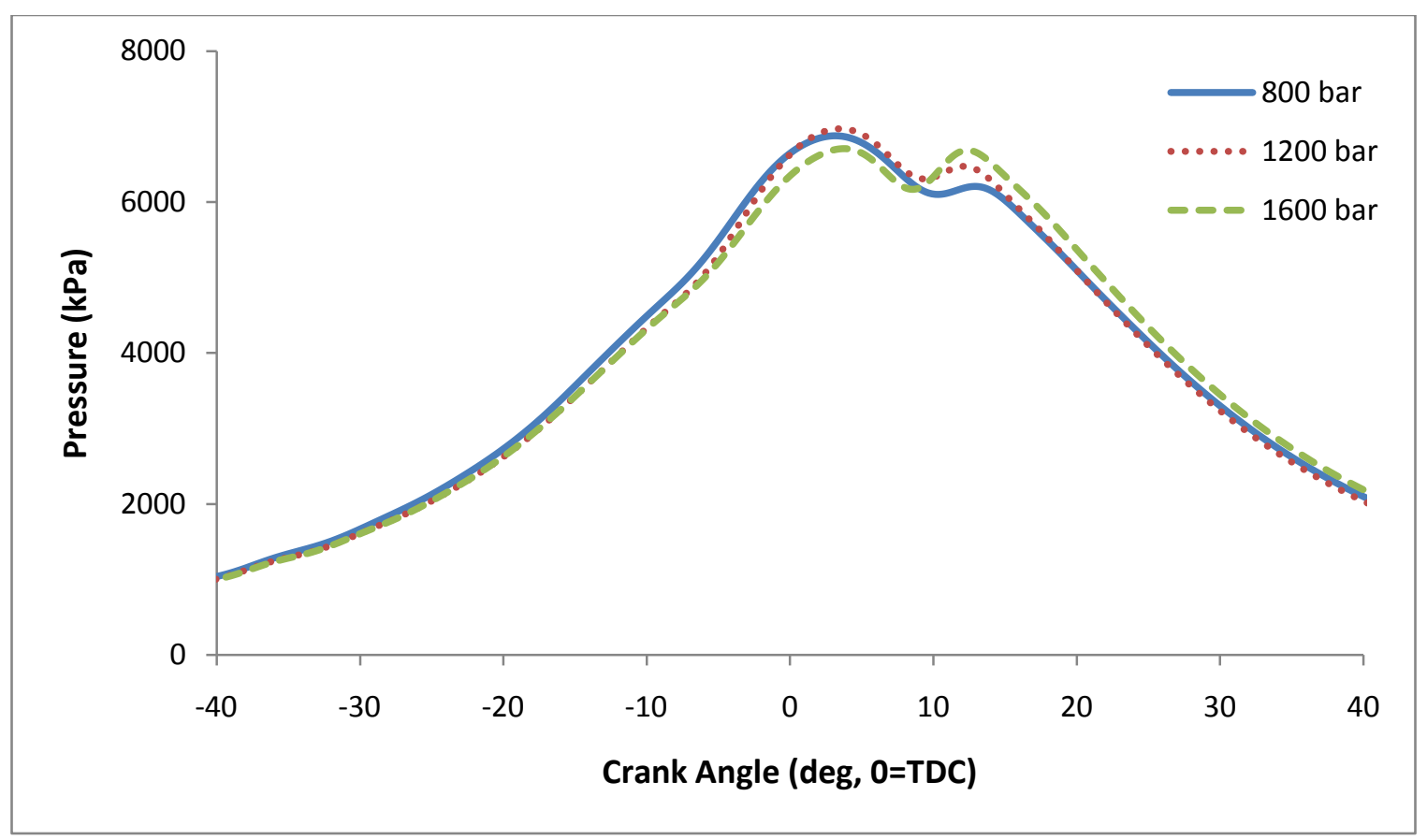

Figure 42: Rail Pressure Sweep Pressure Trace for Fuel B

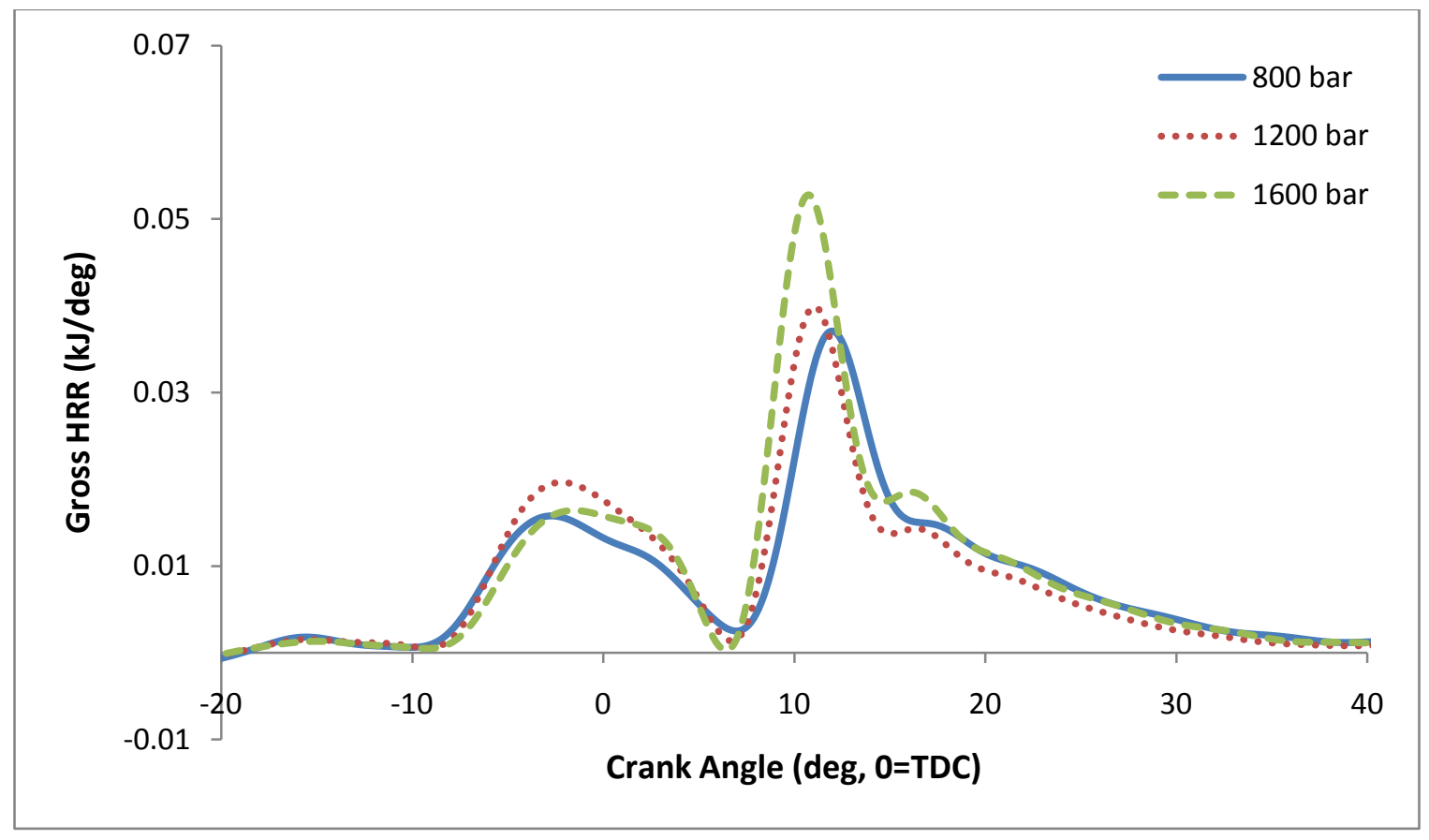

Figure 43: Gross HRR versus Crank Angle of Rail Pressure Sweeps for Fuel B 
Table 15: Rail Pressure Sweep Emissions Data for Fuel B

\begin{tabular}{|c|c|c|c|c|c|c|}
\hline $\begin{array}{c}\text { Rail Pressure } \\
\text { (bar) }\end{array}$ & HC (ppm) & NO $_{\mathbf{x}}$ (ppm) & $\begin{array}{c}\mathbf{H C} \\
\text { (g/kW-hr) }\end{array}$ & $\begin{array}{c}\mathbf{N O x} \\
(\mathbf{g} / \mathbf{k W}-\mathbf{h r})\end{array}$ & $\begin{array}{c}\mathbf{B S F C} \\
\mathbf{( g / k W - h r})\end{array}$ & $\begin{array}{c}\text { Gravimetric PM } \\
\text { (mg/kW-hr) }\end{array}$ \\
\hline 800 & 1547 & 33.59 & 5.512 & 0.393 & 291.6 & 390.9 \\
\hline 1200 & 2145 & 27.15 & 7.116 & 0.291 & 306.0 & 419.4 \\
\hline 1600 & 2313 & 25.57 & 7.138 & 0.249 & 323.5 & 361.5 \\
\hline
\end{tabular}

Upon completion of the discussed engine sweeps, the optimum strategy of the data set for Fuel $B$ is summarized in Table 16 while Table 17 shows the emission concentrations at the respective optimized strategy. Table 18 shows the calculated in-cylinder combustion parameters at the optimized strategy.

Table 16: Optimized Strategy for Fuel B

\begin{tabular}{|l|c|}
\hline EGR & $50 \%$ \\
\hline Rail Pressure & 1200 bar \\
\hline Fuel Split & $30 \%$ \\
\hline Pilot Injection & $40^{\circ}$ BTDC \\
\hline
\end{tabular}

Table 17: Optimum Operating Strategy Emissions Results for Fuel B

\begin{tabular}{|l|c|}
\hline $\mathrm{NO}_{\mathbf{x}}(\mathrm{ppm})$ & 73.2 \\
\hline $\mathrm{HC}(\mathrm{ppm})$ & 791.6 \\
\hline Soot Based PM (mg/kW-hr) & 57.00 \\
\hline Gravimetric PM (mg/kW-hr) & 232.7 \\
\hline BSFC (g/kW-hr) & 312.6 \\
\hline BTE (\%) & 26.9 \\
\hline
\end{tabular}


Table 18: Calculated In-cylinder Combustion Parameters at Optimized Strategy for Fuel B

\begin{tabular}{|l|c|c|}
\hline Heat Released & $\mathrm{kJ}$ & 0.611 \\
\hline Maximum Heat Release Rate & $\mathrm{kJ} / \mathrm{deg}$ & 0.048 \\
\hline Location of Maximum Heat Release Rate & deg ATDC & 10.75 \\
\hline Maximum Pressure & $\mathrm{kPa}$ & 7529 \\
\hline Location of Maximum Pressure & deg ATDC & 2.00 \\
\hline Maximum Pressure Rise & $\mathrm{bar} / \mathrm{deg}$ & 3.63 \\
\hline Location of Maximum Pressure Rise & deg ATDC & -7.75 \\
\hline Maximum Average Bulk Mixture Temperature & $\mathrm{K}$ & 1471 \\
\hline Location of Maximum Temperature & deg ATDC & 21.00 \\
\hline Location of 10\% Mass Fraction Burned & deg ATDC & -7.25 \\
\hline Location of 50\% Mass Fraction Burned & deg ATDC & 11.5 \\
\hline Location of 90\% Mass Fraction Burned & deg ATDC & 23.75 \\
\hline
\end{tabular}




\subsection{Fuel C}

Fuel C was designed with low CN, low aromatic content and low volatility. Specific properties for FACE C are listed in Table 39 from the Appendix. As suggested from Table 1, a low $\mathrm{CN}$ may result in increased $\mathrm{NO}_{\mathrm{x}}$ but decreased PM. Due to the low aromatic content and volatility, both $\mathrm{NO}_{x}$ and PM may be significantly reduced. Because of the low CN of FACE C, the custom intake heating element was implemented for assisted starting and promotion of elevated cylinder temperatures during testing. The first series of testing consisted of performing EGR sweeps to identify an optimum range of EGR fractions that resulted in the lowest $\mathrm{NO}_{\mathrm{x}}$ and $\mathrm{PM}$ emissions, see Table 19. By implementing the heating element, intake manifold temperature was increased approximately $20^{\circ} \mathrm{C}$ but was found to have minimal effect on in-cylinder pressure and heat release rate. For the following EGR sweeps, main SOI and pilot SOI were fixed at $0^{\circ}$ and $40^{\circ}$ BTDC respectively with a $50 \%$ injection split at 800 bar rail pressure. Misfiring was observed for EGR fractions above $45 \%$. Figure 44 illustrates the incylinder pressure as a function of crank angle for the EGR sweeps.

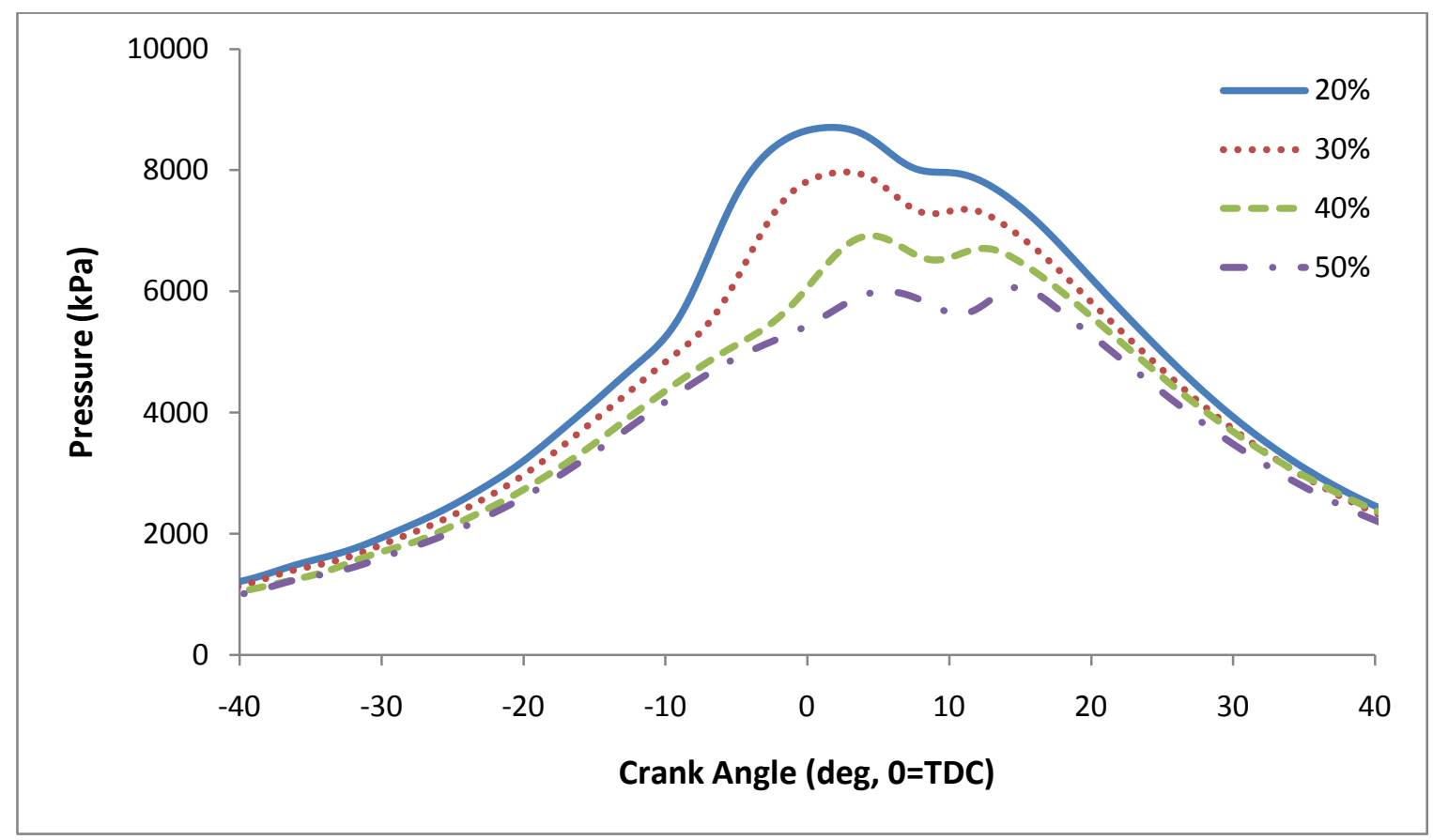

Figure 44: In-cylinder Pressure versus Crank Angle of EGR Sweeps for Fuel C 
As seen from Figure 44, an increasing EGR rate drastically decreases in-cylinder pressure, similar to the trends seen for Fuels A and B. At the lowest EGR fraction (20\%), the highest peak pressure is observed at $8706 \mathrm{kPa}$ while the highest EGR fraction (50\%) resulted in a peak pressure of $6067 \mathrm{kPa}$. Consequently, $\mathrm{NO}_{\mathrm{x}}$ was significantly decreased with increasing EGR fraction but HC emissions were elevated as seen in Table 19. Figure 45 shows the HRR as a function of crank angle for the EGR sweeps. As noted from Figure 45, an increasing EGR not only phases the first stage HRR toward TDC, but also reduces peak HRR over $50 \%$ from 0.053 $\mathrm{kJ} / \mathrm{deg}$ at $50 \% \mathrm{EGR}$ to $0.034 \mathrm{~kJ} / \mathrm{deg}$ at $20 \% \mathrm{EGR}$. Figure 46 shows the corresponding mass fraction burned as a function of crank angle for the EGR fraction sweeps.

Table 19: EGR Sweep Emissions Data for Fuel C

\begin{tabular}{|c|c|c|c|c|c|c|}
\hline EGR & HC (ppm) & NO $_{\mathbf{x}}$ (ppm) & $\begin{array}{c}\text { HC } \\
\text { (g/kW-hr) }\end{array}$ & $\begin{array}{c}\mathbf{N O}_{\mathbf{x}} \\
\text { (g/kW-hr) }\end{array}$ & $\begin{array}{c}\text { BSFC } \\
\text { (g/kW-hr) }\end{array}$ & $\begin{array}{c}\text { Gravimetric PM } \\
\text { (mg/kW-hr) }\end{array}$ \\
\hline $20 \%$ & 956.2 & 170.0 & 4.671 & 2.81 & 298.0 & 321.5 \\
\hline $30 \%$ & 1076 & 115.8 & 4.712 & 1.72 & 290.2 & 236.9 \\
\hline $40 \%$ & 1672 & 60.55 & 6.300 & 0.746 & 282.8 & 209.1 \\
\hline $50 \%$ & 6150 & 32.18 & 22.21 & 0.358 & 320.2 & 659.1 \\
\hline
\end{tabular}

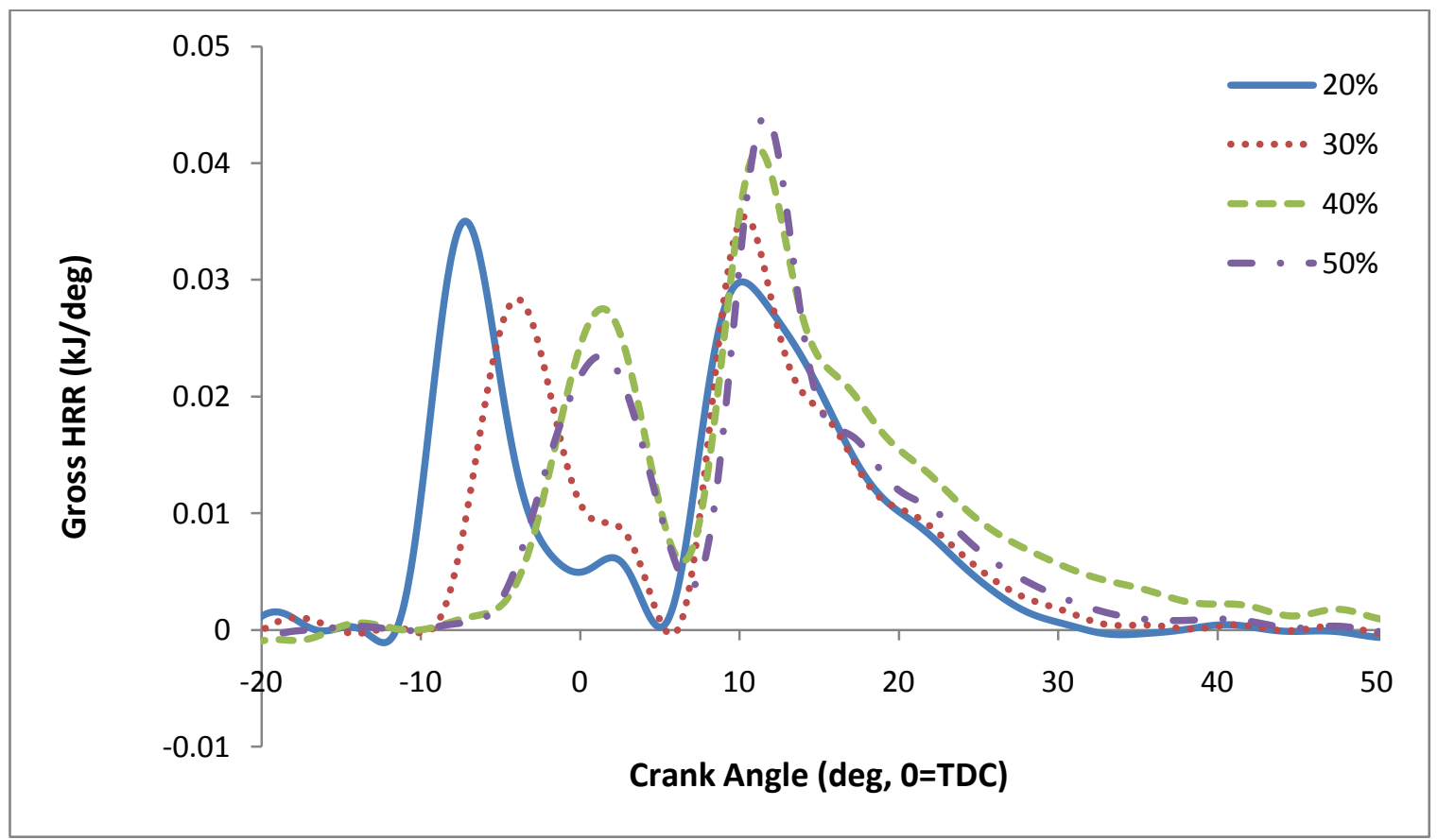

Figure 45: Gross HRR versus Crank Angle of EGR Sweeps for Fuel C 


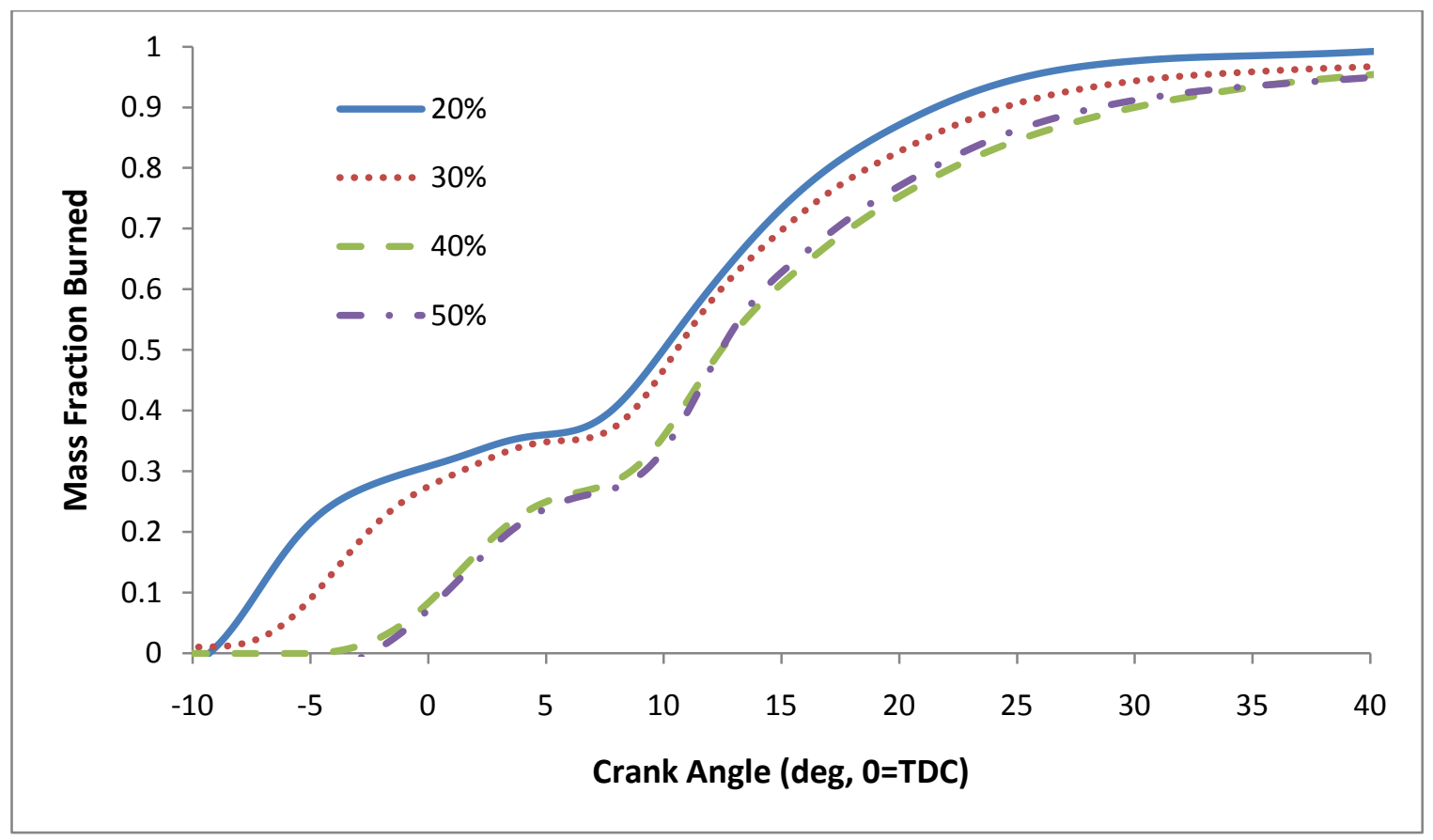

Figure 46: Mass Fraction Burned versus Crank Angle of EGR Sweeps for Fuel C

As illustrated in Figure 46, an increasing EGR fraction significantly retards combustion due to the increased heat capacity and lower oxygen content of the intake mixture. A CA 10$90 \%$ was calculated to determine the approximate duration of combustion, see Figure 47 . A longer $10-90 \%$ burn duration was observed at $40 \%$ EGR while the shortest duration was at $50 \%$ EGR. Figure 47 also shows the corresponding pressure rise rates for the EGR sweeps. 


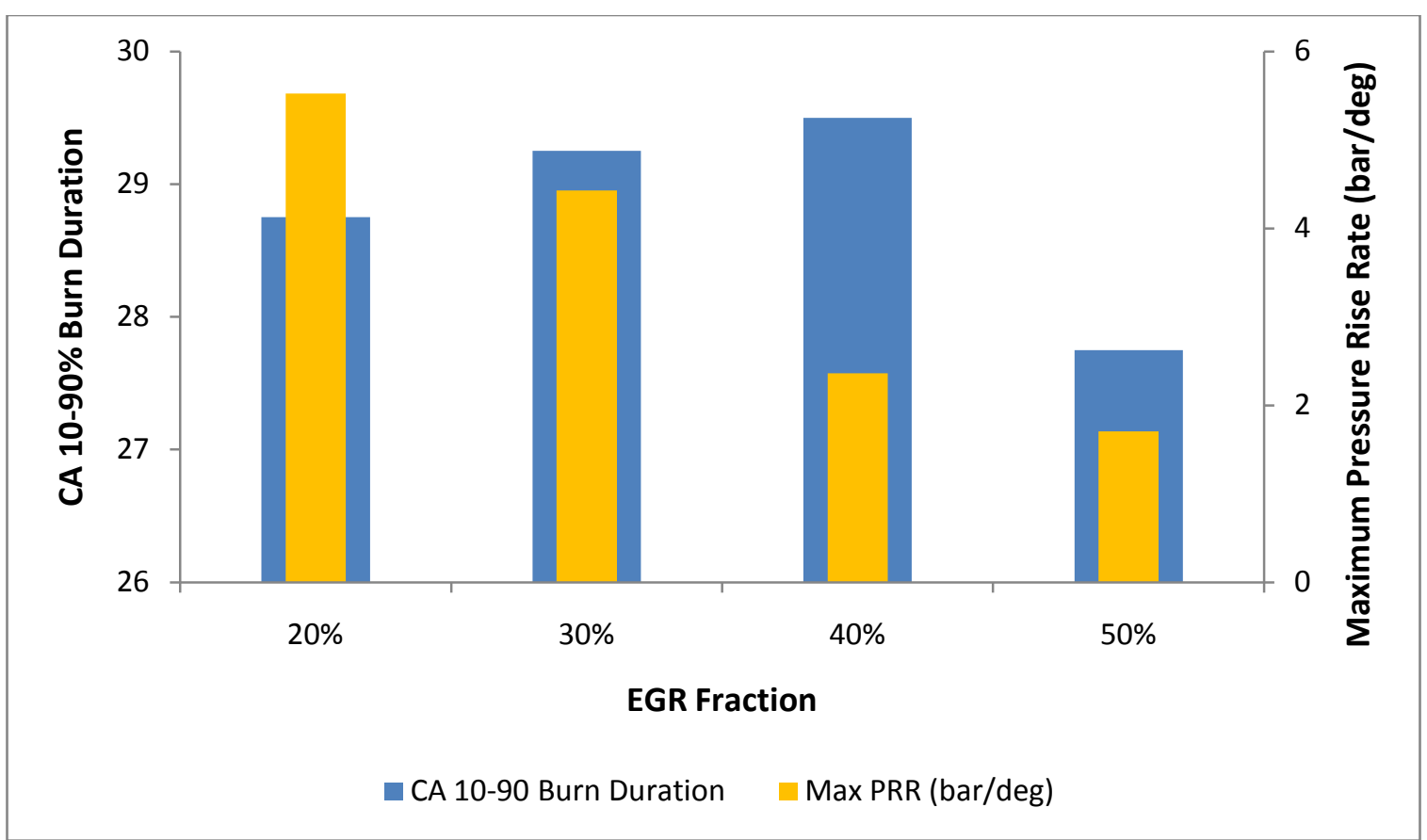

Figure 47: CA 10-90\% Burn Duration and Max PRR of EGR Sweeps for Fuel C

A linearly decreasing maximum pressure rise rate is depicted in Figure 47 as EGR fraction increases, similar to the results for Fuels A and B. An EGR fraction of $20 \%$ resulted in a maximum pressure rise rate of $5.5 \mathrm{bar} / \mathrm{deg}$ compared to just $1.7 \mathrm{bar} / \mathrm{deg}$ at $50 \%$ EGR. Also as EGR fraction increases, the pressure rise rates become retarded with $40 \%$ EGR having a maximum pressure rise rate closer to TDC $\left(1^{\circ} \mathrm{BTDC}\right)$, refer to Table 20 . Figure 48 shows the corresponding BTE and BSFC. As seen from the figure, BTE increases up to $40 \%$ EGR then suddenly drops at $50 \%$ EGR, thought to be due to misfire, with BSFC decreasing to $40 \%$ EGR and suddenly increasing at $50 \%$ EGR. The increase in BTE is directly related to BSFC, thus with an increase in BSFC, a decrease in BTE can be observed, and vice versa. From the in-cylinder pressure analysis and calculated emissions concentrations, it was determined that the optimum EGR fraction for low $\mathrm{NO}_{x}, \mathrm{PM}$ and BSFC was $40-45 \%$. 


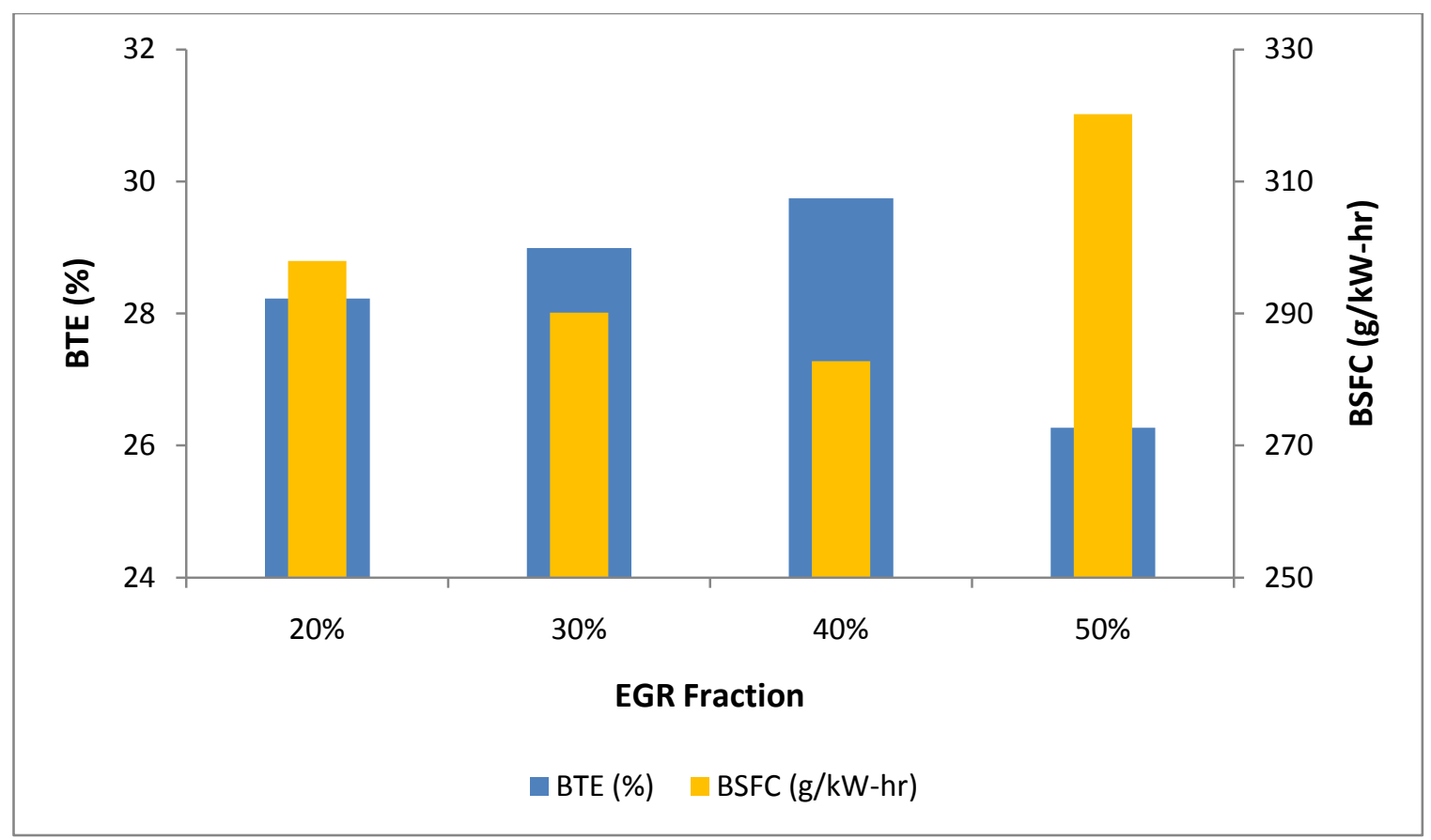

Figure 48: BTE and BSFC of EGR Sweeps for Fuel C

Table 20 shows the calculated in-cylinder parameters for the EGR sweeps. As seen in the table, the location of maximum pressure, pressure rise rate and temperature are phased further away from TDC as EGR fraction increases, as seen in the case for Fuels A and B. Also depicted in the table, and as shown is Figure 46, the start of combustion advances as EGR fraction is increased until misfire at $50 \%$ EGR.

Table 20: Calculated In-cylinder Combustion Parameters of EGR Sweeps

\begin{tabular}{|l|c|c|c|c|c|}
\hline EGR Fraction & - & $\mathbf{2 0 \%}$ & $\mathbf{3 0 \%}$ & $\mathbf{4 0 \%}$ & $\mathbf{5 0 \%}$ \\
\hline Heat Released & $\mathrm{kJ}$ & 0.634 & 0.626 & 0.570 & 0.609 \\
\hline Maximum Heat Release Rate & $\mathrm{kJ} / \mathrm{deg}$ & 0.034 & 0.037 & 0.049 & 0.053 \\
\hline Maximum Pressure & $\mathrm{kPa}$ & 8706 & 7972 & 6893 & 6067 \\
\hline Location of Maximum Pressure & $\mathrm{deg}$ ATDC & 1.75 & 2.75 & 4.25 & 14.75 \\
\hline Maximum Pressure Rise & $\mathrm{bar} / \mathrm{deg}$ & 5.52 & 4.43 & 2.36 & 1.7 \\
\hline Location of Maximum Pressure Rise & $\mathrm{deg}$ ATDC & -7.0 & -4.25 & -1.0 & 12.75 \\
\hline Maximum Average Bulk Mixture Temperature & $\mathrm{K}$ & 1461 & 1460 & 1478 & 1504 \\
\hline Location of Maximum Temperature & $\mathrm{deg}$ ATDC & 19 & 19.5 & 20.5 & 22.5 \\
\hline Location of 10\% Mass Fraction Burned & deg ATDC & -7.25 & -4.75 & 0.5 & 0.75 \\
\hline Location of 50\% Mass Fraction Burned & deg ATDC & 10.0 & 10.75 & 12.5 & 12.5 \\
\hline Location of 90\% Mass Fraction Burned & deg ATDC & 21.5 & 24.5 & 30.0 & 28.5 \\
\hline
\end{tabular}


Pilot injection sweeps were performed from $30-40^{\circ}$ BTDC, at $40 \%$ EGR, 50\% fuel split and 800 bar rail pressure. A longer burn duration was observed at $35^{\circ} \mathrm{BTDC}$ while the shortest burn duration occurred at $40^{\circ} \mathrm{BTDC}$ as seen in Figure 49. At $30^{\circ} \mathrm{BTDC}, \mathrm{NO}_{\mathrm{x}}$ was elevated but $\mathrm{HC}$ was significantly lower compared to the $35^{\circ} \mathrm{BTDC}$ pilot injection. However at $40^{\circ} \mathrm{BTDC} \mathrm{NO}_{\mathrm{x}}$ was minimal but $\mathrm{HC}$ emissions were extremely elevated due to incomplete combustion, see Table 21. It was determined that a pilot injection of $35^{\circ} \mathrm{BTDC}$ provided the best tradeoff of $\mathrm{NO}_{\mathrm{x}}, \mathrm{PM}$ and $\mathrm{HC}$ emissions.

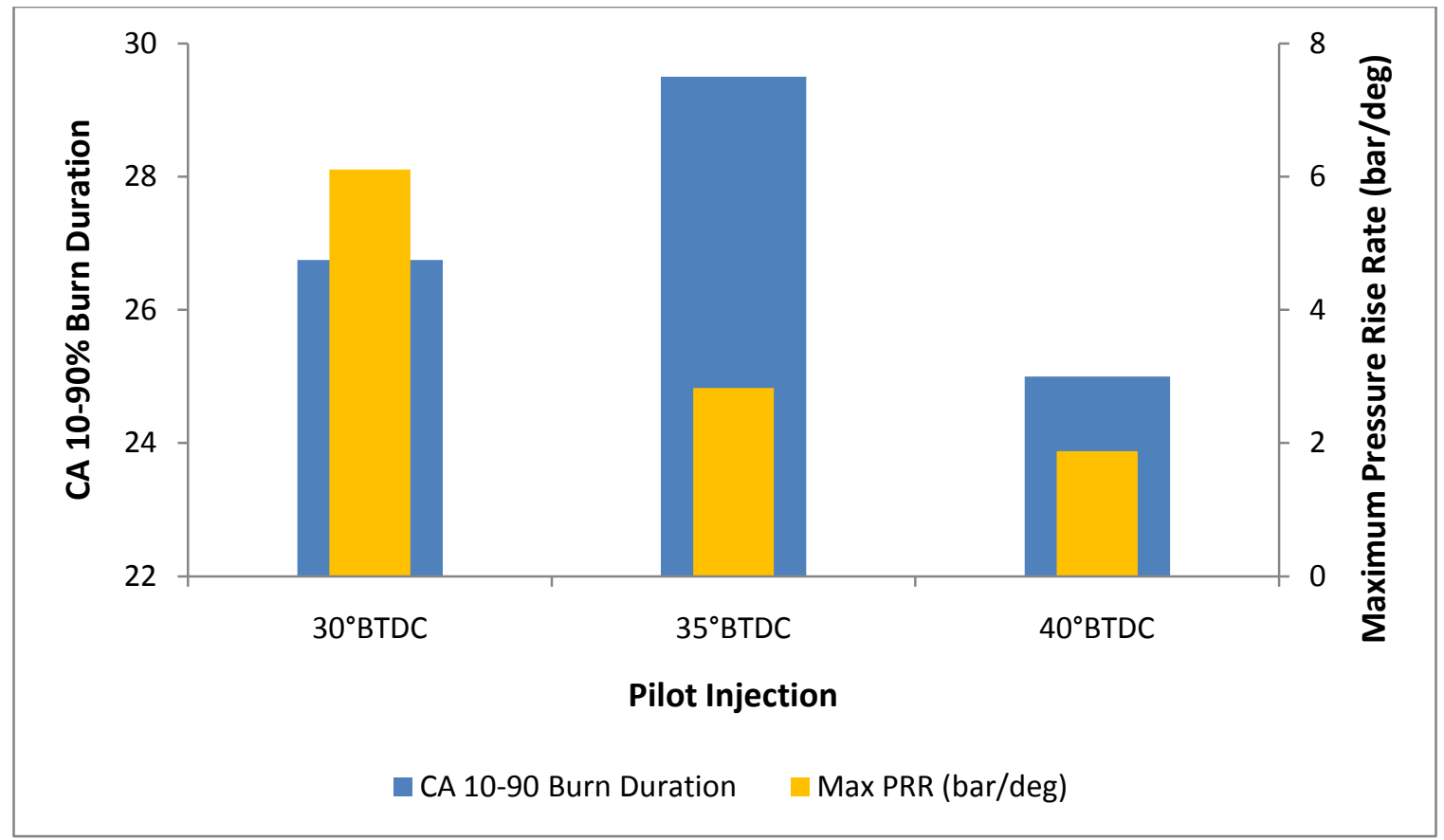

Figure 49: CA 10-90\% Burn Duration and Max PRR of Pilot Injection Sweeps for Fuel C

Table 21: Pilot Injection Sweep Emissions Data for Fuel C

\begin{tabular}{|c|c|c|c|c|c|c|}
\hline Pilot ('BTDC) & HC (ppm) & NO $_{\mathbf{x}}$ (ppm) & $\begin{array}{c}\mathbf{H C} \\
\text { (g/kW-hr) }\end{array}$ & $\begin{array}{c}\mathbf{N O}_{\mathbf{x}} \\
\text { (g/kW-hr) }\end{array}$ & $\begin{array}{c}\text { BSFC } \\
\text { (g/kW-hr) }\end{array}$ & $\begin{array}{c}\text { Gravimetric PM } \\
\text { (mg/kW-hr) }\end{array}$ \\
\hline 30 & 797.1 & 87.47 & 2.804 & 1.075 & 273.7 & 422.6 \\
\hline 35 & 1345 & 54.76 & 4.724 & 0.635 & 281.2 & 225.9 \\
\hline 40 & 2277 & 44.07 & 8.143 & 0.509 & 290.7 & 266.8 \\
\hline
\end{tabular}

Rail pressure sweeps were also conducted to evaluate engine performance and attempt to reduce PM emissions. The effect of varying the rail pressure from $800-1600$ bar and setting the 
EGR fraction to $45 \%$ can be observed in Figure 50 while Figure 51 shows the corresponding HRR.

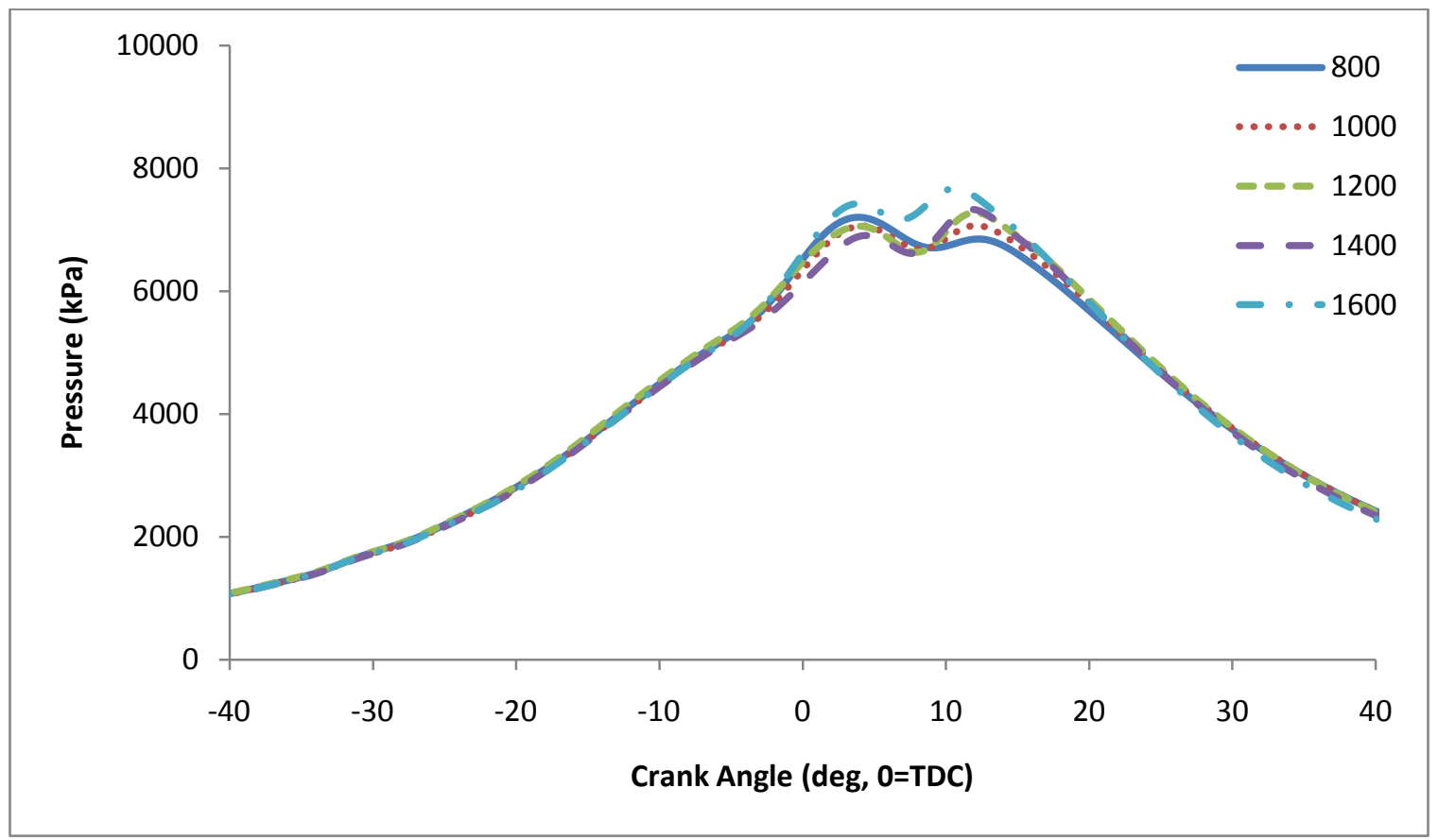

Figure 50: In-cylinder Pressure versus Crank Angle of Rail Pressure Sweeps for Fuel C

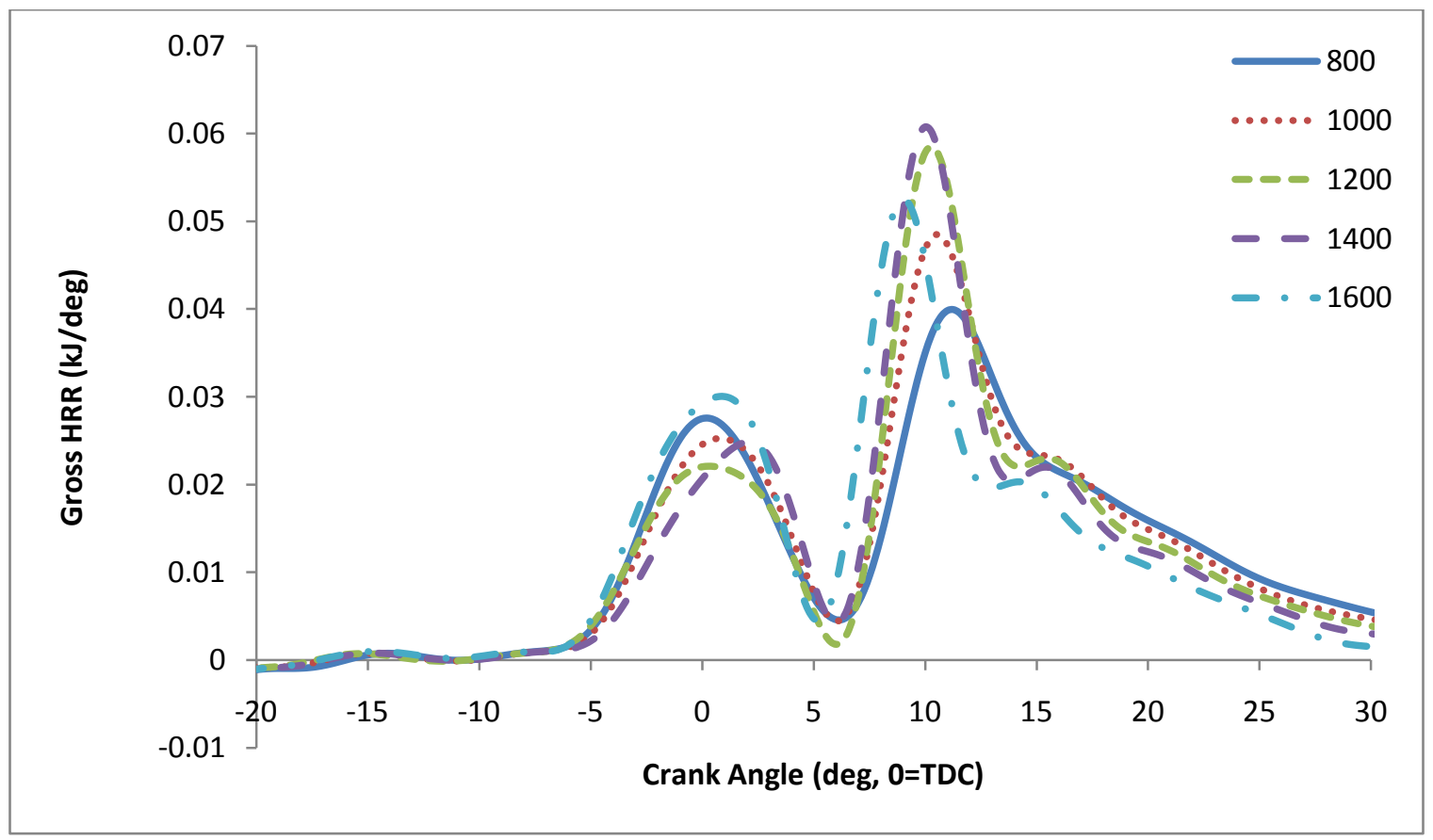

Figure 51: Gross HRR versus Crank Angle of Rail Pressure Sweeps for Fuel C 
As seen in Figure 50, peak pressure is observed at 1600 bar while $800-1400$ bar have similar peak pressures. Gravimetric PM was reduced at 1400 bar but an increase in PM was observed at 1600 bar, see Table 22. The HRR shown in Figure 51 indicates the effect of rail pressure on peak HRR. At 800 bar peak HRR in the first stage heat release is approximately $0.027 \mathrm{~kJ} / \mathrm{deg}$ while at 1600 bar the peak is observed at $0.03 \mathrm{~kJ} / \mathrm{deg}$. The diffusion combustion event shows similar trends but a rail pressure of 1400 bar shows the highest peak HRR at 0.058 $\mathrm{kJ} /$ deg. Figure 52 shows the BTE and BSFC for the respective rail pressure sweeps.

Table 22: Rail Pressure Sweep Emissions Data for Fuel C

\begin{tabular}{|c|c|c|c|c|c|c|}
\hline $\begin{array}{c}\text { Rail Pressure } \\
\text { (bar) }\end{array}$ & HC (ppm) & NO $_{\mathbf{x}}$ (ppm) & $\begin{array}{c}\mathbf{H C} \\
\text { (g/kW-hr) }\end{array}$ & $\begin{array}{c}\mathbf{N O}_{\mathbf{x}} \\
\text { (g/kW-hr) }\end{array}$ & BSFC (g/kW-hr) & $\begin{array}{c}\text { Gravimetric PM } \\
\text { (mg/kW-hr) }\end{array}$ \\
\hline 800 & 1131 & 60.15 & 4.21 & 0.752 & 289.7 & 240.0 \\
\hline 1000 & 1477 & 58.44 & 5.54 & 0.725 & 284.7 & 213.9 \\
\hline 1200 & 1441 & 67.61 & 5.49 & 0.854 & 294.1 & 203.6 \\
\hline 1400 & 1814 & 51.34 & 6.30 & 0.586 & 283.1 & 203.5 \\
\hline 1600 & 1976 & 60.20 & 7.40 & 0.742 & 292.5 & 225.0 \\
\hline
\end{tabular}

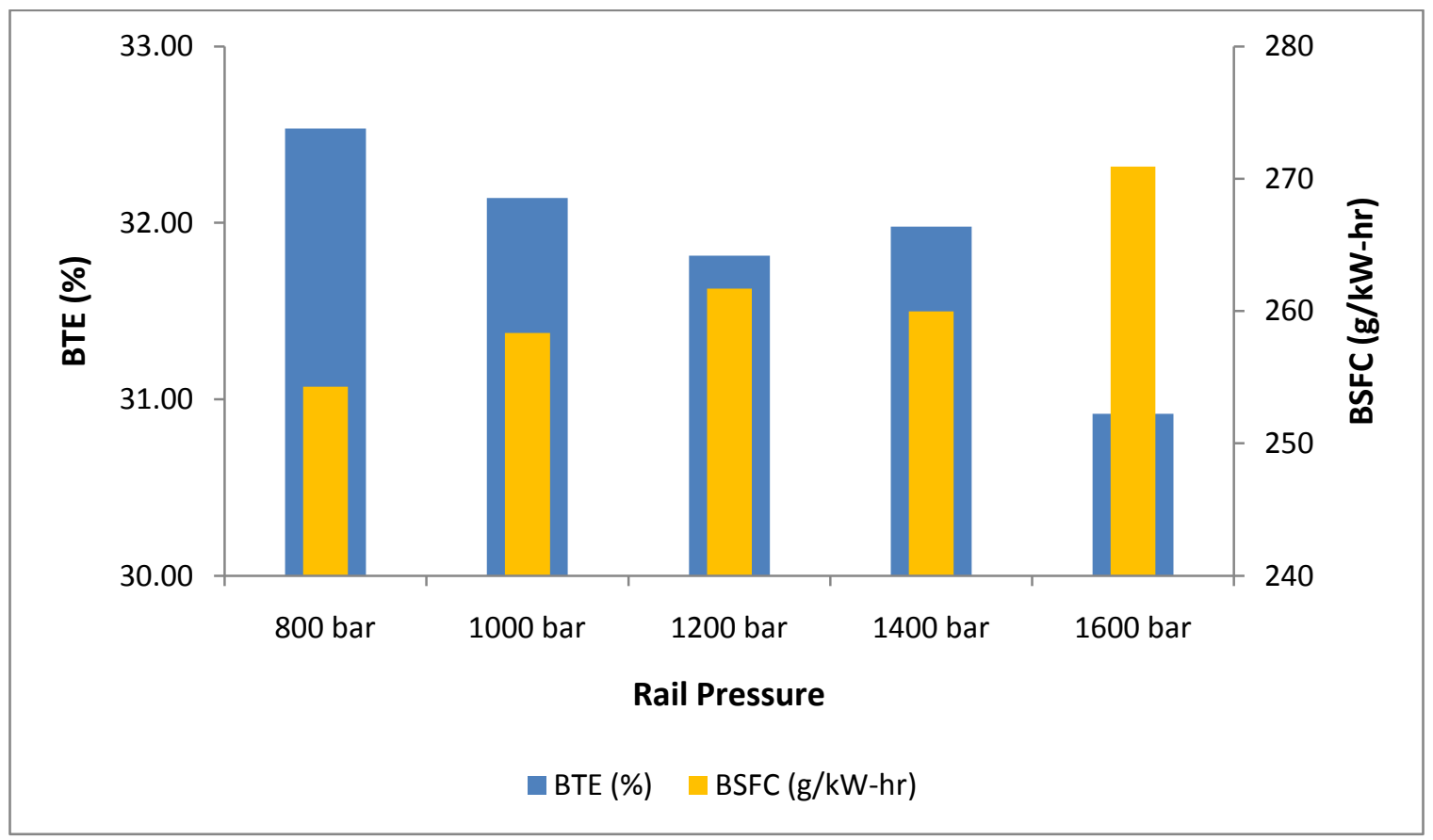

Figure 52: BTE and BSFC of Rail Pressure Sweeps for Fuel C 
Fuel split sweeps were performed from $40-60 \%$ at 1200 bar rail pressure, $40-45 \%$ EGR and a pilot injection of $35^{\circ} \mathrm{BTDC}$ with similar results to Fuels $\mathrm{A}$ and B. Figure 53 depicts the incylinder pressure traces of the respective fuel split sweeps. As seen from Figure 53, maximum in-cylinder pressures are slightly increased as the fuel split is increased. At a $40 \%$ fuel split, the main injection appears to have a much steeper slope ATDC while the $60 \%$ fuel split appears to have similar first stage and diffusion combustion events, as noted by the two similar peaks in the pressure trace. Figure 54 shows the gross heat release rate of the corresponding fuel split sweeps.

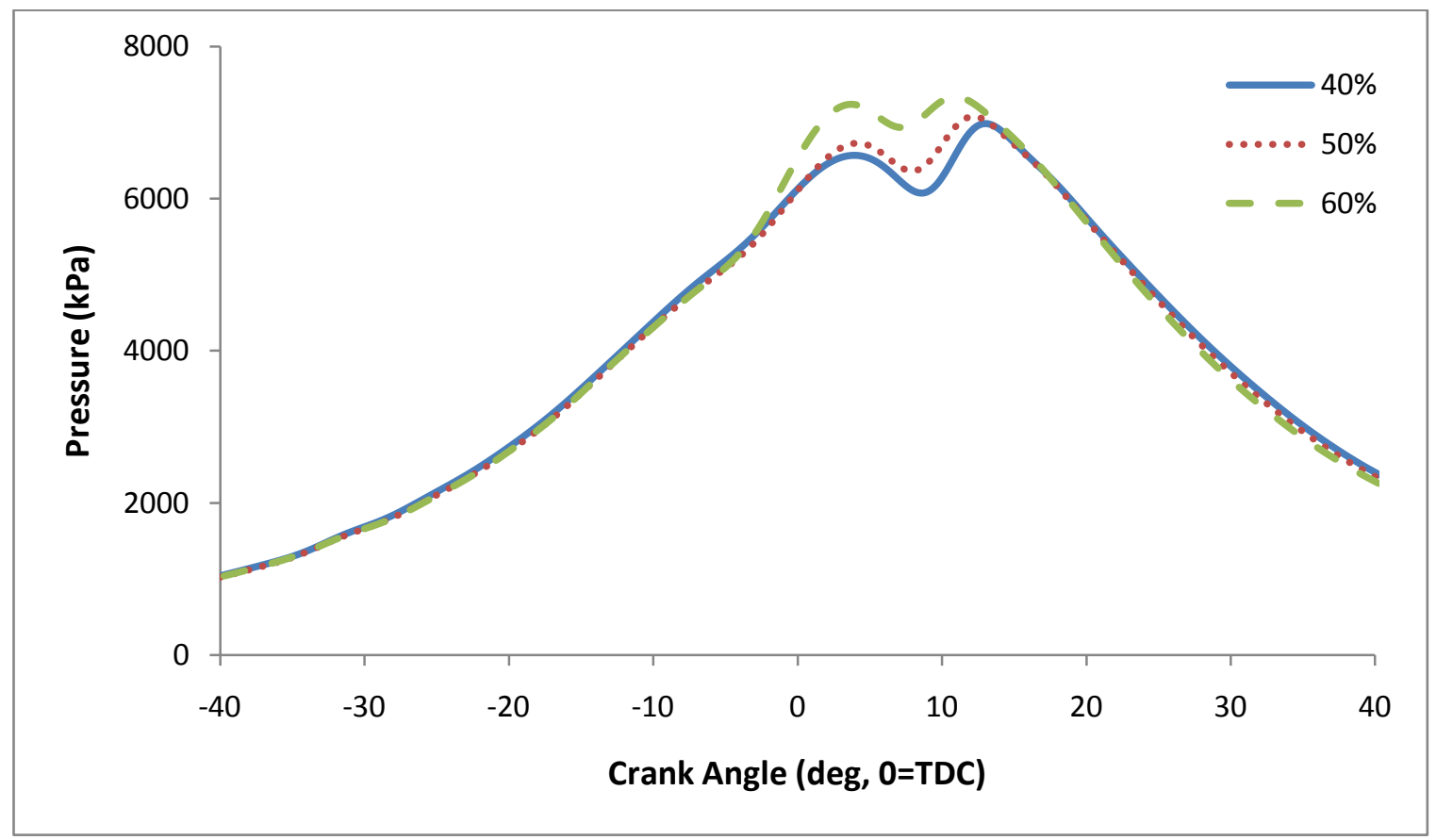

Figure 53: In-cylinder Pressure versus Crank Angle of Fuel Split Sweeps for Fuel C 


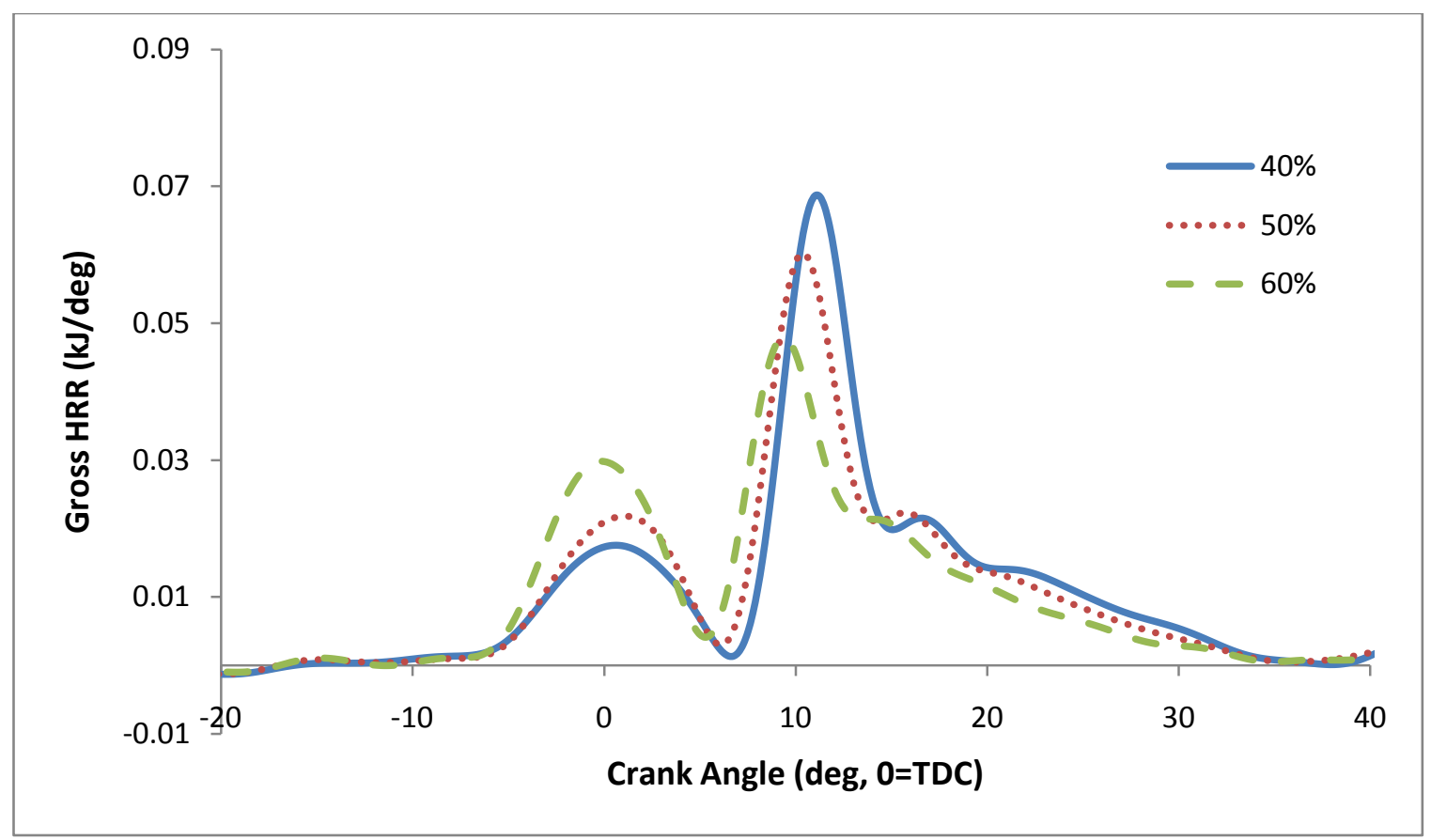

Figure 54: Gross HRR versus Crank Angle of Fuel Split Sweeps for Fuel C

As seen from Figure 54, the HRR of the $40 \%$ and $50 \%$ fuel split are suggestive of an advanced combustion event as denoted by a minimal premixed combustion with a rapid diffusion combustion slightly ATDC. Although a $40 \%$ fuel split provided the more rapid combustion event, $\mathrm{NO}_{\mathrm{x}}$ emissions were elevated due to higher cylinder temperatures. It was determined that a $50 \%$ fuel split provided the lowest $\mathrm{NO}_{\mathrm{x}}$ and $\mathrm{HC}$ emissions tradeoff with similar PM emissions to $40 \%$ and $60 \%$ fuel split. Pressure rise rates were also minimal at a $50 \%$ fuel split while $40 \%$ and $60 \%$ fuel splits had similar pressure rise rates as seen in Figure 55 . Figure 56 shows the brake thermal efficiency and brake specific fuel consumption of the fuel split sweeps while Table 23 shows the respective emissions concentrations. 


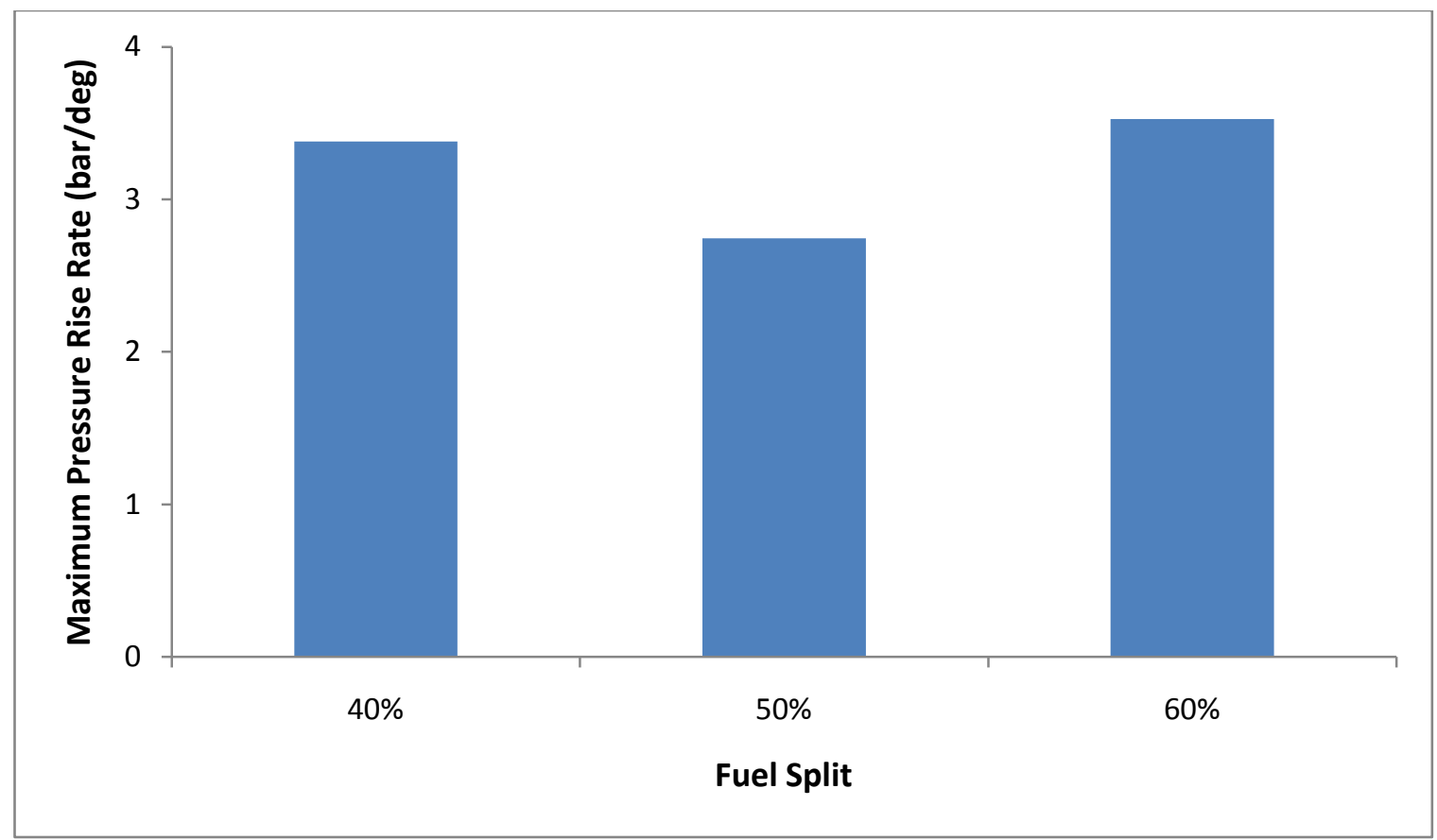

Figure 55: Maximum Pressure Rise Rate of Fuel Split Sweeps for Fuel C

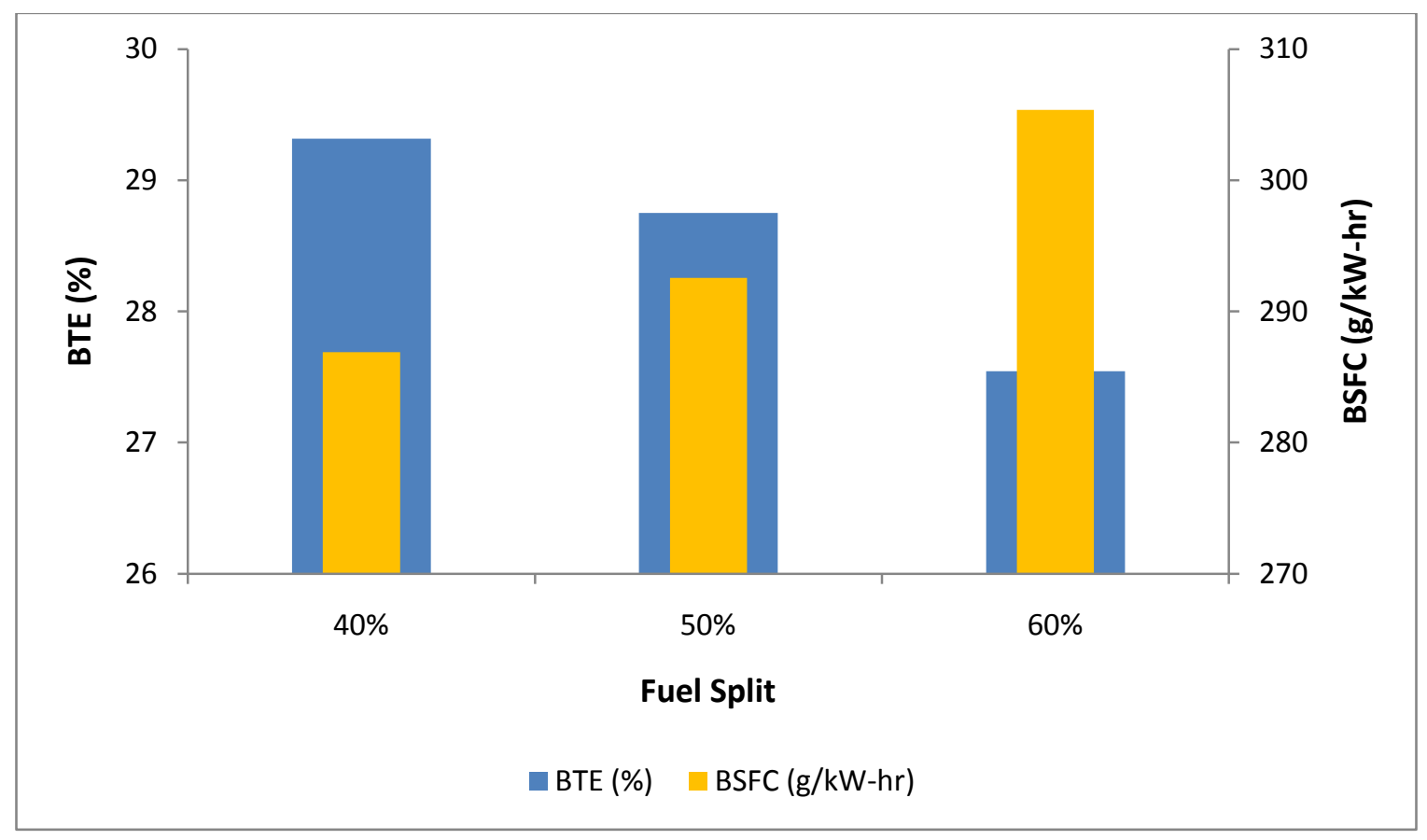

Figure 56: BTE and BSFC of Fuel Split Sweeps for Fuel C 
Table 23: Fuel Split Sweep Emissions Data for Fuel C

\begin{tabular}{|c|c|c|c|c|c|c|}
\hline Fuel Split & $\mathbf{H C}(\mathbf{p p m})$ & $\mathbf{N O}_{\mathbf{x}}$ (ppm) & $\begin{array}{c}\mathbf{H C} \\
\text { (g/kW-hr) }\end{array}$ & $\begin{array}{c}\mathbf{N O}_{\mathbf{x}} \\
(\mathbf{g} / \mathbf{k W}-\mathbf{h r})\end{array}$ & $\begin{array}{c}\text { BSFC } \\
\text { (g/kW-hr) }\end{array}$ & $\begin{array}{c}\text { Gravimetric PM } \\
\text { (mg/kW-hr) }\end{array}$ \\
\hline $40 \%$ & 1137 & 81.37 & 4.381 & 1.060 & 286.9 & 123.6 \\
\hline $50 \%$ & 1342 & 74.48 & 5.220 & 0.972 & 292.6 & 215.7 \\
\hline $60 \%$ & 1271 & 78.53 & 4.948 & 1.028 & 305.4 & 786.6 \\
\hline
\end{tabular}

Upon completing the discussed sweeps for Fuel C, the optimum strategy of the data set for decreased $\mathrm{NO}_{\mathrm{x}}$ and $\mathrm{PM}$ is summarized in Table 24 while Table 25 shows the emission concentrations at the respective optimized strategy. Table 26 shows the calculated in-cylinder combustion parameters at the optimized strategy.

Table 24: Optimized Strategy for Fuel C

\begin{tabular}{|l|c|}
\hline EGR & $40-45 \%$ \\
\hline Rail Pressure & $1200 \mathrm{bar}$ \\
\hline Fuel Split & $50 \%$ \\
\hline Pilot Injection & $35^{\circ} \mathrm{BTDC}$ \\
\hline
\end{tabular}

Table 25: Optimum Operating Strategy Emissions Results for Fuel C

\begin{tabular}{|l|c|}
\hline $\mathrm{NO}_{\mathrm{x}}(\mathrm{ppm})$ & 104.1 \\
\hline $\mathrm{HC}(\mathrm{ppm})$ & 904.3 \\
\hline Soot Based PM (mg/kW-hr) & 14.3 \\
\hline Gravimetric PM (mg/kW-hr) & 232.8 \\
\hline BSFC (g/kW-hr) & 268.7 \\
\hline BTE (\%) & 31.3 \\
\hline
\end{tabular}


Table 26: Calculated In-cylinder Combustion Parameters at Optimized Strategy for Fuel C

\begin{tabular}{|l|c|c|}
\hline Heat Released & $\mathrm{kJ}$ & 0.670 \\
\hline Maximum Heat Release Rate & $\mathrm{kJ} / \mathrm{deg}$ & 0.052 \\
\hline Location of Maximum Heat Release Rate & $\mathrm{deg}$ ATDC & 9.75 \\
\hline Maximum Pressure & $\mathrm{kPa}$ & 7221 \\
\hline Location of Maximum Pressure & $\mathrm{deg}$ ATDC & 11.50 \\
\hline Maximum Pressure Rise & $\mathrm{bar} / \mathrm{deg}$ & 3.64 \\
\hline Location of Maximum Pressure Rise & deg ATDC & -2.50 \\
\hline Maximum Average Bulk Mixture Temperature & $\mathrm{K}$ & 1616 \\
\hline Location of Maximum Temperature & deg ATDC & 20.50 \\
\hline Location of 10\% Mass Fraction Burned & deg ATDC & -2.25 \\
\hline Location of 50\% Mass Fraction Burned & deg ATDC & 10.25 \\
\hline Location of 90\% Mass Fraction Burned & deg ATDC & 23.25 \\
\hline
\end{tabular}




\subsection{Fuel D}

Fuel D was designed with high a CN and volatility but low aromatic content. Specific properties for FACE D are listed in Table 39. From Table 1, a high $\mathrm{CN}$ may result in lower $\mathrm{NO}_{\mathrm{x}}$ but increased PM and the low aromatic content may decrease both $\mathrm{NO}_{\mathrm{x}}$ and $\mathrm{PM}$ emissions. Due to the high $\mathrm{CN}$, the intake heating element was not implemented for each series of testing. The first series of testing consisted of performing EGR sweeps to identify an optimum range of EGR fractions that resulted in the lowest $\mathrm{NO}_{\mathrm{x}}$ and $\mathrm{PM}$ emissions, see Table 27 . For the following EGR sweeps, main SOI and pilot SOI were fixed at $0^{\circ}$ and $40^{\circ}$ BTDC respectively with a $50 \%$ injection split at 800 bar rail pressure. Note misfiring was observed for EGR fractions above $60 \%$. Figure 57 illustrates the in-cylinder pressure as a function of crank angle for EGR fraction sweeps.

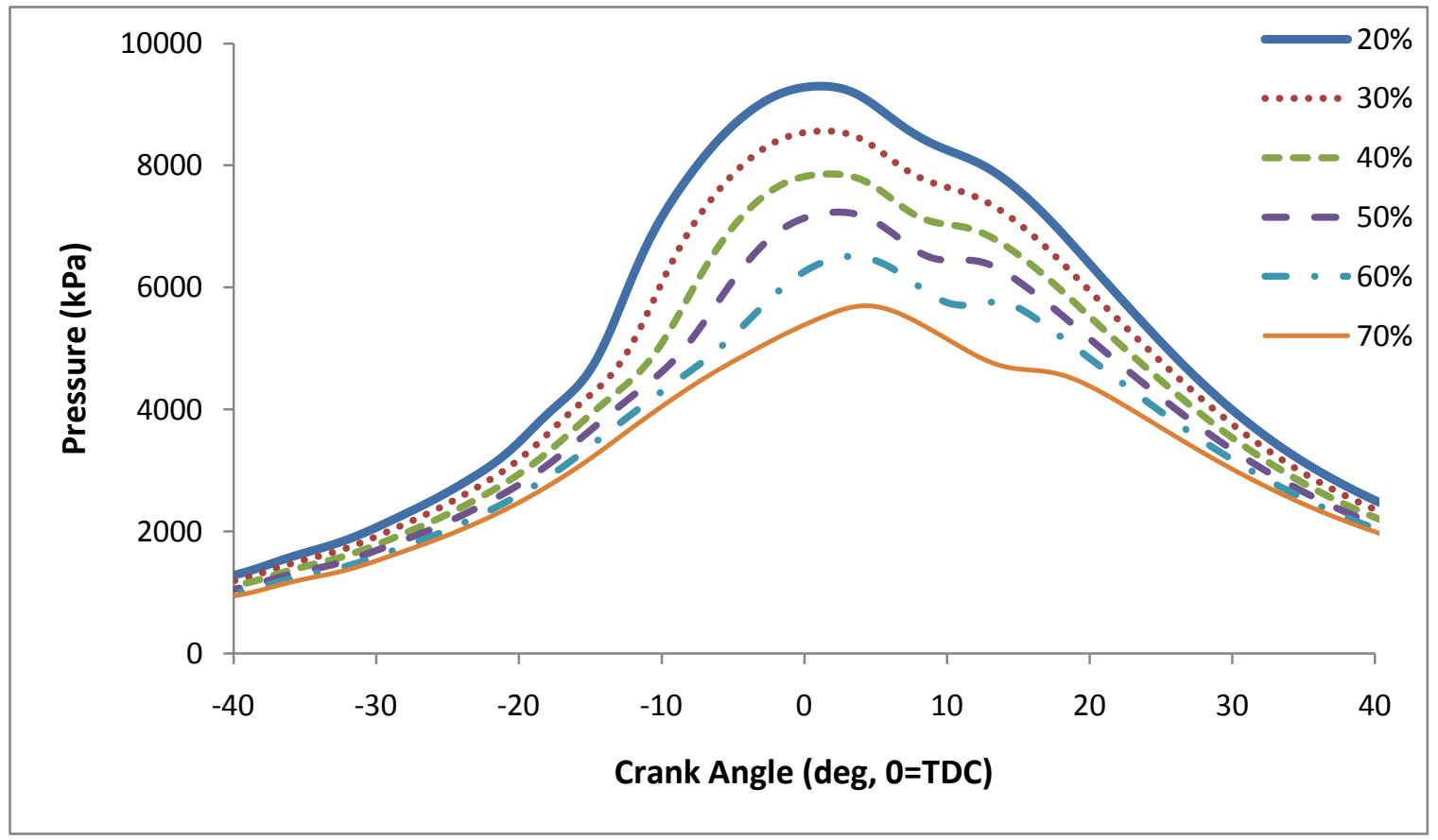

Figure 57: In-cylinder Pressure versus Crank Angle of EGR Sweeps for Fuel D

Similar to Fuels A, B and C, an increasing EGR fraction drastically decreases in-cylinder pressure. At the lowest EGR fraction (20\%), the highest peak pressure is observed at $9300 \mathrm{kPa}$ while the highest EGR fraction (70\%) resulted in a peak pressure of approximately $5703 \mathrm{kPa}$. Due to very low cylinder pressures, erratic combustion was observed at $70 \%$ EGR while $60 \%$ 
was on the threshold of misfire, denoted from $\mathrm{HC}$ and $\mathrm{PM}$ emissions. Consequently, $\mathrm{NO}_{x}$ was significantly decreased with increasing EGR fraction but HC and PM were elevated at high EGR fractions as seen in Table 27. Figure 58 shows the HRR as a function of crank angle for the EGR fraction sweeps.

Table 27: EGR Sweep Emissions Data for Fuel D

\begin{tabular}{|c|c|c|c|c|c|c|}
\hline EGR & HC (ppm) & NO $_{x}$ (ppm) & $\begin{array}{c}\text { HC } \\
\text { (g/kW-hr) }\end{array}$ & $\begin{array}{c}\mathbf{N O}_{\mathbf{x}} \\
(\mathbf{g} / \mathbf{k W}-\mathbf{h r})\end{array}$ & $\begin{array}{c}\text { BSFC } \\
(\mathrm{g} / \mathbf{k W}-\mathbf{h r})\end{array}$ & $\begin{array}{c}\text { Gravimetric PM } \\
\text { (mg/kW-hr) }\end{array}$ \\
\hline $20 \%$ & 546.8 & 181.3 & 3.017 & 3.513 & 330.7 & 576.2 \\
\hline $30 \%$ & 733.2 & 107.5 & 3.587 & 1.813 & 312.4 & 492.5 \\
\hline $40 \%$ & 992.6 & 59.57 & 4.093 & 0.829 & 295.5 & 499.6 \\
\hline $50 \%$ & 1297 & 35.29 & 4.701 & 0.422 & 298.8 & 530.6 \\
\hline $60 \%$ & 1658 & 22.63 & 5.258 & 0.230 & 286.2 & 611.7 \\
\hline $70 \%$ & 2950 & 11.73 & 7.943 & 0.092 & 298.5 & 906.2 \\
\hline
\end{tabular}

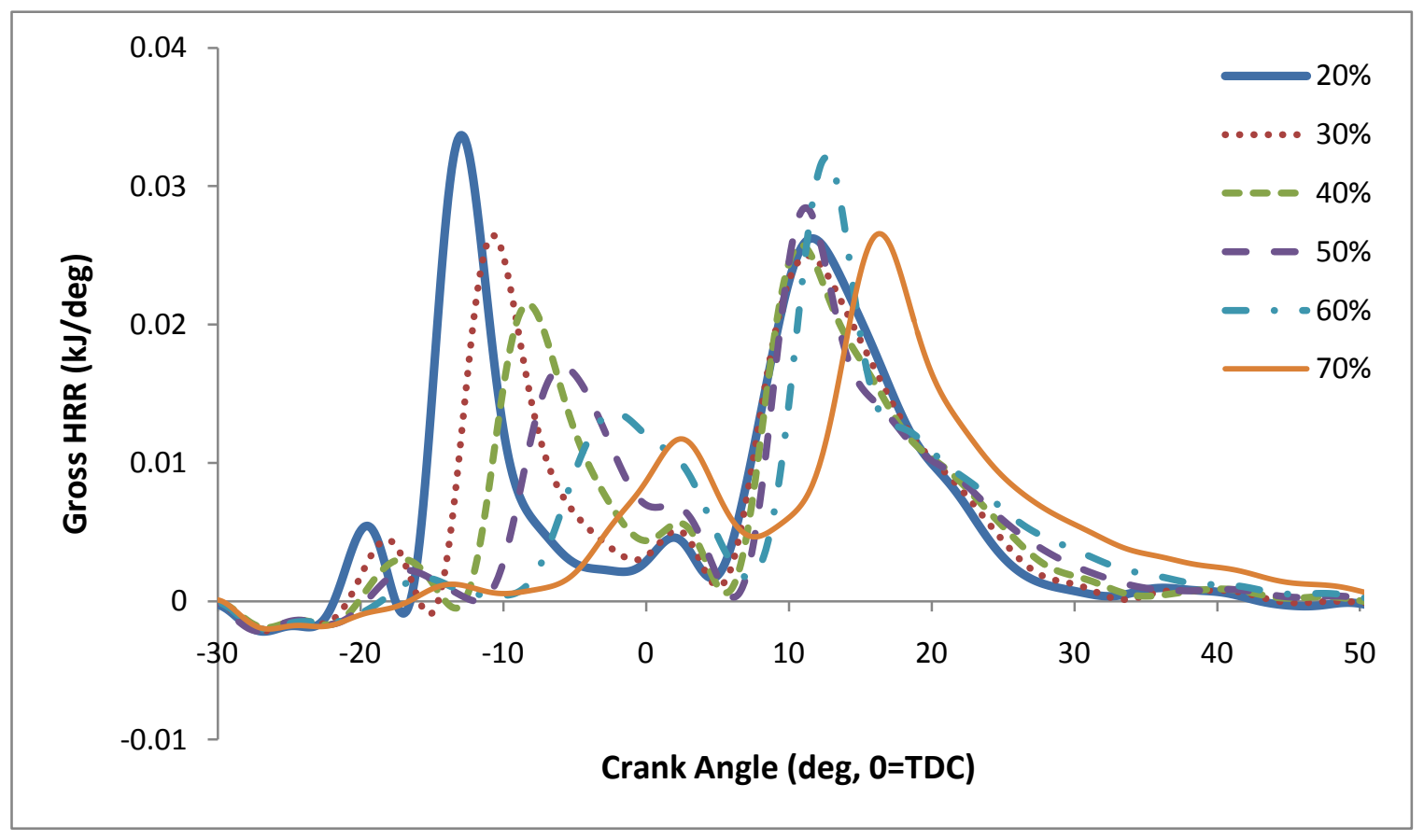

Figure 58: Gross HRR versus Crank Angle of EGR Sweeps for Fuel D

As EGR fraction increases, the first stage heat release peak decreases and phases toward TDC. The peak in the first stage HRR, especially denoted at 20\% EGR could be a result of auto ignition from the fuel since EGR quantities are minimal. At 20\% EGR, the first stage peak HRR is 
approximately $0.035 \mathrm{~kJ} / \mathrm{deg}$ while at $70 \%$ the peak HRR in the premixed zone is just $0.01 \mathrm{~kJ} / \mathrm{deg}$. Although the $60-70 \%$ EGR fraction may represent an advanced combustion event more closely than the $20-50 \%$ EGR fractions, ultimately misfiring and resulting elevated PM and $\mathrm{HC}$ limit the operation of extremely high EGR fractions. An EGR fraction of $45-50 \%$ was thought to be the optimum operating point due to lower BSFC and $\mathrm{NO}_{x}$ and $\mathrm{HC}$ emissions. Figure 59 shows the mass fraction burned as a function of crank angle for the EGR sweeps.

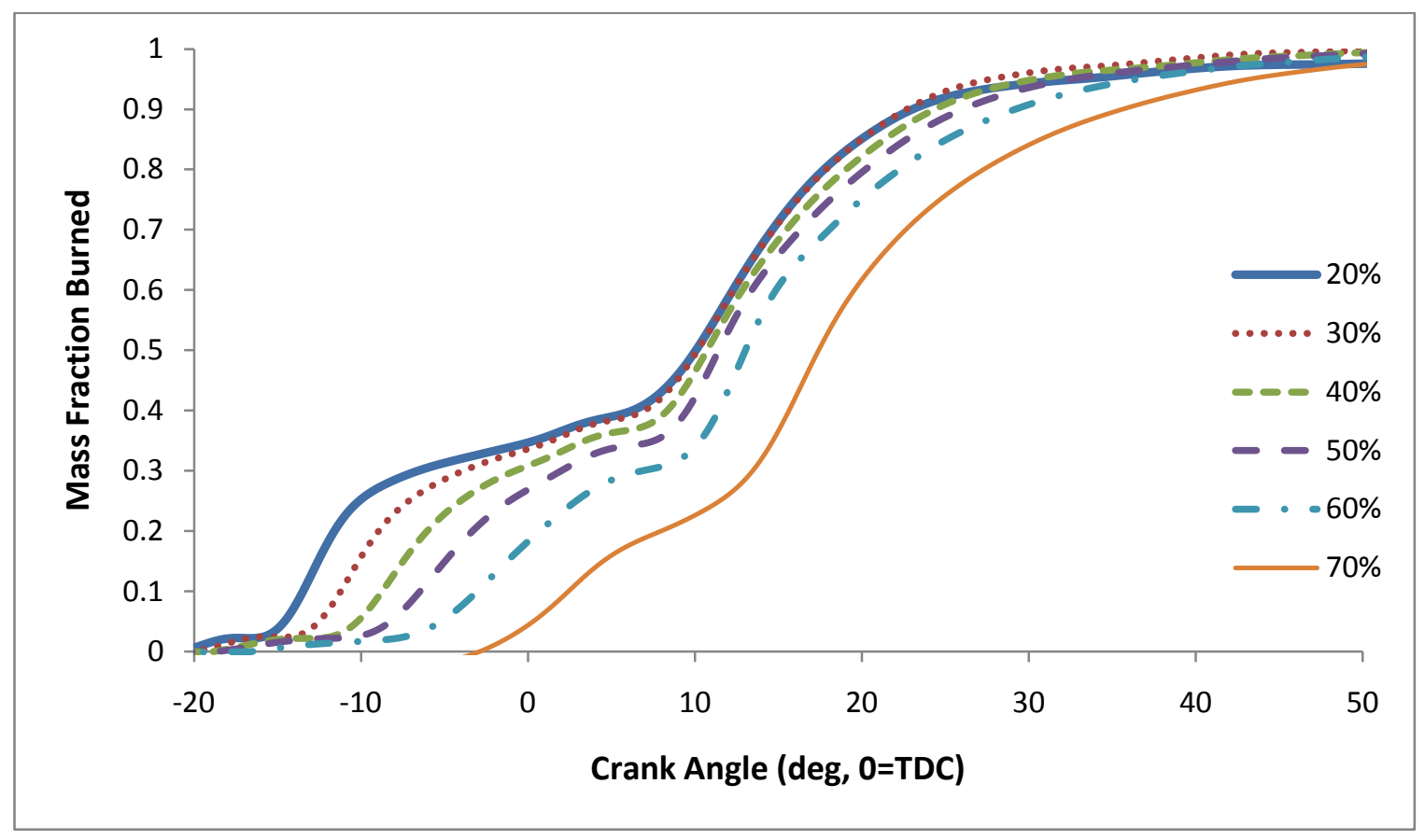

Figure 59: Mass Fraction Burned versus Crank Angle of EGR Sweeps for Fuel D

As illustrated in Figure 59, an increasing EGR fraction phases combustion near and after TDC. The CA $10-90 \%$ burn duration was also calculated, see Figure 60 . An EGR fraction of $70 \%$ results in shortest burn duration due to incomplete combustion while a 20\% EGR fraction results in the longest burn duration at $37^{\circ} \mathrm{CA}$. Figure 60 also shows the corresponding pressure rise rates for the EGR sweeps. 


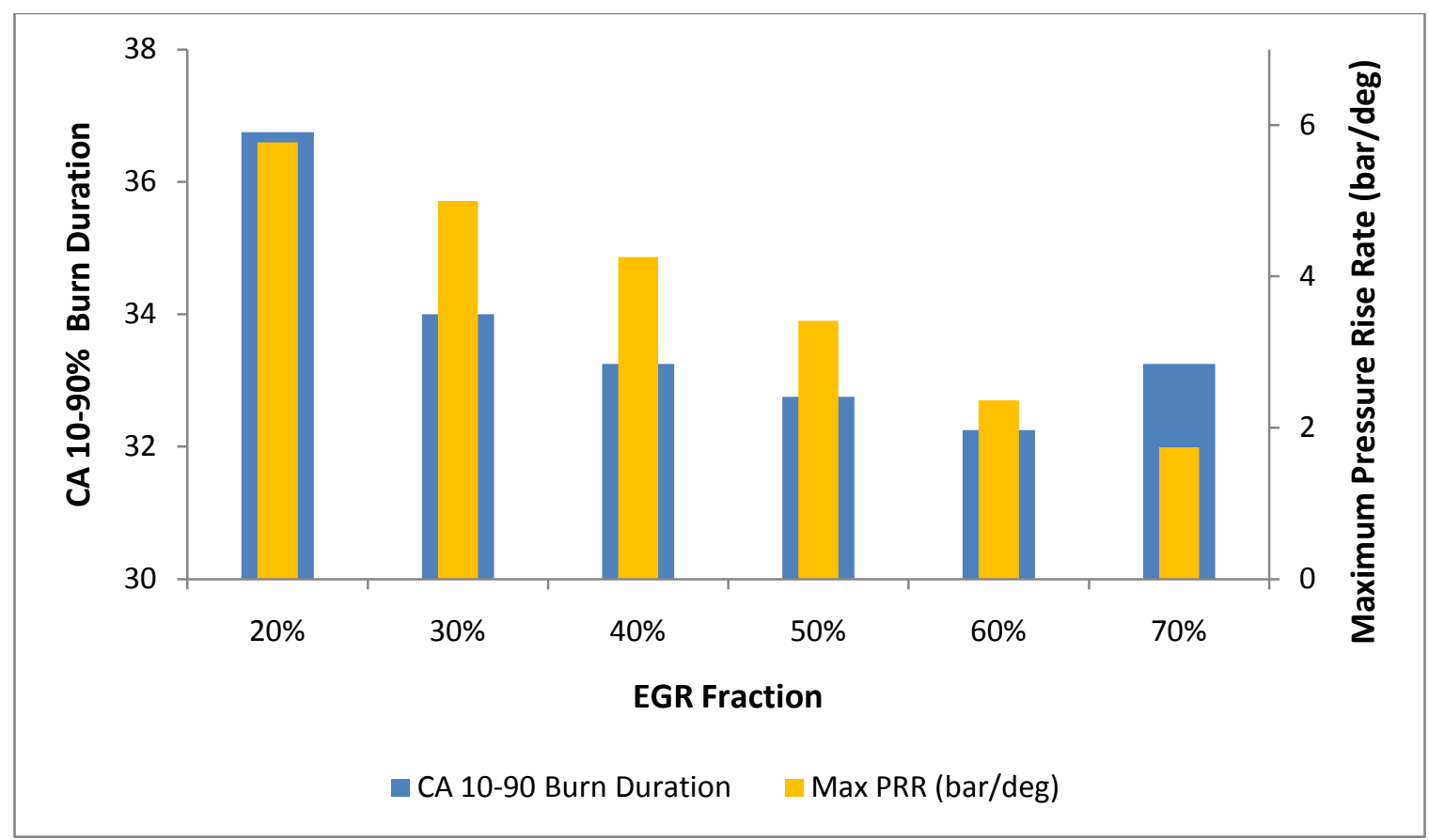

Figure 60: CA 10-90\% Burn Duration and Max PRR of EGR Sweeps for Fuel D

A linearly decreasing maximum pressure rise rate and $10-90 \%$ burn duration is depicted in Figure 60 as EGR fraction increases, also seen from the results obtained from Fuels $A, B$ and C. The increase in burn duration observed at $70 \%$ EGR could be a direct result of incomplete combustion of the fuel. An EGR fraction of $20 \%$ resulted in the highest maximum pressure rise rate at approximately $5.8 \mathrm{bar} / \mathrm{deg}$ compared to just $1.7 \mathrm{bar} / \mathrm{deg}$ at $70 \%$ EGR. Figure 61 shows the corresponding BTE and BSFC. As seen from the figure, BTE generally increases with elevated EGR fraction while BSFC generally decreases. From the in-cylinder pressure analysis and calculated emissions concentrations, it was determined that the optimum EGR fraction for low $\mathrm{NO}_{\mathrm{x}}, \mathrm{PM}$ and BSFC was $45-50 \%$. Table 28 shows the calculated in-cylinder combustion parameters for the EGR sweeps. As seen in the table, the location of maximum pressure and temperature are being phased further away from TDC as EGR fraction increases until incomplete combustion at 70\% EGR. 


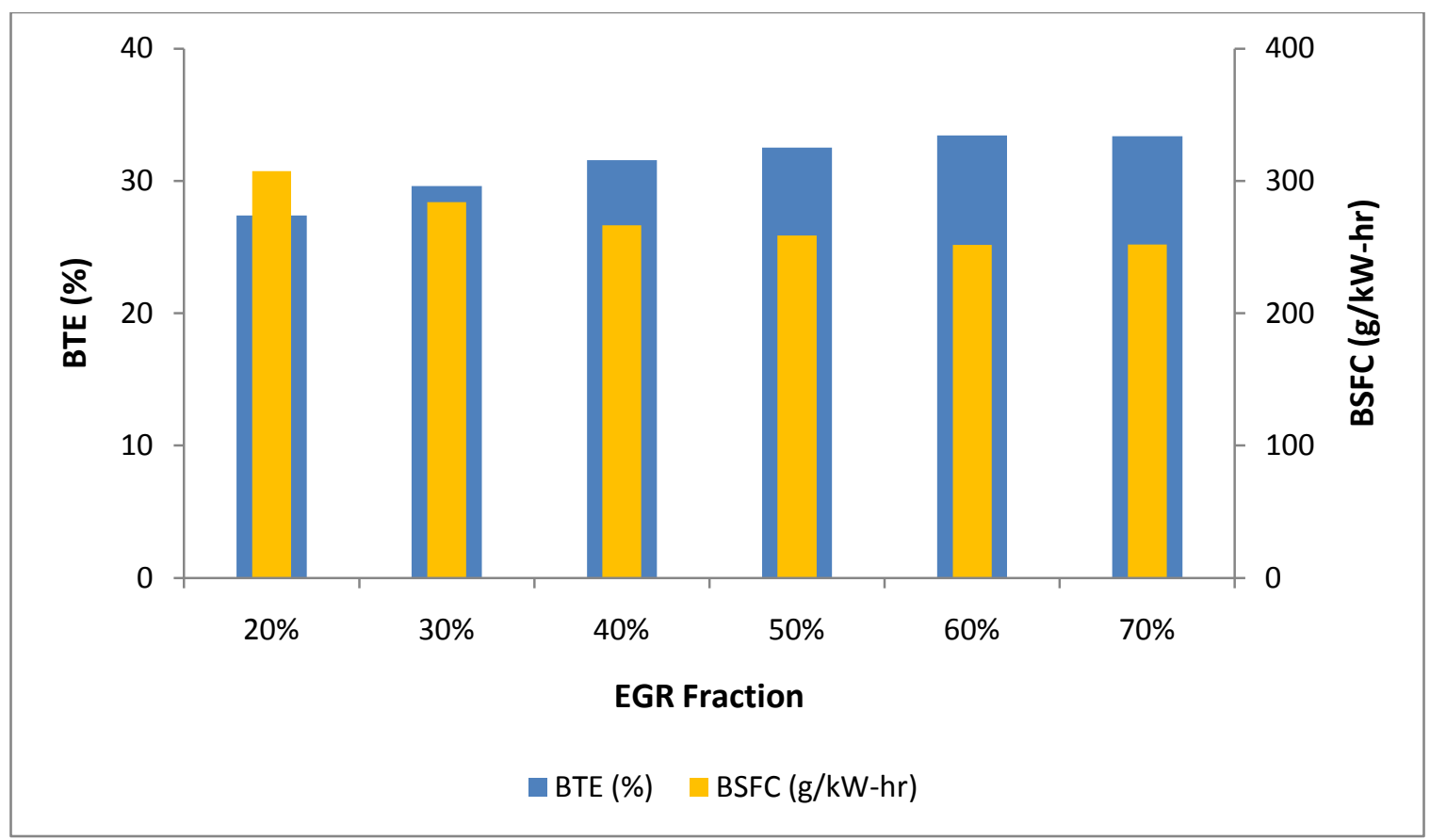

Figure 61: BTE and BSFC of EGR Sweeps for Fuel D

Table 28: Calculated In-cylinder Combustion Parameters of EGR Sweeps for Fuel D

\begin{tabular}{|l|c|c|c|c|c|c|c|}
\hline EGR Fraction & - & $\mathbf{2 0} \%$ & $\mathbf{3 0 \%}$ & $\mathbf{4 0 \%}$ & $\mathbf{5 0 \%}$ & $\mathbf{6 0 \%}$ & $\mathbf{7 0 \%}$ \\
\hline Heat Released & $\mathrm{kJ}$ & 0.609 & 0.573 & 0.552 & 0.526 & 0.514 & 0.484 \\
\hline $\begin{array}{l}\text { Maximum Heat Release } \\
\text { Rate }\end{array}$ & $\mathrm{kJ} / \mathrm{deg}$ & 0.034 & 0.027 & 0.027 & 0.030 & 0.033 & 0.028 \\
\hline Maximum Pressure & $\mathrm{kPa}$ & 9300 & 8563 & 7860 & 7236 & 6512 & 5703 \\
\hline Location of Max Pressure & $\mathrm{deg}$ ATDC & 1.25 & 1.5 & 1.75 & 2.5 & 3.25 & 4.25 \\
\hline Maximum Pressure Rise & $\mathrm{bar} / \mathrm{deg}$ & 5.77 & 4.99 & 4.25 & 3.41 & 2.36 & 1.74 \\
\hline $\begin{array}{l}\text { Location of Maximum } \\
\text { Pressure Rise }\end{array}$ & $\mathrm{deg}$ ATDC & -12.75 & -10.5 & -8.25 & -6.25 & -3.75 & -13.0 \\
\hline $\begin{array}{l}\text { Maximum Average Bulk } \\
\text { Mixture Temperature }\end{array}$ & $\mathrm{K}$ & 1336 & 1334 & 1330 & 1316 & 1317 & 1294 \\
\hline $\begin{array}{l}\text { Location of Maximum } \\
\text { Temperature }\end{array}$ & $\mathrm{deg}$ ATDC & 18.75 & 19.5 & 20.25 & 21.0 & 22.25 & 25.75 \\
\hline $\begin{array}{l}\text { Location of 10\% Mass } \\
\text { Fraction Burned }\end{array}$ & $\mathrm{deg}$ ATDC & -13.75 & -11.5 & -9.0 & -6.75 & -3.25 & 2.25 \\
\hline $\begin{array}{l}\text { Location of 50\% Mass } \\
\text { Fraction Burned }\end{array}$ & $\mathrm{deg}$ ATDC & 10.25 & 10.25 & 10.75 & 11.5 & 13.0 & 17.5 \\
\hline $\begin{array}{l}\text { Location of 90\% Mass } \\
\text { Fraction Burned }\end{array}$ & deg ATDC & 23.0 & 22.5 & 24.25 & 26.0 & 29.0 & 35.5 \\
\hline
\end{tabular}

Pilot injection sweeps were performed from $30-55^{\circ} \mathrm{BTDC}$ at 1200 bar rail pressure, $50 \%$ EGR and 50\% fuel split. As seen in Figure 62, in-cylinder pressure was minimally affected by the 
pilot injection sweeps. At $30^{\circ} \mathrm{BTDC}, \mathrm{NO}_{\mathrm{x}}$ was elevated but $\mathrm{HC}$ were significantly lower than the 40-55 ${ }^{\circ}$ BTDC injection sweeps. At a 45, 50 and 55 BTDC pilot, erratic combustion was observed and can be confirmed by the extremely elevated HC and PM emissions denoted by Table 29.

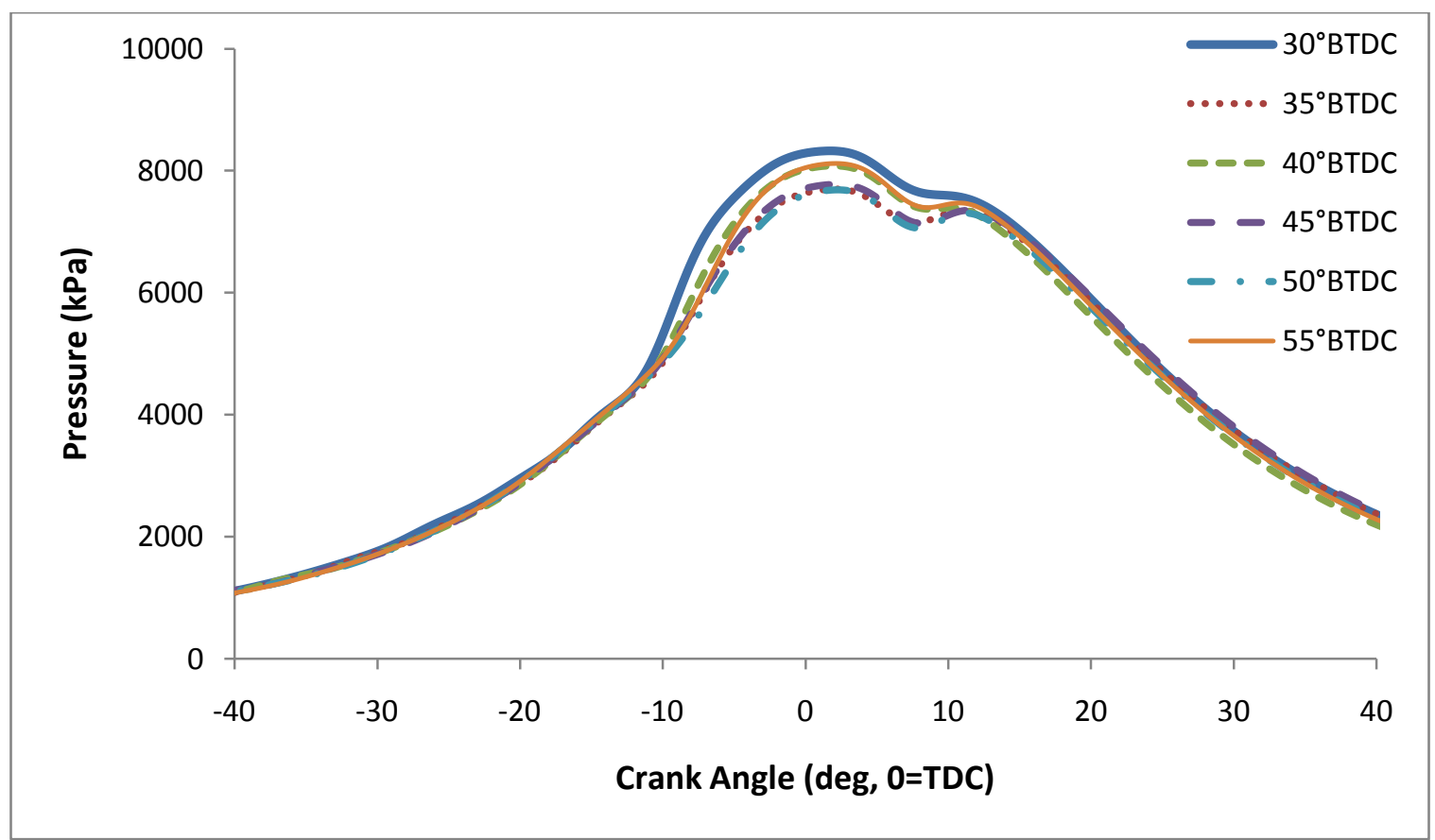

Figure 62: In-cylinder Pressure versus Crank Angle of Pilot Injection Sweeps for Fuel D

Table 29: Pilot Sweep Emissions Data for Fuel D

\begin{tabular}{|c|c|c|c|c|c|c|}
\hline $\begin{array}{c}\text { Pilot } \\
\text { ('BTDC) }\end{array}$ & HC (ppm) & NO $_{\mathbf{x}}$ (ppm) & $\begin{array}{c}\mathbf{H C} \\
\text { (g/kW-hr) }\end{array}$ & $\begin{array}{c}\mathbf{N O}_{\mathbf{x}} \\
\text { (g/kW-hr) }\end{array}$ & $\begin{array}{c}\text { BSFC } \\
\text { (g/kW-hr) }\end{array}$ & $\begin{array}{c}\text { Gravimetric PM } \\
\text { (mg/kW-hr) }\end{array}$ \\
\hline 30 & 572.0 & 122.5 & 2.416 & 1.862 & 306.2 & 372.9 \\
\hline 35 & 729.6 & 60.34 & 2.944 & 0.837 & 303.4 & 379.8 \\
\hline 40 & 1269 & 58.52 & 5.367 & 0.831 & 328.9 & 736.7 \\
\hline 45 & 1489 & 44.84 & 5.711 & 0.573 & 302.3 & 734.5 \\
\hline 50 & 1691 & 48.08 & 7.217 & 0.680 & 333.7 & 1083 \\
\hline 55 & 2031 & 41.12 & 8.189 & 0.547 & 335.9 & 1455 \\
\hline
\end{tabular}

It was determined that a pilot injection of $35^{\circ} \mathrm{BTDC}$ provided the best tradeoff of $\mathrm{NO}_{\mathrm{x}}$, PM and HC emissions. Although soot based PM was extremely elevated for Fuel D, the 
optimum strategy for decreased $\mathrm{NO}_{\mathrm{x}}$ and $\mathrm{HC}$ is summarized in Table 30 . Table 31 shows the emission concentrations at the respective optimized strategy of the data set while Table 32 shows the calculated in-cylinder combustion parameters at the optimized strategy.

Table 30: Optimized Strategy for Fuel D

\begin{tabular}{|l|c|}
\hline EGR & $45-50 \%$ \\
\hline Rail Pressure & $1200 \mathrm{bar}$ \\
\hline Fuel Split & $50 \%$ \\
\hline Pilot Injection & $35^{\circ}$ BTDC \\
\hline
\end{tabular}

Table 31: Optimum Operating Strategy Emissions Results for Fuel D

\begin{tabular}{|l|c|}
\hline $\mathrm{NO}_{\mathrm{x}}(\mathrm{ppm})$ & 60.3 \\
\hline $\mathrm{HC}(\mathrm{ppm})$ & 729.5 \\
\hline Soot Based PM (mg/kW-hr) & 83.42 \\
\hline Gravimetric PM (mg/kW-hr) & 379.7 \\
\hline BSFC (g/kW-hr) & 303.4 \\
\hline BTE (\%) & 27.7 \\
\hline
\end{tabular}

Table 32: Calculated In-cylinder Combustion Parameters at Optimized Strategy for Fuel D

\begin{tabular}{|l|c|c|}
\hline Heat Released & $\mathrm{kJ}$ & 0.620 \\
\hline Maximum Heat Release Rate & $\mathrm{kJ} / \mathrm{deg}$ & 0.039 \\
\hline Location of Maximum Heat Release Rate & $\mathrm{ATDC}$ & 9.75 \\
\hline Maximum Pressure & $\mathrm{kPa}$ & 7697 \\
\hline Location of Maximum Pressure & deg ATDC & 2.00 \\
\hline Maximum Pressure Rise & $\mathrm{bar} / \mathrm{deg}$ & 4.23 \\
\hline Location of Maximum Pressure Rise & deg ATDC & -8.00 \\
\hline Maximum Average Bulk Mixture Temperature & $\mathrm{K}$ & 1452 \\
\hline Location of Maximum Temperature & deg ATDC & 20.0 \\
\hline Location of 10\% Mass Fraction Burned & deg ATDC & -7.0 \\
\hline Location of 50\% Mass Fraction Burned & deg ATDC & 10.75 \\
\hline Location of 90\% Mass Fraction Burned & deg ATDC & 24.25 \\
\hline
\end{tabular}




\subsection{Fuel Characteristic Effects at a Specified Operating Condition}

To examine the effect of fuel properties such as $\mathrm{CN}$, sulfur content, volatility, etc, incylinder combustion analyses were used to develop trends at a single operating condition and correlated to the measured emissions concentrations from Figure 35. The operating condition listed in Table 33 was performed at $2100 \mathrm{rpm}$ and a constant bmep of 3.5 bar. For specific fuel properties, refer to Table 39. Figure 63 shows the in-cylinder pressure at the single operating condition listed in Table 33. Note soot based PM was unavailable for each fuel at this operating condition.

Table 33: Operating Condition to Examine Fuel Characteristic Effects

\begin{tabular}{|l|c|c|}
\hline EGR & $\%$ & 50 \\
\hline Rail Pressure & bar & 800 \\
\hline Fuel Split & $\%$ & 50 \\
\hline Pilot Injection & ${ }^{\circ}$ BTDC & 40 \\
\hline Main Injection & ${ }^{\circ}$ BTDC & 0 \\
\hline
\end{tabular}

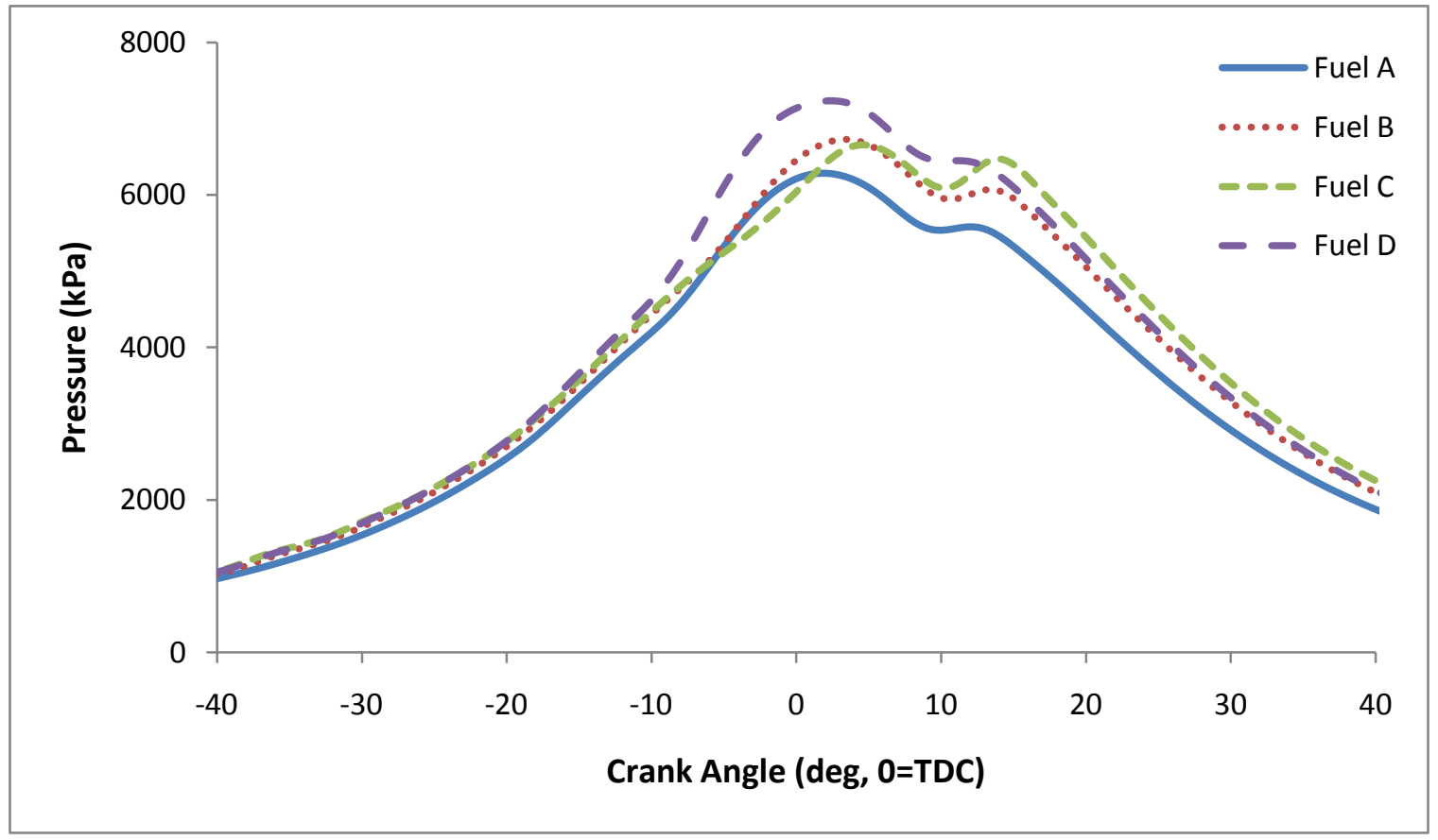

Figure 63: In-cylinder Pressure versus Crank Angle at Specified Operating Condition of Each Fuel

As seen from Figure 63, Fuel A was observed to have the lowest peak pressure at $6284 \mathrm{kPa}$ while Fuel $\mathrm{D}$ had the highest peak pressure of $7235 \mathrm{kPa}$, a $15 \%$ difference while Fuels $B$ 
and $C$ had a $1 \%$ difference in peak pressure. Although Fuels $A$ and $D$ have a similar $C N$, the net heat of combustion per unit mass of Fuel $A$ is much higher than Fuel D. However since Fuel $A$ has a low specific gravity, it ultimately has a lower heat of combustion per unit volume. The decrease in peak pressure of Fuel A may be contributed to the lower net heat of combustion per unit volume since fuel was injected on per volume i.e. less fuel, lower BSFC and lower cylinder temperatures as verified by Figure 67 and $\mathrm{NO}_{\mathrm{x}}$ emissions in Table 34. Figure 64 illustrates the gross HRR for each fuel at the specified operating conditions.

Table 34: Emissions Data at Specified Operating Condition

\begin{tabular}{|c|c|c|c|c|c|c|}
\hline & $\mathbf{H C}(\mathbf{p p m})$ & $\mathbf{N O}_{\mathbf{x}}$ (ppm) & $\begin{array}{c}\mathbf{H C} \\
\text { (g/kW-hr) }\end{array}$ & $\begin{array}{c}\mathbf{N O}_{\mathbf{x}} \\
\text { (g/kW-hr) }\end{array}$ & $\begin{array}{c}\text { BSFC } \\
\text { (g/kW-hr) }\end{array}$ & $\begin{array}{c}\text { Gravimetric PM } \\
\text { (mg/kW-hr) }\end{array}$ \\
\hline Fuel A & 1484 & 21.14 & 4.566 & 0.211 & 298.1 & 368.6 \\
\hline Fuel B & 1581 & 31.51 & 5.423 & 0.352 & 284.7 & 398.0 \\
\hline Fuel C & 2068 & 44.30 & 7.778 & 0.543 & 320.2 & 249.5 \\
\hline Fuel D & 1297 & 35.29 & 4.701 & 0.422 & 298.8 & 530.6 \\
\hline
\end{tabular}

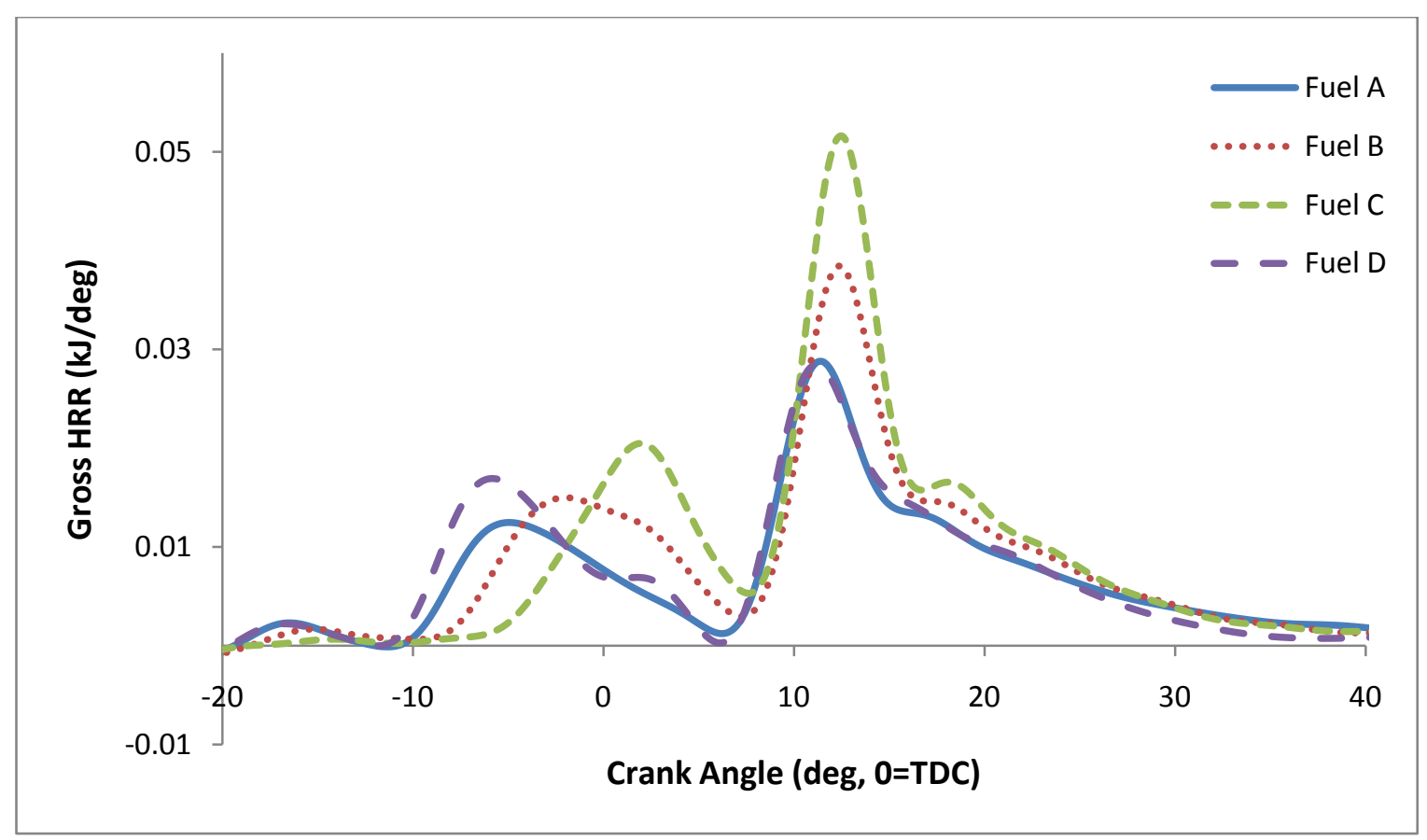

Figure 64: Gross HRR versus Crank Angle at Specified Operating Condition of Each Fuel 
The increased ignition delay and higher HRR associated with lower CN fuels is verified by Figure 64 and Figure 66. As seen from the figure, Fuel $C$ has a much longer ignition delay as well as a higher peak HRR during the first stage and diffusion combustion events, indicating elevated cylinder temperatures. Figure 65 shows the effect of $\mathrm{CN}$ on ignition delay. Note ignition delay was calculated by taking the difference of $10 \%$ mass fraction burned from the first noticeable heat release event. As expected, ignition delay is reduced with a higher CN fuel. The effect of the increasing peak HRR during the first stage heat release and diffusion combustion events on cylinder temperature can directly be related to a decreasing $\mathrm{CN}$ as seen in Figure 67.

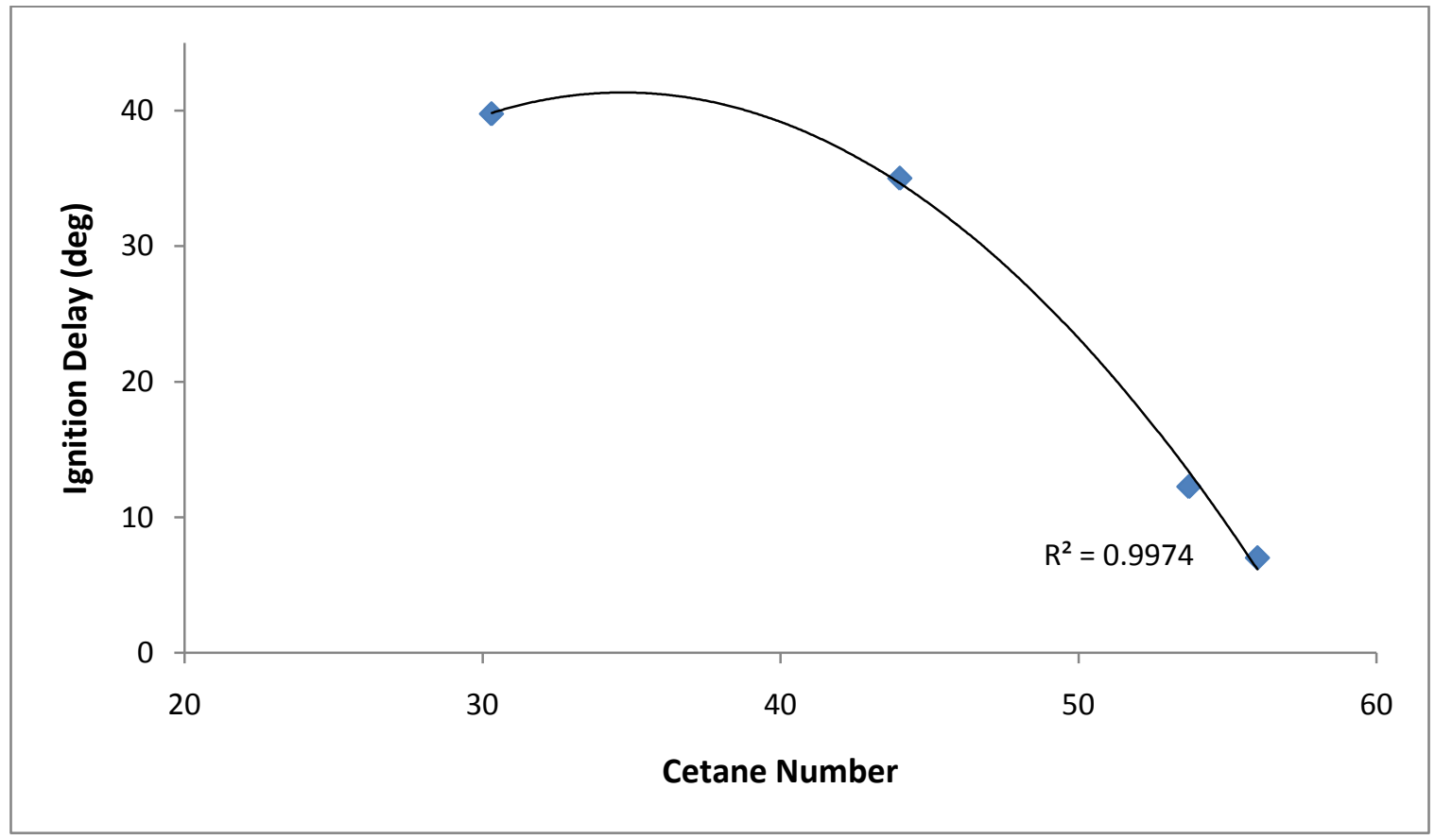

Figure 65: Ignition Delay versus CN at Specified Operating Condition 


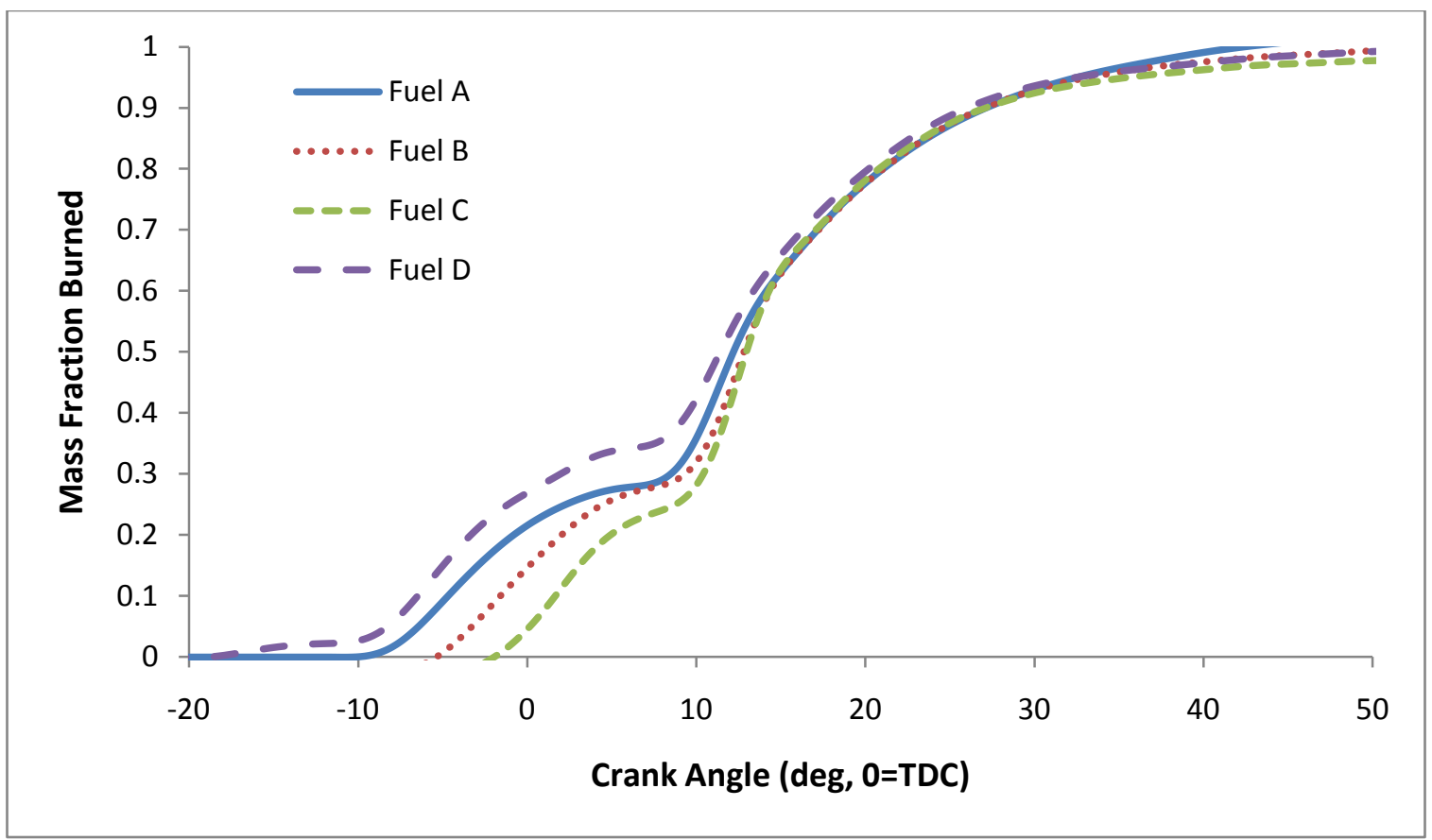

Figure 66: Mass Fraction Burned versus Crank Angle at Specified Operating Condition

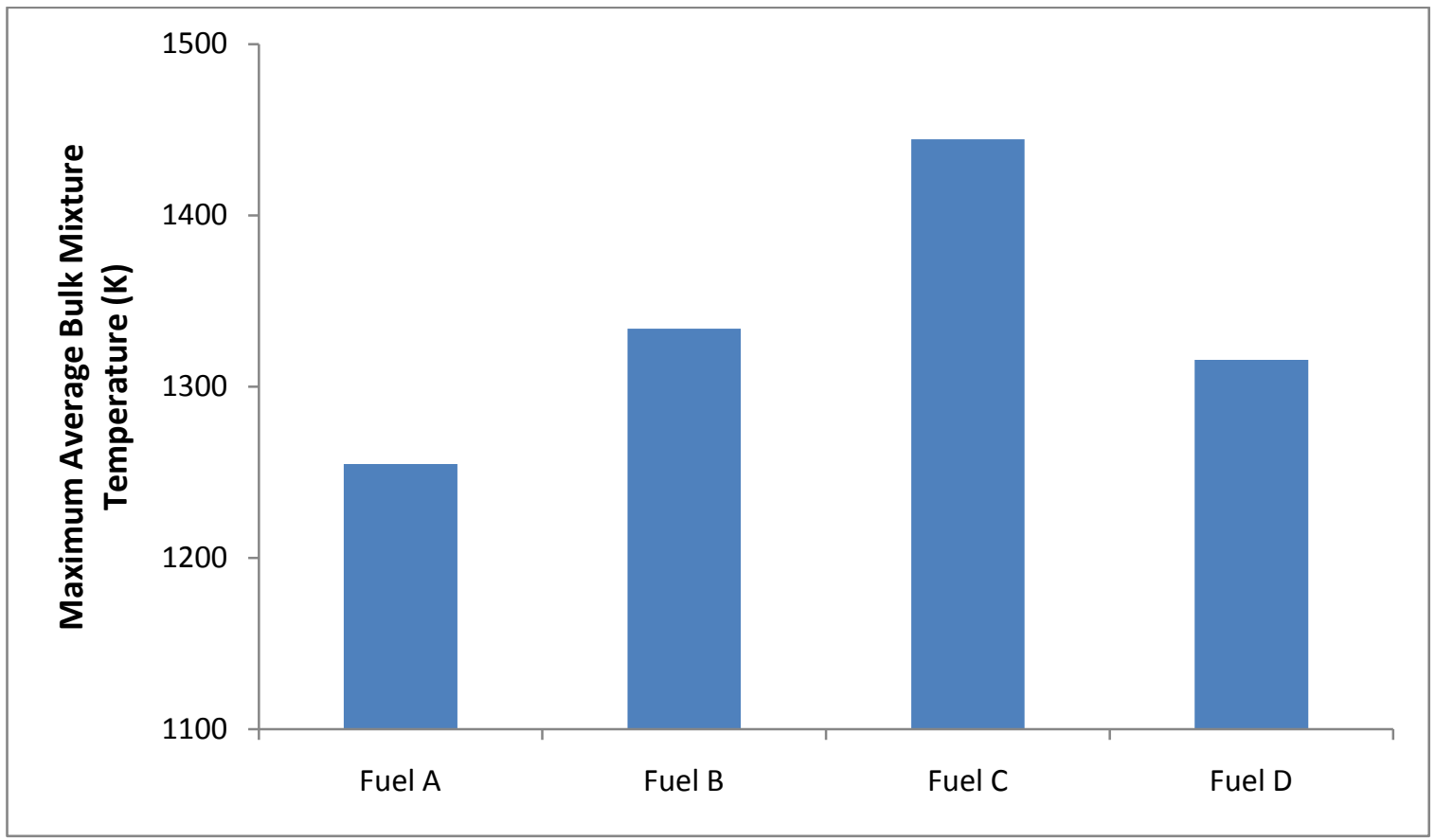

Figure 67: Maximum Average Bulk Mixture Temperature from Each Fuel at Specified Operating Condition

As the $\mathrm{CN}$ increases i.e. from Fuel $\mathrm{A}$ to $\mathrm{C}$, the maximum in-cylinder temperature also increases. The increase in cylinder temperature can also be correlated to the $\mathrm{NO}_{x}$ plot in Figure 
70. The effect of fuel properties on the CA $10-90 \%$ burn duration and maximum pressure rise rate becomes less apparent as seen in Figure 68.

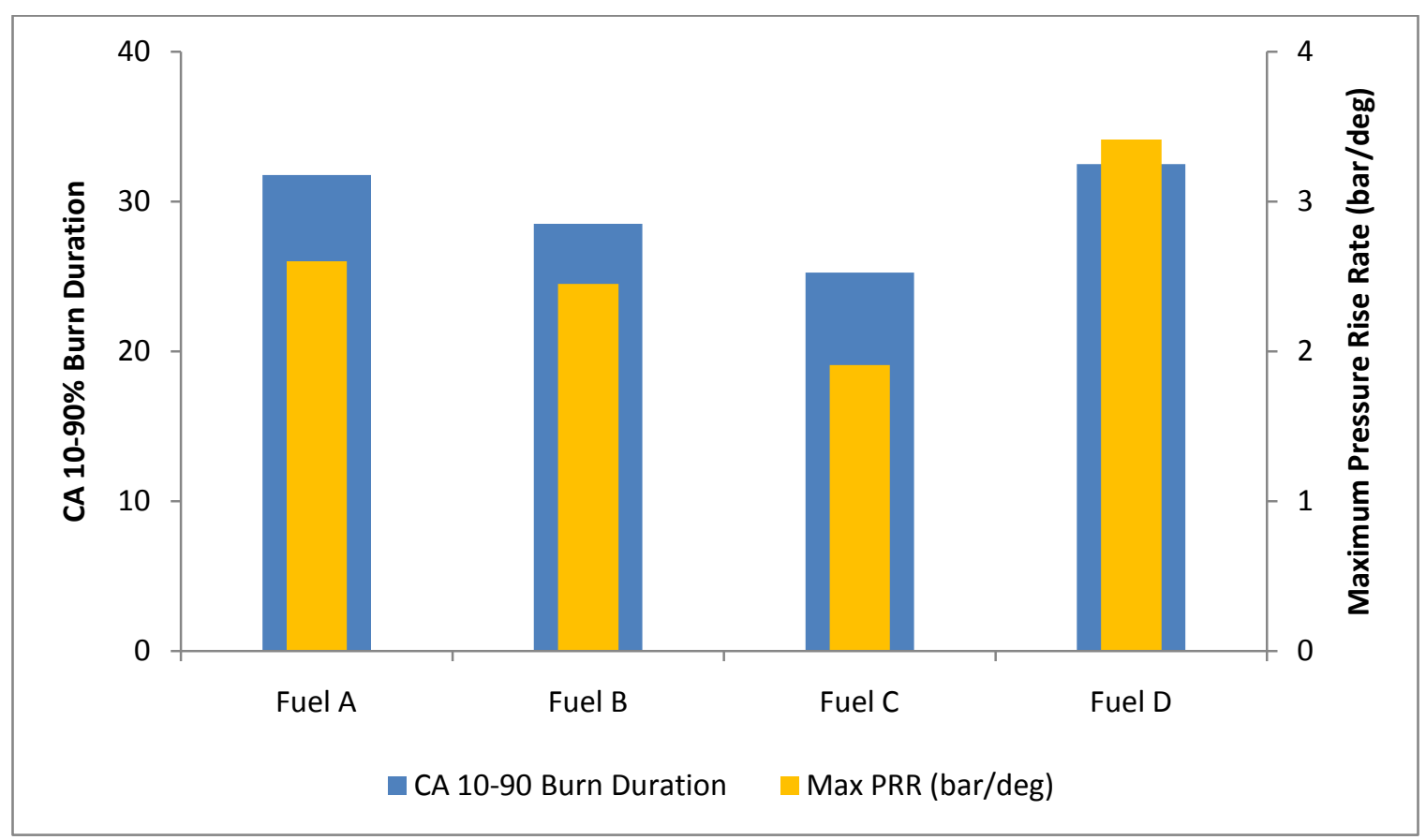

\section{Figure 68: CA 10-90\% Burn Duration and Max PRR of Each Fuel at Specified Operating Condition}

The decreasing PRR trend from Fuel A to C may be contributed to a decreasing T90 distillation temperature (increasing volatility) however the effects of the $\mathrm{CN}$ outweigh the contribution of volatility on combustion as established from Figure 64. Fuel characteristics become less apparent on the CA $10-90 \%$ burn duration as there seems to be no relation to the fuel properties listed in Table 39 and is more of a function of the HRR curve. Figure 69 shows the BTE and BSFC at the specified operating condition. 


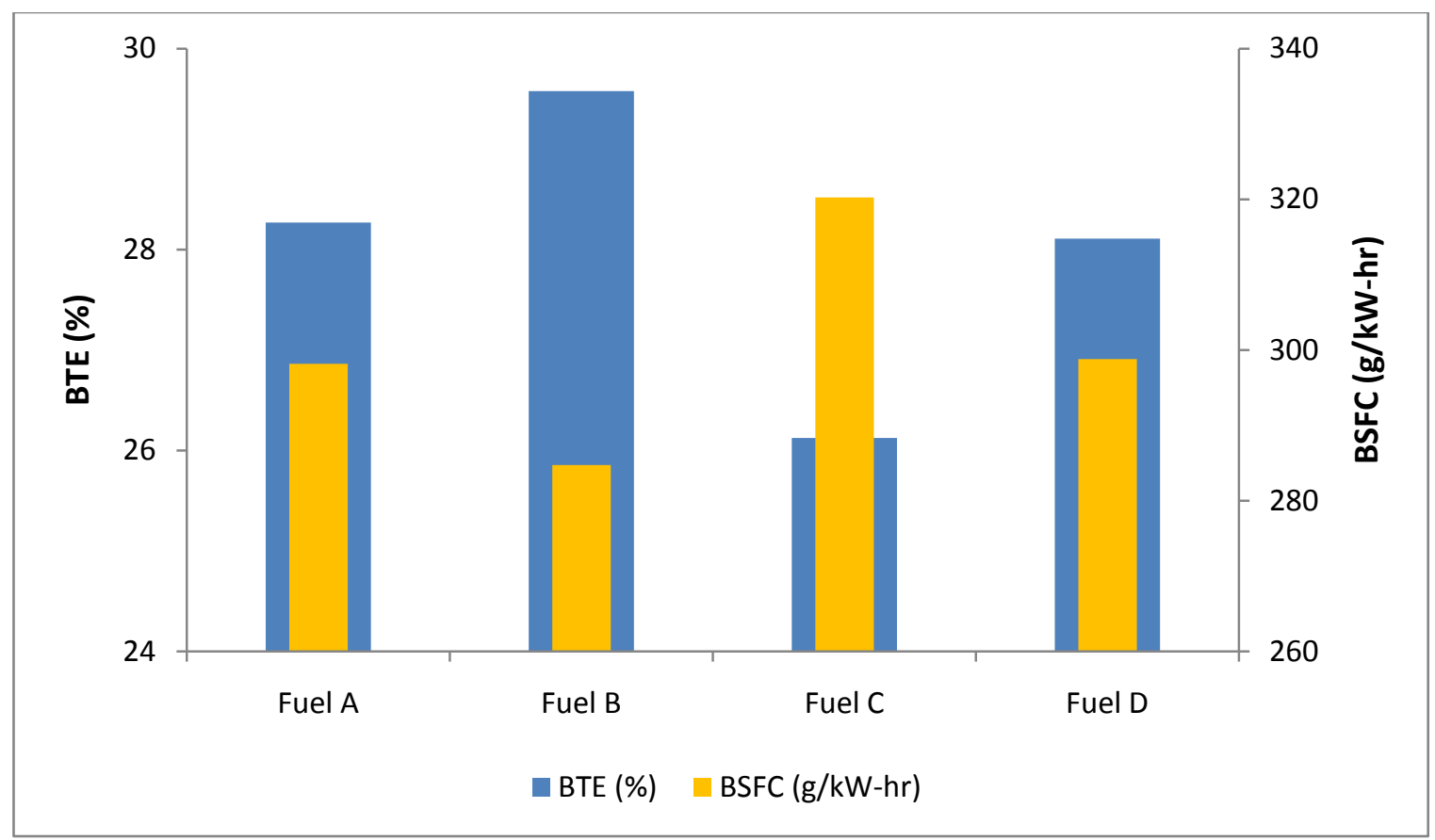

Figure 69: BTE and BSFC at Specified Operating Condition of Each Fuel

As seen in Figure 69, BTE deceases linearly while BSFC increases linearly. Fuel A has the highest BTE at $31.7 \%$ while Fuel D has the lowest BTE at $28.1 \%$. The decrease in BTE may be attributed to the increasing quantity of fuel being injected to maintain the desired load as the net heat of combustion is reduced. The same trend can be correlated to BSFC i.e. with less fuel BSFC is higher from Equation 2-7. Table 35 shows the calculated combustion parameters at the specified operating condition for each fuel. 
Table 35: Calculated In-cylinder Combustion Parameters of Each Fuel at Specified Operating Condition

\begin{tabular}{|l|c|c|c|c|c|}
\hline EGR Fraction & - & Fuel A & Fuel B & Fuel C & Fuel D \\
\hline Heat Released & $\mathrm{kJ}$ & 0.424 & 0.498 & 0.569 & 0.526 \\
\hline Maximum Heat Release Rate & $\mathrm{kJ} / \mathrm{deg}$ & 0.029 & 0.038 & 0.052 & 0.034 \\
\hline Maximum Pressure & $\mathrm{kPa}$ & 6284 & 6729 & 6657 & 7236 \\
\hline Location of Max Pressure & $\mathrm{deg}$ ATDC & 1.75 & 3.25 & 4.5 & 2.5 \\
\hline Maximum Pressure Rise & $\mathrm{bar} / \mathrm{deg}$ & 2.60 & 2.45 & 1.91 & 3.41 \\
\hline Location of Maximum Pressure Rise & $\mathrm{deg}$ ATDC & -6.0 & -3.5 & 0.75 & -6.25 \\
\hline Maximum Average Bulk Mixture Temperature & $\mathrm{K}$ & 1255 & 1334 & 1444 & 1316 \\
\hline Location of Maximum Temperature & $\mathrm{deg}$ ATDC & 20.25 & 21 & 21 & 21 \\
\hline Location of 10\% Mass Fraction Burned & $\mathrm{deg}$ ATDC & -4.5 & -1.5 & 1.75 & -6.5 \\
\hline Location of 50\% Mass Fraction Burned & $\mathrm{deg}$ ATDC & 12.25 & 13.0 & 13.0 & 11.5 \\
\hline Location of 90\% Mass Fraction Burned & deg ATDC & 27.25 & 27.0 & 27.0 & 26.0 \\
\hline Brake Thermal Efficiency (BTE) & \% & 31.69 & 29.58 & 28.80 & 28.11 \\
\hline Brake Specific Fuel Consumption (BSFC) & g/kW-hr & 262.9 & 284.7 & 292.7 & 298.8 \\
\hline
\end{tabular}

As seen from Table 35 and verified by the pressure and HRR curves at the specified operating condition, in-cylinder temperature increases as $\mathrm{CN}$ decreases. This trend can also be seen in Figure 67. Figure 70 shows radar plots of $\mathrm{NO}_{x}, \mathrm{HC}$ and PM emissions as well as BTE of each fuel at the specified operating condition. As seen in the figure and verified by in-cylinder temperatures, $\mathrm{NO}_{\mathrm{x}}$ emissions are higher for the low $\mathrm{CN}$ fuel. $\mathrm{HC}$ emissions are also highest for the lower CN fuel but PM emissions are lowest due to the increased time available for mixing. 


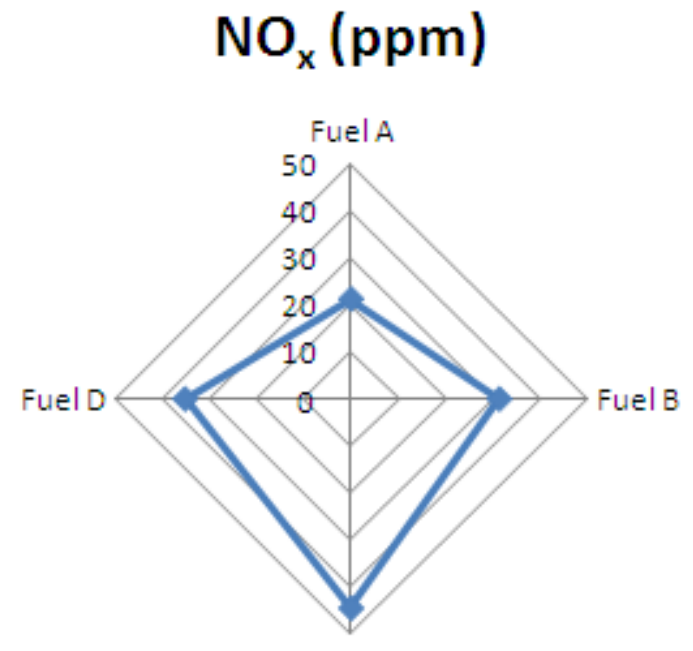

Fuelc

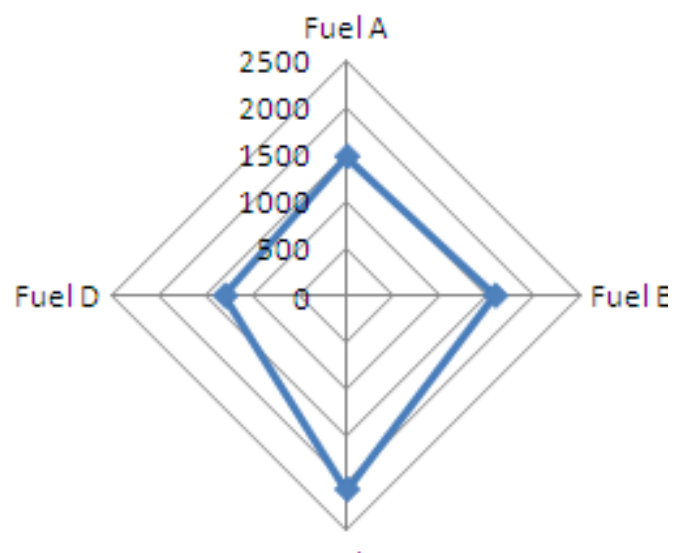

Fuelc

$\mathrm{PM}(\mathrm{mg} / \mathrm{kW}-\mathrm{hr})$

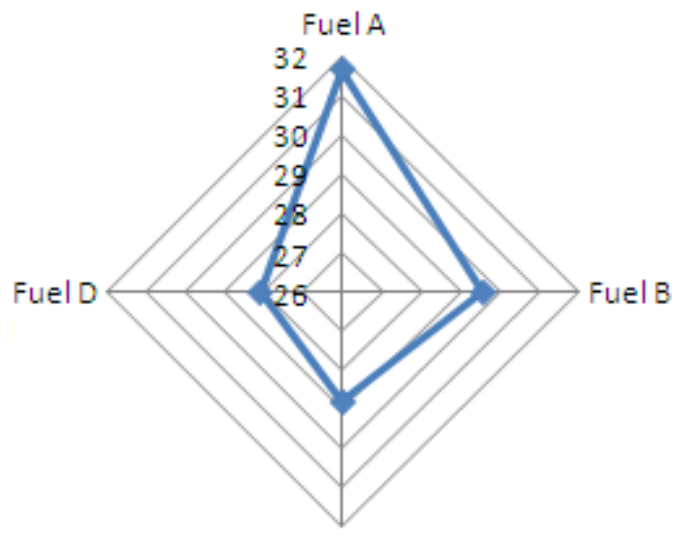

Fuelc

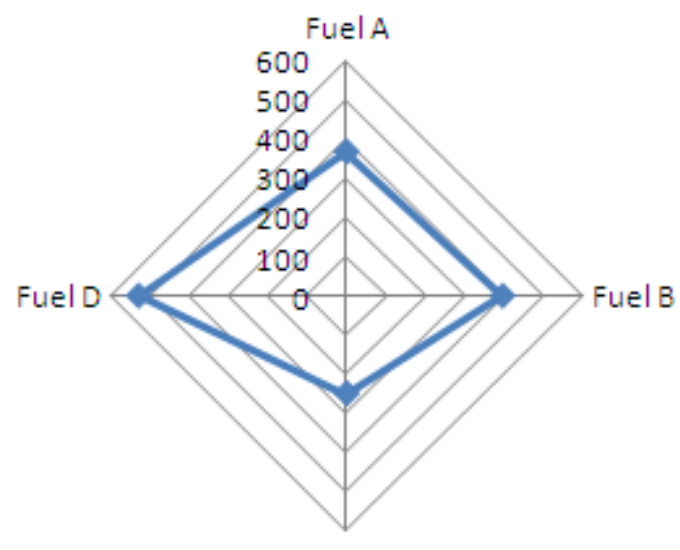

Fuel C

Figure 70: Radar Plots of NOx, HC, BTE and PM of Each Fuel at Specified Operating Condition

\subsection{Fuel Characteristic Effects at Optimized Control Strategies}

To examine the effect of fuel properties at the optimized control strategy, in-cylinder combustion analyses were used to develop trends while examining emission concentrations from each fuel. Table 36 shows the optimized control strategies for each fuel as determined from the previous sections. 
Table 36: Optimized Control Strategy of Each Fuel

\begin{tabular}{|l|c|c|c|c|c|}
\hline & & Fuel A & Fuel B & Fuel C & Fuel D \\
\hline EGR & $\%$ & 55 & 50 & $40-45$ & $45-50$ \\
\hline Rail Pressure & bar & 800 & 1200 & 1200 & 1200 \\
\hline Fuel Split & $\%$ & 50 & 30 & 50 & 50 \\
\hline Pilot Injection & ${ }^{\circ}$ BTDC & 40 & 40 & 30 & 35 \\
\hline Main Injection & ${ }^{\circ}$ BTDC & 0 & 0 & 0 & 0 \\
\hline
\end{tabular}

As seen from the table, optimum EGR rates can mainly be correlated to the $\mathrm{CN}$ of the fuel. Fuel $\mathrm{A}$ has the highest $\mathrm{EGR}$ rate at $55 \%$ which consequently also has the highest $\mathrm{CN}$. The higher the $\mathrm{CN}$, the more EGR that can be introduced. A higher $\mathrm{CN}$ fuel has a shorter ignition delay, while more EGR increases the ignition delay, verified by the pressure and HRR curves generated in the previous sections. Conversely, the lowest optimal EGR rates correspond to Fuel $\mathrm{C}$ with the lowest $\mathrm{CN}$. Figure 71 shows the in-cylinder pressure at the optimized control strategy of each fuel.

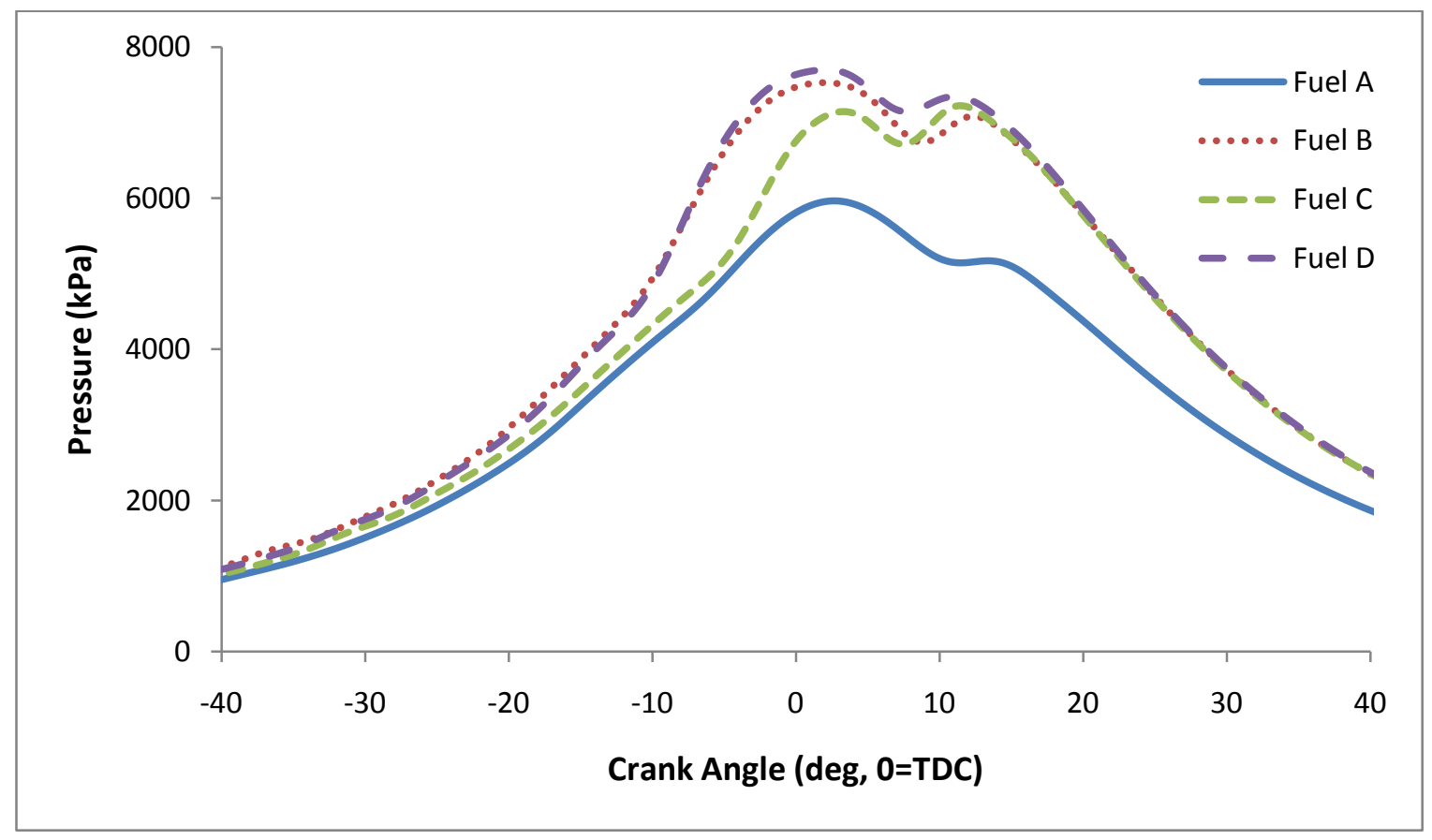

Figure 71: In-cylinder Pressure versus Crank Angle at Optimized Control Strategy of Each Fuel

From Figure 71, Fuel A appears to have a significantly lower peak pressure than the other fuels. The decrease in cylinder pressure may be a direct result of the high EGR rate since Fuel A has the highest CN. As seen in the previous sections, in-cylinder pressure drastically 
decreases due to the higher heat capacity and corresponding lower oxygen concentration at high EGR rates. The lower cylinder temperatures of Fuel A also resulted in the lowest peak HRR and more retarded combustion compared to the other fuels as seen in Figure 72 . Due to the decreased cylinder temperatures associated with Fuel $\mathrm{A}, \mathrm{NO}_{\mathrm{x}}$ was significantly lower compared to the other fuels as seen in Table 37.

Table 37: Emissions Data at Optimized Control Strategy

\begin{tabular}{|c|c|c|c|c|c|c|c|}
\hline & HC (ppm) & NO $_{\mathbf{x}}$ (ppm) & $\begin{array}{c}\text { HC } \\
\text { (g/kW-hr) }\end{array}$ & $\begin{array}{c}\mathbf{N O}_{\mathbf{x}} \\
(\mathbf{g} / \mathbf{k W}-\mathbf{h r})\end{array}$ & $\begin{array}{c}\text { BSFC } \\
(\mathbf{g} / \mathbf{k W}-\mathbf{h r})\end{array}$ & $\begin{array}{c}\text { Soot Based } \\
\mathbf{P M} \\
(\mathbf{m g} / \mathbf{k W}-\mathbf{h r})\end{array}$ & $\begin{array}{c}\text { Gravimetric } \\
\mathbf{P M} \text { (mg/kW- } \\
\mathbf{h r})\end{array}$ \\
\hline Fuel A & 1911 & 13.6 & 5.22 & 0.118 & 261.4 & $\mathrm{~N} / \mathrm{A}$ & 319.2 \\
\hline Fuel B & 791.6 & 73.2 & 3.35 & 1.05 & 312.6 & 59 & 232.7 \\
\hline Fuel C & 904.3 & 104.1 & 3.40 & 1.33 & 268.7 & 14.3 & 214.2 \\
\hline Fuel D & 729.5 & 60.3 & 2.94 & 0.837 & 303.4 & 83.42 & 379.7 \\
\hline
\end{tabular}

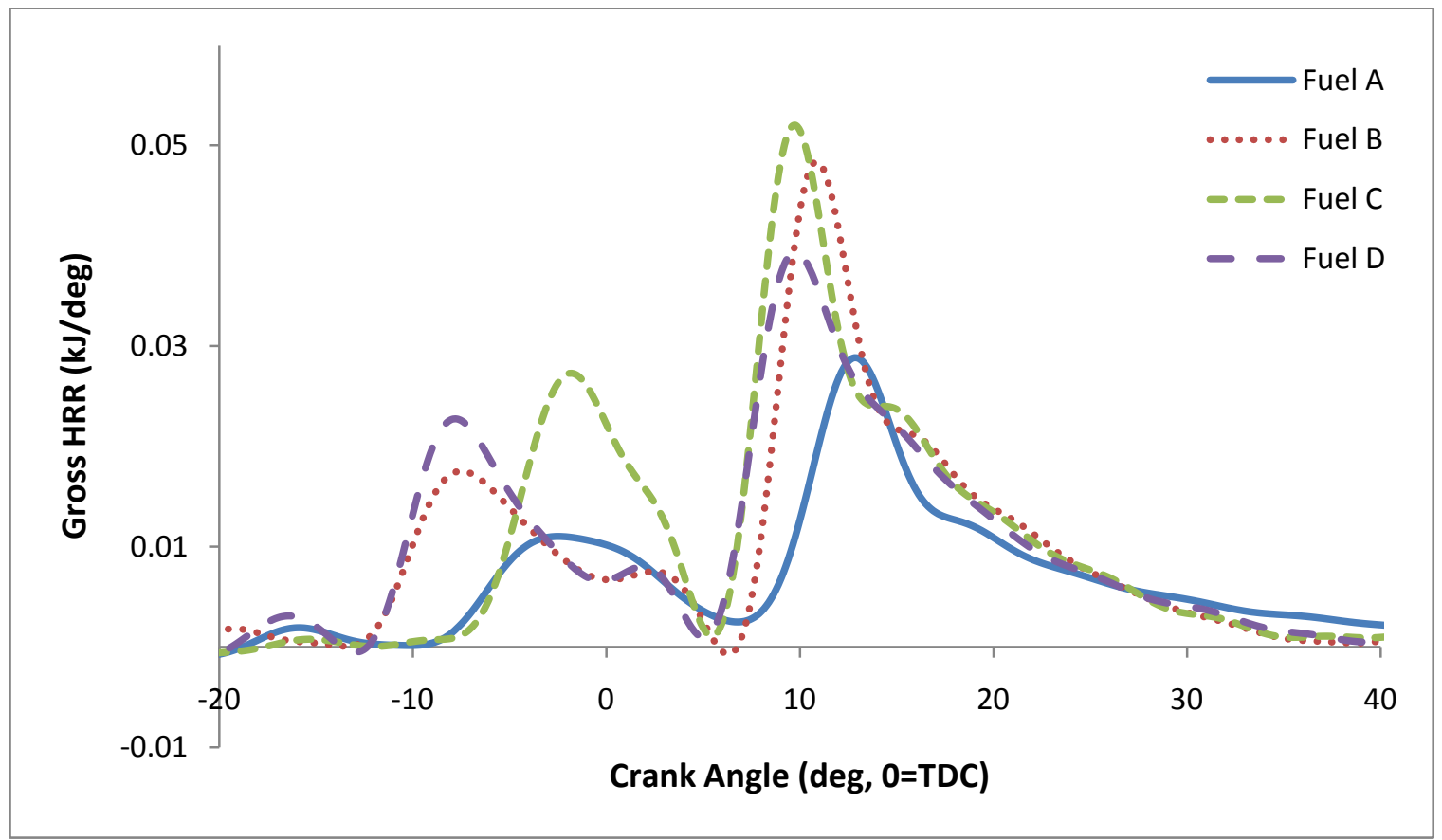

Figure 72: Gross HRR versus Crank Angle at Optimized Control Strategy of Each Fuel

As seen in the figure, combustion becomes significantly retarded with the lower $\mathrm{CN}$ fuel (Fuel A) as opposed to Fuels $B$ and $D$ which have a premixed combustion event at $10^{\circ}$ BTDC compared to TDC for Fuels $A$ and $C$. Due to the higher EGR rate for Fuel A, combustion is 
phased with Fuel C (10-15\% less EGR) as seen in the HRR curve. Although Fuel C has the highest peak HRR during the main injection, it also has the highest peak HRR at premixed combustion. As previously mentioned, an increase in peak HRR can be correlated to higher cylinder temperatures as verified by the $\mathrm{NO}_{\mathrm{x}}$ plot in Figure 77. Although $\mathrm{NO}_{\mathrm{x}}$ is reduced with the higher $\mathrm{CN}$ fuels, PM is also consequently higher. The increase in PM with higher $\mathrm{CN}$ fuels may be attributed to the decrease in ignition delay as seen in Figure 73. As ignition delay decreases, the time available for mixing becomes limited, as a well mixed, homogenous burn is required for low PM emissions.

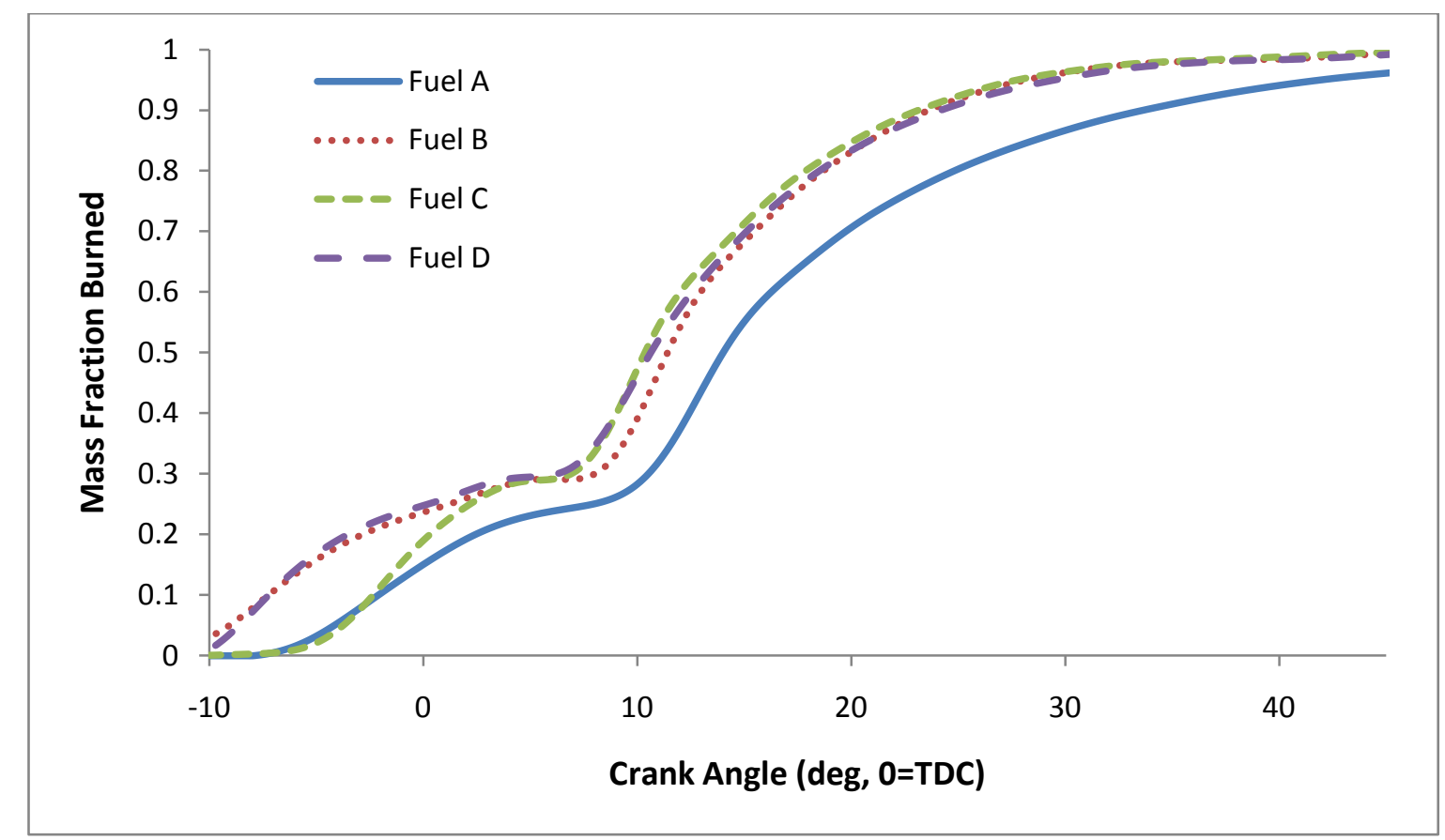

Figure 73: Mass Fraction Burned versus Crank Angle at Optimum Control Strategy of Each Fuel

Figure 73 illustrates the effect of the $\mathrm{CN}$ on the ignition delay of each fuel. Fuel $\mathrm{C}$, with the lowest $\mathrm{CN}$, shows a much more retarded combustion starting at approximately $8^{\circ} \mathrm{BTDC}$ compared to Fuels $B$ and D. The increased ignition delay with high amounts of EGR can again be seen in the MFB curve, as the start of combustion for Fuel A is nearly identical to that of Fuel C. The effects of parameters such aromatics, sulfur content and volatility on combustion were not evident, as the $\mathrm{CN}$ was the contributing factor for trends discovered through the 
combustion analysis. The effect of $\mathrm{CN}$ on combustion can also be seen in the PRR and burn duration, refer to Figure 74 .

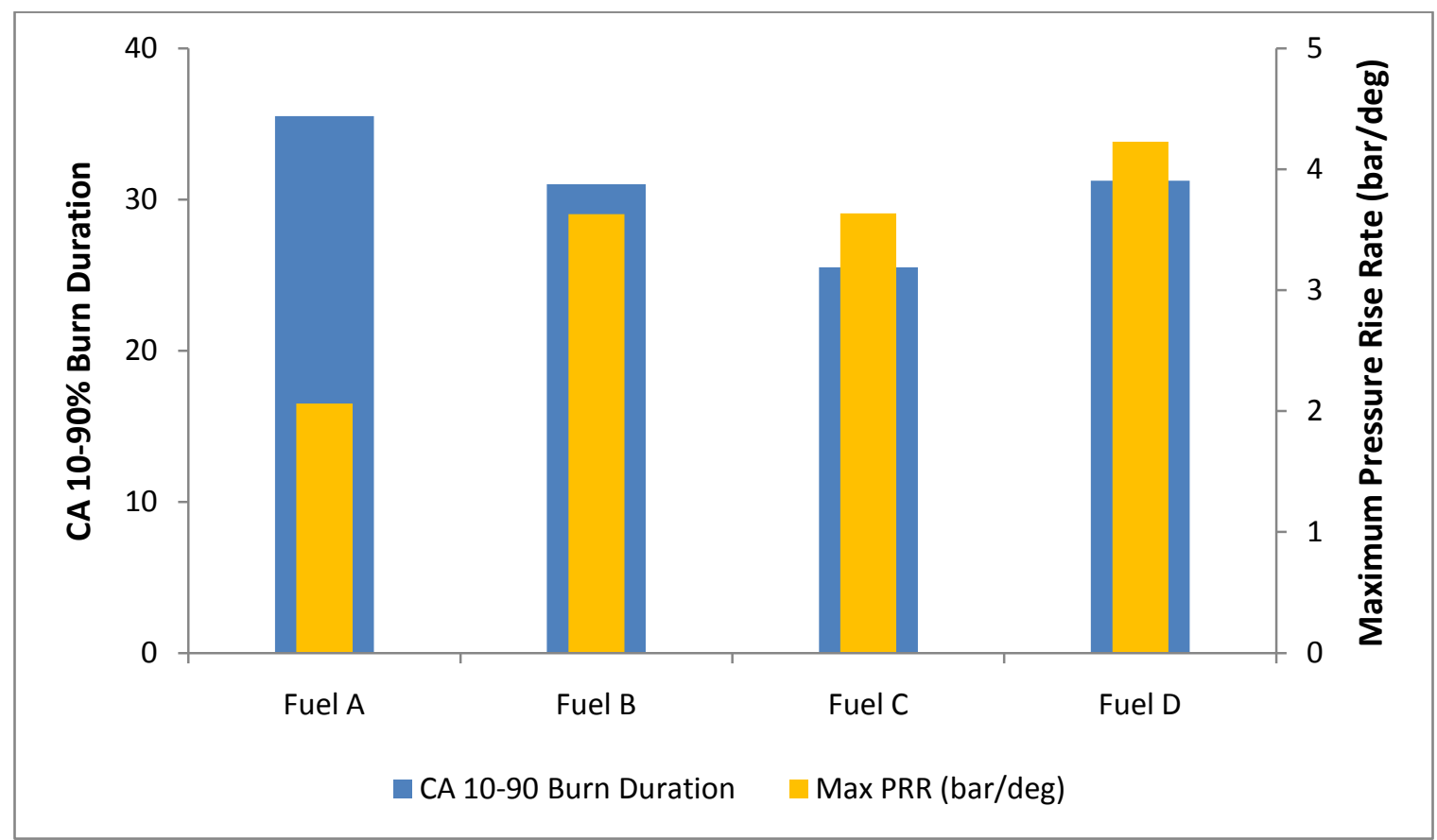

Figure 74: CA 10-90\% Burn Duration and Max PRR at Optimum Control Strategy of Each Fuel

As seen from Figure 74, the maximum PRR for Fuel $C$ is comparable to Fuel $B$ which has a $5-10 \%$ higher PRR rate at $3.5 \mathrm{bar} / \mathrm{deg}$, while the highest CN fuel (Fuel $A$ ) has the lowest maximum PRR at $2 \mathrm{bar} / \mathrm{deg}$. The 10-90\% burn duration is shortest for the lower CN fuel, a good indicator of better mixing during the increased ignition delay. Figure 75 shows the BTE and BSFC at the optimized control strategy for each fuel. 


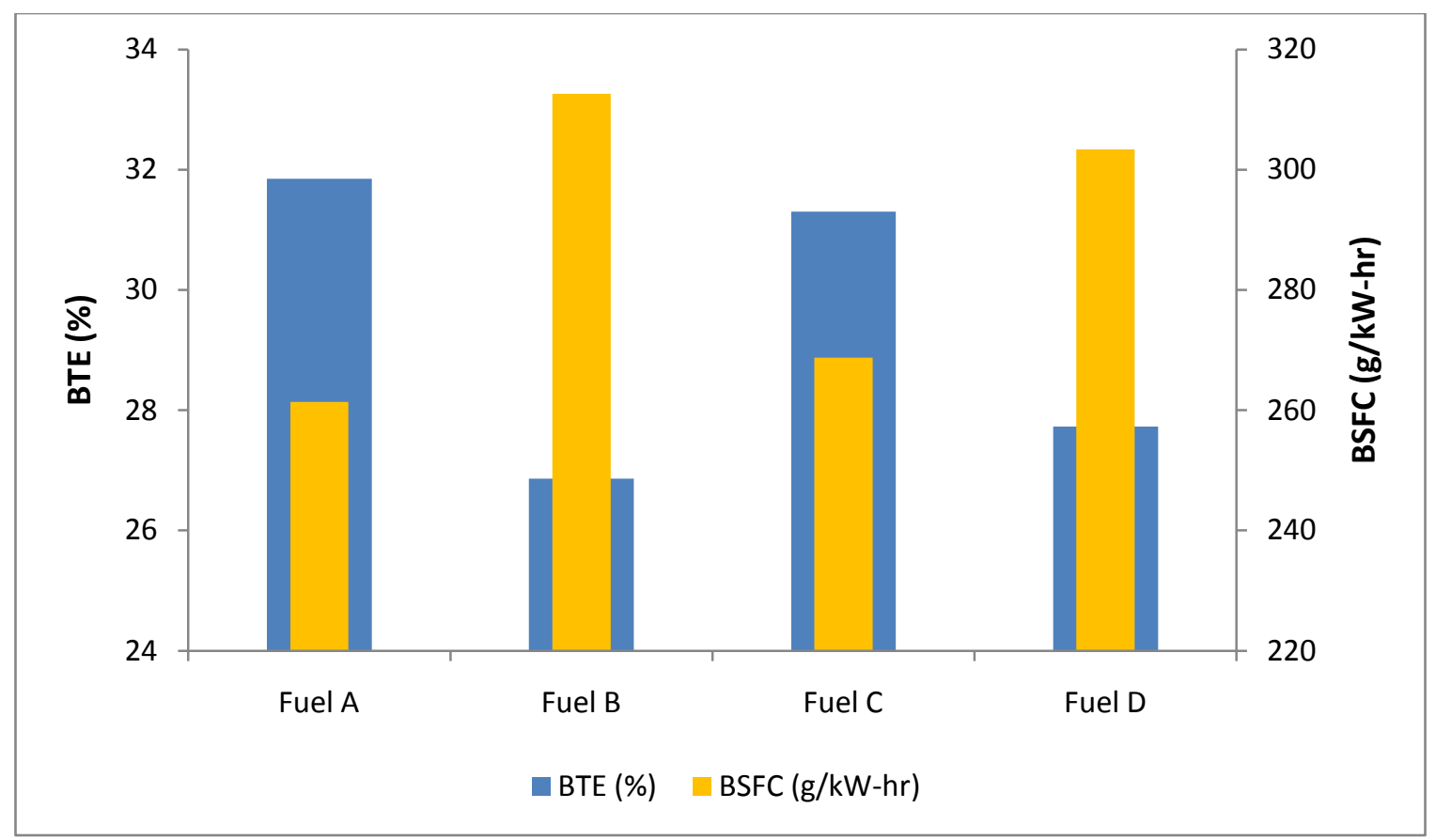

Figure 75: BTE and BSFC at Optimum Control Strategy of Each Fuel

Fuels $A$ and $C$ have the highest BTE at nearly $32 \%$ and $31.5 \%$ respectively. The significant increase in BTE can be contributed to the increase in ignition delay due to high EGR rates for Fuel A and low CN of Fuel C. As depicted in Figure 72 and Figure 73, the HRR and MFB curves for Fuels $A$ and $C$ are very similar. Both fuels have a premixed combustion event occurring around TDC while the diffusion combustion events occur $5-15^{\circ}$ ATDC. Fuels A and C also have the lowest BSFC for the optimized control strategy at $260 \mathrm{~g} / \mathrm{kW}$-hr and $270 \mathrm{~g} / \mathrm{kW}-\mathrm{hr}$ respectively. Table 38 shows the calculated in-cylinder combustion parameters at the optimized control strategy for each fuel. 
Table 38: Calculated In-cylinder Combustion Parameters at Optimized Control Strategy of Each Fuel

\begin{tabular}{|l|c|c|c|c|c|}
\hline & & Fuel A & Fuel B & Fuel C & Fuel D \\
\hline Heat Released & $\mathrm{kJ}$ & 0.606 & 0.611 & 0.670 & 0.620 \\
\hline Maximum Heat Release Rate & $\mathrm{kJ} / \mathrm{deg}$ & 0.029 & 0.048 & 0.052 & 0.039 \\
\hline Maximum Pressure & $\mathrm{kPa}$ & 5965 & 7529 & 7221 & 7697 \\
\hline Location of Max Pressure & $\mathrm{deg}$ ATDC & 2.75 & 2.0 & 11.5 & 2.0 \\
\hline Maximum Pressure Rise & $\mathrm{bar} / \mathrm{deg}$ & 2.06 & 3.63 & 3.64 & 4.23 \\
\hline Location of Maximum Pressure Rise & $\mathrm{deg}$ ATDC & -4.25 & -7.75 & -2.5 & -8.0 \\
\hline Maximum Average Bulk Mixture Temperature & $\mathrm{K}$ & 1254 & 1471 & 1616 & 1452 \\
\hline Location of Maximum Temperature & $\mathrm{deg}$ ATDC & 21.50 & 21.0 & 20.5 & 20.0 \\
\hline Location of 10\% Mass Fraction Burned & $\mathrm{deg}$ ATDC & -1.75 & -7.25 & -2.25 & -7.0 \\
\hline Location of 50\% Mass Fraction Burned & $\mathrm{deg}$ ATDC & 14.0 & 11.5 & 13.0 & 10.75 \\
\hline Location of 90\% Mass Fraction Burned & $\mathrm{deg}$ ATDC & 33.75 & 23.75 & 23.25 & 24.25 \\
\hline
\end{tabular}

As depicted in Table 38 and verified by Figure 72 , the heat released for Fuel A is slightly lower than for Fuels B-D. The lower heat released for Fuel A may be a direct result of the high EGR rate as previously explained. Similarly, maximum in-cylinder temperature is approximately $200 \mathrm{~K}$ less than the next lowest temperatures of Fuels B and D which can also be correlated to the $\mathrm{NO}_{\mathrm{x}}$ plot in Figure 77 and maximum average bulk mixture temperature in Figure 76 , as $\mathrm{NO}_{\mathrm{x}}$ is mainly a function of in-cylinder temperature. The dependency of in-cylinder temperature on $\mathrm{NO}_{\mathrm{x}}$ emissions can also be verified by Fuel $\mathrm{C}$. 


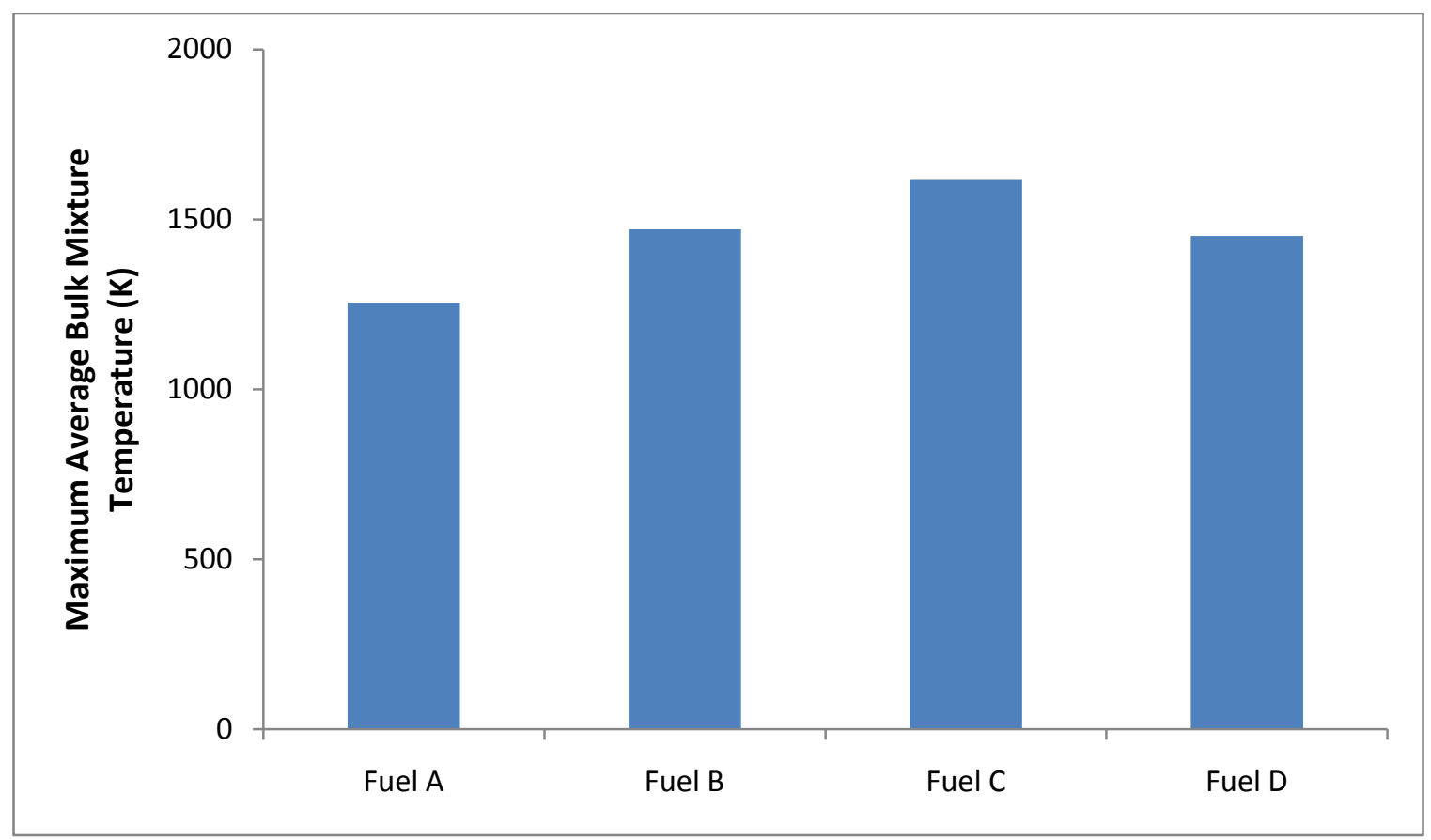

Figure 76: Maximum Average Bulk Mixture Temperature from Each Fuel

Figure 76 shows the maximum average bulk mixture in-cylinder temperature at the optimized strategy from each fuel. As seen in the figure, maximum temperature is greatest from Fuel $\mathrm{C}$ which can also be correlated to the higher $\mathrm{NO}_{\mathrm{x}}$ values shown in Figure 77 . The higher cylinder temperatures from Fuel $\mathrm{C}$ may be attributed to the high HRR before and after TDC. 
$\mathrm{NO}_{\mathrm{x}}(\mathrm{ppm})$

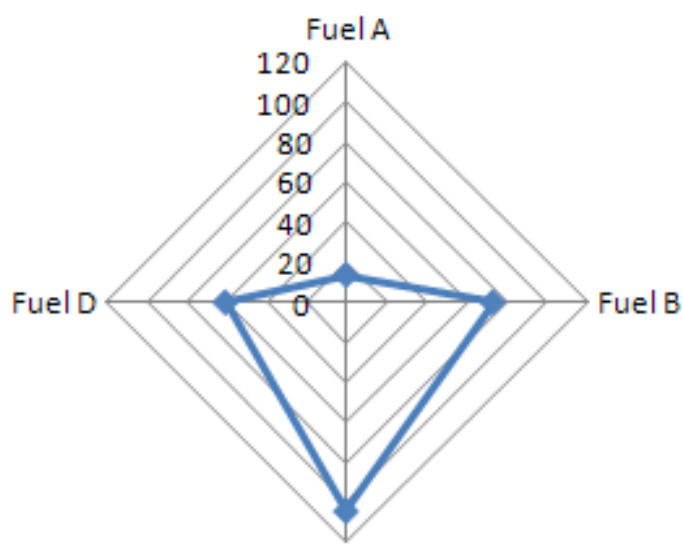

Fuelc
HC (ppm)

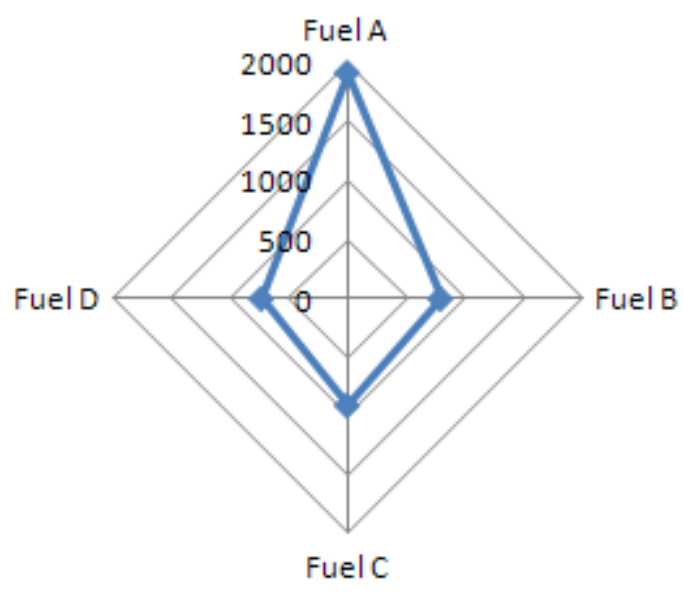

PM (mg/kW-hr)

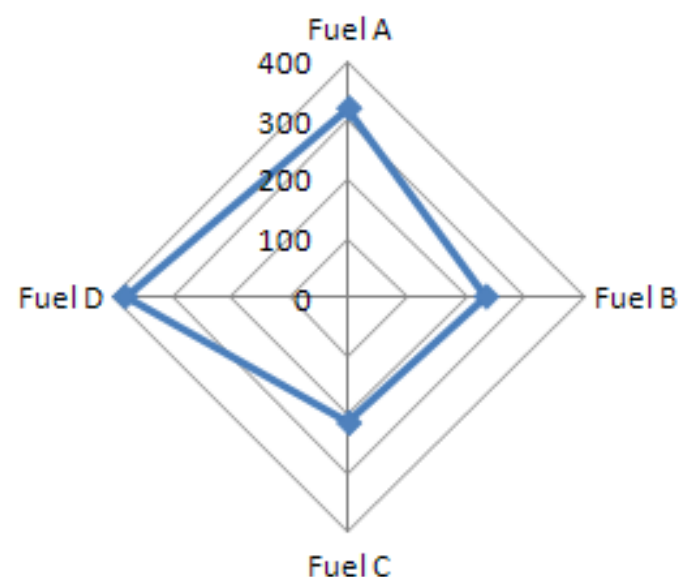

Fuel C

Figure 77: Radar Plots of $\mathrm{NO}_{\mathrm{x}}, \mathrm{HC}, \mathrm{BTE}$ and PM at Optimized Control Strategy of Each Fuel 


\section{Conclusions and Recommendations}

\subsection{Conclusions}

Advanced combustion strategies were examined by implementing a GM 1.9L diesel engine with an open source controller capable of controlling operating parameters such as EGR fraction, fuel quantity, injection timing and rail pressure. Four fuels were tested on the engine at 2100 RPM and $53 \mathrm{~N}-\mathrm{m}$ in order to examine the effects of EGR and fuel characteristics on advanced combustion strategies.

In the data presented here, it was discovered that the amount of EGR can drastically influence the allowable range of injection timings by increasing ignition delay and lowering combustion temperatures. Due to the lower cylinder temperatures, $\mathrm{NO}_{\mathrm{x}}$ emissions were reduced nearly $80 \%$ for the highest $\mathrm{CN}$ fuel, however $\mathrm{HC}$ and $\mathrm{PM}$ emissions increased $60 \%$. At large amounts of EGR, especially greater than 55\%, pilot injection events could be further advanced to allow additional mixing time until wall wetting became the contributing factor for $\mathrm{HC}$ and PM emissions.

In order to examine the effect of fuel characteristics on both the emissions and the combustion process, a single operating strategy was selected. It was discovered that the $\mathrm{CN}$ of the fuel was the contributing factor for phasing combustion and allowing additional mixing time. The low $\mathrm{CN}$ fuel showed a 33\% reduction in PM emissions over the high $\mathrm{CN}$ fuel due to the reduction in fuel rich zones from the additional mixing time. $\mathrm{NO}_{\mathrm{x}}$ and $\mathrm{HC}$ emissions of the low $\mathrm{CN}$ fuel were however increased $85 \%$ compared to the higher $\mathrm{CN}$ fuel at the optimum operating condition for the discussed parameter sweeps.

Upon completion of the data analyses and comparing the range of fuels both through emissions and combustion data, it was determined that a low CN fuel shows favorable characteristics for low PM emissions but may require an aftertreatment device such as a catalyst to suppress the elevated $\mathrm{NO}_{x}$ and $\mathrm{HC}$ emissions. A high $\mathrm{CN}$ fuel however provides favorable characteristics for low $\mathrm{NO}_{\mathrm{x}}$ emissions, but may require an aftertreatment device such as a DPF to suppress the elevated PM emissions. 


\subsection{Recommendations}

The following are some recommendations to further aid fundamental research in the area of advanced combustion relative to this document.

- Further testing at a second, much lower speed and load set point

- Use of a 16-valve engine as opposed to 8-valve for enhanced intake charge mixing to align with recently published advanced combustion research studies

- Obtain soot based PM data for all tests

- Further exploration of a single injection strategy

- Further exploration of main injection strategies at each fuel

- Use of CFD to establish intake flow dynamics of the test engine 


\section{References}

1. United States. Presidential Memorandum Regarding Fuel Efficiency Standards. Washington DC, 2010. Web. 12 Oct 2010.

2. Juttu, S., Thipse, S., Marathe N.V. and Babu M.K., "Homogeneous Charge Compression Ignition ( $\mathrm{HCCl}$ ): A New Concept Near Zero NOx and Particulate Matter (PM) from Diesel Engine Combustion". SAE Paper No. 2007-26-020, 2007.

3. Ebert, Jessica, "The Ideal Engine". Biodiesel Magazine. 2010 <http://www.biodieselmagazine.com/article.jsp?article_id=1753>.

4. Kawano, D., Suzuki, J., Ishii, H., Goto, Y., Odaka, M., Murata, Y., Kusaka, J. and Daisho, Y., "Ignition and Combustion Control of Diesel HCCl". SAE Paper No. 2005-01-2132, 2005.

5. Andreae, M. and Cheng, W., “On HCCI Engine Knock”. SAE Paper No. 2007-01-1858, 2007.

6. Neely, G., Sasaki, S., Huang, Y., Leet, J. and Steward, D., “New Diesel Emission Control Strategy to Meet US Tier 2 Emissions Regulations". SAE Paper No. 2005-01-1091, 2005.

7. Christensen, M. and Johansson, B., "The Effect of Combustion Chamber Geometry on HCCI Operation". SAE Paper No. 2002-01-0425, 2002.

8. Szybist, J. and Bunting, B., "Cetane Number and Engine Speed Effects on Diesel $\mathrm{HCCl}$ Performance and Emissions". SAE Paper No. 2005-01-3723, 2005.

9. Taylor, J., Sluder, S. and Wright, K., "Fuels for Advanced Combustion Engines (FACE)". National Renewable Energy Laboratory, Diesel Engine Efficiency and Emissions Research (DEER) Conference, August 17, 2007.

10. Kukwon, C., Han, M., Sluder, S. and Wagner, R., "Experimental Investigation of the Effects of Fuel Characteristics on High Efficiency Clean Combustion in a Light-Duty Diesel Engine". SAE Paper No. 2009-01-2669, 2009.

11. Vanegas, A., Won, H. and Peters, N., "Influence of the Nozzle Spray Angle on Pollutant Formation and Combustion Efficiency for a PCCI Diesel Engine". SAE Paper No. 2009-011445, 2009. 
12. Parks, J., Prikhodko, V., Barrone, T., Lewis, S. and Storey, J., "Emissions from Premixed Charge Compression Ignition (PCCl) Combustion and Affect on Emission Control Devices". The North American Catalysis Society, 2006.

13. "Standard Test Method for Calculated Cetane Index by Four Variable Equation". American Society for Testing and Materials, West Conshohocken, PA, ASTM-D4737-10, 2010.

14. "Standard Test Method for Determination of Ignition Delay and Derived Cetane Number (DCN) of Diesel Fuel Oils by Combustion in a Constant Volume Chamber". American Society for Testing and Materials, West Conshohocken, PA, ASTM-D6890-10a, 2010.

15. Yates, A., Viljoen, C. and Metcalf, O., "An Accurate Determination of the Cetane Number Value of GTL Fuel”. SAE Paper No. 2007-01-0026, 2007.

16. "Standard Specification for Diesel Fuel Oils". American Society for Testing and Materials, West Conshohocken, PA, ASTM-D7170-09, 2010.

17. United States Environmental Protection Agency Office of Transportation and Air QualityNational Vehicle and Fuel Emissions Laboratory, "Fluorescent Indicator Adsorption Analysis of Petroleum Fuels Method". NVFEL Reference No. 124, Ann Arbor, MI, 2002.

18. McCarthy, C., Slodowske, W., Sienicki, E. and Jass, R., “Diesel Fuel Property Effects on Exhaust Emissions from a Heavy Duty Diesel Engine that Meets 1994 Emissions Requirments". SAE Paper No. 922267, 1992.

19. Ullman, T., Spreen, K. and Mason, R., "Effects of Fuel Aromatics, Cetane Number, and Cetane Improver on Emissions from a 1991 Prototype Heavy-Duty Diesel Engine". SAE Paper No. 902171, 1990.

20. Kwon, Y., Mann, N., Rickeard, D., Haugland, R., Ulvund, K., Kvinge, F. and Wilson, G., “Fuel Effects on Diesel Emissions - a New Understanding”. SAE Paper No. 2001-01-3522, 2001.

21. Baranescu, R., "Influence of Fuel Sulfur on Diesel Particulate Emissions”. SAE Paper No. 881174, 1988.

22. Speight, J., The Desulfurization of Heavy Oils and Residua. New York, NY, Marcel Dekker Inc., 1981. 
23. Rose, K., Samaras, Z., Jansen, L., Clark, R., Elliot, N., Fontaras, G., Zemroch, P., Hall, D., Almena, M., Higham, C. and Kalogirou, M., "Impact of Biodiesel Blends on Fuel Consumption and Emissions in Euro 4 Compliant Vehicles". SAE Paper No. 2010-011484, 2010.

24. Hills, F. and Schleyerbach, C., "Diesel Fuel Properties and Engine Performance". SAE Paper No. 770316, 1977.

25. Kouremenos, D., Hountalas, D. and Kouremenos, A., "Experimental Investigation of the Effect of Fuel Composition on the Formation of Pollutants in Direct Injection Diesel Engines". SAE Paper No. 1999-01-0189, 1999.

26. Ochoterena, R., Larsson, M., Andersson, S. and Denbratt, I., “Optical Studies of Spray Development and Combustion Characterisation of Oxygenated and Fischer-Tropsch FuelsGTL Fuels". SAE Paper No. 2008-01-1393, 2008.

27. Pulkrabek, W.W., Engineering Fundamentals of the Internal Combustion Engine. Second Edition, Pearson Prentice-Hall, Upper Saddle River, NJ, 2004.

28. Heywood, J.B., Internal Combustion Engine Fundamentals. McGraw Hill, New York, NY, 1988.

29. Nuszkowski, J., "The Effects of Fuel Additives on Diesel Engine Emissions during Steady State and Transient Operation". Doctor of Philosophy Thesis, West Virginia University, 2008.

30. Hasegawa, R. and Yanagihara, H., "HCCl Combustion in DI Diesel Engine". SAE Paper No. 2003-01-0745, 2003.

31. Dec, J., "A Conceptual Model of DI Diesel Combustion Based on Laser-Sheet Imaging". SAE Paper No. 970873, 1997.

32. Dec, J. and Canaan, R., "PLIF Imaging of NO Formation in a DI Diesel Engine". SAE Paper No. 980147, 1998.

33. Aceves, S., Flowers, D., Martinez-Frias, J., Smith, J., Dibble, R., Au, M. and Girard, J., "HCCl Combustion: Analysis and Experiments". SAE Paper No. 2001-01-2077, 2001.

34. Daniels, C., "The Comparison of Mass Fraction Burned Obtained from the Cylinder Pressure Signal and Spark Plug Ion Signal". SAE Paper No. 980140, 1998. 
35. Mobley, C., "Non-Intrusive In-cylinder Pressure Measurement of Internal Combustion Engines". SAE Paper No. 1999-01-0544, 1999.

36. Zhu, J. and Lee, K., "Effects of Exhaust Gas Recirculation on Particulate Morphology for a Light-Duty Diesel Engine". SAE Journal of Fuels and Lubricants. Vol. 114, No. 2, pp. 99105, 2005.

37. Sjobberg, M. and Dec, J., "Influence of EGR Quality and Unmixedness on the High Load Limits of HCCI Engines". SAE Paper No. 2009-01-0666, 2009.

38. Murari R., "Effect of Exhaust Gas Recirculation on Combustion and Odorous Emissions in Direct Injection Diesel Engines". SAE Paper No. 2008-01-2482, 2008.

39. Lundqvist, U., Smedler, G. and Stalhammar, P., “A Comparison Between Different EGR Systems for HD Diesel Engines and Their Effect on Performance, Fuel Consumption and Emissions". SAE Paper No. 2000-01-0226, 2000.

40. “CAFE Overview". Web. 20 Nov 2010. <http://www.nhtsa.dot.gov/CARS/ rules/CAFE/overview.htm.>

41. Kreso, A., Johnson, J., Gratz, L., Bagley, S. and Leddy, D., "A Study of the Effects of Exhaust Gas Recirculation on Heavy-Duty Diesel Engine Emissions". SAE Paper No. 981422, 1998.

42. Maiboom, A., Tauzia, X., Shah, S. and Hetet, J-F., "Experimental Study of an LP EGR System on an Automotive Diesel Engine, compared to HP EGR with respect to $\mathrm{NO}_{\mathrm{x}}$ and PM Emissions and Specific Fuel Consumption". SAE Paper No. 2009-24-0138, 2009.

43. Wrap Off-Road Diesel Retrofit Guidance Document, "Low Pressure Exhaust Gas Recirculation". Emissions Advantage, Vol. 2 Sec. VII. 2005.

44. Walt Moore, "Living With Cooled-EGR Engines". Trade Association Business Publications. pp 68-69. Dec. 2003.

45. Yang, F. and Minggao, O., "Experimental Research on EGR in a Diesel Engine Equipped with Common Rail Injection System". SAE Paper No. 2003-01-0351, 2003.

46. Haiyong Peng, Yi Cui, Lei Shi and Kangyao Deng, Effects of EGR on Combustion Process of DI Engine During Cold Start. Higher Education Press and Springer-Verlag, 2008. 
47. Dennis, A.J., Garner, C.P. and Taylor, D., "The Effect of EGR on Diesel Engine Wear". SAE Journal of Engines. Vol. 108, pp. 7, 1999.

48. Szybist, J., Kirby, S. and Boehman, A., "NO $\mathrm{NO}_{\mathrm{x}}$ Emissions of Alternative Diesel Fuels: A Comparative Analysis of Biodiesel and FT Diesel". Energy \& Fuels, Vol. 19, No. 4, pp. 1492, 2005.

49. Code of Federal Regulations, Title 40 CFR Part 1065 \& 86, Washington, D.C., Office of Federal Register National Archives and Records Administration, 2007.

50. “Gas Phase Measurments," Dieselnet, September 2008, <http://www.dieselnet.com/tech/measure_gas.html\#tech>

51. Alpha Omega Instruments, “Oxygen Sensor Types”. Alpha Omega Instruments, 2006. <http://www.aoi-corp.com/additional_information/oxygen_sensor_types/>.

52. AVL, "AVL Micro Soot Sensor". Impressum, 2010. < https://www.avl.com/micro-sootsensor>.

53. Yu, R., Bai, X.S., Lehtiniemi, H., Ahmed, S.S., Mauss, F., Richter, M., Alden, M., Hildingsson, L., Johansson, B. and Hultqvist, A., "Effect of Turbulence and Initial Temperature Inhomogeniety on HCCl". SAE Paper No. 2006-01-3318, 2006. 


\section{$7 \quad$ Appendix}

Table 39: Test Fuel Properties

\begin{tabular}{|c|c|c|c|c|c|c|c|c|}
\hline Fuel & $\begin{array}{c}\text { Cetane } \\
\text { Number }\end{array}$ & $\begin{array}{c}\text { Specific } \\
\text { Gravity }\end{array}$ & $\begin{array}{c}\text { Flash } \\
\text { Point } \\
\left.\mathbf{(}^{\circ} \mathbf{C}\right)\end{array}$ & $\begin{array}{c}\text { Sulfur } \\
(\mathbf{p p m})\end{array}$ & $\begin{array}{c}\text { T 90 } \\
\text { Distillation } \\
\text { Temperature } \\
\left.\mathbf{(}^{\circ} \mathbf{C}\right)\end{array}$ & $\begin{array}{c}\text { Aromatics } \\
(\text { Vol \%) }\end{array}$ & $\begin{array}{c}\text { Net Heat of } \\
\text { Combustion } \\
(\mathbf{M J} / \mathbf{k g})\end{array}$ & $\begin{array}{c}\text { Net Heat of } \\
\text { Combustion } \\
\left(\mathbf{M J} / \mathbf{m}^{\wedge} \mathbf{3}\right)\end{array}$ \\
\hline A & 56 & 0.8095 & 58.9 & 1.7 & 311 & $35^{*}$ & 43.32 & 35001 \\
\hline B & 44 & 0.8496 & 70 & 8.4 & 307 & 28.8 & 42.86 & 36338 \\
\hline C & 30.3 & 0.8081 & 58.7 & 1.2 & 274 & 23.5 & 42.80 & 34520 \\
\hline D & 53.7 & 0.8411 & 74.4 & 2 & 340 & 20.4 & 42.80 & 35924 \\
\hline
\end{tabular}

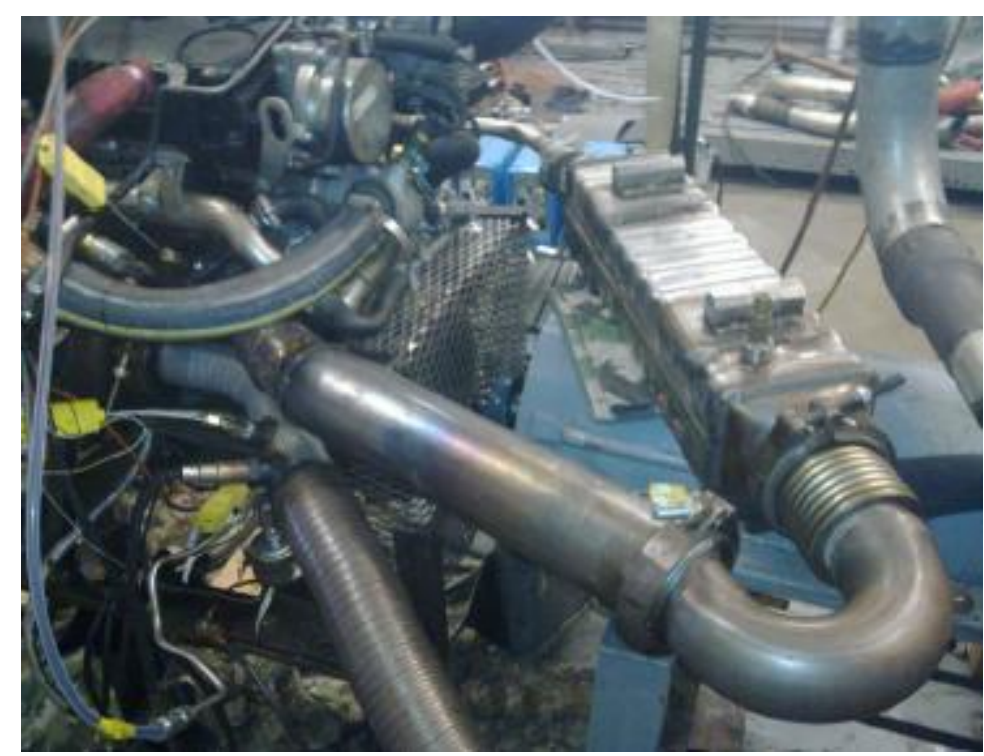

Figure 78: HDDE EGR Cooler 


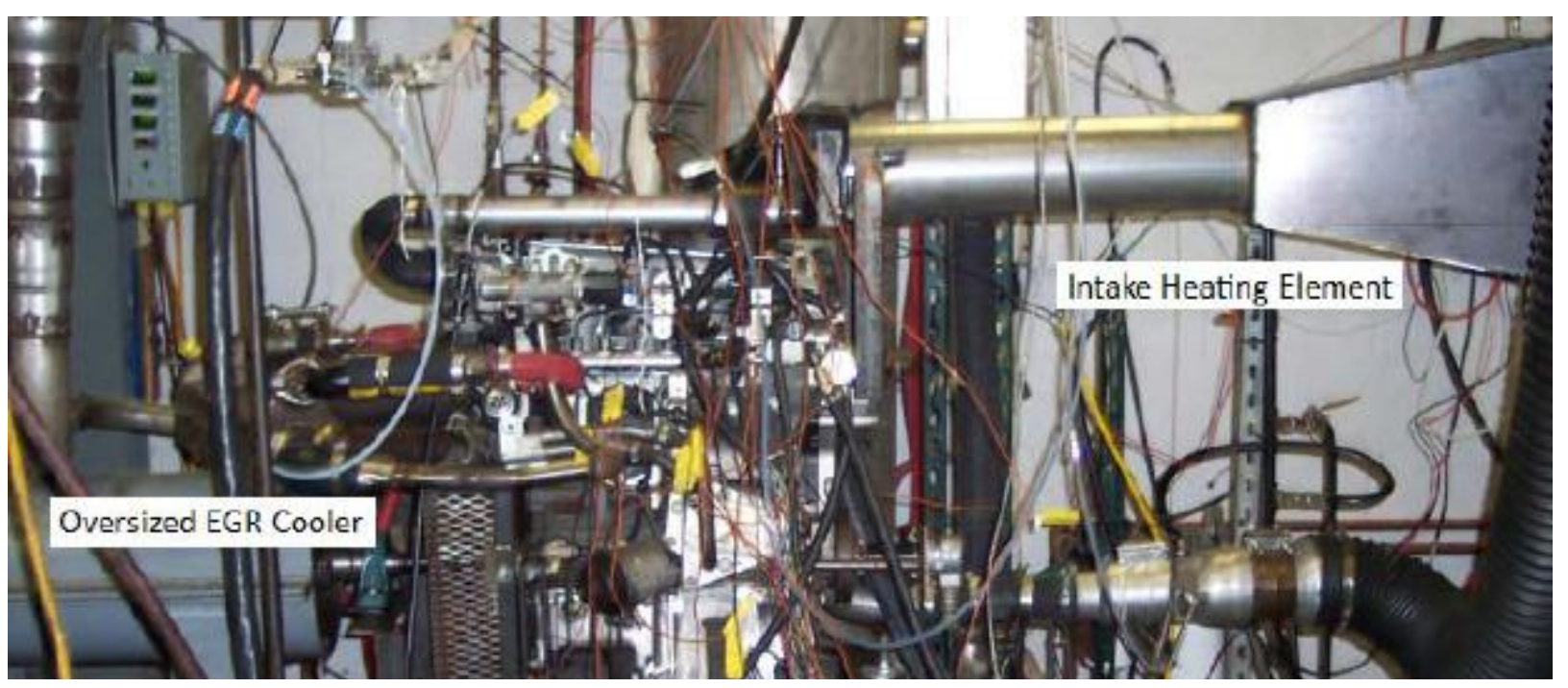

Figure 79: Engine Retrofitted with HDDE EGR Cooler and Heating Element

Table 40: In-cylinder Pressure Sensor Manufacturer Specifications

\begin{tabular}{|l|c|c|}
\hline \multicolumn{3}{|l|}{ Type 6056A Piezoelectric Crystal Pressure Transducer } \\
\hline Measuring Range & bar & $0-250$ \\
\hline Overload & bar & 300 \\
\hline Sensitivity & $\mathrm{pC} / \mathrm{bar}$ & -20 \\
\hline Natural Frequency & $\mathrm{kHz}$ & 160 \\
\hline Shock Resistance & $\mathrm{g}$ & 2000 \\
\hline Capacitance & $\mathrm{pF}$ & 5 \\
\hline
\end{tabular}




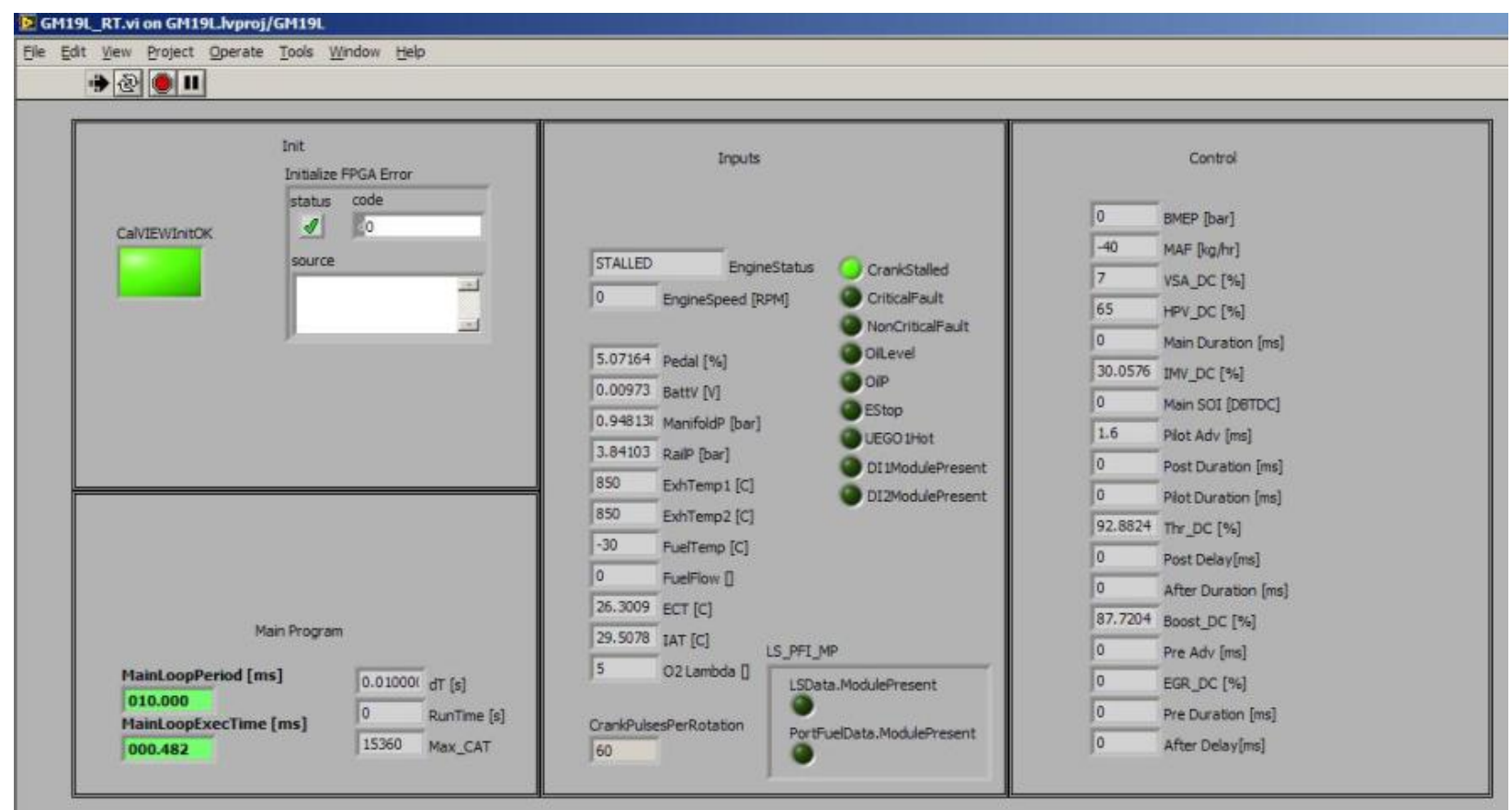

Figure 80: LabVIEW Screenshot

Table 41: Single Injection Emissions Data for Fuel A

\begin{tabular}{|c|c|c|c|c|c|c|c|}
\hline EGR & HC (ppm) & NO $_{\mathbf{x}}$ (ppm) & $\begin{array}{c}\mathbf{H C} \\
\text { (g/kW-hr) }\end{array}$ & $\begin{array}{c}\mathbf{N O}_{\mathbf{x}} \\
(\mathbf{g} / \mathbf{k W}-\mathbf{h r})\end{array}$ & $\begin{array}{c}\text { BSFC } \\
\text { (g/kW-hr) }\end{array}$ & BMEP & $\begin{array}{c}\text { Gravimetric PM } \\
\text { (mg/kW-hr) }\end{array}$ \\
\hline $45 \%$ & 1948 & 287.0 & 7.883 & 3.884 & 325.0 & 3.34 & 338.3 \\
\hline $50 \%$ & 2099 & 457.2 & 8.789 & 6.420 & 335.2 & 3.03 & 621.0 \\
\hline $65 \%$ & 4075 & 18.66 & 10.701 & 0.158 & 244.6 & 3.66 & 654.3 \\
\hline $70 \%$ & 7757 & 7.544 & 16.415 & 0.048 & 229.6 & 3.75 & 739.9 \\
\hline
\end{tabular}

